\title{
Health, knowledge and the demand for medical care : an econometric analysis
}

Citation for published version (APA):

Doorslaer, E. K. A. (1987). Health, knowledge and the demand for medical care : an econometric analysis. [Doctoral Thesis, Maastricht University]. Rijksuniversiteit Limburg.

https://doi.org/10.26481/dis.19871217ed

Document status and date:

Published: 01/01/1987

DOI:

10.26481/dis.19871217ed

Document Version:

Publisher's PDF, also known as Version of record

\section{Please check the document version of this publication:}

- A submitted manuscript is the version of the article upon submission and before peer-review. There can be important differences between the submitted version and the official published version of record.

People interested in the research are advised to contact the author for the final version of the publication, or visit the DOI to the publisher's website.

- The final author version and the galley proof are versions of the publication after peer review.

- The final published version features the final layout of the paper including the volume, issue and page numbers.

Link to publication

\footnotetext{
General rights rights.

- You may freely distribute the URL identifying the publication in the public portal. please follow below link for the End User Agreement:

www.umlib.nl/taverne-license

Take down policy

If you believe that this document breaches copyright please contact us at:

repository@maastrichtuniversity.nl

providing details and we will investigate your claim.
}

Copyright and moral rights for the publications made accessible in the public portal are retained by the authors and/or other copyright owners and it is a condition of accessing publications that users recognise and abide by the legal requirements associated with these

- Users may download and print one copy of any publication from the public portal for the purpose of private study or research.

- You may not further distribute the material or use it for any profit-making activity or commercial gain

If the publication is distributed under the terms of Article $25 \mathrm{fa}$ of the Dutch Copyright Act, indicated by the "Taverne" license above, 
health, knowledge and the demand for medical care 



\section{HEALTH, KNOWLEDGE AND THE DEMAND FOR MEDICAL CARE}

\section{AN ECONOMETRIC ANALYSIS}

\section{Proefschrift}

ter verkrijging van de graad van doctor in de Sociale Wetenschappen aan de Rijksuniversiteit Limburg te Maastricht, op gezag van de

Rector Magnificus, Prof.Dr. F.I.M. Bonke,

volgens het besluit van het College van Dekanen, in het openbaar te verdedigen op donderdag 17 december 1987 om 16.00 uur

$$
\text { door }
$$

Edy Karel Alina Van Doorslaer

geboren te Willebroek op 24 februari 1958 
Promotor: Prof.Dr. F.F.H. Ruten

Referenten: ProfDr.Ir. A. Kapteyn

Prot.Dr. F.Ch. Palm

Prof.Dr. W. M.M. van de Ven 


\section{CONTENTS}

Acknowledgements

Chapter 1. Introduction

1.1. The subject of analysis

1.2. The relevance of the subject matter

Chapter 2. Economic models of health and medical care decision-making 5

2.1. Introduction 5

2.2. Static models of the demand for medical care 6

2.3. Static models of the demand for health 7

2.4. Lifecycle models of the demand for health 9

2.5. Stochastic models of the demand for health 16

2.5.1. Uncertainty with respect to health 16

2.5.2. Uncertainty with respect to the effectiveness of medical care

2.6. Conclusions and implications for research strategy 22

Notes 25

\section{Part I. CONSUMER INFORMATION AND THE DEMAND FOR MEDICAL CARE

Chapter 3. The demand for information on the quality of medical care 29

3.1. Introduction. 29

3.2. Asymmetry of information in health care 29

3.3. A Bayesian approach to the derived demand for therapeutic information

3.3.1. The Kihlstrom model of Bayesian consumer behaviour

3.3.2. Comparative static predictions of the demand for information

$\begin{array}{ll}\text { 3.4. From theoretical to empirical model } & 38 \\ 3.41 \text { Joint product problems } & 38\end{array}$

3.4.2. Income, prices, expectations and preferences 39

3.4.3. Effects of information manipulation 40

3.5. Conclusions and assessment of the theoretical model 44

Notes 45

Chapter 4. Empirical analysis 46

4.1. Description of data and Belgian health care characteristics 
42. Measurement of health 47

4.2. Methodology: the LiSREL model 47

4.2.2. A latent health vector 51

4.2.2.1. Model specification and testing 51

4.2.2.2. Model modification 56

4.2.3. A MIMIC health model 58

4.3. Measurement of intomation 61

4.3.1. Previous studies 61

4.3.2. A MIMIC model of consumer inlormation 62

4.3.2.1. Medical knowledgeability 63

4.3.2.2. Perceived quality of GP's $\quad 66$

4.4. A structural equation model of the demand for intormation and medical care $\quad 70$

4.4.1. Specification ofthe demand equations 71

4.4.2. Estimation results 74

4.4.3. Robustness analysis 80

4.4.3.1. Sample selection 81

4.4.3.2. Model structure 83

4.5. Conclusions and discussion 85

Notes 89

Part II. EDUCATION AND HEALTH

Chapter 5. Economic analysis of the schooling health relationship 93

5.1. Introduction 93

5.2. The effect of education on health demand and production 95

5.3. Methodological issues: a survey of previous research 99

5.3.1. Reverse causality (B) 100

5.3.2. Third factor (C) 101

5.3.3. Intervening variables (D) 103

5.4. Conclusions 105

$\begin{array}{ll}\text { Notes } & 107\end{array}$

Chapter 6. "The marginal health productivity of schooling: a longitudinal latent variable model $\quad 108$

6.1. Introduction 108

6.2. Data 108

6.3. Measuring health changes over time 110

6.3.1. Variability of health indicators 110

6.3.2. Stability of latent health status 112

6.4. A structural equation model of health production 117

6.4.1. The schooling-health association 117

6.4.2. Cumulative and dymamic effects 118

6.4.3. Direct and indirect effects 122

6.5. Conclusions 125

Notes $\quad 127$ 
Chapter 7. Use-related health depreciation and education: a fixed-effects model

7.1. Data

7.2. Measurement of health

7.3. Analysis of covariance

7.3.2. Cumulative effects

7.4. Interaction effects

7.5. Conclusions

Chapter 8. General summary and conclusions 



\section{Acknowledgements}

Although there is only one author on the front page of this book, he could never have written it without the help and encouragement of a large mumber of people. In chronological order, I would like to thank all those who have contributed to its accomplishment in some way or another.

Without Walter Nonneman I would probably never have heard of anything like 'health economics", let alone become interested in it. It was his conviction that a good Ph.D. in economics has to start with a study abroad that provided the stimulus for me to try to go to the University of York. The financial support of the CIM-fellowship made it possible to realize these plans. During my stay there, graduate supervisors Alan Williams and Alan Maynard made sure that this interest was further sharpened and that I returned even more enthusiastic about the subject than when I left. Although I can say that the roots of this book lie in Antwerp and York, most of the work was done in Maastricht at the Department of Health Economics under the supervision of Frans Rutten. I am very grateful to him for encouragement and advice in all stages of this research, and for giving me the opportunity to work in a small but stimulating team of researchers in the project on Determinants of Health Care Utilization. I owe many thanks to Jose Geurts, for intelligent assistance (and shared frustation) with the data processing and analysis; to Richard Janssen, for the transmission of some of his energy when it was needed; to Ellen Breevoort and Jan van Emmerik for skillful research assistance in a ready-while-you-wall-style; and to Frans Tan and Arnold Kester for their numerous valuable advices on statistical problems.

Furthermore, I would like to thank the referees for their comments and suggestions for improvement on various parts of the book, Ger Haan for this thorough proofread. ing of the manuscript and common-sense advice, Jaap van den Berg (CBS) for his willingness to participate in the research of Chapter 7 and, last but not least, Brigitte Kerbusch. It would be a severe understatement to say that she typed the text because she really processed it fast and accurately, thereby transtoming a sometimes dreadful manuscript into a perfect-looking document.

Thanks are also due to the Belgian National Research Program for the Social Sciences, the Nederland Oké Project and the Netherlands Central Bureau of Statistics for letting me use their data files and to the Intercollegiate for Doctoral Studies in Management Science for financial support.

Finally, I thank my parents for investing in my health and education, Gerd for her support and encouragement throughout and my sons Stijn and Joris for letting me sleep during so many nights when $\mathbb{I}$ badly needed it. 



\section{Chapter 1. Introduction}

"The greatest potential for improving health jies in what we do and don't do to and for ourselves" (Fuchs, 1974)

\subsection{The subject of analysis}

This thesis attempts to establish whether, how and to what extent an individual's knowledge affects his or her decisions with respect to health behaviour in general and the use of medical care in particular. The approach is economic in the sense that the (neo-classical) paradigm of rational behaviour under constraints is used as the basic underlying theory. Within the field of economics, the subject is located on the boundary between the economics of health and the economics of education, sometimes placed under the common label of the "economics of human resources" (Blaug, 1970, p. 317). The theoretical part also draws on some developments in the theory of consumer behawlour under uncertainty.

Although the analysis encompasses the three relationships between essentially three main variables of interest (health knowledge and medical consumption depicted in Figure 1.1) we have concentrated on two of them in particular.

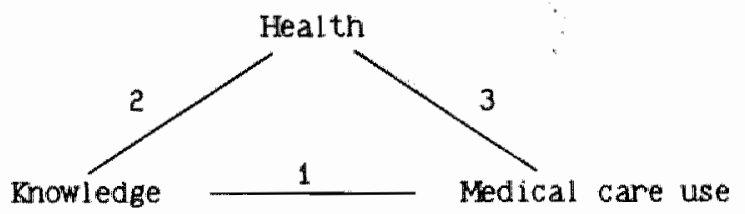

Figure 1.1. Basic relations under study

In Chapter 2, where we review the economic models of the demand for health and medical care, we also make more explicit the reasons for 
subdividing the renainder of this study into two main parts.

The flrst part then concentrates on relationship 1 between consumer information and the demand for medical care, while controlling for health status. Information asymetry between the patient/demander and the phys 1clan/supplier is formally modelled us ing a Bayesian approach. important questions we seek to answer include: How does the consumer's medcal knowledge affect his demand for medical care? Does a patient's prior information affect his response to medical advice and how does this responsiveness vary with respect to his perception of such advice?

The second part of this study is concemed with relationship 2 between individual health and education level (as a proxy for knowledge and skills). The focus there is on the possible causality muning from more schooling to better health. In the human capital framework, declsions with respect to health and education are considered as investment behaviour in a lifetime perspective. Education is assumed to enhance the individual's ability to improve his health by investing time and resources in the use of medical care (the technical efficlency effect) or to actively prevent health from deteriarating by adopting a healthy lifestyle (the allocative effect). Crucial questions addressed in this chapter are: To what extent can health inequalities be attributed to differences in schooling levels? Does the schooling-health correlation also represent causality or can it entirely be explained by an amitted third factor?

Different datasets are used in the empirical analysis to study the different sub-themes. In Part one some predictions of the theory on the demand for information are tested by means of a sample of individuals taken from the Primary Health Care Survey conducted by the Belgian National Research Program for the Soclal Sclences in 1975. The advantage offered by this questionnaire was that it extensively asked for respondents' health status, medical consumption, knowledge and perceptions.

For the analyses of education and nealth which are reported in the second part, two Dutch datasets were employed: the Nederland Oke Panel Survey carried out by the University of Limburg in 1981 and 1983, and the 1984 Health Interview survey of the Central Bureau of Statistics. These datasources were selected because they contalned a longltudinal measurement of health status (at two points in time).

\subsection{Relevance of the subject matter}

Opinion polls have repeatedly shown that a good health is one of the most highly rated values for a large number of people. "There are also indications that the proportion of people considering good health as 
the most important thing in their life has increased over the last few decades. 1 This is not so surprising because according to the definition of the World Health Organlzation ("a state of complete physical, mental and social well-being" health comes very close to the more general concept of consumer welfare used in economics. But if health is apparently deemed so valuable, why then is there so much concern about the rising, mainly public but also private, expenditures for health care? In answering this question van de ven (1987) argues that "It is the waste and inefficiency and an insufficient meeting of the consumer"s preferences rather than the absolute level of cost which is the fundamental issue in the nealth care cost problem" (p. 254). He advocates a change in the incentive structure to achieve a more efficient allocation of resources within the health care sector. However, the concern does not only apply to the allocation of resources within the health care sector but also to the allocation between health care and other determinants of health. Especially the strong and consistent positive correlation between education and overall good health has often attracted the attention: "The same research by health economists that reveals the small marginal contributions of medical care and of income to health reports a strong positive relation between health and years of schooling." (Fuchs, 1986, p. 27T) This book is an attempt to find out whether more knowledgeable and more informed individuals behave differently both as consumers of medical care and as non-consumers taking decisions which may directly or indirectly affect their health status. Such an investigation seems to be timely and warranted both from a theoretical and a policy point of view. The theory of the demand for health and medical care is complemented and extended with elements borrowed from other subdisciplines within economics and subjected to new empirical tests making use of more advanced econometric methods. But the analys is also has some relevance for public policy makers who consider health education programs as one of the major instruments to achieve health targets for the year 2000 (Nota 2000, 1986). Such policies are entirely based on the assumption that more health information leads to healthier behavlour, or to put it in econonic terms, that it either reduces the costs or increases the (percelved) benefits of health investment. We do not intend an evaluation of speciflc interventions but w11 rather attempt to establish at a more aggregate level whether specif lc medical knowledge and a general cognltive development through schooling do matter in terms of health. 


\section{Hote:}

1. Van de Ven (1987) meports the flgures of the Ketherlands Social and oulural Plarning Bureau (1964) indlcating that this percentage has risen from 35 to $52 \%$ over the last 20 years. Also Adrianse et. al. (1981) find very nign valuations of personal health in conparison to other iteas lite peace, freedca friendship famly, etc. 


\section{Chapter 2. Economic models of health and medical care decision-making}

"To try to formulate models of 'demand" for medical care which exclude the direct influence of the physician, is to try to stage "Hamlet" without the Prince of Demark" (Evans, 1984, p. 911

\subsection{Introduction}

Undoubtedly, the most distinguishing feature of the economic approach towards human behaviour of individuals from other social sciences, is the adoption of a formal framework of rational decision-making under certain constraints. Human behaviour with respect to health and utilization of medical care constitutes no exception to this rule. Ever since economists started investigating the use of nealth care, the nicro-economic neo-classical paradigm of constrained utility maximization has been a guidel ine for any theoretical underpinnings of empirical research efforts. As in any other subfleld of economics, there has been accelerating growth in the literature on the denand for health care, extending the basic textbook model in numerous ways to allow for various special characteristics of the health care good. Michael Grossman's (1972a) book, however, stands out as the seminal work in the theory of the demand for health and medical care. His treatment of health as a human capital stock which yields consumption and investment benefits, and medical care demand as being derived from the more fundamental demand for good health provided the foundation for most of the work which has been published afterwards. His model will occupy a fairly central place in the survey presented in this chapter because it can be seen as a bencmark with which other models can be compared.

In what follows, we will not give a detalled description of all models which are being discussed. For the purposes of our study, we will only 
emphas ize the mechanisms through which education or knowledge enters each of these behavioral frameworks explicitly or implicitly. The survey is not in strict chronological order but rather structured according to three important distinctive features of the models. First, we distinguish between (mostly early) models in which medical care itself directly enters the individual's utility function and those in which the demand for medical care is derived from the defind for health. Secondly, we divide between static one-period models and those which are inherently dymanic because of a multi-period objective function or constraints in which changes over time are explicitly taken into account. Thirdly the models can be classified as either deterministic or stochastic depending on whether or not uncertainty is introduced through the presence of randon variables. In fact the stochastic models can be further subdivided according to which variable is assumed to be random health status or the marginal health product of medical care. The latter category of models makes it possible to introduce the special role of the physician in health care decision-making under conditions of asymetric information. In the last section, some conclusions are draw with respect to the cholce of a theoretical model wich suits best the purposes of our own study.

\subsection{Static models of the demand for medical care}

Some of the earlier studies were primarlly intended as explorations of the price and income elasticities of the demand for medical care (for a survey, see e.g. Feldstein (1974) or Newhouse (1981)). The estimated demand equations were, explicitly or implicitly, derived from the standard utility maximization model in which purchases of medical care are tradled off against those of a composite good under a budget restriction (i.e. $\max U(m, c)$ subject to $p_{m} M+p_{c} C=Y$ with $M$ medical care, $c$ a composite good, $\mathrm{P}_{\mathrm{m}}$ and $\mathrm{p}_{\mathrm{C}}$ their respective market prices and $\checkmark$ incomel. Apart from prices and income, other background variables included in the empirical equations like age, sex, health status indicators or education are assumed to be 'taste shifters'. Very often these variables proved to be important predictors of utilization but the interpretation of their effects was mostly based on ad hoc explanations. Education effects. nowever, were inconsistent across studies which led Newhouse (1981), in his review of these demand studies, to the remark that 'the effect of education has been more difflcult to isolate (p. 92)'.

Some authors adopted this simple framework in order to concentrate on the effects of time prices in the demand for health care. Acton (1975) observed that health care consumption often involves significant inputs of the consumer's time which may be much larger than the monetary price of medical treatment. He therefore defines the total cost per unit of health care as the monetary cost (net of insurance) plus the required time input valued at its opportunity cost and 
adjusts the budget constraint accordingly. His empirjcal work supports the model prediction that time prices (proxied by travel time) becone more important when money user prices are low. Phelps and Newhouse (1974) showed that the elasticity of demand with respect to each of the components of the total price is approximately equal to the elasticity of demand with respect to the total cost of care per unit multiplied by the proportion of the total cost made up by each of the components.

Although some of these studies have offered useful empirical evidence on the relative effects of traditional economic variables like income and prices on the demand for medical care, the ir treatment of health care as a direct argument in the individual's utility function ignores the fact that the basic trade-off is between nealth and other fundamental objects of cholce (comodities). The endogenous nature of health in decision-making was first recognized by Mushkin (1962) who regarded health as a human capital stock yielding both investment and 'pure consumption" benefits. Although this article can be seen as the first attempt to view health as an economic sood it does not present a formal model of health behaviour. This was developed first by Grossman (1972a) and w11 be discussed in Section 2.4. In the next section, and in the logical order of increasing complexity, we will first describe an example of a static one-period model of the demand for health.

\subsection{Static models of the demand for health}

In order to explore the trade-off between income and health which is often made in decisions with respect to accupational choice, Kerna (1985) developed a static one-period model of the demand for health by

labour force participants. Workers are assumed to maximize utility derived from consuming 'comodities' which are produced in the housenold by combining goods bought in the market with own time investment (Becker, 1965, Lancaster, 1966). Medical care does not enter the utility function directly but appears in the housenold production function for health as one of the market inputs. Kema (1985) shows that, under certain conditions, maximizing $U(\mathbb{H} C)$ is equivalent to maximizing $\mathrm{U}\left(\mathrm{H}_{4} \mathrm{Y}\right)$ where $\mathrm{y}$ is 'full income' in the Becker (1965) sense, defined as the market value of the individual's healthy time $H$ and $C$ is the composite good. This objective function is maximized subject to the following constraints:

$$
\mathrm{Y}=\mathrm{WH}+\mathrm{R}-\mathrm{P}_{\mathrm{m}} \mathrm{M} \quad \text { (budget constraint) }
$$

Where $w$ is the wage rate, $R$ denotes other non-wage income and $\mathrm{fin}_{1} \mathbb{1 s}$ the market price of medical care.

$$
\mathrm{H}=\mathrm{H}\left(\mathrm{H}_{0}, \mathrm{M}, \mathrm{S}, \mathrm{Z}\right) \text { (nealth production function) }
$$

where $H_{0}$ is the individual's predetermined health at the beginning of 
the period, $M$ is inedical care input, $S$ is the level of schooling assumed to affect the efficiency of production and $z$ denotes exposure to occupational nealth hazards as a consequence of an unhealthy work enviroment. The latter variable is introduced because the objective of the study was to investigate an occupational linkage in the relationship between schooling and health. It is therefore also introduced in the third constralnt wich describes the rarket clearing wage function:

$$
w=w(2, H, S, A)
$$

Apart from the individual"s own health $H$ and the health risks of the job $(z)$, the wage rate is assumed to be dependent on the worker's muan capital as measured by schooling (S) and experience proxied by age (A).

By solving this problem with respect to the decision variables $z$ and $M$ Kema (1985) is able to derive their demand functions. However, because health is endogenous in this model, a "demand for health" function can also be derived from the first order optimality conditions for $z$ and $M$. In general and implicit form it can be specifled as:

$$
H=H\left(R_{H}, W^{*}\right)
$$

where $\mathrm{P}_{\mathrm{H}}$ is the shadow price of health and $\mathrm{w}^{\text {is }}$ is called "real full wealth" " The "optimal" health level is then not exogenously given to the individual but can be increased or decreased by changing $\mathrm{z}$ or $\mathrm{M}$. The shadow price of health assoclated with $z$ defined by ( $\mathrm{P}_{\mathrm{H}}(\mathrm{z})=$

$=-\mathrm{Y}_{Z} / \mathrm{H}_{Z}$ ) is the amount of incone foregone to obtain a marginal unit increase in health by choosing a lower $z$. Alternatively, health can be marginally increased by foregoing the amount of income associated with a marginal increase in medical care $M$ the shadow price equals ( $P_{H}(M)=$ $=-(\mathrm{M} / \mathrm{H} \mathrm{M})$. The shadow prices of health associated with $\mathrm{z}$ and with $\mathrm{M}$ $P_{H}(z)$ and $P_{H}(M)_{1}$ are equal at the optimm.

Because both the shadow price (or marginal cost) of health $\mathrm{PH}_{\mathrm{I}}$ and real full wealth $w^{*}$ are a function of the exogenous variables, the effects of changes in any of these exogenous variables on the demand for health can be calculated. Even though the comparative static results do not always yield unambiguous sign predictions, it is illustrative to show how the effects of schooling on health for instance, can be decomposed into direct and indirect effects as follows (see Kema, 1985, p. 42):

$$
\mathrm{dH} / \mathrm{dS}=\mathrm{H}_{\mathrm{Z}}\left(\mathrm{z}_{\mathrm{S}}\right)+\mathrm{H}_{\mathrm{M}}\left(\mathrm{M}_{\mathrm{S}}\right)+\mathrm{H}_{\mathrm{S}}
$$

where $f_{1}$ denotes the partial derivative of the variable $f$ with respect to variable 1 .

The first term on the right hand side of the equation represents the "occupation effect" of schooling on health through the demand for job nazands. The second term is indicated as the 'medical care 
consumption' effect of schooling on health. Finally, the third term gives the direct 'efficient production" effect of schooling on health. Kema's (1985) empirical work brings out that the total effect of schooling on health is positive, the largest part of which is accounted for by the direct effect $\mathrm{H}_{\mathrm{S}}$. Schooling is found to have a strong negative impact on the empirical construct measuring $z$, but only a weak positive effect (in magnitude and significance) on the demand for doctor visits. Moreover, $\mathrm{H}_{\mathrm{M}}$ turned out to be negative (!)and strongly significant. We w111 not discuss the estimation problems that were encountered in the empirical testing of this model here but refer to Chapter 5 of this thesis for that purpose.

In this section we only want to assess the merits of the household production approach to individual behaviour with respect to health. The model described above assumes that people choose their optimal level of health with reference to other desired comodities. Health is not valued above anything else. This implies that the desired health level will be adjusted downward if the marginal costs of maintaining it exceed the marginal benefits in terms of utility. In contrast to health, the level of schooling obtained is exogenously determined in this model. It 1 s, however, no longer assumed to be a mere taste shifting factor but entered explicitly in the household production function as an efficiency-increasing factor according to standard practice in household production theory (see e.g. Michael, 1972). It is not a direct factor of production because its use in the production of health does not diminish its avallability for use in other productive processes.

Although this model of the demand for health certainly has some clear advantages over the models of the demand for medical care discussed in the previous section, because it offers a better insight in the tradeoffs involved in deciding whether or not to consume medical care, it. is somewhat unfortunate that it does not provide an unambiguous prediction of the effect of schooling on the demand for health care. As a consequence, the determination of the 'medical care consumption effect of schooling', as referred to by the author remains an empirical matter. Moreover, a one-period time horizon overiooks the fact that decisions about activities which may be harmful or beneficial to one's health I1ke choosing a job, carry over to later periods of life. Enlarging the time horizon extends the range of trade-offs that can be considered from current to future costs and benefits. This aspect of health behaviour leads us to the class of models discussed in the next section.

\subsection{Life-cyclle models of the demand for health}

As was mentioned already in the introduction to this chapter, the most important breakthrough in the demand for health theory, has been 
Grosman's (1972a, 1972b) developnent of a formal framework to analyze nealth behaviour. 3 The point of departure in Grossman's work is that health can be viewed as a durable capital stock which depreciates with age but can be augmented through health investments. The fundamental difference between nealth capital and other numan capital is that the first determines the total time available to the individual for market and non market household production while the stock of knowledge affects housenold productivity. The stock of health therefore has to be distinguished from the services it generates in the form of healthy time over a certain period. The initial endowed stock of nealth is assumed - after early adulthood - to depreciate over time at an increasing rate, but gross investments can be produced by combining own time inputs of the consuner and market goods bought such as medical care, food, exercise, etc. As a consequence of the introduction of the stock concept, consumer decislons about health can no longer only depend on marginal costs and benefits in each period separately because benefits of health also accrue in the future. The decision framework then becomes intertemporal, extending to the rest of the 11 fe cycle. Even the length of 1 ife becomes endogenous because death occurs when the stack of health falis below a critical leveli: at some age the individual is no longer able or willing to compensate increased depreciation by gross health investment.

To gain some more insight into the basic model set up, it is useful to reproduce here the basic equations (see Grossman, 1972 b or Murinen, 1982): Each individual is assumed to maximize life-time utility which is a function of $C_{t}$ a compositecommodity, and $h_{t}$ the healthy time in period $t$ :

$$
u=u\left(c_{0}, \ldots, c_{t} ; n_{0}, \ldots, n_{t}\right)
$$

The relation between health services $h_{t}$ and health stock $H_{t}$ is given by $t_{t}$, the service flow per unit stock:

$$
n_{t}=\Phi_{t}\left(H_{t}\right) \quad \text { with } \Phi_{t}^{\prime}>0
$$

By definition, in each period net investment in the stock of nealth equals gross investment minus depreciation:

$$
\mathrm{H}_{t+1}-\mathrm{H}_{t}=I_{t}-\delta_{t} H_{t}
$$

where $I_{t}$ denotes gross investment and ot the rate of depreciat-ion during period $t$. The length of life $T$ is determined by the condition that

$$
\mathrm{H}_{\mathrm{t}} \geq \mathrm{H}_{\min }
$$

where $H_{\text {min }}$ represents a munimal stock of health which isnecessary to survive. Death takes place at $\mathrm{T}$ when $\mathrm{H}_{\mathrm{t}}<\mathrm{H}_{\text {hin }}$. Both $\mathrm{I}_{\mathrm{t}}$ and $\mathrm{z}_{\mathrm{t}}$ are produced using time and market goods as inputin the following housenold production functions:

$$
\mathbf{z}_{t}=\mathrm{z}_{\mathrm{t}}\left(\mathrm{x}_{\mathrm{t}}, \mathrm{T}_{\mathrm{t}}^{\mathbf{z}}: \mathrm{E}\right)
$$




$$
I_{t}=I_{t}\left(M_{t}, T_{t}^{n} ; E\right)
$$

where $x_{t}$ is the market good input and $T_{t}{ }^{2}$ the time input inproducing $\mathrm{Z}_{;} \mathrm{M}_{\mathrm{t}}$ is medical care and $\mathrm{T}_{\mathrm{t}}{ }^{\mathrm{h}}$ time spent investing in health. $\mathrm{E}_{\mathrm{s}}$ the level of education, is not a direct input factor in household production, but operates as a production efficiency-increasing factor. Maximization of (2.6) is also constrained by the total time avallable per period and a 11 fe-time budget. The time constraint equals

$$
\Omega_{t}=T_{t}^{W}+T_{t}^{z}+T_{t}^{n}+T_{t}^{s}
$$

where $\mathrm{T}_{t}{ }^{w}$ is working time and $\mathrm{T}_{t}{ }^{s}$ sick time. The health capital stock determines the amount of time available for market and non-market production according to $(2.7)$ as total time $\Omega_{t}$ minus sick time $T_{t}{ }^{s}$ :

$$
\Omega_{t}-T_{t}^{s}=n_{t}=\Phi_{t}\left(H_{t}\right)
$$

The budget constraint requires that the present value of current and future market purchases equals the present value of earnings income over the 1 ife cycle plus any initiall assets $A_{0}$ (the discounted nonwage income):

$$
\sum_{t=0}^{T} \frac{P_{t}^{x_{x}}+P_{t}^{M} M_{t}}{(1+r)^{t}}=\sum_{t=0}^{T} \frac{W_{t} T_{t}^{W}}{(1+r)^{t}}+A_{0}
$$

The new symbols introduced here are $F_{t}{ }^{X}$ and $F_{t}{ }^{M}$ the prices of $x_{t}$ and $M_{t}$, the wage rate $w_{t}$ and the interest rate $r$. By maximizing $(2.6)$ subject to the constraints $(2.9),(2.12)$ and $(2.13)$ and taking into account the production relationships $(2.10)$ and (2.11), the following equilibrium condition can be derived for investment in health $I_{t}$ in period $t$ (see Grossman, 1972b, pp 228-231, or Murinen, 1982a, pp 2223).

$$
\frac{U_{t}(1+r)^{t}}{\lambda} \frac{\Phi_{t}^{\prime}}{\pi_{t-1}^{n}}+\frac{w_{t} \Phi_{t}^{\prime}}{\pi_{t-1}^{n}}=r+\sigma_{t}-\pi_{t-1}^{n}
$$

(a)

(b)

Where $\mathrm{U}_{\phi t}$ is the marginal utility of healthy time, $A$ the marginal ut111ty of wealth $\Phi^{\prime}$ the marginal product of health capital in terms of healthy time, $\pi_{t-1}$ the marginal cost of health investment in period $t-1$, and $\tilde{\pi}_{t-1}$ the percentage rate of change in marginal costs between periods $t-1$ and $t$.

Equation (2.15) fully determines the optimal stock of health capital for the individual: basically, it states the fundamental optimality condition from investment theory that the total rate of return on an investment equals the user cost of capital at the margin. The first term (a) on the left hand side of the equation represents the marginal consumption benefits of health (Grosman (1972b) also calls it the 
'physic" rate of retum) and the second tem (b) is the marginal monetary rate of return of health (also called the marginal efficiency of health capital).

For further analys 1s, Grosman distinguishes between the 'pure investment" submodel wich assumes that healthy time does not yield direct ut1lity (1.e. term (a) is zero) and the "pure consumption' submodel in which the monetary beneflts are assuned to be negligible (1.e. term (b) equals zerol. Comparative static predictions for the effects of changes in the exogenous variables (1.e. age, education, wage rate and incomey on the demand for health and medical care are derived for the 'pure investment' submodel in Grossman (1972b).

We will restrict our discussion nere to a verbal description of the effects of education. A higher education level enables the same increase in health to be produced with fewer inputs of both time and medical care. This implies lower marginal costs of health investment, and therefore a nigher demand for health. on the other hand, the education effect on the demand for medical care is negative if the elasticity of the marginal efficiency of health capital in producing healthy time is less than unity. This means that more knowledgeable consumers are expected, ceteris paribus, to demand more health and less medical care. Most of Grosman's (1972a) empirical analysis is restricted to white males in the labour force with positive sick time. A number of additional assumptions nad to be made regarding the explicit functional forms of the utility, investment and production functions in order to be able to derive estimable demand functions for health and a reduced form demand for medical care function. The findings support the positive health effect of education but education does not show a statistically significant effect on the demand for medical care.

One of the critlcisms directed at Grossman's basic model by Murinen (1982a) was concermed with the role of education. According to conventional practice in the household production approach education is assumed to operate as a purely technical effect at the level of the specific production relationships. However, several authors (e.c. Welch (1970) and Michael (1972)) have argued that education also enhances allocative ability, 1.e. it does not only raise the marginal product per input but may also increase knowledge about innovative production methods and therefore alter the choice of input mix" "In the context of health the allocative benefits of education may be seen as consisting of life-style selection, diet and exercise decisions, and the more technical benefits as showing up in more efficlent production of health from better medical knowledge, more information about altemative sources of care, etc.' (Murinen, 1982a, p. 9). To incorporate these allocative benefits of education, she introduces the concept of use-related depreciation of health by andogy with the firm's investment theory. The rate of health depreciation $\delta$ then becomes a function, not only of age, but also of the intensity with which this stock is used. 4 The use intensity itself 
is dependent an a number of envirommental variables (such as stress or pollution) which also includes education. The change of the health stock over time in Murinen's (1982a) continuous time version of Grossman's model is defined by the following equation:

$$
H(t)=\frac{d H}{d t}=f(t) \cdot M(t)-d[t, x] H(t)
$$

where $f(t)$. $M(t)$ is the new health produced by the use of medical care $M(t)$ multiplied by its marginal health product $f(t)$. The depreciation rate $\delta$ is a function of age $t$ and environmental variables $x$ including education. An advantage of the use-related depreciation device is that education (and enviromental varlables in general) can then be operative on health also in periods without health investment (1.e. When $M(t)$ is zero). Note also that the traditional housenold production framework and the role of time inputs and wages as time prices have been dispensed with in this model. Health investment has a narrow interpretation of medical care use. Despite the claim of superiority of this model over Grossman's model, the comparative static results with respect to education are practically the same, though somewhat less dependent on additional assumptions (see Murinen, $1982 \mathrm{a}_{1}$ pp 18-19). The effects of education were not examined in detail in Murinen's (1982b) empirical analys is of Finnish Health Survey Data because of data 1 imitations. The distinction between the hypotheses about education as an efflciency-improving or a use-related depreciation factor therefore seems to be more relevant on the conceptual than on the empirical level.

The most recent attempt to test empirically some of the predictions generated by Grossman-type models of the demand for health was made by Wagstaff (1986). He advocates the estimation of structural rather than reduced form equations of the demand for health and medical care and shows that the latter may fail to detect inconsistencies between the model predictions and the data. His theoretical model is basically a continuous time version of Grossman's original model but with a broad view of health investment as including all types of health-promoting behaviour and with use-related depreciation as affected by healthdamaging behaviour and environmental influences (see also cropper, 1981). The standard household production framework is adopted with wage rates acting as time prices and education as a productivityincreasing factor. In contrast to earlier studies which estimated either the 'pure investment' on the 'pure consumption" model, he derives empirically estimable structural and reduced form demand functions for both submodels. His findings also have important implications for the effects of education. Three of them need to be mentioned here. First of all, it is shown that the coefficient of education in the reduced form demand for medical care equation can have the right (predicted) sign for the wrong reason. If Grossman's assumption is followed that health investment I is produced by combining time and medical care according to a cobb-Douglas. constantretums-to-scale production function, the derived marginal cost of health investment $\pi^{H}(t)$ becomes a loglinear function of education (see 
Wagstaff, 1986, p. 199 or Grossman, 1972a, p. 97):

$$
\ln n^{H}(t)=(1-\alpha) \ln w(t)+\alpha \cdot i m^{m_{P}}(t)+B E
$$

where $\mathrm{p}^{\mathrm{m}}$ is the price of medical care, $a$ is the Cobb-Douglas parameter Which indicates the share of medical care in the total cost of gross investment $10<\alpha<1), W(t)$ is the wage rate and $E$ is education. The parameter $B$ should be negative if education increases health productivity. Now, in the reduced form demand for medical care equation of the pure investment model the coefficient of education becomes

- $[B(\epsilon-1)]$, where $\in$ Is Grossman's elasticity of the marginal efficiency of capital. It is defined as $\epsilon=\frac{1}{1+c}$ and $c$ is deriwed from the healthy days production function with decreasing marginal productivity $n(t)=b . H(t)^{-c}$, with $n(t)$ healthy time, $H(t)$ is health stock and $\mathrm{b}$ and $\mathrm{c}$ are positive constants. Note that $0<\epsilon<1$ if $c>0$. The education-efficiency hypothesis $(B<0)$ cannot simply be tested by checking the sign of the reduced form parameter because $-\beta(e-1)$ is negative:

(a) If $B<0$ and $0<e<1$

This would be consistent with both the education-efficiency hypothesis and diminishing marginal product of health $(c>0)$. But also:

(b) if $B>0$ and $\epsilon>1$

In this case two inconsistencies of the model could result in the same sign prediction as that of the model. Similarly, if the estimated reduced form parameter were found to be positive, it is impossible to determine which of the two hypotheses is violated. Wagstaff (1986) shows that the structural parameter estimates provide a stronger test of the Grossman model predictions because the coefficient of education in the structural derand for medical care equation equals $\beta$. Its sign and magnitude can therefore be tested directly.

A second interesting result on education derived by Wagstaff is that exactly the same problems occur when cropper's (1981) and Mirurinen's (1982a) assumption is made that education affects the rate of depreciation $\delta$ rather than the efficiency of non-market production. If, for example, the depreciation rate function o(t) is assumed to be of the logl inear form suggested by cropper (1981):

$$
\text { In } \delta(t)=\gamma_{0}+\alpha_{0} t+\beta_{0} E
$$

then $B_{0}$ should be negative if it decreases the use intensity of health by lowering the decay rate. However, the reduced form coeffucient of education in the demand for medical care equation then becones

- Bo $(\epsilon-1)$ and its estimation gives rise to 1dentical interpretation problems as described earlier. Wagstaff (1986) therefore concludes that, al though conceptually distinct, both approaches to the impact of education cannot be distinguished at the operational level.

The third important point about the effect of education raised by Wagstaff (1986) is related to the pure consumption sumodel of the denand for health. Recal॥ from (2.15) that when the production 
benefits of health (term (b)) are neglected, the remaining expression for the equilibrium condition contains the Lagrange multiplier $\lambda$ which is called the marginal utility (or shadow price) of wealth. In the continuous time model formulated by wagstaff (1986), the analog is $\lambda(0)$ e $(\pi-r) t$ where $\lambda(0)$ is the shadow price of initial assets $r^{5}$ is the interest rate and $p$ is the rate of time preference $(r=p$ in Grossman (1972a) and Murinen (1982)). The unobservable $\lambda(0)$ then becomes an important variable in the demand for health function. Murinen(1982b) and Grossman (1972a) approximated $1 / \lambda(0)$ by income, but Wagstaff (1986), using results from lifecycle models of labour supply and consumption (e.g. Heckman, 1976; Macurdy, 1981), assumes $\lambda(0)$ to be a fumction of education besides other variables such as life-time wage income, and initial assets. When predicted, respectiveIy postdicted, values of the latter two variables are added to the structural demand function, the effect of education changes from significantly positive to significantly negative! This is not so surprising since education is one of the variables used to estimate the values of the other two variables, and therefore the degree of multicollinearity is raised considerably, but the finding casts doubt on the earlier prediction-confiming positive estimates of the education coefficient. Wagstaff (1986) concludes: 'In view of the fact that "years of education" tends to be highly correlated with both initial assets and lifetime wages, there can be little doubt that in many of the studies in this field education is acting as a proxy for the real Iffe-time wealth variable $\lambda(0),(p .223)$. As a response to the fact that in the pure consumption version of the model both education and a number of other varlables change sign in both the demand for health and some demand for medical care equations, other methods are suggested to overcome the unobservability of $\lambda(0)$ which avoid the multicollinearity problems (Wagstaff, 1986, p. 229). Altematively, one could question the theoretical model from which the equations have been derived, especially because other crucial model ingredients like the derived demand hypothesis and the use-related depreciation nypothes is are also rejected by the econometric tests.

This last digression serves to 11lustrate the problems which are encountered when one tries to establish the effects of education in a lifecycle model of the demand for health and medical care. Wagstaff's (1986) rigorous testing of Grosman's (1972a) basic model certainly does not reinforce the confidence in the model as a description of decision-making about medical care use. Perhaps the view of medical care as an investment in health is not very adequate for the bulk of curative medical care consumed. This refers to an early criticism by Usher (1975): 'Most medical expenditure is not a profitable investment uniess I happen to be 111" (p. 215). Indeed, the marginal health product of most curative care is zero or negative unless people are sick or disabled. Moreover, even if the Grossman model is more designated to describe preventive health behaviour, it may well be the case that medical inputs represent only a minor share in effective preventive activities compared to general lifestyle. How then could 
the decision to demand (curative) medical care be modelled more appropmiately? A suggestion was made by Usher (1975)" "An altemative way of modelling the decision to purchase medical care is to suppose that health is a disposition not to be sick too often. that falling 111 is a randon process dependert on the state of one's health and that medical expenditure can be either a cost of being sick today or an irvestment in health tomorrow" (p. 215). This idea will be one of the subjects of attention in the next section where uncertainty about future health 15 introduced in the demand models.

Another major concern with the deterministic models described so far 15 expressed by Evans (1981) as follows: 'A more serious weakmess. however, is the cormon but aggressively counterfactual assumption that consumers possess full information about health production functions" (p. 354). Indeed, the second type of uncertainty, referred to by Arrow (1963) as a crucial characteristic of the demand side in the health care market and leading to the issue of the patient-physician relationship as belng one of agency, is completely ignored. In the following section, we will examine the consequences of relaxing the assumptions of complete certainty and full information in a static framework.

\subsection{Stochastic models of the demand for health}

In order to introduce uncertainty into behavioral models, usually some parameter is assumed to be a random variable with a known probability distribution. Consequently, in the consumer's objective function utility is replaced by expected utility. In this section we will distingulsh between two types of uncertainty models, following Arrow's (1963) distinction: uncertainty with respect to health status and uncertainty with respect to the effectiveness of medical care. Both types of uncertainty lead to different derived demands: uncertain health leads to a derived demand for health insurance, and uncertainty as to the quality of the product of medical care leads to a derived demand for information.

\subsubsection{Uncertainty with respect to neal th}

Grossman (1972a) made some suggestion as to how uncertainty could be introduced into his model. It could be postulated that the consumer faces a probability distribution of depreciation rates. Using the state-preference approach (see Enrlich and Becker, 1972) to cholce under uncertainty, some results can be reached, none of which, however, tend to alter the major conclusions of his deterministic framework. General1y, consumers might have an incentive to hold 'excess stocks' of health in relatively desirable states in order to avoid 'losses' in more unfavourable 'states of the world". No formal 
An uncertainty model in which the random losses approach is elaborated in a static framework in order to derive sone predictions regarding the demand for health insurance is given by Phelps (1973, 1976). Health $H$ enters the utility function together with a composite good $c$ and is produced by medical care (m) and own time in fixed production coefflclents. The stock of health is subject to random losses I having a known distribution $f(\tilde{I})$. The health equation then becomes

$$
\mathrm{H}=\mathrm{H}_{\mathrm{O}}-\tilde{1}+\mathrm{g}(\mathrm{m})
$$

where $\mathrm{H}_{0}$ is the endowed level of health. $\tilde{I}$ the random amount of losses (11inesses) and $g(m)$ the health product of medical care. An optimal coinsurance rate and maximm payment amount are derived from maximizing expected utility over all possible states of iliness and subject to a budget constraint. In later work (e.g. Keeler, Newhouse and Fhelps, 1977), this basic model is extended to a multi-period model in order to examine the effects of deductibles and coinsurance rates on the derand for medical care services.

In all the above mentioned applications of the random losses approach the uncertainty of health is exogenous, i.e. the probabilities of falling ill are not influenced by the individual"s decisions about medical care use. As was mentioned before, this does not seem to be a realistic assumption in the case of preventive activities (such as the use of preventive medicine) because one would hope that these have a negative impact on the probability of future illness occurrence. In order to allow for this endogeneity of the probability distribution of 111 health, Phelps (1978) has modified his original model so as to make this distribution a function of preventive inputs. As before, expected utility is defined as the sum of all utility states multiplied by the probability of being in the corresponding state of health. For simplicity, only two states are being considered: the sick state (with probability $\pi$ ) and the healthy state (probabllity 1-il):

$$
E(U)=\pi\left(C_{1}, H_{1}\right)+(1-\pi)\left(C_{2}, H_{2}\right)
$$

where $\mathrm{c}_{1}, \mathrm{H}_{1}$ and $\mathrm{c}_{2}, \mathrm{H}_{2}$ refer to the consumption of other boods and health in the healthy and the sick state respectively. The consumers health level in period $t$ is now determined by

$$
\mathrm{H}_{t}=\mathrm{H}_{0}-\tilde{\mathrm{l}}+\mathrm{g}(\mathrm{P}, \mathrm{m})
$$

with $\mathrm{H}_{0}$ endowed health, i a stochastic varlable which takes the value zero with probability $1-\pi$ and the value 1 with probability $\pi$. Health production $g$ is a function of both the use of preventive medical care (F) and acute medical care (m). However, preventive care is also assumed to have a negative effect on both the 11 lness probability $(\pi \mathrm{p}<0)$, and on length of 1 llness perlod $\mathrm{L}\left(\mathrm{L}_{\mathrm{p}}<0\right)$, whereas acute medical care $m$ only offsets total sick time: $L_{m}<0$. Sick time $L$ 
enters the model trrough the "full income' budget constraint which also incorporates the time and money prices of preventive and acute care and other goods. Phelps (1978) formulated first-order optimality conditions for this problem but did not expllcitly derive comparative static predictions for the demand for preventive and acute medical care. Rather, he assessed the value of preventive medical care such as direct utility gains, work-loss-time and acute medical care expenditure avolded with the view to draw some implications for private and public health insurance. It is shown, for instance, that under certain conditions and because prevention and acute care are substitutes, extending medical care insurance could reduce the demand for preventive care (see Phelps, 1978, p. 190). He does not discuss the introduction of schooling effects into this framework.

The latter modification is made by rema (1985) in the stochastic version of his model of the demand for health and occupational hazards. He makes the probablilty of falling 111 not only a function of the consumption of preventive medical care $F$, but also of the endowed health level $H_{0}$ of the job hazards $z$ and of the schooling level $s:$

$$
\pi=\pi\left(H_{0}, P_{n} \mathbf{z}, S\right)
$$

with $\pi_{z}>0 ; \pi_{H_{0}} \pi_{S^{\prime}} \pi_{P^{<}}<$; and $\pi_{1 j}=0$ except $\pi_{P, S} \leq 0$.

Th1s last second-order cross derivative is non-positive to reflect Grossman's education-efflciency nypothesis for preventive care: schooling is assumed to reinforce the negative marginal impact of preventive care on the illness probability. The marginal product of curative medical care, however, is assumed to be zero in the healthy state. The distinction between curative and preventive medical care introduces an additional decision variable in the optimization problem. It $1 \mathrm{~s}$ demonstrated that maximization of expected utility by a risk averse individual leads to similar comparative static predictions as the deterministic model regarding the effect of education on the demand for curative medical care. Recall from section 2.3 that this effect was amblguous. The marginal impact of schooling on the demand for preventive medical care can be shown to be positive under certain conditions, which is not surprising given the assumptions. Neither Phelps (1978) nor Kema (1985), have estimated demand functions for preventive medical care.

Sindelar (1982) uses a very similar two-period model to explain sex differences in the use of preventive medical care. It predicts that individuals with a higher probability of death (or health loss) from causes of death which cannot be deterred by the prior use of medical care w111, ceteris paribus, use less of that care. The nigher risk of violent death for males is estimated to account for about $30 \%$ of the observed difference in average expenditures on doctor's care. Coyte (1983) adopts essentially the same assumptions to define the difference between preventative and remedial services in modeliing consumer behaviour on the demand side of a market equilibrium 
Finally, endogenous uncertainty in health has been incorporated in a lifecycle model of health investment by cropper (1977). She also uses the distinction between the sick and healthy state but in a more dynamic context than the models discussed previously. The health stock is assumed to decay at a constant rate over time but depreciation can be prevented by investment in preventive medical care $\mathrm{M}_{t}$ i.e. $\mathrm{H}_{\mathrm{t}}=\mathrm{M}_{\mathrm{t}}{ }^{*}-\mathrm{d}_{\mathrm{t}}$.

When the health stock $H_{t}$ falls below a certain critical sickness level $H_{1}$ no utility is derived from consumption of other goods. This critical level of exposure to lliness $H^{-}$has a known random probability distribution $f(H)$. The probability of being healthy then becomes

$$
F(H)=\int_{0}^{H_{t}} f(\bar{H}) d \bar{H}
$$

As a result, expected utility at time $t$ can be written as

$$
\mathrm{EU}_{\mathrm{t}}=\mathrm{F}(\mathrm{H}) \mathrm{U}\left(\mathrm{Y}-\mathrm{PM}_{\mathrm{t}}\right)
$$

where $c_{t}=Y-M_{t}$ is the consumption of other goods when total income $Y$ minus medical expenditure (FM) is spent on $C$. Maximizing discounted lifetime expected utility, given an initial stock of health and a fixed time of death, an optimal path of investment and health capital is derived. The most interesting prediction from this version of Cropper's (1977) mode ${ }^{6}$ is that investment in nealth is $11 \mathrm{kely}$ to decrease steadily with age after early adulthood. This striking contrast with Grossman's (1972a) result of increasing investment in health over time is, of course, a consequence of the preventive nature of medical care expenditures in this model which yield returns over a shorter remaining period of life at higher age.

Although this model is illustrative of the way in which intertemporal decision-making and the randomess of illness can be and perhaps should be, conblned in a stochastic lifecycle model, it is not inmediately useful for our purposes because the role of education or Knowledge is not explicitly taken into account. Furthermore, the lack of empirical testing is indicative of the fact that increased mathematical complexity at the theoretical level also increases the difficulties involved in deriving testable predictions. For the time being, it therefore probably remains an elegant conceptual framework which may help to shape thinking about health behaviour as investment.

\subsubsection{Uncertainty with respect to the effectiveness of medical care}

All models we have alscussed so far implicitly assume that consumers of medical services know exactly what medical care can or cannot 
contribute to their nealth. In other words: they possess full Information on the nature of their health production functions. Mmong others, in particular Pauly (1980) has drawn the attention to the inappropriateress of this assumption iven the widespread recognition of consumer lgnorance in medical matters. He has also suggested now this type of uncertainty could be introduced in the dernand for health models. Starting from the simple single perlod model with utility determined by health $\mathrm{H}$ and other goods $c_{s}$ 1. e. $U=U(H, c)$, and with the health production

$$
\mathrm{H}=\mathrm{H}_{\mathrm{O}}+\mathrm{B}, \mathrm{M} \text {, }
$$

and the budget constraint given by

$$
\mathrm{Y}=\mathrm{c}+\mathrm{pM}
$$

he assumes the marginal health product of medical care $g$ to be uncertain. So, in this model not $H$ but rather becomes a random variable with a know (subjective) probablilty distribution $f(\tilde{\mathrm{B}})$. Substituting all constraints into the objective function results in the following expected utility maximization problem

$$
\operatorname{Max} \mathrm{E}(\mathrm{U})=\int_{\mathrm{G}} \mathrm{U}\left(\mathrm{Y}-\mathrm{AM}, \mathrm{H}_{0}+\tilde{\mathrm{g}}, \mathrm{M}\right) \mathrm{f}(\tilde{\mathrm{g}}) \mathrm{d} \mathrm{g}
$$

where $\mathrm{G}$ denotes the integration interval for $\mathrm{g}$.

Optimality conditions for this problem require medical care to be consumed so that expected marginal utility is equalized for all poss lble values of $g$ :

$$
\forall i, j: \pi_{1} U^{\prime}\left(B^{i}\right)=\pi_{j} U^{\prime}\left(B^{j}\right)
$$

In a second stage, Pauly (1980) adds the possibility for the consumer to obtain additional information on $\tilde{B}$ from a physician. In order to be able to combine the physician's advice of the effectiveness of medical care $M$ in the particular health state $H_{0}$ with the individual's own prior belief it is necessary to assume that patients behave as Bayesian decision-makers. If it is assumed that diagnostic and therapeutic information supplied by the physician also comes in the form of a probability distribution, Bayes" rule provides a mechanism to transform prior knowledge and external advice into a posterior distribution. If $f(\tilde{g})$ is the prior (subjective) probability distribution, $f\left(\tilde{g}^{\mathrm{a}}\right)$ is the (unconditional) distribution of the physician's advice $f\left(\tilde{B}^{\mathrm{a}} \mid \mathrm{g}\right)$ indicates the conditional distribution (or the likelinood function) of the advice and $f\left(\tilde{b} \mid \tilde{B}^{a}\right.$, is the posterior distribution then Bayes' rule can be written as

$$
f\left(\tilde{B} \| \tilde{B}^{\mathrm{a}}\right)=\frac{f\left(\tilde{B}^{\mathrm{a}} \mid \tilde{\mathrm{B}}\right)}{f(\tilde{\mathrm{B}})} f(\tilde{\mathrm{B}})
$$

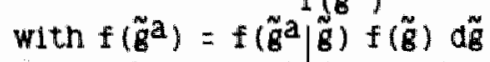

since the ex post (1.e. after recelving advice) decision of the consumer about treatment will depend on $f\left(\tilde{\mathrm{g}} \mid \tilde{\mathrm{g}}^{\mathrm{a}}\right)$, and not on $\mathbf{f}(\hat{\mathrm{B}})$, it. is important to know which characteristics of the prior distribution 
and of the adjustment factor (the ratio of the conditional and unconditional distribution of the advice g) determine how much the posterior deviates from the prior. Pauly (1980) shows what happens in two extreme degenerate cases (complete certainty and complete ignorance of the patient) but does not derive any general comparative static results: "One can say that the response to new information of the indiwidual's use of care is likely to be different for persons with different prior bellefs or prior stocks of information. But it does not appear that one can make any general a priori conjectures about the direction of this relationship" (p. 47). However, he does show that in the bivariate case, when the distribution of is characterized by only one (prior) probability $\pi_{3}$ the effect of the physician's advice $\mathrm{g}^{\mathrm{a}}$ on the change in this $\pi$ is smaller the larger is $|\pi-1 / 4|$. The proposition that the more informed are less responsive to Information than the ignorant (with $\pi$ close to $/ /$ ), becomes the bas is of his empirical work. We will defer the discussion of this empirical analys is to chapter 4.

The cruclal thing to note from Pauly's (1980) suggestion is that the Bayesian approach provides the missing $1 \mathrm{ink}$ between on the one hand the demand models based on sovereign, fully informed, rational consumers discussed in previous sections, and, on the other hand, the so-called 'need' models discussed in various health economics textbooks (e.e. Cul1s and West (1979), Newhouse (1978)) which imply that the decision about how much medical care to use is entirely determined by the medical expert. These two opposed viewpoints become in the Bayesian context just two extreme cases of the general principle that decisions are based on a mixture of own and expert information. As a consequence, patients do not only demand treatment but also diagnostic and therapeutic information which is often obtained from the same provider. The provision of information then becomes the vehicle through which suppliers can manipulate demand. The accuracy of information also becomes a new decision variable in the models of physician behaviour which are discussed by Pauly (1980) at a rather global conceptual level. In sum the main message of Pauly's (1980) reasoning is that the demand for and supply of information should form an integral part of any attempt to model medical care transactions. Although his analysis is primarily conceptual, it clearly indicates that the Bayesian approach has a lot of potential to offer in derlving the demand for information and explaining its effect on the demand for medical care.

The Bayesian approach to modelling information asymetry is also adopted by coyte (1984). In order to be able to explain the 'stylized fact' of demand creation in health care, he relaxes the full information assumption in his equllibrium analysis of the market for medical services based on hedonic price theory. Consumers are assumed to be uncertain about the effectiveness of medical care in reducing the length of an lilness episode. Physiclans can raise demand for the ir services by overstating the value of medical care but this abllity is 
constrained by the patient"s possibilities for monitoring physicians. They only engage in monitoring whenever the marginal benefit from wonitoring exceeds its marginal cost. The predictions derived from this model are basically the same as in Pauly (1980) but no empirical testing is pursued.

\subsection{Conc lus lons and implications for research strategy}

The survey of 1 iterature presented in this chapter was set up in such a way as to indicate the development in the theory of the demand for medical care. Basically, four major characteristics could be identifled: (1) the derivation of the demand for medical care from the more fundamental demand for health (2) the investment character of medical care use when health is regarded as a durable stock of human capital. (3) the randon nature of health losses which causes a derived demand for insurance and allows for a distinction between preventive and curative care, and (4) the imperfect information on the effectiveness of medical care which induces a derived demand for diagnostic and therapeutic information. In table 2.1 most of the models discussed in this chapter are ordered according to three dividing lines. This survey is not exhaustive but it does present a useful description of what modifications are necessary in order to extend the basic textbook model of consumer demand.

Table 2.1. Survey of formal models of the demand for health and medical care

DETERMINISTIC

STOCHASTIC

Health losses $\begin{gathered}\text { Effect of } \\ \text { medical } \\ \text { care }\end{gathered}$

\begin{tabular}{|c|c|c|c|}
\hline STATIC & $\begin{array}{l}\text { Fhelps \& Newhouse (1974) } \\
\text { Acton (1975) } \\
\text { Kerma (1985) }\end{array}$ & $\begin{array}{l}\text { Ehelps }(1976,1978) \\
\text { Sindelar (1982) } \\
\text { Kema (1985) } \\
\text { Coyte (1983) } \\
\text { Keeler et al. (1977) }\end{array}$ & $\begin{array}{ll}\text { Pauly } & (1980 \\
\text { Coyte } & (1984\end{array}$ \\
\hline DRNAMIC & $\begin{array}{l}\text { Grossman }(1972 a, b) \\
\text { Murinen }(1982 \mathrm{a}) \\
\text { Cropper (1981) } \\
\text { Wagstaff (1986a) }\end{array}$ & $\begin{array}{l}\text { Cropper }(1977) \\
\text { Hey \& Patel (1983) } \\
\text { Ippolito }(1981)\end{array}$ & \\
\hline
\end{tabular}

What have we learned from this overview of demand models that is useful for the objectives of this study? First, the relationship between the demand for medical care and the consumer's stock of 
Knowledge cannot be investigated in a meaningful way without also incorporating the more fundamental demand for health. The main reason for this is that in most models the influence of education (as a proxy for knowledge and skill) is channelled through the individual's production function of health. It is then assumed to operate at the purely tecmical level of health production as an efflciency-improving factor. This means that in circumstances when medical care is potentially beneficial to one's health the better schooled get more health out of the same use or, alternatively, need less care to achieve the same health improvement. This assumption is standard practice in household production theory and ylelds - under certain conditions - testable predictions reganding the effect of education on the demand for health and medical care in the structural form equations of the model (cfr. Wagstaff 1986a). However, it overlooks the basic criticism that, even for very informed consumers, the nature of the health production function remains highly uncertain. If as argued by Pauly (1978, 1980), the demand for medical care is Iargely a demand for information in order to reduce this uncertainty, the predictions regarding the effect of education may well differ from Grossman's (1972a). Especially because also empirical tests of the education-efficiency hypothesis were not convincing, it is worth pursuing a different approach. This will be done in Chapter 3 and 4 where it will be assumed that education induces a reduction in the uncertainty around - rather than an increase in the magnitude of - the marginal effectiveness of medical care. In addition, by distinguishing between general knowledge (e.g. education level) and specific knowledge (e.g. medical), it may be possible to discriminate both approaches empirically.

An alternative route to introducing education into the demand for health models was advocated by Murinen (1982a). She suggested that the direct, and permanent, effect of education as an enviromental variable on the use-intensity of the health stock might be much more important. In her model, education is not seen as an intervening variable in household production processes but rather as having a beneficial influence on decisions about the allocation of time and resources to production and consumption. Although the distinction between both approaches is basically a matter of convention because they lead to similar predictions about the effect of education on the demand for health and medical care, the "allocative" nealth benefits of education indeed intuitively seem to be more important than the purely technical benefits. In the second part of this thesis, we will attempt to test for these allocative benefits directly by analyzing health changes over time using panel data. So, rather than estimating structural or reduced form demand equations from cross-section data, we w11 concentrate on the basic identity which describes the net investment in health (equation 2.8 in section 2.4).

From the above, it has become clear that we have split the remainder of this thesis into two parts. The first part explores the relation- 
ship between knowledge and the demand for medical care using a static but stochastic theoretical model. In the second part, the more direct Inkage between education and health is exarnined in an explicitly dynamic but deterwinistic context. Ideally of course, one would prefer to tackle all issues sirultaneously by means of a comprenensive theoretical model of 1 ifecycle behaviour incorporating all sources of uncertainty. However, the literature review has show that the most complex models were not necessarily also the most fruitful in producing testable predictions. Stochastic lifecycle models found in the literature on health behaviour (e.g. Cropper, 1977; Ippolito, 1981; Hey and Patel, 1983) were not accompanied by any empirical analysis. Some support for the approach adopted in this thesis can be found in the following quotation from Murinen (1982) in the appraisal of her own econoralc model of health behaviour: "The generality of the mode 1 and the extent of problems it can analyse are its main advantages. However, in order to analyse specif ic problems in greater detail, it is necessary to concentrate on particular aspects of the model and to develop these submodels further, possibly at the expense of major simpliflcations in the rest of the framework." (p. 22). 
toves

1. Real full wealth $w^{*}$ is def uned as full income y plus healthy time valuad at its shadow price and divided by an average weithed price level isee rema 1985 , p. 39 ).

2. The atbiguity is caused by the fact that schooling ralses both the income and the healthy time component of full wealth and elther increases or decreases the shadow price of health (see Rema (1985), Appendices $B$ and $C$ ).

3. A formulation of essentially Grasman's model in a single period static fromew can be foumd in wasstaff $(1986 \mathrm{~b})$.

4. A similar procedure was also adopted by cropper (1981) an a pure unvestnent model of the demand for preventive health came whout explicit reference to the concept of use intens ity.

5. In terms of optimal control theory $2(0)$ is the value at $t=0$ of the co-state Wariable of the dynamic asset accumilation constraint (see e. 8 . Dorfman (1969) or Kanien and Schwartz (1981) for this terminology).

6. In the same article, she also analyzes the dynamics of two other variants of this model, one with time of death endogenous and one in which the trade-off between nidher wages and occupational hazardis is examined. 



\section{Part I. CONSUMER INFORMATION AND THE DEMAND}

FOR MEDICAL CARE 



\title{
Chapter 3. The demand for information on the quality of medical care
}

\begin{abstract}
"Frequently, the anly way a person can know whether he needs to see a physician, is to see a physician" (Fuchs, 1974 p. 147 )
\end{abstract}

\subsection{Introduction}

The 1 iterature survey of Chapter 2 has brought out that one potentialIy interesting approach to the relationship between a consumer's knowledge or information and his use of medical care has been left somewhat underdeveloped. The idea to view patients as Bayesian decision makers has been suggested by Pauly (1980) but he did not explore its consequences in great detail. In this chapter, we attempt to explore the issue further. First, we will briefly point out how the asymetry of information between demanders and suppliers has generated some special features of the market for medical care. A distinction will be made between intrinsic special characteristics of health care and characteristics which are largely responses (e.g. govermment intervention) to these peculiarities. Secondly, we present a formal model of consumer behaviour which is essentially an application of Kinlstrom's (1974) model of the demand for information about uncertain product quality to the demand for medical care. Some of its predictions will be tested in Chapter 4. Finally, before we draw some conclusions, section 3.4 illustrates Pauly"s (1980) informationmanipulation hypothes is in the Bayesian context.

\subsection{Asymetry of information in medical care}

Several authors have reviewed the peculiarities in the health care sector in order to derive welfare economic implications for the functioning of the market mechanism. Arrow (1963) drew the attention to the pervasiveness of uncertainty: "I will hold that wirtually all 
the special features of this industry, in fact, stem from the prevalence of uncertainty" (p 19). He distinguished between two types of incertainty (cfr. section 2.5). Type one is the uncertainty with respect to the occurence of illness. Insurance markets have developed to cover the financial losses associated with health risks. This did not occur for the (type 2) uncertainty about the effects of medical treatment. Ideally, such an insurance against a fallure to benefit from medical care would involve the transfer of the risk from the patient to the physician. We did not see the emergence of this sort of insurance contracts, according to culyer (1971), "because of the enormous costs of discovering whether treatment had been successful" (p. 58). The informational imbalance between patient and physician makes enforcement of standards of care very difficult. Therefore, other mechanisms have been used instead to reduce the uncertainty to the patient. In order to protect ignorant consumers, govermments have created barriers to entry in the medical profession. Exclusive licensure of medical doctors is assumed to ban low quality providers from the market. The special trust relationship between patients and their physicians, guided by an ethical code which also prohibits commercial advertising, and the requirement to obtain a prescription for ethical drugs, are other examples of institutional arrangements of this industry which are in fact a consequence of the basic uncertainty about product quality.

But patients can also engage themselves actively in informational activities: "When there is uncertainty, information or knowledge becomes a cormodity. .... Information, in the form of skilled care, is precisely what is being bought from most physicians, and indeed from most professionals" (Arrow, 1963, p. 18). Instead of considering medical care consumption merely as a delegation of decision-making to an expert-agent, it can also be viewed as a transfer of information. Pauly (1978) argues that most medical care contacts indeed consist for a large part of provision of diagnostic and therapeutic information. Especially primary care providers spend a great deal of their time informing patients about their health status and about the health outcames to be expected from different therapies. This advice has to be distinguished from the role played by advertising in other markets because the provision of information and services is integrated in one joint product.

The natura $\downarrow$ question which arises then is whether neo-classical demand theory can handle this problem. Arrow (1963) is sceptical: "the demand for information is difficult to discuss in the rational terms usually employed.... The elusive character of information as a comodity suggests that it departs considerably from the usual marketability assumptions about commodities (p. 18) $)^{\text {tr }}$. Other authors do not see any obstacles at alli compare Telser (1981): "the demand for drugs is related to the demand for the more general good health in the same way that the demand for automobile parts is related to the demand for automobiles". In fact, the solution to the problem may be somewhere in 
between these two positions: the neo-classical paradigm can be extended to allow for uncertainty about product quality.

Kinlstrom (1974a, b) has adopted a Bayeslan approach to consumer decision making to develop a general theory of the demand for information. He showed that, as soon as product quality is uncertain, information or knowledge becomes a comodity wich is demanded by consumers, not because of any desirable attributes it possesses in itself, but because it nelps them to make 'better' purchases of the uncertain product. This may give rise to 'unusual' demand behaviour in the neo-classical sense. Igmoring this in models of the demand for medical care could mean a serious misspecification because: "very few industries could be named where the consumer is so dependent upon the producer for information concerning the quality of the product"

(Fuchs, 1966, p. 137). In the next section, we will present Kinlstrom's (1974a) model and investigate its applicabllity to the demand for medical care.

\subsection{A Bayes lam approach to the derived demand for information}

\subsubsection{The Kinlstrom model of Bayesian consumer behaviour}

In this section, we describe a static model of consumer behaviour under uncertainty which resembles the one discussed in Pauly (1980), It draws heavily on Kinlstrom (1974a) who discussed the demand for information about the quality (1.e. the amount of carbohydrates provided) of cereal. Consumers are assumed to derive utility from two commodities: health $\mathrm{H}$ and some other composite good $\mathrm{c}$. The latter can be bought in the market at a constant price $\mathrm{P}_{\mathrm{Z}}$, but health is not for sale. Instead, health improvernents can be obtained from using medical care $m$ bought at the unit price $A_{m}$. The health production function has the following simple form:

$$
\mathrm{H}=\mathrm{H} \mathrm{O}^{+} \mathrm{bm}
$$

where $\mathrm{m}=$ amount of medical care utidization

$\mathrm{H}_{\mathrm{O}}=$ endowed health level at the begming of the period

and $b=$ marginal health product of medical care

Note that in this framework, in contrast to the dymamic health models described in chapter 2, $\mathrm{H}_{0}$ is predetermined. The consumer may lack both perfect diagnostic information (what is $\mathrm{H}_{0}$ ?) and therapeutic information (what is b?). We will assume that he knows what his initial health level $\mathrm{H}_{0}$ is, but that he is uncertain about the marginal effect of medical care, 1 .e. b becomes a randon variable $\tilde{b} .1$ of course, the effect of medical treatment b does have some relationship with the initial health condition $H_{0}$. It can altematively be written as fallows:

$$
b=\frac{H-H_{0}}{m}=\frac{\Delta H}{m}
$$


Th1s expression indicates clearly that $b$ measures the mareinal health increment per unit of medical care consumed. It was pointed out in the previous chapter that the marginal product of preventive and curative medical care can be distinisuished if health is assumed to be subject to random losses. Preventive care reduces the probability of a loss (11lness episode) but curative care is only effective in reducing sick time if a loss has occurred. Strictly speaking this implies that there 13 no (or at least very little) uncertainty about the effectiveness of curative medical treatment in the healthy state because it is percedved to be zero. Without this uncertainty, there can be no demand for information in the healthy state. This means that for curative care - which represents the major part of health care delivery - the demand for information can only arise in periods with some (perceived) nealth losses.

Although the consumer does not know the value of $b$ with certainty, he does feel able to attach probabilities to the various possible states of the world. This prior bellef is sumarized by a normal probability distribution with mean $b_{0}$ and variance $\frac{1}{\Phi} \cdot 2$

So let $\tilde{b}-N\left(b_{O}, \frac{1}{\phi}\right)=f\left(\tilde{b} \mid b_{0}, \frac{1}{\Phi}\right)$

In the consumer's subjective bellefs, the parameter $\mathrm{b}_{0}$ is his best guess of the marginal effectiveness of medical care for his health status. The parameter $\Phi$ expresses the confidence in his estimate. When he is unfamillar with medical care, $\$$ w1ll be very small and thus the variance of $\tilde{b}$ around $b_{0}$ very large. W1thout any extra information avallable to him the consumer maximizes expected utility subject to nis budget constraint, $1 . e_{\text {. }}$;

$$
\begin{gathered}
\max _{m z} E(U)=\int_{-d}^{+\infty} U\left(z, H_{0}+b m\right) f\left(b \mid b_{0}, \frac{1}{\Phi}\right) d D \\
\text { s.t. } y=p_{z} z+m_{m}
\end{gathered}
$$

where: $y=$ Income

$A_{n}=$ unit price of medical care $m$

$\mathrm{p}_{\mathrm{z}}=$ unit price of composite good $\mathrm{z}$

This maximization problem leads to a unique solution $\left(z^{*}, \mathrm{~m}^{*}\right)$ if $U$ is strictly concave in $z$ and $H$. The presence of uncertainty, implied by $\frac{1}{\phi}=0$, makes additional information on $b$ valuable to the consumer.

This information can be acquired from several sources; e.g.:

1. personal observations on $b$ by ow experience,

2 . observations taken from the experiences of others, or

3. purchased expert medical advice.

Regandless of the information source, the acquisition is usually costly, elther in terms of time or money. These costs have to be weighted against the benefits of making more informed and therefore 
'better" purchases. In this way the demand for information about. medical care is derived from the uncertainty of its effect on the consumer's health. Bayesian decision theory provides a method to incorporate this (sample) information into the decision-making process. In Kinlstrom (1974a), the consumer can obtain sample information about the quality of cereal from a research laboratory. It is assumed that this information comes only in the form of a "summary" given by the likelinood function $f\left(x \mid b, \frac{1}{b}\right)$. This is the conditionall density of a random variable $x_{\theta}$ given $b$ where

$$
\tilde{\mathrm{x}}_{\theta}=\frac{1}{\theta} \sum_{i=1}^{\theta} \tilde{y}_{1} \quad \text { with } \tilde{x}_{\theta}-\mathbb{N}\left(b, \frac{1}{\theta}\right)
$$

$\tilde{x}_{\theta}$ is in fact the sample mean of $\theta$ independent observations $\tilde{y}_{1} \ldots \ldots$ $\tilde{y}_{\theta}$. Each observation $y_{i}$ is itself a random variable, nomally distributed with mean $b$ and variance 1 . In that case, the sample mean is said to be a sufficient statistic which means that observing $\tilde{x}_{\theta}$ is equivalent to observing $\tilde{y}_{1}, \ldots, \tilde{y}_{\theta}$ (see e.g. Degroot, 1970, p. 155). By using sample means of normally distributed observations as the units in which to acquire information, $\theta$ provides a measure of the amount of information units provided by observing $\tilde{\mathrm{x}}_{\theta} \cdot{ }^{3}$ A nigher $\theta$ implies more information. If $\theta$ is large, the consumer can be falrly confident that observing $x$ is much like observing $b$.

It is further hypothesized that the consumer can choose the amount $\theta$ of information to be obtained at a $\operatorname{cost} q \theta$ where $q$ is the price of one observation $\tilde{y}_{1}$. In the present context and at this stage of the discussion, it is useful to think of $\ddot{y}_{1}$ as one physician advice. This means that in order to acquire more information, more opinions have to be obtained.

In deciding how much information to obtain (which sample to observe) the consumer will have to weight the costs of purchase against its value in terms of utility gains. How mach utility can be gained from better decisions as a consequence of better information? It is useful to consider first the extreme but simpler case in which perfect information can be obtained. Recall from $(3.4)$ that $E\left(U\left(z^{*}, m^{*}\right)\right)$ is the utility maximm for the individual when he only has his subjective prior distribution of $\mathrm{b}$ to rely on. Now suppose that he is able to observe what the value of $\tilde{b}$ w11 be. His optimal decision is then to choose $\mathrm{m}$ and $\mathrm{c}$, given $\tilde{\mathrm{b}}=\mathrm{b}$, so that $\mathrm{U}(\mathrm{z}, \mathrm{m})$ is maximized, which gives nim U(c(b), m(b)). This could be called the 'ex post utility', 1.e. after receiving perfect information. To arrive at the expected ut 11 ity (ex ante) with perfect information, this procedure has to be repeated for each possible $b$. In fact, the ex post utility of observing $\tilde{b}=b$ has to be weighted by its probabilitles of occurring given by the a prior 1 density function $f\left(b \mid b_{0}, \frac{1}{\Phi}\right)$. Expected utility of having perfect information therefore equals

$E[U(z(b), m(b))]=\int_{-\infty}^{+\infty} U\left(z(b), H_{0}+b m(b)\right) f\left(b \mid b_{0}, \frac{1}{d}\right) d b$ 
It can be shown that the expected value of receiving (perfect) inform ation is non-negative, i.e. 4

$$
E \mathbb{E}(z(b), m(b))]-E\left(U\left(z^{*}, m^{*}\right)\right) \geq 0
$$

In other words: acquiring perfect information costlessly cannot make the consumer worse of $f$.

In General, however, he will not be able to obtain perfect information. Instead, imperfect statistical information may be acquired in the form of $x$, the value taken by $\tilde{x}_{\theta}$, before a cholce is made about now much $z$ and $m$ to purchase. This imperfect information does not consist of an observation of the actual $\mathrm{b}$ ex post, but of the sample information provided by $x_{\theta}$.

Again, in order to derive an expression for the ex ante expected utility under conditions of imperfect information, a two step

procedure has to be followed. First, we compute the utility of $\theta$ units of information abtained by observing that $\tilde{\mathrm{x}}_{\theta}$ equals $\mathrm{x}$. This is called the expected a posterlori ut111ty when $x$ has been observed. We can then no longer use the a prlorl density of $b$ for the weighting procedure, but have to welght with the revised probabilities of $b$ determined by the posterlor density. Since the consumer is a Bayesian decision-maker, and both the prior density of

$$
\tilde{b}\left(\hat{b} \approx N\left(0, \frac{1}{\Phi}\right)\right)
$$

and the conditional density of $\tilde{x}_{\theta}$ given $\mathrm{D}\left(\tilde{\mathrm{x}}_{\theta} \sim \mathrm{N}\left(\mathrm{b}, \frac{1}{\theta}\right)\right)$ are noma $\amalg y^{\prime}$ distributed, it can be shown (cfr. e.g. Degroot, 1970) that the posterior will also nave a normal distribution with mean $b_{X, \theta}$ and varlance $\sigma_{\theta}^{2}$ where

$$
b_{x_{0} \theta}=\frac{\theta}{\theta+\varphi} x+\frac{\varphi}{\theta+\Phi} b_{0}
$$

and $\sigma_{\theta}=\frac{1}{\theta+\phi}$

The posterior mean of $b^{\prime}$ is a welghted average of the prior expectation $b_{0}$ and the observed sample mean $x$. The weights represent the balance of the confidence in the prior belief $(\Phi)$ and the 'accuracy' of the sample information $(\theta)$. The relative magnitude of $\theta$ and $\Phi$ determines whether the posterior w111 be closer to the prior or to the sample mean.

Note also that the posterior variance is always lower than the prior varlance. This implies that adding the sample information always results in an increase of the prior confidence. Now the expected posterior ut11ity when $x$ has been observed can be written as

$$
\mathrm{DU}_{\mathrm{x}_{1}, \theta}(\mathrm{z}, \mathrm{m})=\int_{-\infty}^{+\infty} \mathrm{U}\left(\mathrm{z}, \mathrm{H}_{0}+\mathrm{bm}\right) \mathrm{f}\left(\mathrm{b} \| \mathrm{b}_{\mathrm{x}, \theta}, \sigma_{\theta}^{2}\right) \mathrm{db}
$$

If information can be bought at a constant unit price qu the consumer's budget is accordingly to be reduced to $y$ - qe when $\theta$ units of information are acquired. The utility of these $\theta$ units of inform- 
ation is now to be weighted with the probability of observing $x$. For this purpose, we must use the marginal (or unconditional) density of $x$. This can be derived by integrating the product of the conditional density of $\tilde{x}_{\theta}$ given $b\left(i . e . f\left(x \mid b, \frac{1}{\theta}\right)\right.$ and the marginal density of $b$ (i. e. $f\left(b \| b_{0}, \frac{1}{\phi}\right)$ over the entire interval $(-\infty,+\infty)$ of $b$. Thus, the marginal distribution of $x_{\theta}$ with mean $b_{0}$ and variance $\frac{1}{\theta}+\frac{1}{\phi}$, becomes $f\left(x \mid b_{0}, \frac{1}{e}+\frac{1}{\Phi}\right)=\int_{\rightarrow \infty}^{+\infty} f\left(x \mid b, \frac{1}{\theta}\right) f\left(b \mid b, \frac{1}{\Phi}\right) d b$

The unconditional probabilities of $x$ represented by this distribution are the relevant weights to be used in computing the ex ante expected utility of $\theta$ units of information (that is, before we know which $x$ is going to be observed) by means of the following expression:

$H(\theta)=\int_{-\infty}^{+\infty} \mathbb{E U}_{x_{1}, \theta}(\mathbb{z}(x, \theta), m(x, \theta)) f\left(x \mid b_{0} \frac{1}{\theta}+\frac{1}{\Phi}\right) d x$

The resulting consumer's demand for information is the value of $\theta$ which maximizes $H(\theta)$ subject to the budget constraint $y=p_{z} z+P_{m} m+$ q日. It is clear from this expression that the maximm value of $H(\theta)$ will be a function of the "standard" determinants like relative prices $\mathrm{p}_{\mathrm{Z}}$ and $\mathrm{p}_{\mathrm{m}}$ and income $\mathrm{y}_{1}$ but also of the parameters $\mathrm{b}_{0}$ and $\theta$ which characterize the consumer's a priori expectations. It is through these parameters that consumer knowledge about medical matters will influence the demand for diagnostic and therapeutic information.

\subsubsection{Comparative static predictions}

The basic model described in the previous section has been modified and extended by Kinlstrom and others in various ways. First of all, there is a more general version, outlined in Kinlstrom (1974b), which extends the analysis beyond the two-goods case and the assumption of normal densities. Some general theorems can be derived which areanalogous to the neo-classical theory of consumer demand - stated in terms of the slutsky matrix of substitution terms. The analys is does not, however, provide very specific and empirically veriflable predictions about the effects of prior information on demand.

When, in addition to strict concavity, an additional assumption is being made about the functional form of the utility function, stronger results can be obtained. Assuming the following utility function with constant elasticity of substitution one-half

$$
U(\mathrm{c}, H)=-\frac{\alpha}{c}-\frac{\beta}{H}
$$

where $\alpha, \beta>0$, Kinlstrom (1974a) is able to derive a number of interesting comparative static predictions about the demand for information. 5 We restrict ourselves to a discussion of the most important results here and refer to Kihlstrom (1974a) for the mathematical derivations. The propositions are: 
1. $\frac{\delta \hat{\theta}}{\delta y}>0$ and $\frac{\delta \hat{\theta}}{\delta q}<0$

When information demand is positive $(\hat{\theta}>0)$, it increases with income and falis when the price of information rises.

2. $\frac{d \hat{\theta}}{d \phi}<0$

The amount of information demanded falls with increasing confidence in the a prior 1 expectations (or famillarity with the product).

3. Information demand is highest for goods for which the expected quality level is nelther very high nor very low. This is essentially because with $b_{0}$ very large or near zero the consumption decisions for $z$ and in are relatively independent of the observation of $x$.

4. Ho demand for information w111 arise when:

a. the uncertain product is elther very expensive or very cheap relative to other products

b. the consumer has very skewed preferences in favour of one commodity

c. the uncertain product is of either very nigh or very low quality.

Proposition 1 states that information is in neo-classical terms nonGiffen and non-inferior and proposition 2 is a logical consequence of the way in which uncertainty is defined. Though less straightforward than the previous ones, proposition 3 is also consistent with intuitive reasoning that additional quality information is most valuable when expectations are not extremely optimistic or pessimistic but rather intermediate. A more surprising result is that, not only for very cheap but also for very expensive uncertain products, no quality information will be demanded (unless this means that very expensive products will never be bought either). It seems less relevant for health care where typically very expensive treatment will almost always be covered. It does question the rationale of the legal requirement to buy information (in the form of a prescription) for a number of relatively cheap drugs, $4 \mathrm{~b}$ is also interesting in the case of medical care. When a serious 11 iness causes preferences to become very skewed in favour of health again demand for information (relative to demand for treatment) will be $10 \%$, $4 \mathrm{c}$ is simply the inverse of proposition 3 . The first three propositions will be tested in the empirical analysis presented in Chapter 4.

The basic KInlstrom model described above has been modified in later work in order to enable further investigation of other aspects of decision making about the acquisition of information. In section 3.3 .1 it was assumed that additional information could only be bought at a constant unit price in the market for information. Information was vlewed as the summary of the results of a number of experiments comparable to the sample "information used in Bayesian statistical decision theory. Intertemporal effects of information demand were not considered because sequential sampling was explicitly ruled out. In 
other words, the consumer could only decide whether or not to buy the information (or message) $\tilde{x}_{\theta}$ as a wole at price $q^{\theta}$ in that period. It was not possible to observe some of the $\theta$ observations $\left(e, g, \theta^{\prime}<\theta\right.$ ) and then to decide whether or not to observe the remaining observations $\left(\theta-\theta^{\prime}\right)$. However, obviously the information acquired in one period carries over to the mext period where the prior information becomes the posterior information of the previous one. This intertemporal extension was modelled explicitly by Grossman, Kinlstrom and Mirman (1977). In their model it is assumed that information is not bought from experts (11ke medical doctors) but accumulates from one's own previous experience with the product of uncertain quality. Simply buying and consuming medical care allso provides observations on its effectiveness which "update" the prior expectations for future decisions. In order to incorporate such production of information through experimentation in the model of consumer behaviour, the utility function has to be extended to include these 'learning by doing" effects. Bayes' rule again provides the updating mechanism. It is shown that the possibility of learning from experience induces experimental consumption behaviour: consumption is higher than the optima l level without learning opportunities. The cost of the information is the utility foregone in the current period (by overconsumption) and the benefits are the utility gains from 'better' future purchases.

Although we will not be concerned with the experimental aspects of medical care as an 'experience good' (see e.g. Nelson, 1970) in what follows, the results of the intertemporal approach do offer same insight as to where the prior expectations come from. This will prove useful in the next section.

Finally, for completeness one last result concerning the determinants of the demand for product quality information deserves mentioning. Freixas and Kihlstrom (1984) have examined theoretically the effect of attitudes toward risk using a very similar model to the one presented in section 3.3. The remarkable conclusion is reached that quality information demand declines with increasing risk aversion. 6 This may seem counter-intuitive because one would expect more risk-averse decision makers to have a stronger preference for reductions in uncertainty. But the authors point out that the uncertainty reduction only occurs ex post, i.e. only after the informative message has been received: "Thus, ex ante, the returns to information are uncertain, and more risk averse buyers should be less willing to accept the risks. associated with its acquisition" (Freixas and Kihlstrom 1984, p. 93). Unfortunately, due to data limitations, the prediction on risk aversion could not be tested in our empirical analysis. How we will attempt to test some of the other comparative static results in the context of the demand for (primary) health care is described in the next section. 


\subsection{From theoretlcal to empirical model}

Before presenting our empirical work it is worthwile to discuss some of the problems which arise when one wants to test some of the predictions of the Kinistrom model. It seens as if the practical difficulties encountered have put off researchers because we could not find any examples of empirical studles testing the theory of the demand for product quality information.

For ease of reference, we have sumarized the sign predictions of the model in table 3.1. Some of the theoretical vamiables included in this table need some further operationalization in the specific context of medical care demand. Without going into detalls about the data and measurement problems (which are deferred to the next chapter), we will discuss at the conceptual level: (a) the distinction between the demand for the product and for information about its quality; (b) the interpretation of the demand determining factors; and (c) the incorporation of information-manipulation effects. Because the empirical analysis is based on Belgian health care utilization data, the discussion is witten with the institutional context of Belglan health care organization in mind.

Table 3.1. Sign predictions of the static Binlstrom (1974a) mode 1

\begin{tabular}{cccccccc} 
Income & Prices & $\begin{array}{c}\text { quality } \\
\text { expectations }\end{array}$ & Preferences \\
\hline$y$ & $\mathrm{q}$ & $\frac{\mathrm{p}_{\mathrm{m}}}{\mathrm{p}_{\mathrm{z}}}$ & $\oplus$ & $\mathrm{b}_{\mathrm{o}}$ & $\frac{\mathrm{a}}{\mathrm{B}}$ \\
\hline
\end{tabular}

Demand for information $\hat{\theta}$ $+\quad-n 1-n 1$ nl

(ni) indicates a non-1inear effect: information demand becones zero at the extremes and is positive in between

3.4.1. Joint product problems

As we already pointed out in section 3.2 , a peculiar characteristic of the nealth care market is that physicians to a large extent supply both information and medical services. The "informative-prescriptive" component of the care provided may be difficult to separate from the 'active-therapeut1c' component. In Kinistrom's (1974a) application, the cereal was not purchased from the research laboratory from which the sample information was bought. A parallel can be drawn with the 
consumption of drugs. In Belgium and in many other countries, drugs can only be bought from the pharmacist whereas the information on advice about the drugs is mostly obtained from a physician. It seems logical then to use the two most frequent acts of medical consumption, 1.e. the general practitioner visits and the use of medicines as empirical counterparts of the demand for information $(\theta)$ and the demand for medical care (m).

There are some drawbacks, however, in this approach. First, although drug prescribing and other advice constitutes by far the largest share of activities in Belgian general practice, some of the contacts result in active treatment by the GP. By considering only the GP contacts which occurred at the initiative of the patient it may be expected that at least the initial reason for the contact was to seek advice. Another snag has to do with the institutional arrangements. Most drugs cannot be bought in a pharmacy without a prescription from a medical professional. This legal requirement may artificially raise the demand for information anong informed consumers who perhaps do not need the advice. Because the presciption requirement also considerably raises the (time and money) cost of these ethical drugs, it may induce better informed consumers to substitute them to some extent by over-thecounter drugs.

\subsubsection{Income, prices, expectations and preferences}

Some of the exogenous variables listed in table 3.1 need some further specification with respect to their application to the demand for therapeutic information. The effects of income $y$ and the relative price ratio $\mathrm{P}_{\mathrm{m}} / \mathrm{p}_{\mathrm{Z}}$ have to be interpreted in the context of the Belgian public health insurance system which is described in Chapter 4, section 3.2. Extensive insurance coverage of medical services nas caused what Newhouse (1979) calls "the erosion of the medical marketplace". It implies that the traditional market model of arm's length transactions guided by relative price signals does not apply very well to the patient-physician contacts. All patients pay the same fixed deductible amount for a physician visit or for the purchase of a prescription drug: $\operatorname{Pn}_{n}$ will therefore show no variation in cross section studies and money price elasticities of demand can therefore only be obtained from time series analysis (see $e_{i} g$. Van Doorslaer (1984) or Carrin and Van Dael (1984)). The only price of medical care which varies between individuals is the price of travel, waiting and treatment time.

This does not apply to $q$ the price of information in the theoretical model. In the cereal example, the consumer could choose the size of the sample $(\theta)$ from which he wanted to observe the sample mean $(x)$ at a cost of $q \theta$. In the case of a patient with a health problem the decision to be taken is more often about whether or not to seek professional advice, rather than about how much advice to obtain. Now, 
If consumers differ in their perception of the accuracy of the advice (Which is $\theta$ if $1 / \theta$ is the variance of the sample mean), then the Imilicit price of information also varles. If $\mathrm{P}_{\mathrm{y}}$ is the (constant) out-of-pocket price of a GP visit and $\theta_{p}$ is the perceived accuracy of the advice, then the implicit price of information $q=P_{v} / \theta_{p}$ varies across individuals according to their perceptions of the informative content of a G.P. Visit. T Variation in the perceived accuracy of GP's thus generates variation in the percelved implicit price of inform ation. The consumer's estimate of $\theta_{\mathrm{p}}$ is derived from own previous experience with his physician's advice and the information acquired from the experience of others. When faced with some health problem and the decision whether or not to seek professional medical advice, a common practice is to discuss this with friends and relatives in order to obtain "information about the accuracy of information". Especially primary care physician's services can be viewed as a "reputation good" (Pauly and Satterthwaite, 1981) for which percelved accuracy of diagnostic and therapeutic information is an important determinant of percelved quality. In section 3.4 .3 it is shown that the accuracy perception not only increases the demand for information by lowering Its price, but also influences the responsiveness to the advice when it is recelved. Consequently, perceived accuracy of advice $\theta_{p}$ becomes an explanatory variable in the demand function for information through its impact on q.

The a priori expectations, sumarized by the parameters $b_{0}$ and $\Phi$ are also not directly observable. The confidence in the a priori estimate of the effectiveness of medical care $b$ will in general increase with knowledge about health and medical care. More knowledgeable consumers are therefore assumed to demand less information, ceteris paribus. The relationship between $b_{0}$ and medical knowledge is not so straightforward. Whereas it is plausible to hypothesize that knowledge reduces the variance of the prior distribution it is not clear whether it raises or lowers the average expectations about medical care effectiveness. What can be seen from equation (3.2) in section 3.3 .1 is that it will be negatively related to percelved initial health status $H_{0}$. This means that the demand for therapeutic information only becomes positive when $b_{0}$ has exceeded some threshold level, or simllarly when $\mathrm{H}_{0}$ goes below some threshold level (cfr. propositions 3 and $4 \mathrm{c}$ in section 3.3 .2 ).

Finally, the "relative taste for health" prediction stated in proposition $4 b$ will not be tested in our empirical analysis. The emphasis will be on estimating the effects of the two components of information, $₫$ and $\theta_{\mathrm{p}}$. In the next section we will 11 lustrate how they interact in Bayesian decision analys is.

\subsubsection{Effects of information manipulation}

Apart from generating predictions on the factors which determine the 
demand for information, this behavioural model also yields insight into individuals" responsiveness to such information once they have acquired 1t. This is not unimportant in health care because of the alleged possibilities for physicians to manipulate the demand for their own services by lowering the accuracy of their advice (Pauly, 1980). According to this information-manipulation theory, the ability to create supplier-induced demand is constrained by two characteristics of the demanders: the confidence in one's own subjective bellefs and the perception of the accuracy of the advice.

Recall that the physiclan"s advice changes the prior distribution sumarizing consumer bellefs into a posterior distribution according to Bayes" formula:

$$
f\left(b \mid b^{A}\right)=\frac{f\left(b^{A} \mid b\right)}{f\left(b^{A}\right)} f(b)
$$

$$
\text { with } f\left(b^{A}\right)=\int_{R} f\left(b^{A} \mid b\right) f(b) d b
$$

where $f(b) \quad=$ subjective prior aistribution of $b$

$f\left(b^{A} \mid D\right)=11 k e l$ inood function of the doctor advice $b^{A}$

$f\left(b^{A}\right)=$ unconditional distribution of $b^{A}$

$f\left(b \mid b^{A}\right)=$ posterior distribution of $b$

$\mathrm{R} \quad=$ the integration interval of the variable $\mathrm{D}$

Since the ultimate consumer decision about treatment w111 depend on $f\left(b \mid b^{A}\right)$, not on $f(b)$, it is important to know which characteristics of the prior distribution and the likelihood function determine how much the posterior deviates from the prior. In general, these deviations will be larger, the more diffuse the prior, and the less diffuse (and therefore more informative) the likel ihood function.

To 11 lustrate this general proposition and to enhance intuitive understanding, it is useful to consider some numerical examples of four degenerate situations. Let the patient have a subjective discrete prior distribution function $f(b)$ over 2 possible effects, $b_{1}$ and $b_{2}$, of a particular treatment. His beliefs about the accuracy of his doctor's advice on these outcomes are represented by the likellhood function $f\left(b^{A} \mid b\right)$.

\section{(a) Consumer certainty}

This situation is characterized by a variance of the prior distribution equal to zero. One could think of a consumer who has had the same symptoms before and knows wich treatment worked and which did not. On the other hand, he perceives the accuracy of his doctor's advice to be less than perfect. For instance, if the actual outcome of the treatment is $b_{1}$, there is only $60 \%$ chance that the doctor had predicted 1t. In $80 \%$ of the cases when $\mathrm{b}_{2}$ was the outcome, it was also predicted to be so by the doctor. 
In tabular form this looks as follows.

prior distribution

\begin{tabular}{l|l} 
& $f(b)$ \\
\hline$b_{1}$ & 1 \\
$b_{2}$ & 0
\end{tabular}

conditional distribution (likelihood)

\begin{tabular}{l|ll}
$\mathrm{f}\left(\mathrm{b}^{\mathrm{A}} \| \mathrm{b}\right)$ & $\mathrm{b}_{1}$ & $\mathrm{~b}_{2}$ \\
\hline $\mathrm{b}_{1}$ & .6 & .4 \\
$\mathrm{~b}_{2}$ & $\cdot 2$ & .8
\end{tabular}

In order to obtain the posterior, the unconditional probabllities of b are determined by multiplying each conditional probability of $b^{A}$ with the corresponding prior probabllity of $b$. The posterior probabllities are then given by the following Bayes' formula in the discrete case (suming over $1=1,2$ instead of integrating over the interval of $\mathbb{1}$ ).

$$
P\left(b_{1} \mid b^{A}\right)=\frac{P\left(b^{A} \mid b_{1}\right) \cdot P\left(b_{1}\right)}{\sum_{1=1}^{n} P\left(b^{A} \mid b_{1}\right) \cdot P\left(b_{1}\right)} \quad(n=2)
$$

unconditional distribution $f\left(b^{A}\right)$

\begin{tabular}{c|rr}
$f(b) f\left(b^{A} \mid b\right)$ & $b_{1}$ & $b_{2}$ \\
\hline$b_{1}$ & .8 & .2 \\
$b_{2}$ & 0 & 0 \\
\hline$f\left(b^{A}\right)$ & .8 & .2
\end{tabular}

posterior distribution

\begin{tabular}{c|cc}
$f\left(b \mid b^{A}\right)$ & $b_{1}$ & $b_{2}$ \\
\hline$b_{1}$ & 1 & 1 \\
$b_{2}$ & 0 & 0
\end{tabular}

It is clear that in this case the doctor advice has no effect on the decision of the patient.

(b) Consumer ignorance

The other extreme is when the consumer/patient has no idea about the probabilistic outcome of the treatment alternatives. They are then both equally likely to him. After having recelved the therapeutic advice, these probabilities are revised into a more informative lless uncertain) posterior distribution.

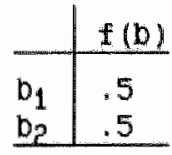

\begin{tabular}{c|cc}
$f\left(b^{A} \mid b\right)$ & $b_{1}$ & $b_{2}$ \\
\hline$b_{1}$ & .6 & .4 \\
$b_{2}$ & .2 & .8 \\
\hline
\end{tabular}

\begin{tabular}{c|cc}
$f\left(b_{\mid} \mid b^{A}\right)$ & $b_{1}$ & $b_{2}$ \\
\hline$b_{1}$ & .75 & .33 \\
$b_{2}$ & .25 & .67
\end{tabular}

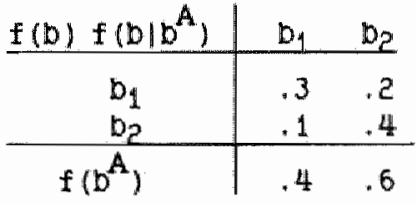

Notlce, however, that some uncertainty about the outcomes remains when the advice is perceived to be not perfectly accurate. This implies that the patient will not undoubtedly comply with the prescribed 
treatment. It is sti11 possible that he prefers to purchase (or obtain elsewhere) additional information (e.g. a second opinion).

\section{(c) Perfectly accurate doctor}

It is interesting to see that if the advice is perceived as perfectly accurate and there is some uncertainty in the consumer's a priori expectations, then the advice will always be followed.

\begin{tabular}{c|cc|cc} 
& $f(b)$ & $f\left(b^{A} \mid b\right)$ & $b_{1}$ & $b_{2}$ \\
\hline$b_{1}$ & .9 & $b_{1}$ & 1 & 0 \\
$b_{2}$ & .1 & $b_{2}$ & 0 & 1
\end{tabular}
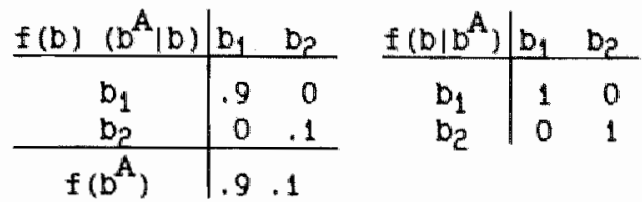

This is perhaps one of the most comon situations, not because physicians are always so accurate but because the belief that "the doctor knows best" is widespread and professional uncertainty often underestimated (see e.g. Wennberg et al., 1982).

\section{(d) Completely inaccurate doctor}

When the advice is perceived to be completely random it will not affect the patient's subjective estimate of treatment outcomes. In such cases, he w111 not even seek (costly) advice. 8

\begin{tabular}{l|l} 
& $f(b)$ \\
\hline$b_{1}$ & .7 \\
$b_{2}$ & .3
\end{tabular}

\begin{tabular}{c|cc}
$f\left(b^{A} \mid D\right)$ & $b_{1}$ & $b_{2}$ \\
\hline$b_{1}$ & .5 & .5 \\
$b_{2}$ & .5 & .5
\end{tabular}

\begin{tabular}{c|cc}
$f\left(b \mid b^{A}\right)$ & $b_{1}$ & $b_{2}$ \\
\hline$b_{1}$ & .7 & .7 \\
$b_{2}$ & .3 & .3
\end{tabular}

The examples given above serve to lliustrate the fact that in this Bayesian framework consumer information has two distinct components:

1. prior information about effectiveness of medical care

2. Information about the accuracy of medical advice

This second factor turns out to be at least as important in the demand for and the effect of information. It is wortrwile to explore this 1s sue further in the case of medicall care because the asymetry in the first type of information between patient/consumer and doctor/agent will always remain and may even increase in the future with growing specialization. It may, nowever, be easier for consumers to obtain, or for regulators to provide, information of the second type. If indeed, as Pauly argues, doctors are able to generate demand for their own services through manipulation of the accuracy level of the information they provide, then it is clear than an important 1 imiting factor on this ability is the accuracy perception of their clients. Consequent$1 Y_{1}$ the rather irreducible uncertainty about therapeutic performance of medical care may become less relevant to a discussion on the desirablilty and feasibility of competition in medical care if the consumers are reasonably wel1-informed about the degree of ignorance of the medical experts. Pauly (1978) puts it like this:

"The ironic conclusion is that one of the most useful types (and probably one of the least expensive types) of information that could be provided to patients is information on what is not known by medical 
About the relationship between these two types of information little can be conjectured a priori on a theoretical basis except that people without much kowledge about and experience with medical care wil in general ind accuracy of information hard to judge. There is, however: a tendency in the literature to observe that the typical medical lay people systematlcally underestimate professional uncertainty. Compare Breyer (1982): 'Casual observation would tend to suggest that many patients overestimate what medicine can do for them thereby biasing the expected benefits of diagnos is upward." (p. 155)

In the empirical analysis we will return to this point to see whether medical knowledge and percelved accuracy of medical advice are indeed negatively associated.

\subsection{Conclus ions and assessment of the theoretical model}

Before we proceed with the empirical specification of this model, it 1s useful to sumarize its main advantages and limitations compared to other economic models of the demand for health and medical care. The main distinguishing feature of this model is that it explicitiy takes account of the agency relation which exists between the doctor and the patient by introducing a central role for information. Although individuals remain the final decision makers about medical care utilization, they are assumed to do this on the basis of their own beliefs and medical advice. Bayesian decision analysis combines these two into a posterior belief about the effectiveness of medical care. In this way, consumer sovereignty is no longer an on/off characteristic but varies continuously with the degree to which the prior expectations are altered into posterion beliefs. Secondly, if the consumer's medical information is assumed to be a positive function of the level of education, the Bayesian approach provides a more explicit mechanism to explain the positive effect of schooling on health and the negative impact on the demand for care. In Grossman's

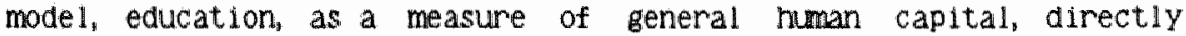
enters the individual's healtr production function as an efficiencyenhancing factor.

Finally, the analysis predicts that 'perceived accuracy of physician's advice' is an important determinant of the decision whether or not to consult a doctor. In this way, an attitude or belief variable about health and medical care, which is often found arrong the predisposing factors in behavioural models of health care utilization (e.g. Andersen, et al., 1975), is here explicitly derived from an economic model of utility maximizing behaviour. 
1. This assumption is exactly opposite to the one made by e. Ereyem (1982) in his analysis of rational purchase of medical care when Ho is uncertain but ls known.

2. A normal distribution is chosen because it has scme convenient properties in bayeslan preposterlor analysis (see e. Hey 1979).

3. Kinlstrom (1974a) actually assumes to vary continuous ly in order to make functions differentiable th respect to (see p. $103 \mathrm{~h}$.

4. To avold confusion, we not adopt Kinstron's (1.974a) terminology there. He calls expression (3.6) the expected utility perfect information. For the sake of clarity; it is better to call it the expected utility with or under pertect information and to use the former term for expression (3.7) which indicates the expected Litility difference between no (or anly prior) and pertect information (see e. Hey. 1979).

5. It is also assumed that not by but rather 108 b is nomally distributed. The definition $b=e^{e}$ with $e$ nomally astributed, is acopted to avold negative values for $b$

6. Interesting enough a similar result was deriwed by Eecithoudt, et al (1985) who studied the effects of risk aversion on the demand for diagnostic test untometion by phys licians.

7. Note the sinilarity between this interpretation ano the hedonic approach adopiced by Goliman Grossman (1978) to distinguish between the quality and quantity of physicjan visits. Mey also define the total pnice of a physiclan wisit (p) as the protuct of quality (q) and the quality-2djusted price (p). However, in the hedonic approach quality is not uncertain. It is traded-off against the quantity of visits in the production of health and consumers can substitute both inputs freely to maxime utilty. Hedonic price theory is more sultable in order to explain the cholce of physician when physician characterdstics are avallable to measure mis quality.

B. It is important to mention nere what Pauly has termed a "censoring problem" More informed consumers will in general de less responsive to additional information, but they may in the first place also be less inclined to wy information and thereby be 'censored out" inltally. 


\section{Chapter 4. Empinical analysis}

"Potential observability seems to me to be an unnecessarily severe requirement. Hypothetical constructs such as 'perwanemt income' or 'human capital' are useful even if one cannot think of any procedure which would measure them directly" (Griliches, 1977, p. 9)

\subsection{Description of data and Belgian health care characteristics}

Because of the central role of consumer information in our theoretical model, it was necessary to look for a dataset which offered sufficient perspective for exploring this issue. The Health interview survey of the Belgian National Research Project on Primary Health Care conducted in 1976 among a representative sample of 1745 adults drawn from the Dutch-speaking (Flemish) population, showed several advantages in this respect. The stratifled cluster sampling design and observation methodology are described in Foets et al, (1985) and Nuyens (1980).

Health care utillzation and health and 11 lness behaviour of the respondents during a total period of 9 weeks were registered in three health interviews about a 3 week recall period each. For the last two interviews, respondents were also asked to keep a health diary. Because the research project was largely set up from a soclological point of view, the questionnaires were designed to measure, apart from 'need' and 'enabling' factors, also so-called predisposing factors like attitudes, bellefs and knowledge which form the 'health perspective' of the individual (see e.8. Kom and white, 1976). It is particularly this category of factors which is of ten included vaguely in the 'taste' variables in economic models, but becomes more explicit in the Bayesian approach to modelling the demand for information.

From secondary data sources, regional characteristics such as health care supply densitles were added to the survey materlal. The strat if led sampling procedure guaranteed that sufficient variation was 
present according to degree of urbanization and health care supply density. The varlables that were used for our analys is are described in appendix $4 . A$ and w11 be discussed in more detall in the following sections. After listwise deletion of cases with missing values on these varlables, the sample size retained for further analysis was reduced to $n=949$. This reduction was primarily caused by the high non-response rate (19\%) on the income varlable. We did neither test nor correct for possible sample selection blas as a result of this non-response.

Due to the 1 imited sample size, we have restricted our analys is to the two most frequently used types of medical care: about two-thirds of the individuals in the sample $(63 \%)$ have used medicines during the observation period, and about one-third (36.1\%) has consulted a general practitioner (Foets, et al., 1985, p. 184). We w111, however, distinguish between medical consumption at the patient"s ow initiative and physician-prescribed utilization.

In Belgium, a public health insurance scheme covers medical expenses of virtually all inhabitants. In 1976, the cost-sharing for general practitioners and prescription drugs only consisted of a small fixed deductible amount ( $40 \mathrm{BF}$ ) per visit or per standard package delivered. A subgroup of high-risk beneficlarles, the wldows, orphans, pensioners and invalids (the WOPI's) were exempted from this co-payment. Financial accessibility of health care therefore did not seem to be a large problem in 1976. 1 The same applies to geographical accessibility in a country with one of the highest general practitioner and pharmacy densities in the world (see OBCD, 1985). The average level of GP contacts and in particular drug consumption per capita is quite high.

Before we estimate demand functions for information (1.e. GP consultations) and medical care (1.e. prescribed and non-prescribed medicines) in a structural equation model, we will first pay special attention to the measurement problems associated with two important determinants: health and knowledge, because: "the stock of health IIke the stock of knowledge, is a theoretical concept; one that is difficult to define and quantify empirically" (Grossman, 1975, p. 165). The health and the information measurement 'modules' w111 be integrated in the full model in section 4.4 .

\section{2. Heasurement of health}

\section{2.1. MethodologY: the LISREI model}

Obviously, the health measurement problem has recelved a great deal of attention among health economists and health services researchers in general. Almost without exception, health care utllization studies have found health status - or the variables used to measure it - to be 
the single rost important predictor. Moreover, Manning et al. (1982) have shown that wore compreherisive health measurement leads to a substantial Gain in explanatory power and better (unbiased) estimates of the impact of other determinants of the demand for medical care services.

One approach is to use more indicators of the several dimensions (phys1cal, wental, social) of health in equations explaining ut111zation (see e.b. Brook et al., 1979, for an overwlew of health measures used in the Rand study). Another approach is to try to combine several variables into one "health index" using factor or principal component analys is (see e. B. Levine and Yett, 1973). The develoment of accessible computer programes has stimulated the use of latent variables in structural equation models. The convenient property of the so-called MIMIC methodologY that latent variables can be characterized by both observable multiple indicators and multiple causes has not been left unnoticed by health economists. Robinson and Ferrara's (1977) example has stimulated a large number of applications of the latent variable technique, mostly in studies of the demand for health or health care. The 11st includes Van de ven and Van der Gaag (1982), wolfe and Van der Gaag (1981), Lee (1982), Hooymans and Van de Ven (1982), Van der Gaag and Wolfe (1983), Leu and Dopman (1984), Wolfe and Behrman (1984), Wagstaff (1986), Van Vllet and Van Praag (1987). In most of these studies one (MIMI) health index is constructed, although sometimes this involves a two-step procedure. First a large number of indicators is combined into a smaller number of nealth status dimensions using factor or principal component analysis. These constructs are then used as indicators for the health index.

In the construction of these MMIIC health indices for individuals all too often the important distinction between the stock and flow component introduced by Grossman (1972) through his human capital framework tends to be neglected. The unobservability of the health capital stock as opposed to the flow of sick time in a certain period led researchers to assume that the latent varlable represents the stock of health and is indlcated by sick time and medical consumption. A similar distinction is made by Van de Ven and Van der Gaag (1982) but for a different reason. In adopting the Andersen et al. (1975) behavioural model of health care utillzation, they considered 'permanent' health as an (unobservable) predisposing varlable which influences the att 1 tude towards health care utidization but is in itself no reasing for seeking care. 'Mmber of days 111 ' reported by the respondent was used both as an indicator of permanent health and as a variable reflecting 'medical need' in the consumption equations.

Although our theoretical model does not make the distinction between a stock of health and a flow of sick time, we will distinguish between these two concepts in the health measurement module. In particular, we will hypothesize that not (permanent) health status but rather transitory distortions or 11 lness periods throughout the observation 
period determine the demand for information and care. The probability of occurrence of these distortions is, however, assumed to be increasing with reductions in the initial level of health $\mathrm{H}_{0}$. $\mathrm{H}_{0}$ therefore only affects demand through its influence on these temporary health deviations. Our demand equations can then be interpreted as conditional upon the actual state of health of the individual at the beginning of the period $\left(\mathrm{H}_{0}\right)$ rather than as structural demand for medical care functions in which the desired health level (A) should have a positive effect due to the derived demand hypothesis (see Wagstaff, 1986, p. 201).

The Primary Health Care survey (from now on abbreviated as PHCS) included the following indicators of 111 health (see Appendix 4. A for a more detailed description of the variables):

1. Health complaints (COMPL) reported during the 9 weeks period and classified into 14 general categories of perceived morbidity (see Muyens, 1980 , p. 80 ).

2. Nuber of restricted activity days (RAD) in the observation perlod.

3. Number of non-activity or in bed days (NAD) in the observation period.

4. A score on an index of behavioural impact of 11 iness (DISAB) measured by questions about the ability to perform activities of dally living and feelings of well-being.

5. Number of serious chronic conditions and/or handicaps which the respondent was suffering from at the time of interview (CoON).

6. Average frequency of GP visits in the past (PGPC).

In order to investigate whether these items represent observable indicators of one or more components of the (not directly observable) individual health status, we estimated a system of structural equations which is a special case of the general LISREL (Linear structural Relations) model described in Jöreskog and Sörbom (1979). They developed the LISREL computer program for specifying, estimating and testing systems of 1 inear structural relations. Their most general model consists of a structural part, a measurement part and a set of assumptions.

We will not first present the fuil model configuration but rather describe the relevant components as we go along. Because at this stage we only want to use the measurement part of the model, the structural part of the LISREL model (see equation 4.7 ) reduces to

$$
\eta=5 \text { with } \zeta \sim \mathrm{N}(0, \psi)
$$

where $\eta=a(\operatorname{mx} 1)$ vector of endogenous (1atent) variables

$\zeta=a(n \times 1)$ vector of disturbance terms

$\psi=$ the (mom) covariance matrix of $\zeta$

In addition we can wite the following general measurement model for the n's:

$$
y=\Lambda \eta+\epsilon \text { with } \epsilon \sim \mathbb{N}\left(0, \theta_{e}\right)
$$


where $\eta=a(m a 1)$ vector of latent unobservable variables (e.g. health)
$\Lambda=a$ (paia) matrix of $\lambda$ coefficients
$y=a(p \times 1)$ vector of observable indicators
$\epsilon=a(\mathrm{px} 1)$ vector of errors of measurement
$\theta_{\epsilon}=a(p x p)$ covariance matrix of $\epsilon$

This LISREL measurement model can be seen alternatively as a confirmatory factor analys is model in wich multiple indicators of one unobserved variable are used in order to correct for measurement errors (Jöreskog and Sörbom 1979). The usual assumptions are that $E(Y)=E(\zeta)=E(\eta)=E(\epsilon)=0$. Furthermore, the $e^{\prime} s$ (errors-invariables) are assumed to be uncorrelated with the $\eta$ variables ( $E(\eta)$ $\left.\epsilon^{\prime}\right)=0$ ) and with the $\zeta^{\prime} s$ (errors-in-equations) $\left(E\left(\zeta \epsilon^{\prime}\right)=0\right)$. Maximm likel inood $(M)$ estimates of the $\lambda$-coefficients, their standard emors and the varlances of the disturbance terms of $\theta_{\epsilon}$ can be obtained If the model is identified. The $\mathrm{M}$ estimation method also assumes that the observed variables have a multivariate normal distribution.

Equation (4.1) assumes that the latent varlable (or "true score") is proportional to each of the indicators (or "observed scores"), except for a random disturbance term (to allow for measurement error). The rellab11ity of the indicators can be checked by means of the standardlzed solution measurement model. If we rescale appropriately, every relationship in (4.2) can be rewritten as

$$
y_{1}=\eta+\epsilon_{1} \quad(1=1, \ldots, p)
$$

Dividing both sldes by $\sigma_{y 1}$ gives: $\frac{y_{1}}{\sigma_{y 1}}=\frac{\eta}{\sigma_{y 1}}+\frac{e_{1}}{\sigma_{y 1}}$

If we define standardized variables as $y^{*}=\frac{y_{1}}{\sigma_{y_{1}}}$, we get

$$
y^{*}=\frac{\sigma_{\eta}}{\sigma_{y i}} \cdot \frac{\eta}{\sigma_{\eta}}+\frac{\epsilon}{\sigma_{y 1}}
$$

or $y_{1}^{*}=\lambda_{1}^{*} \eta^{*}+\frac{e_{1}}{\sigma_{y}}$

where $x^{*}{ }_{1}=\frac{\sigma_{n}}{\sigma_{y 1}}$

The reliability coefficlent $p$ of each indicator is now defined as the standardized $\lambda^{*}{ }_{1}$-coefficlent squared. It glves the ratio of the true score variance and the observed score varlance. Tests of hypotheses about the reliability can only be performed when more than two indicators are avaliable and overidentifying restrictions can be imposed on the model structure. Examples will be provided in the following sections.

Furthermore, the standardized solution can be used to test whether the indicators are congeneric (1.e. measure the same theoretical varlable), tau-equivalent (1.e. have the same true score but different error variances) or parallel (i.e. have identical true scores and 
error variances) (for an example of psychonetric testing with LISRE. see .8. Jöreskog and Sörbom 1979, Chapter 3).

\subsubsection{A latent health vector}

\subsubsection{Model speciflcation and testing}

In this section, we will proceed stepwise to the construction of a LISREL health measurement model for our dataset. First, we will compare the goodness-of $f 1 t$ and rellabllity performance of a twocomponent model with the usually estimated one-component model. Secondly, by adding health-determining varlables, we can check the validity of the constructs as measures of individual health in section 4.2.3. The correlation matrix of the variables used in this section is given in appendix $B$, table B.1. Some of the variables (1,e. RAD NAD, DISAB, PGPC, IHIS) have been transformed by taking the natural logaritrm of the variable plus one. This (arbitrary) transformation procedure was applied to reduce the skewness of the distribution of these variables and the impact of some outller values.

In order to make such a system of equations like (4.2) estimable, the problem of the scale of the latent variables has to be solved. This is in fact an identification problem because multiplying each $\eta$-variable by some constant and dividing the $\lambda$ "s by the same constant produces the same y-variables. As such an infinite number of different solutions to this system can be produced. Two normalization procedures exist to remedy this scale problem (see Jöreskog and Sörbom 1979). one is to $f 1 x$ one $\lambda$-coefficient for each latent variable equal to a constant. For instance, by fixing one $A$ equal to 1 , the latent variable obtains the same unit of measurement as one of the indicators. The alternative identification procedure is to $f$ ix the variances of the unobservable variables in this particular case (the diagonal elements of $\psi$ ) equal to one. An advantage of the second method is that it directly gives the standardized solution of the model which facilitates testing of psychometric properties (see section $4.2,1)$.

We first tested the hypothes is that all six varlables listed in the previous section can be seen as indicators of one underlying latent variable health. The results are presented in table 4.1 , Model 1A $p=$ $=6, m=1)$. Table 4.1 contains both unstandardized estimates of the $\lambda$ and $\psi$ coefficlents (first colum) and standardized results (second colum) for two model versions ( $1 \mathrm{~A}$ and $1 B$ ). In model $1 \mathrm{~A}$ all $\$ 1 \mathrm{x}$ variables are assumed to be indicators of one unobservable varlable 'good health' because the coefficlent of coowd is set equal to -1 . All coefficients have the expected sign and small standard errors but the maximm IIKelinood parameter estimates and the $t$-values have to be interpreted with caution due to the non-normal distribution of most $y-$ varlables. 
Table 4.1. Estimation results of health measurement models (6 indicators)

MDEE, 1A

MDDEL 1B

(one health variable) (two health variables)

\begin{tabular}{|c|c|c|c|c|c|c|}
\hline$y$ & $\hat{\lambda}$ & (1) & $\hat{p}(2)$ & $\hat{\lambda}$ & (1) & $\hat{\rho}(2)$ \\
\hline COCWD & $-1,000$ & & .279 & -1.000 & & .269 \\
\hline FGPC & -1.054 & $(9.6)$ & .308 & -1.080 & $(10.5)$ & .314 \\
\hline COMPL & $-1 \cdot 238$ & $(10,4)$ & .339 & $-1 \cdot 194$ & $(10.9)$ & .384 \\
\hline LRAD & -1.165 & $(10.1)$ & .231 & -.590 & $(12.5)$ & .256 \\
\hline LNAD & $-1 \cdot 236$ & $(10.4)$ & .237 & -.650 & $(13,4)$ & .310 \\
\hline LDISAB & -1.748 & $(11.6)$ & .488 & -1.000 & & .735 \\
\hline$\Psi_{11}$ & .199 & $(6.3)$ & 1.00 & .269 & $(6.9)$ & 1.00 \\
\hline+22 & - & & - & .735 & $(12.1)$ & 1.00 \\
\hline$\sqrt{21}$ & - & & - & .326 & $(10.4)$ & .733 \\
\hline$x^{2}$ & \multicolumn{3}{|c|}{84.6} & \multicolumn{3}{|c|}{28.6} \\
\hline$d f$ & \multirow{2}{*}{\multicolumn{3}{|c|}{${ }^{9} .924$}} & \multicolumn{3}{|c|}{8} \\
\hline AGFI & & & & & \multicolumn{2}{|c|}{.971} \\
\hline
\end{tabular}

Notes:

1) Approximate absolute t-values $(\hat{\lambda}$ coefficlent divided by standard error) are given in parentheses. When no $t$-value is reported, this means that the parameter was $f$ ixed to be equal to the given value.

2) The rel1ability coeff lclents were calculated from the estimated $\hat{\theta}_{\epsilon}$ variances using the following formula: $\widehat{\phi}=1-\widehat{\theta}_{\epsilon}$

Boomsma (1983) has examined the robustness of LISREL against nonnormal ity by means of a Monte Carlo study. He found that for a sample size of 400, LISREL is rather robust against categorization but not against skewness. Large skewnesses affect the confidence of parameter estimates and the $x_{2}$ goodness-of $f$ it statistic. Overestimation of standard errors of parameters causes confidence intervals to be too large and therefore tests based on these intervals too conservative. on the other hand, skewness increases the chi-square test statistic and therefore too often leads to model rejection. These consequences w111 have to be kept in mind because skewness is an important characteristic of the dependent variables in our sample (see appendix 4.A). The suggestion of Muthèn (1983) and others to use polychoric and polyserlal rather than the ordinary product-moment correlations as unput measures of assoclation for LISREL estimation does not seen to be a good alternative in our case because it is based on the assumption that the underlying latent varlables have a normal distribution. This assumption seems to be very questionable in the case of medical consumption and health status which are intrinsically skewly distributed across individuals. 
The rellability coefficients given in the second colum $6=$ $=A^{* 2}=1-\theta_{\epsilon}$, are not very high. Moreover, the $x^{2}$ test statistic rejects the null hypothesis that the observed correlations between the variables could have been generated by the specified causal model. However, this test statistic is proportional to the sample size and therefore very often leads to model rejection in the case of a large sample size like ours $(n=949)$. Jöreskog and Sörbom (1981) warn that: "large sample sizes and departures from nomality tend to increase $x^{2}$ over and above what can be expected due to specification error in the mode1. "(P. I.39) It is therefore recommended to use the $x^{2}$ measure in such cases rather for nested model comparison than for the evaluation of just one model (Jöreskog: 1971) ${ }^{2}$

The goodness-of $f$ it index, adjusted for the degrees of freedom (ACFI), measures the extent to which the model accounts for the varlances and covariances between the observable variables in the model $10 \leq \mathrm{AGFI} \leq$ 1). Its advantage is that it is independent of the sample size and reasonably robust against departures from normality, but on the other hand its distribution is unknown. It can therefore also be used only for model comparisons (see Jöreskog and Sorbom 1981).

In order to test our proposition that health consists of two distinct parts, 1.e. a fairly permanent health state and the transitory health distortions during a certain period, we explored the consequences of subdividing the health indicator variables between these two latent variables (Model $1 B_{\|} p=6, m=2$, see also Figure 4.1). Clearly, the presence of chronic illnesses or impairments (CCOND) and the average vis $\Perp t$ rate of the GP in the past (PGFC) can be regarded as indicators of the general level of health. on the other hand, restricted (LRAD) and non-activity days due to illness in the 9 week period and the behavioral impact index (LDISAB) which measures sleeping problems, worries and normal activity interruption in the same period are indicators of the amount and intensity of sick time. They were therefore expected to load on the transitory nealth component. The only interpretation problem was caused by the variable "number of different health complaints expressed by the respondent during the 9 weeks" (COMPL). Although we conjectured it to be a measure of the flow of sick time, it turned out to be a better indicator of permanent $\left(\eta_{1}\right)$ than of transitory health $\left(m_{2}\right)$.

Model $1 B$ in table 4.1 shows the results when CCOND PGPC and COMPL are taken to be indicators of permanent health $\left(\eta_{1}\right)$ and when IRAD LNAD and LDISAB indicate transitory health ( $\left.\eta_{2}\right)$. As can be seen from the reliability coefficients and $x^{2}$ test statistic, this model fit represents a substantial improvement to model 1A. The statistical significance of the difference between the chi-squared tests was not formally tested because both models are not hierarchical (see Bentler and Bonett, 1980), and we did not perform a likelihood ratio test of the non-nested hypothes is that IB has a better fit than $1 A$. But it is clear from a comparison of the goodness of $f$ it statistics that iB its 
Figure 4.1. Path-diagram for the sequence of health measurement models a. Model $1 \mathrm{~A}$

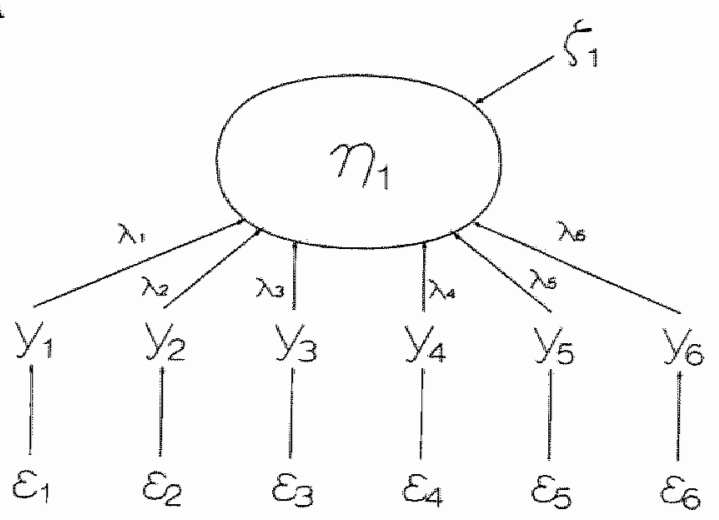

Restrictions $\lambda_{1}=-1$

b. Mode I 1B

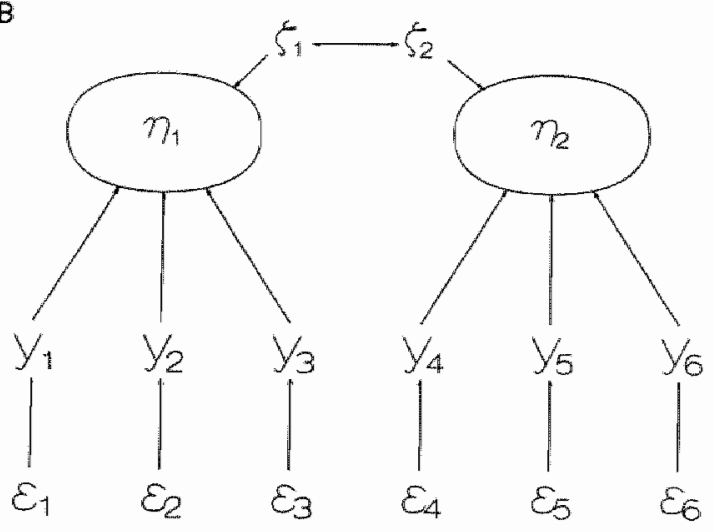

Restrictions

$\lambda_{1}=-1$

$\lambda_{6}=-1$

c. Model $1 \mathrm{C}$

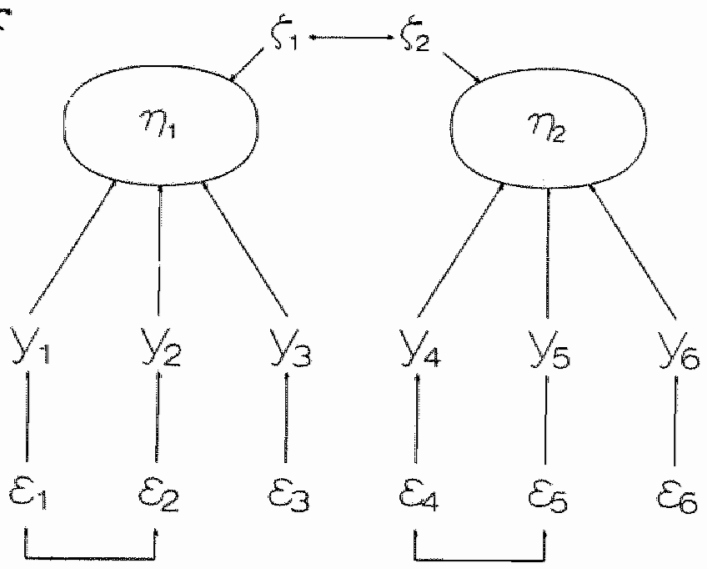

Restrictions

$\lambda_{1}=-1$

$\lambda_{6}=-1$

d. Model $1 D=$ Model $1 C$ but with additional restrictions $\lambda_{3}=\lambda_{4}$ and $\theta_{e 5}=\theta_{e 4}$ 
Because more information was available on the (total) complaints variable (COMPL), we attempted to discriminate between the more chronic and acute complaints. Respondents had been asked how lone they had been bothered by each of these complaints. Because the chronicity of complaints varied considerably between the fourteen categories of perceived morbidity, we divided COML into three subcategorles: Muber of complaints in any of the 'acute' categorles (ACUTE = less than $20 \%$ is reported as chronic i.e. Lasting for over a year already), in the "chron1c" disease category (CHRONIC = more than $45 \%$ chronic) or in the intermediate range $(A C O H R=$ between 20 and $45 \%$ chronic) (see appendix 4. A for a more detalled description).

Table 4.2. Estimation results of health measurement models ( 8 indicators)

MDDEL 2A

MODEL 2B

\begin{tabular}{|c|c|c|c|c|c|c|}
\hline & $\hat{\lambda}$ & (1) & $\hat{p}\left(L^{2}\right)$ & $\hat{\lambda}$ & (1) & $\hat{\rho}(2)$ \\
\hline CCOND & -1.000 & & .177 & -1.000 & & .208 \\
\hline PGPC & -1.068 & $(8.9)$ & .187 & -1.017 & $(9.2)$ & .215 \\
\hline QHRON & -1.123 & $(9.4)$ & .224 & -1.144 & $(9.8)$ & .272 \\
\hline$A C C H$ & -1.312 & $(10.1)$ & .305 & -1.310 & $(10.4)$ & .357 \\
\hline ACUIE & -.604 & $(6.2)$ & .065 & -.297 & $(6.6)$ & .060 \\
\hline LRAD & -1.251 & $(9.9)$ & .278 & -.634 & $(13.5)$ & .273 \\
\hline LNAD & -1.318 & $(10.1)$ & .308 & -.688 & $(14.4)$ & .322 \\
\hline LDISAB & -1.836 & $(11.2)$ & .597 & -1.000 & & .679 \\
\hline$\psi_{11}$ & .177 & $(6.0)$ & 1.00 & .208 & $(6.2)$ & 1.00 \\
\hline$\sqrt{22}$ & - & & - & .679 & $(12.3)$ & 1.00 \\
\hline$\$_{21}$ & - & & - & .310 & $(10.1)$ & .824 \\
\hline$x^{2}$ & \multicolumn{3}{|c|}{138.2} & \multicolumn{3}{|c|}{108.6} \\
\hline$d f$ & \multicolumn{3}{|c|}{20} & \multicolumn{3}{|c|}{19} \\
\hline AGFI & \multicolumn{3}{|c|}{.934} & & \multicolumn{2}{|c|}{.942} \\
\hline
\end{tabular}

Notes: see table 4.1

Table 4.2 reports the results of the estimations with this extendied set of indicators. The attempt to distinguish better between permanent and transitory health did not prove very successful. Model $2 A$ is the one-health-component analag of $\mathbb{A A}$ and $2 B$ the two-component model with only ACUTE as an indicator of transitory health. However, ACUTE has a very low reliablity coefficlent. The lower estimated rellabilities of the other indicators and the worse goadness-of-fit statistics do not give rise to any support to the hypothes is that this solution improves the discrimination between two health components. 
Moreover, the standardized covariance between the two latent variables $\left(\psi_{21}^{*}\right)$ in model $2 \mathrm{~B}$ is .824 and was only .733 in model $1 \mathrm{~B}$. when this correlation is equal to one, both constructs can be seen as representing one underlying factor. This hypothes is can be tested formally by imposing the restriction that $\psi_{21}^{*}=1$ and re-estinating the model. The difference in $x^{2}$ statistlcs between the restricted and unrestricted model then itself has a $x^{2}$ distribution with one degree of frecdon (Sar1s and stromknorst, 1984, p. 276). When we performed this "parameter nesting" to model $1 B$, the more restricted model yleided a $x^{2}$ statistic of 34.6 . Compared to the $28.6 x^{2}$ value of model $1 B$ the increase (56) leads us to reject the hypothesis that both health components actually measure the same thing. We, therefore, preserved the distinction between permanent and transitory health and model $1 \mathrm{~B}$ was selected as our preferred model specification for further development.

\subsubsection{Model modiflcation}

As it stands, however, the $x^{2}$ test still rejects the hypothesis that this model has generated the observed correlation matrix. The LISREZ $V$ program does produce also so-called 'modification indices" for each constrained parameter. These indices are based on the first and second derlvatives of the likelinood function with respect to the zero constrained parameters. They equal the expected minimal decrease In the value of the model's $x^{2}$ statistic if the zero restrictions on these parameters are relaxed. As such they provide an indication as to the possible source and location of misspecifications in the model. clearly, modification indices are a purely statistical criterion to be used cautiously and in combination with theoretical considerations.

Table 4.3. Modification indices for constrained parameters in mode $1 \mathrm{~B}$

\begin{tabular}{lcccccccc} 
& LAMBDA & $(\lambda)$ & MATRIX & \multicolumn{7}{c}{ THETA EPSLLON } & $\left(\theta_{e}\right)$ & MATRIX \\
\hline & FH & TH & COOND & PGPC & COMPL & LRAD & INAD \\
& $\eta_{1}$ & $\eta_{2}$ & $y_{1}$ & $y_{2}$ & $y_{3}$ & $y_{4}$ & $y_{5}$ \\
\hline COOND & - & .219 & - & & & & \\
FGPC & - & .539 & 0.180 & - & & & \\
COMPL & - & 1.052 & 2.536 & 0.704 & - & & \\
LRAD & 1.472 & - & 5.519 & 0.081 & 2.037 & - & \\
LNAD & 0.000 & - & 0.006 & 0.187 & 0.087 & 6.261 & - \\
LDISAB & .363 & - & 3.770 & 1.859 & 1.458 & 0.000 & 1.423
\end{tabular}

By way of example, we have reproduced the modification indices of model $1 B$ in table 4.3. Because there are six $\lambda$ parameters constrained to zero in this model plus all the non-diagonal elements of $\theta_{\epsilon}$, two 
types of model modifications based on these indices can be contemplated: indicators loading on both latent variables or correlations between the disturbances of the measurement equations. The first possibility does not seem to cause any problems in this case, but the measurement errors of two indicators seem to be correlated for both Latent variables: FGPC and COOND for $\eta_{1}$, and LRAD and LNAD for $\eta_{2}$. That the latter two variables produce correlated errors in measuring transitory health seems logical because they both have (the logarithm of) a number of days as the unit of measurement. When the zero covariance restriction on their disturbance terms was relaxed, the $x^{2}$ aropped to 19. Despite the significant fit improvement, it still means rejection at the $5 \%$ level of slanificance (with 7 degrees of freedom).

It was only when, in addition, in model 1C (table 4.4 and figure 4.2) the error terms of COOND and PGPC (besides those of LRAD and LNAD) were allowed to covary in model $1 \mathrm{C}$ (table 4.4$)$ that a $\times 2(6)=7.9$ was obtained which did not exceed the $5 \%$ critical value of 12.59 . Apparently, the presence of one or more chronic conditions or handicaps and the average use of GP services show some correlation which is insufficiently explained by one comon component "permanent health') with the number of complaints. Health model $1 \mathrm{C}$ in table 4.4 is a specification which acconding to the goodness-of-fit tests, fits to our data very well, i.e. the predicted correlations between the observed variables deviate very little from the actual correlations.

Table 4.4. Estimation results of nealth measurement models $1 \mathrm{C}$ and $1 \mathrm{D}$

\begin{tabular}{|c|c|c|c|c|c|c|}
\hline & \multicolumn{3}{|c|}{ MDEL $1 \mathrm{C}$} & \multicolumn{3}{|c|}{ MODEL 1D } \\
\hline & $\hat{\lambda}$ & (1) & $\hat{p}(2)$ & $\hat{\lambda}$ & (1) & $\hat{p}(2)$ \\
\hline CCOND & -1.00 & & .221 & -1.00 & & .222 \\
\hline PGPC & -1.087 & $(10.2)$ & .261 & $-1,084$ & $(10,3)$ & .261 \\
\hline COMFL & -1.353 & $(9.8)$ & .405 & $-1,351$ & $(9.8)$ & .405 \\
\hline LRAD & -.653 & $(12.2)$ & .289 & -.684 & $(15.0)$ & .316 \\
\hline LNAD & -.709 & $(13.0)$ & .341 & -.684 & $(15.0)$ & .316 \\
\hline LDISAB & -1.000 & & .678 & -1.00 & & .674 \\
\hline$\psi_{11}$ & .221 & $(5.9)$ & 1.00 & .222 & $(5.9)$ & 1.00 \\
\hline$\sqrt{22}$ & .678 & $(11.5)$ & 1.00 & .674 & $(11.5)$ & 1.00 \\
\hline$\psi_{21}$ & .301 & $(9.5)$ & .778 & .302 & $(9.5)$ & .780 \\
\hline$\theta_{\in 54}$ & -.086 & $(3.0)$ & -.086 & -.088 & $(3.0)$ & -.088 \\
\hline$\theta_{\in 21}$ & .108 & $(3.4)$ & .108 & .108 & $(3,4)$ & .108 \\
\hline$x^{2}$ & \multicolumn{3}{|c|}{7.94} & \multicolumn{3}{|c|}{9.43} \\
\hline$d f$ & \multicolumn{3}{|c|}{6} & \multicolumn{3}{|c|}{ B } \\
\hline $\mathrm{AGFI}$ & \multicolumn{3}{|c|}{.989} & \multicolumn{3}{|c|}{.990} \\
\hline
\end{tabular}

Notes: see table 4.1 
There is one last hypothesis about this model which can be tested by the LISEE framework us ing the same straightforward nesting procedure. We would expect one day of non-activity to be worse in terms of 111 (transitory) health than one day of restricted activity as reported by the individuals. In other words, the same change in the "true" health score would imply a higher number of restricted than non-activity days. Consequently, the A-coefficient for LRAD would have to be larger than that for $1 \mathrm{KAD}$. But the results of madel $1 \mathrm{C}$ indicate exactly the opposite situation $\left(\left|\lambda_{42}\right|<\left|A_{52}\right|\right)$.

We can state the null hypothesis more formally as: $\lambda_{42}=\lambda_{52}$. The equality of these two parameters can be tested using the same difference (in $x^{2}$ ) test statistic as before. The difference test statistlc was found to be equal to

$$
D=x^{2}(7)-x^{2}(6)=8.88-7.94=0.94
$$

which means that imposing the equality restriction does not raise the $x^{2}$ statistic significantly and that the nypothesis cannot be rejected. It implies that in terms of classical test theory both indicators can be seen as congeneric instmments (see section 4.2 .1 ).

Moreover, when the additional restriction was imposed that both indicators have also equal variances, 1.e. $H_{0}: \theta_{\epsilon 44}=\theta_{\epsilon 55}$, we obtained model 1D presented in table 4.4 and described in figure 4.1 . It can be seen that the test statistic now equals

$$
D=x^{2}(8)-x^{2}(7)=9.43-8.88=0.55
$$

which again implies that also this restriction cannot be rejected, and we have to conclude that $\angle R A D$ and $L N A D$ are even parallel instmments of transitory health. In other words, in our sample the number of restricted and non-activity days reported by the respondent not only measures the same thing but they also appear to represent measurements on the same scale (see Joreskog, 1979). Adding these restrictions to the measurement model for health leaves the estimates of the other coefficients virtually unaffected. Model ID will be retained for further analysis because it is the most restricted measurement model which fits the data and conforms to our theoretical distinction between two health components.

\subsubsection{A MMIIC nealth model}

In this section we extend the basic measurement model $1 D$ with a structural equation part. By specifying a model of causal relationships between the latent variables and their determining factors, a Mutiple Indlcator Muliple Causes model is obtained (see Joreskog and Goldberger, 1975). Although we did not derive a demand for health function from the theoretical model, and initial permanent health $\mathrm{H}_{0}$ is assumed to be predetermined, we will estimate a sort of auxillary equation to relate permanent and transitory nealth to a number of 
background characteristics in order to investigate their validity.

We specify in addition to (4.2) and instead of (4.1) the following equation:

$$
\eta=B \eta+\Gamma x+5
$$

with $\eta=a(2 x 1)$ vector of latent health variables $=[\mathrm{HH}, \mathrm{TH}]$

$\mathrm{x}=\mathrm{a}(5 \mathrm{x} 1)$ vector of exogenous variables

= (AGE FEM EDUC, PSPR, LIHIST)"

$B=a$ (2xe) matrix of beta-coefficients (with zero diagonal elements)

$\Gamma=\mathrm{a}(2 \times 5)$ matrix of gamma-coefficlents

$\zeta=\mathrm{a}(2 \times 1)$ random disturbance vector $(\zeta \sim \mathbb{N}(0,4))$

We expected health to be negatively related to age, female gender (FEM), the number of psycho-social problems (PSPR) (at home, on the job or in relations with friends and relatives) reported by the respondent and to his or her 11 mess history (LIHIST, see appendix $A$ ), and positively related to the level of education. With respect to the relation between the n's, it is assumed that permanent health (FH) has a drect positive effect $\left(\beta_{21}\right)$ on transitory health (TH). In a pathdiagram the specified MMIC-model can then be deplcted as in Figure 4.2.

Figure 4.2. Path-diagram of MIMIC-health model

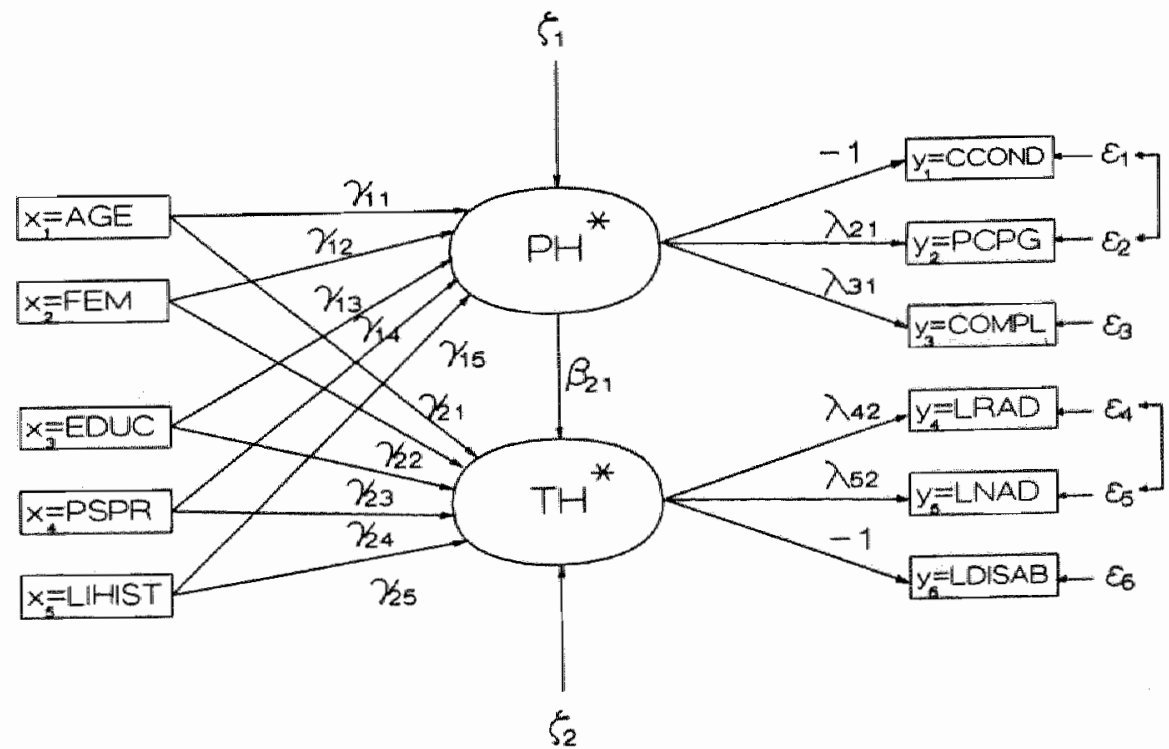


The maximu 1 inelihood estimation results for this specification are given in table 4.5. All sim expectations for the effects of the exogenous determinants on $\mathrm{FH}$ are confirmed except $\mathbb{f}$ or EDUC which has a non-significant coefficient. FH also shows a large positive impact on TH (B2).

The findings with respect to the level of transitory health are more pecullar. Except for FSFR, the coefficlents of all other determinants show the opposite sign from that in the PH-equation! The effects of EDUC, PSPR and LIHIST are small and only significant at the 10\% level, But the results clearly show that, given their generally inferior permanent health status, women and older persons are less likely to report sick time, ceteris paribus. Because the latter is primarily measured as interruption of normal activities, this may have something to do with the kind of activities performed by these groups of people. If the major part consists of housenold work "which has to be done some way or another even if one is nat feeling well", this may contribute to an explanation of this remarkable result.

However, these direct effects $\left(\gamma_{21}\right.$, for $\left.1=1, \ldots 5\right)$ are in general much smaller than the indirect effects through $\mathrm{PH}$ on $\mathrm{TH}\left(\beta_{21} * \mathrm{y}_{11}\right.$, for $1=1, \ldots 5$ ) which implies that the total effects (direct plus indirect) often are of the opposite sin. This decomposition into direct and indirect effects again brings out the importance of distinguishing between the permanent stock and transitory flow component of health: not only the indicators but also the 'causes' of nealth seem to indicate this distinction.

Table 4.5. Estimation results of MIMIC health model of figure 4. 2

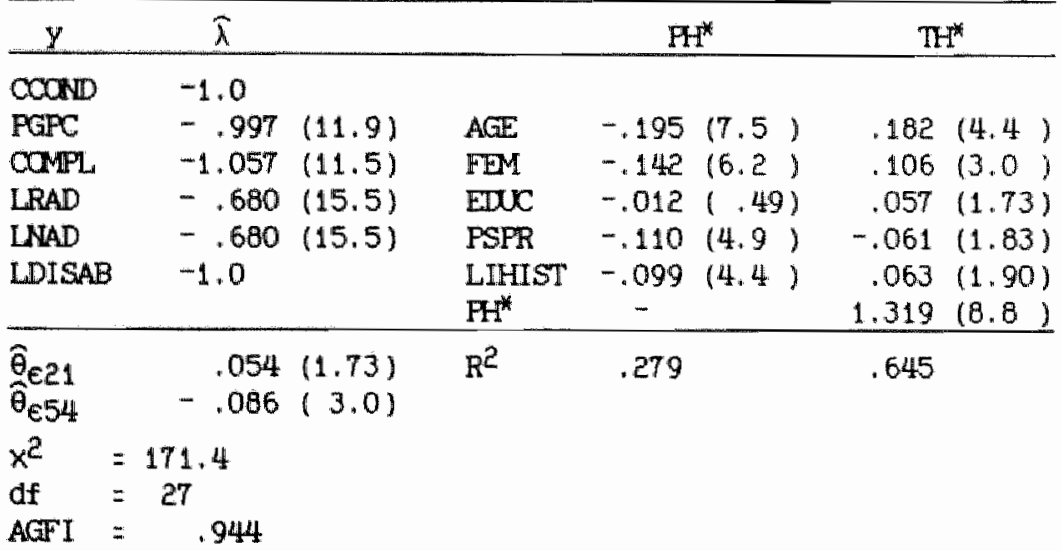

Notes: see table 4.1 
Finally, note that, despite the addition of the structural part of the model, the measurement model estimations are virtually unaffected. On the other hand, the extension did influence the goodness-of $f$ it of the model: the $x^{2}$ test now rejects the hypothesis that this simple linear and additive model specification can account for the correlations between the observed variables. But even on the basis of these five general background characteristics the percentages of explained variance (28\% for $\mathrm{FH}$ and $65 \%$ for $\mathrm{TH})$ are pelatively high already and this leads us to conclude that this MIMIC model is useful as the health measurement 'module' to be implemented in the total structural model in section 4.4 .

\subsection{Measurement of information}

\subsubsection{Previous studies}

In contrast to the vast literature on health measurement in medical care demand models, the issue of how to measure consumer knowledgeablilty about health and medical care matters has received relatively little attention from economists. In testing his informationmanipulation theory, Pauly (1980) used 'education of the household head" as a proxy for the prior stock of consumer information and the 'degree of urbanization of their place of residence' as a measure of the difficulty that individuals have in determining the accuracy of the physician advice. He hypothesized that it is easier to obtain such information in non-metropolitan areas where there are relatively fewer physicians to choose from.

Such cmude proxies are also used by Pauly and Satterthwalte (1981) to investigate the relationship between consumer information about primary care physician's reputations and their pricing behaviour. Regional informational levels and search possibilities of consumers are assuried to be negatively related to the total number of phys 1 cians within a given market area, the proportion of residents who have moved in that area the past five years and the proportion of housenolds neaded by females with less possibilities for soclal contact and cormunication. They admit themselves that: "A primary data collection project that drectly measures consumer information would have the potential for yielding more definite results' (p. 496).

A slightly less indirect approach towards measuring the medical knowledge and expertise of consumers has been to assume that members of a family with at least one member in a medical occupation are better informed. In contradiction with the demand inducement hypothes is, Hay and Leahy (1982) found these medically informed patients to have the same or even higher utilization rates for physiclan offlce visits than individuals without family member with some medical education. Using a similar approach, Bunker and Brown (1974) had shown earlier that 
doctors and their spouses had either higher or the same utilization rates for surgical procedures as other professional groups when standardized by age and sex. The problem with both studies is that it is unclear to what extent the proxies used for consuner medical information do not also capture other factors than medical knowledge. Moreover, no distinction is made between the two components of information derived from the Bayesian analysis.

An atteript to measure the individual sophistication or knowledgeabllity about the medical care delivery system in a direct manner was made in the Health Insurance Study of the Rand corporation. Newhouse et al. (1981) acministered a 10-item questlonnaire, covering a range of information about the medical care delivery system to a sample of 4976 non-elderly persons. These ltens refer to whether consumers are knowledgeable both in choosing medical care providers and in making decisions at the time when serwices are used. By means of a factor analysis, eight of these iterns were selected to score a consumer sophistication sumary scale by counting the number of correct responses. This scale correlated substantially with education ( $r=$ .40) and showed a small but slgnificant positive association with the number of physiclan visits during the prior year. Age and female sex were positively and race negatively related to consumer sophistication. Correlations with health status measures were low and inconsistent. Ferhaps the most important finding with respect to our own analysis was: "The consistent negative and significant correlations with the belief and attitude measures suggest that consuners who tend to be more knowledgeable regarding medical care services also tend to view doctors and their semices less favourably" (Newhouse et al., 1981, p. 323). This evidence points in the direction of a negative relationship between a priori medical knowledge and perceived accuracy of medical advice. Finally, the authors rightly stress the difficulties in examining the relationship between knowledgeability and overall utilization: "because a more sophisticated consumer could utilize more frequently when appropriate and less frequent $\| y$ when inappropriate' (p. 324). This indeterwinancy is conf irmed in another study of the Rand researchers (Manning et al." 1982). The consumer sophistication scale is indeed found to nave an insignificant (negative) effect on annual outpatient expenditures for health care when a large number of other variables are controlled for in the regression equation.

\subsubsection{A MIMIC model of consumer information}

It seems logical to take the latter analysis one methodological step further by investigating whether the relevant consumer information concepts can adequately be modelled as latent variables in a structural equation model explaining health care utilization. While some authors have concentrated on proxy determinants of consumer information and others on proxy indicators to measure it directly, we will 
combine both approaches while preserving the distinction between consumer knowledgeablity of health and medical care, and percelved accuracy of general practitioner advice. The former is assumed to be inversely related to consumer prior uncertainty before seeking advice or therapy, and the latter represents the information on for perception of the accuracy of professional advice.

\subsubsection{Medical knowledgeability}

With regard to medical knowledge, the FHC survey included 43 test itens. These questions could be subdivided into four broad categories: 14 items were related to purely theoretical medical knowledge which does not have much relevance for the individual behaviour (TEST 1): 16 items measured aspects of theoretical knowledge which potentially could have some practical relevance (TEST 2); 11 items referred to very practical knowledge about what action one should undertake in certain circumstances (e.g. first ald or preventive activities) (TEST 3); finally, 2 items asked for some knowledge about the organization of the medical care dellvery system (whether doctors need a 1 icence to practice medicine and whether it is possible to see a speciallst without a referral from the GP) (TEST 4). These four types of knowledge were scaled by suming the scores on the individual items. An answer was coded 0 if false, 1 if the respondent answered do not know" or did not answer, and 2 if correct. The four knowledge scales are highly intercorrelated (see appendix $4 . B$ ).

A simple measurement model with all four TEST variables used as indicators of the same underlying latent variable was not mejected by the $x^{2}$ test (see model 1 in table 4.6). TEST 4 has a low rellability $(\rho=.104)$, mainly because this score shows less variability as it is based on only 2 items. In mode 12 it was deleted but this did not have men impact on the performance of the other indicators. We therefore decided to retain TEST 4 on theoretical grounds and to select the model 1 specification as the measurement model for a prior 1 consumer knowledgeabll ity about health and medical care.

Although the latter concept is exogenously given in the theoretical model of Chapter 3 by the parameter $\Phi$ of the prior distribution. we will attempt to explain it by means of a number of background characteristics. As such the index becomes again determined by both multiple indicators and multiple causes. Simulaneously, the vallalty of the construct can be checked from the signs of the coefflcients of the determining factors. We w111 regard knowledge as a humar capital stock which is bullt up initially through fomal education early in the 1 ifecycle, accumulates with experience but depreclates with ageing. It is therefore expected to be positively related to the level of schooling (EDC) and negatively to age (AGE). Investment in medical knowledge is assumed to take place through owr experience and learning from the experlence of others. To operationalize this learning from 
Table 4.6. Estimation results of measurement models for medical knowledge

\begin{tabular}{|c|c|c|c|c|c|c|c|c|}
\hline & \multicolumn{2}{|c|}{ MODEL 1} & \multicolumn{3}{|c|}{ MDEI 2} & \multicolumn{3}{|c|}{ MIMIC MDDEL } \\
\hline & $\hat{n}$ & $\widehat{\rho}$ & 2 & & $\hat{\rho}$ & 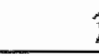 & & $\hat{\mathrm{p}}$ \\
\hline TEST 1 & 1.00 & .542 & 1.00 & & .551 & 1.00 & & .567 \\
\hline TEST 2 & $.941(15.5)$ & .480 & .920 & $(14,9)$ & .466 & .902 & $(17.2)$ & .461 \\
\hline TEST 3 & $.914(15.3)$ & .453 & .912 & $(14.9)$ & .458 & .890 & $(17.1)$ & .449 \\
\hline TEST 4 & $.438(8.4)$ & .104 & $\ldots$ & & - & .421 & $(8.6)$ & .101 \\
\hline$x^{2}$ & 2.77 & & & a & & & & \\
\hline df & 2 & & & 0 & & & & \\
\hline AGFI & .992 & & & 1.00 & & & & \\
\hline
\end{tabular}

Notes: see table 4.1

others through cormunication of experience, we use the size of the household ( $\mathrm{HSZ}$ ), the number of direct famly menbers with a medical or paramedical occupation (MEDFAM) and the socio-econcmic status as measured by the occupational level of the head of the household (SES). Finally we control for possible sex differences by including a dumy for females (FEM). These are the $x$-variables in the following LISREI. structural equation model:

$$
\eta=\Gamma x+\zeta
$$

where $\eta=$ a latent variable (knowledge)

$x=a(6 \times 1)$ vector of exogenous variables

$=$ (EDUC, SES, MEDFAM HSL, ALE, FEM)'

$\Gamma=\mathrm{a}(1 \times 6)$ vector of coefficients

$\zeta=$ a random distumbance term $(\zeta \sim \mathbb{N}(0, \psi))$

and $\eta$ Is measured by a mode 1 like equation $(4.2)$ with $y^{\prime}=$ [TEST 1 , "TEST 2, TEST 3, TEST 4]. The estimation results of this model are presented in table 4.6 (measurement part) and in table 4.7 (structural part). From the estimated $\lambda$-coefficients it can be seen that the measurement model is hardly affected by the extension of the model with a structural part. The estimated $\gamma$-coefficlents in table 4.7 show that education, socio-economic status and medical family members improve medical knowledge signiflcantly while older people and males are less knowledgeable. Household size does not have a signiflcant effect on knowledge production. Despite the rather high percentage of explained varlance $(38 \%)$ in knowledge and a very high ALFI $(.985)$, the model is rejected by the $x^{2}$ statistic.

In order to 11lustrate the differences and similarities between the latent variable model and the ordinary maximm likelinood regression model, we have presented the regression results in the second colum of table 4.7 . The dependent variable is TESTTOT which is the sum of 
Table 4.7. Estimation results of the "medical knowledge" equation

\begin{tabular}{|c|c|c|c|c|}
\hline & $\begin{array}{l}\text { MIIMIC } \\
\text { METKN }\end{array}$ & $\begin{array}{l}\text { RESRESSION } \\
\text { TEST TOT }\end{array}$ & $\begin{array}{l}\text { REGRESSION } \\
\text { UNCERTAIN }\end{array}$ & $\begin{array}{c}\text { REGRESSION } \\
\text { CORRECT }\end{array}$ \\
\hline Eux & $.246(7.2)$ & $.278(7.1)$ & $-.190(4.5)$ & $.269(6.9)$ \\
\hline SES & $.206 \quad(6.5)$ & $.236(6.5)$ & $-.188(4.9)$ & $.243(6.8)$ \\
\hline MEDFAM & $.075(3.0)$ & $.089(3.1)$ & $-.077 \quad(2.5)$ & $.095(3.4)$ \\
\hline HSZ & $.011(.42)$ & $.016(.56)$ & $-.071(2.3)$ & $.047 \quad(1.6)$ \\
\hline $\mathrm{AGE}$ & $-.064(2.3)$ & $-.076(2.4)$ & $.092(2.7)$ & $-.094(3.0)$ \\
\hline FEM & $.062(2.6)$ & $.079(2.9)$ & $-.035(1.2)$ & $.067 \quad(2.4)$ \\
\hline $\mathrm{R}^{2}$ & .378 & .282 & 182 & .298 \\
\hline$x^{2}$ & 45.9 & 0 & 0 & 0 \\
\hline df & 20 & 0 & 0 & 0 \\
\hline AGF I & .985 & 1.0 & 1.0 & 1.0 \\
\hline
\end{tabular}

Notes: see table 4.1

the 4 indicators used in the MIMIC model. The coefficlents cannot directly be compared due to the different units of measurement but the t-values show that the results are almost identical. The only substantial difference is the lower percentage of explained variance in the total sum score $(28 \%)$. This reflects the fact that, through 'purging' the observed variables from a certain amount of measurement error in the MIMIC model, the remaining variance in the 'true score' of knowledge is better explained by this set of exogenous variables. In this particular case, this seems to be the only gain from treating knowledge as a latent factor rather than as a simple sum score of tests.

Finally, we explored the consequences of our arbitrary choice of test scoring method. Recall that we constructed TESTTOT by suming the score 2 if the answer was correct and 1 when the answer was 'don't know' "One could argue that, in order to measure a priori uncertainty (the parameter $\$$ ). the 'don't know' answer should be treated in the same way as an incorrect answer or should even be treated separately. Perhaps no answer gives a better indication of uncertainty than a wrong answer. We therefore examined the performance of two alternative knowledge variables: CORRECT was defined as the sum of all correct answers on the 43 items, and UNCERTAIN was constructed as the sum of all 'don't know" answers. Correlations, range and mean values of these variables and TESTTOT are presented in table 4.8.

The correlations between these constructs are very high and this similarity is also confirmed by the regressions presented in the last two colums of table 4.6. UNCERTAIN is inversely related to the determinants of the medical knowledge scores and, with the exception of household size (HISZ), all variables show similar relative effect magnitudes and signs in each of the three equations. We therefore 
Table 4.8. Correlations, range and mean values of knowledge scores

\begin{tabular}{lccccc} 
& \multicolumn{2}{c}{ CORFELATIONS } & RANGE & MEAN \\
\cline { 2 - 4 } & TEST TOT CORPET & UCERTAIN & & \\
\hline TEST TOT & 1.0 & & & $31-86$ & 53 \\
CORRECT & .89 & 1.0 & $0-43$ & 19 \\
ULCERTAIN & -.54 & -.86 & 1.0 & $0-43$ & 14
\end{tabular}

conclude that our knowledge measurement is fairly robust with respect to alternative scoring procedures and we will continue to work with the four-indlcator and six-causes MIMIC model in what follows.

\subsubsection{Percelved quality of GP's}

The empirical operationalization of the second (Bayesian) component of information, the perceived accuracy of information provided by general practitioners, is somewhat more difficult because no examples are avallable in the health economics literature and the theory does not offer much empirical guidance. What we actually would like to measure is the analog of the likelinood function in Bayesian decision theory which represents the sample information. In our situation, this could be captured by probabllistlc statements like: 'In $x$ \% of the cases, the diagnostic or therapeutic information given by the doctor turns out to be correct."

A number of statements approximating this example were included in the FHC sumey questionnaire. The respondents were asked whether they agreed or disagreed with 34 statements evaluating general practitioner services. Most of these were not used in the analysis because they referred to aspects such as accessibility or general satisfaction which were not relevant for our purposes.

Twe Ive items were selected which referred to an evaluation of either the diagnostic accuracy or the therapeutic effectiveness of general practitioners. A translation of these items is listed in appendix $C$. The answer categorles to these statements range from 0 ( $=$ disagree) to 4 (= agree) which is an ondinal or ranking scale over whlch the variables are not nomally but at reast rather symetrically distributed (see appendix $C$ for frequency distributions). The correlation matrix of these items is iven in table B3 in appendix $4 \mathrm{E}$.

In order to investigate what proportion of the variation expressed by the scores on these 12 items could be reproduced by a smaller number of underlying factors, we performed a factor analys is using the (SPSS$x)$ method of principal components for factor extraction. The objective is to find linear combinations of the observed variables which account 
for the largest proportion of sample variance. Two factors with an eigenvalue larger than one were obtained which after varimax rotation, produced the factor loading matrix presented in table 4.9.

It can be seen that these two components account for almost half (46\%) of the total variance expressed by all items. The items divide equally over the two factors with 6 items loading on each factor. With the exception of 1tem EVGFT which loads positively on both factors, the factors distinguish between positively and negatively formulated items. Therefore, we arrive at the remarkable conclusion that stating the proposition in a posltive or in a negative way seens to make more difference than the content of the proposition: For example, EVaPs and EVGP10 are in fact the positive and the negative formulation of the same statement ('GP's do or do not examine you thoroughly') but they do not load on the same factor. We could not interpret these two components otherwise than as the inverse concepts idstrust about GP quality' and 'confidence in GP quality'. However, by construction (the rotation procedure) both principal components are orthogonal and camnot be used as (positive and negative) indicators of the same underlying concept. We therefore also performed a principal component analys is with the maximum numer of components restricted to one. Its solution is presented in the third colum of table 4.8. The percentage of explained variance is now, of course, only $32.6 \%$ but all items (except EVGPT again) have fairly high loadings on this factor.

Table 4.9. Principal component analysis of items on GP evaluation $(n=949)$ : factor loadings

TWO-COMPONENT SOLUTION ONE-COMPONENT SOLUTION (VARIMAX ROTATED)

\begin{tabular}{cccc}
\hline & FACIOR 1 & FACTOR 2 & FACTOR \\
\cline { 2 - 4 } EVGP 1 & .736 & -.053 & .576 \\
2 & -.127 & .717 & -.580 \\
3 & -.343 & .680 & -.714 \\
4 & -.133 & .721 & -.587 \\
5 &. .625 & -.126 & .544 \\
6 & -.168 & .568 & -.509 \\
7 & .200 & .545 & -.223 \\
8 & .623 & .008 & .452 \\
9 & -.280 & .586 & -.603 \\
10 & .665 & -.268 & .670 \\
11 & .599 & -.338 & .669 \\
12 & .659 & -.115 & .562 \\
\hline EIGENVALE & 3.91 & 1.62 & 3.91 \\
\% Vf VAR & 32.6 & 13.5 & 32.6 \\
CUMU. \% & 32.6 & 46.1 & 32.6
\end{tabular}


In order to calculate the scores of the individuals on each of these factors, the factor coefficlents presented in table 4.10 were used. By mutiplying each item with its coefficlent and adding up these products, factor scores for each individual are obtained for the inaccuracy perception (INACP2) and the accuracy perception (ACORP2) from the two-component solution and for the inaccuracy perception (INACPT) based on the one-component solution. It is difficult to declde at this stage which of the two solutions or which factors should be retained for further analys is. We will therefore postpone the selection of the empirical counterpart for our theoretical concept unt 11 we have examined the relationships with the determining factors in the MIMIC model.

Table 4.10. RCA of GP evaluation items $(n=949)$ :

factor coefficients

TWO-COMPONENT SOLUTION ONE-COMPONENT

\begin{tabular}{rrrr}
\hline & INACP2 & ACCURP2 & INACPT \\
\cline { 2 - 4 } EVGP 1 & .301 & .108 & .147 \\
2 & .075 & .300 & -.148 \\
3 & -.023 & .244 & -.183 \\
4 & .073 & .301 & -.150 \\
5 & .241 & .056 & .139 \\
6 & .031 & .226 & -.130 \\
7 & .183 & .281 & -.057 \\
6 & .264 & .115 & .116 \\
9 & -.013 & .213 & -.154 \\
10 & .233 & -.001 & .172 \\
11 & .192 & -.045 & .172 \\
12 & .258 & .067 & .144
\end{tabular}

Because theory offers little indications as to what factors ought to determine this perception (in act $_{\mathrm{p}} \theta_{\mathrm{p}}$ is assumed exogenous in chapter 3) we have used the same set of "causes" as for the equation explaining medical knowledgeability. We also assume causality between knowledge and perception to run from the flrst to the second because knowledge will in general increase patients' ability to judge the accuracy of the information received. If indeed professional ignorance and uncertainty tend to be underestimated ${ }^{*}$ as several authors have suggested (e.g. Pauly, 1978; Wennberg et al., 1982 or Breyer, 1982), then more information should lead, ceteris paribus, to a lower accuracy perception. The model specification used is given by the path diagran in figure 4.3 .

In table 4.11 the estimation results are presented of the structural equations for percelved accuracy for three MTMIC models, one for each princlpal component. The full model also includes the measurement 
Figure 4.3. Path-diagram of MTMC-information model

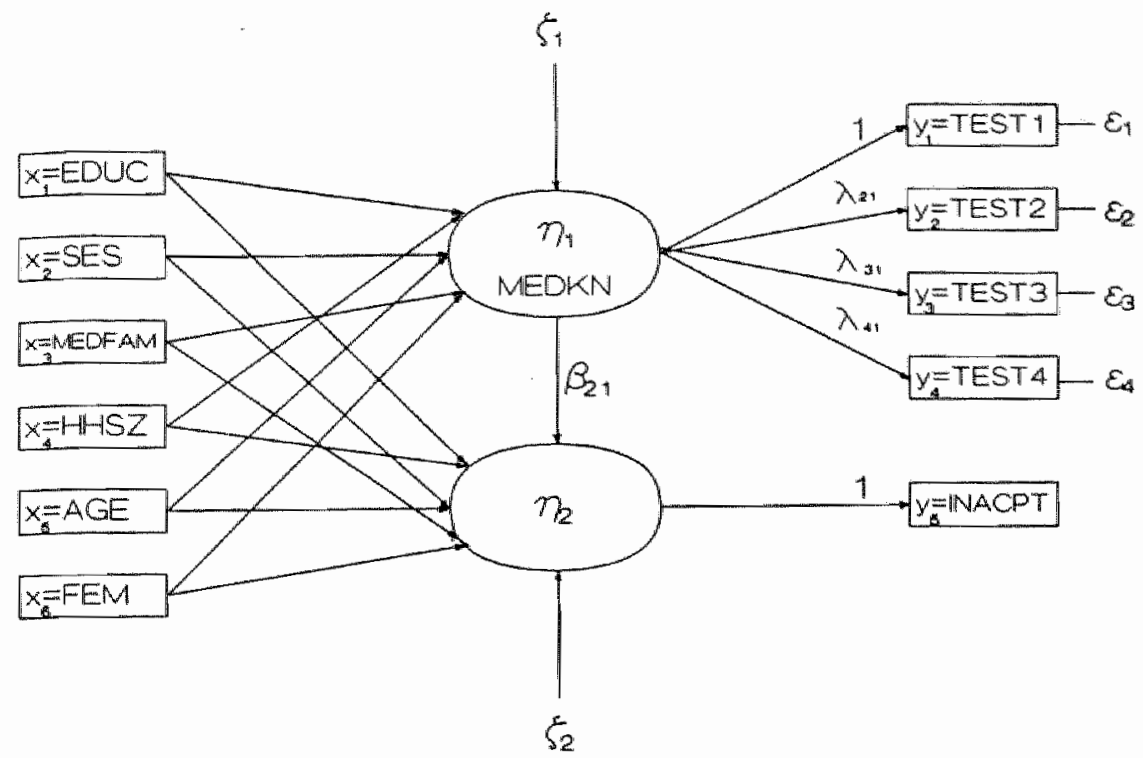

equations and structural equation for medical lnowledge ( $\eta_{1}=$ MEDKN) but these are not reported since the estimation results only differ sometimes in the third decimal from those presented in tables 4.6 (last colum) and 4.7 (first column).

In fact, the reported equations are SIMIC models (M- regression equations) because 'perceived accuracy' is always measured by a single Indicator and Muliple causes. From the first colum in table 4.1.1 we can see that the 'inaccuracy perception', as measured by all 12 items combined in one component INACPT, is positively affected by medical knowledge $\left(\eta_{1}\right)$ and negatively by age. This implies that younger people and those with more medical knowledge have less confidence in the quallty of GP services. All other background characteristics snow insigniflcant effects and the proportion of explained vardance is rather low $(4.4 \%)$.

When the same model was estimated separately for each of the factor scores derived from the two-component-PCA, very different results were obtained. INACP2 was only positively related to MEDFAM at the 5\% level of signiflcance. This would imply that, controlling for other factors, only the individuals with medical family members had a significantly nigher score for perceived inaccuracy of GP's. The explanatory power of this equation is very poor. On the other hand, a positive accuracy perception (ACCURPe) was found to be strongly positively determined by 
Table 4.11. Estimation results of the MIMIC model in 1igure 4.2 for three definitions of percelved accuracy of GP

\begin{tabular}{lccc}
$\eta_{2}$ & INACPT & INACP2 & \multicolumn{1}{c}{ ACOURP2 } \\
\cline { 2 - 5 }$\eta_{1}=$ MEDKN & $.143(2.2)$ & $-.099(1.5)$ & $-.332(5.1)$ \\
EDC & $-.012(.24)$ & $-.081(1.7)$ & $-.073(1.6)$ \\
SES & $.011(.25)$ & $-.004(.09)$ & $-.021(.51)$ \\
MELFAM & $.049(1.5)$ & $.073(2.2)$ & $.007(.23)$ \\
HHSZ & $-.026(.78)$ & $.033(.96)$ & $.077(2.4)$ \\
AGE & $-.139(3.8)$ & $-.052(1.4)$ & $.153(4.3)$ \\
FEM & $-.046(1.4)$ & $.006(.17)$ & $.077(2.5)$ \\
$\mathrm{R}^{2}$ & .044 & .018 & .144 \\
$x^{2}(23)$ & 46.4 & 49.7 & 50.1
\end{tabular}

Note: The $x^{2}$ test statistic refers to the full model and not only to the equation reported here.

age, female sex and household size and negatively by medical knowledge.

It has to be pointed out that the coefficients given in table 4.11 represent the direct effects of the background characteristics on the dependent variable. In order to find the total effects, the indirect effects (through $\eta_{1}$ ) have to be added. In most cases, the total effects are larger (in absolute value) than the direct effects which means that the indirect effect reinforces the direct effect.

All three fitted models are rejected by the $x^{2}$ test with 23

degrees of freedom. We will select the INACPT variable as the measure of accuracy perception to be used in the full structural model because it has the lowest $x^{2}$ test statistic $(46.4)$ and because it sumarizes a11 12 EVGP iterns in one construct. In section 4.4 we will examine whether the predictions made in chapter 3 regarding the effects of prior information $\Phi_{i}$ as measured by the medical knowledge latent varlable, and of the percelved accuracy of $\mathrm{GP}$ information $\Phi_{\mathrm{p}} \mathrm{as}$ measured by the INACPT factor score, are compatible with our sample data.

\subsection{A structural equation model of the demand for information and medical care}

This section is divided into three parts. Before we present and discuss the estimation results, we will first describe the specification of the full model explaining the demand for care and information. The section is concluded with an investigation of the 
robustness of the results with respect to some modifications of the basic model.

\subsubsection{Specification of the demand equations}

In the theoretical model outlined in chapter 3 , it was argued that especially a visit to a general practitioner at the patient's own initiative could be seen as largely consisting of a demand for advice. We will therefore concentrate in this empirical analysis on the explanation of the number of contacts with 2 GP initiated by the respondents curing the observation period (GPCON) to test some of the predictions of the demand for information theory. As an altemative avallable to the patient we consider self medication (SMED). For minor 11 messes, consumers can use medicines without a prescription instead of - or before - going to see a doctor. As a measure of this sort of medical consumption, we will use the number of different types of self medication taken during the nine weeks period.

In addition, we examine two types of prescribed medical consumption: the number of GP visits made on referral (GFREF) and the number of types of medicines used on prescription (PMED). These are clearly demands for medical care conditional upon the physician's advice which can be used to test for demand creation effects. We also hypothesized these demands to be interrelated in a hierarchical manner. Because self-medication is likely to be an option only prior to seeking professional advice, we included SMED in the GPCON and in the PMED equation in order to see whether it is used as a substitute for or complement of prescribed medication. The number of referred $G F$ contacts is assumed to be dependent on the number of patient initiated contacts and the use of prescribed medicines is conditional upon both patient- and physician-initiated contacts.

The specification of the equations to explain these demands for care and information is guided by the variables included in table 3.1 of Chapter 3. The main explanatory varlables of interest in this study are, of course, the varlables measuring the two Bayesian components of consumer information $\phi$ and $\theta_{\mathrm{p}}$. It is expected that both prior inform ation and perceived inaccuracy will reduce the initial demand for information from general practitioners. Ceteris paribus, the opposite effects should occur for the demand for self-medication: more knowledgeable consumers and those with less confldence in general practitioner advice are expected to be more inclined to engage in "self-doctoring". If physiclans are assumed to manipulate the accuracy of their advice in order to create additional demand for their services then again the possibilities for such manipulation should be more restricted for informed and/or sceptical consumers. We thus expect similarly negative effects of knowledge (as a proxy for $\$$ ) and percelved inaccuracy $\mathbb{1} / \theta_{p}$ (as a proxy for $q$ ) on the demand for repeat visits and prescribed medicines. 
As we argued in section 3.4.2, the initial health of the individual $\left(\mathrm{H}_{0}\right)$ is assumed to have a negative impact on $\mathrm{b}_{0}$, the consumer's prior estimate of the effectiveness of medical care. Although the comparative static effects of $b_{0}$ on the demand for information were shown to be non-1 inear and approaching zero at the extremes of $D_{0}$ it seens reasonable to assume that it is positive in the range which is relevant for our sample of individuals. It is concelvable that the demand for information becomes negatively related to the expected marginal effectiveness of health care at very high levels of 1 liness severity but such individuals are likely to be in hospital already and not participating in the Primary Health Care Survey. We can therefore expect a negative effect of $\mathrm{H}_{0}$ on both the demand for information and the demand for medical care.

The question then arises how we should enter $\mathbb{H}_{0}$ in the demand equations. In the section on health measurement we argued that it makes sense to distinguish between two components of an individual's general health status. In princlple, one could expect that variations in both the permanent health state and the transitory flow of sick time may give rise to a demand for (information about) medical care. However, we w111 impose some additional restrictions on the direct effects of health on demand. It is plausible to assume that individuals w11 consult a doctor or take prescribed medicines at their own initiative only if they experience a deviation from their permanent health status, 1.e. a transitory health loss. This means that permanent health influences this patient demand only indirectly through its impact on transitory nealth.

On the other hand, the use of prescribed medicines or GP services on referral may be a consequence of a (permanent) health problem that was present already before the beginning of this observation period. Permanent health therefore directly affects prescribed consumption of medical services. Transitory health can only indirectly exert an influence because the individual will have to consult a doctor 3 first at least once. The hypothesized interrelationships between health and medical care utidlzation are sumarized in figure 4.4. This recursive structure w111 be used in the basic model specification but in a later stage we will examine the validity of some of these model restrictions.

Because information and care are assumed to be normal boods, family income (FINC) should have a positive effect on their demand, ceteris paribus. However, as was pointed out before, due to the presence of extensive insurance coverage the impact of income level on medical consumption may be much weaker than for other goods and services. The same argument applies to the effect of money prices. We explained in section 3.4 .2 that all sickfund beneficlaries paid the same fixed deductible amount for prescription drugs and general practitioner visits but there is one exempt category: the so-called woPI-category (the widows, orphans, pensioners and invalids) paid a lower deductible 


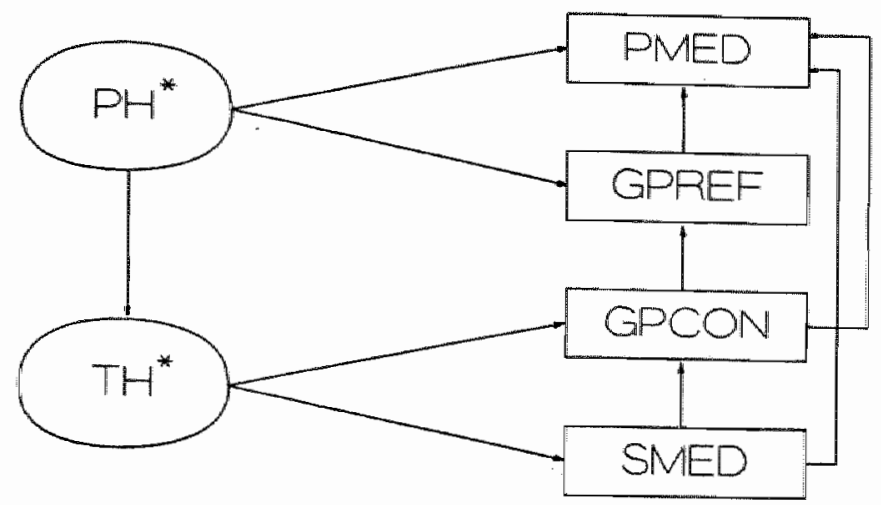

Figure 4.4. The relationships between health

status and medical care utilization

for prescribed medicines and received full reimbursement of GP fees. 4 It is wel1-know that these beneficiarles have a much higher medical consumption (see e.g. Dejardin and Praet, 1980). A dumy variable wOPI is included in the demand equations to test for possible differences in consumption between these two types of insurance beneficiaries, after correction for other differentials (health status, income, knowledge, etc.).

In order to adjust for differences in travel and time costs between different regions, we have added one or two indicators of health care supply availability" the pharmacy (FHARD) and general practitioner density (GPDENSI) in the municipality of residence of the respondent. In the equation for GP contacts on referral, the coefficient of this variable may also represent to some extent an effect of supplierinduced demand (Pauly, 1978). In reglons with high provider densities average fee-for-service income is lower unless the suppliers are able to induce additional demand (e.g. repeat visits) for their services.

Finally, four background characteristics (AGE, FEM EDUC and MEDFAM) nave been entered into the demand equations to control for a possible direct influence apart from their indirect effects trirough nealth and information. The MIIC measurement models for health and information are almost identical to the ones estimated and presented in sections 4.2 and 4.3 . The only difference is that we nave here assumed that knowledgeability may exert a direct positive influence on health status, irrespective of consumption behawlour (e.g. through healthier habits). On the other hand individuals with a lower permanent health status, and therefore probably higher levels of health care utilization in the past, may have acquired more knowledge about health and medical care. In the structural model estimation, we have tested for this simultaneity by not restricting the coefficients of MEDN in the 
FH and TH equations, and that of PH in the MEDaN equation to be zero.

\subsubsection{Estimation results}

The total I inear structural equation model comprises eight structural equations and fifteen measurement equations. The LISREL equation $(4,2)$ now becones

$$
y=\Lambda \eta+\epsilon
$$

where $y^{\prime \prime}=$ (SMED, GPCON, GPREF, PMED, CCOND, PGPC, COMP, LRAD, LNAD LDISAB, TEST1, TEST2, TEST3, TEST4, INACFT)

$\eta "$ (SMED GPCON GPREF, FMED, FHEALTH*, THEALTH*, MEDAN", INACPI)

Wote that the first four and the last $\eta$-variable are by definition identical to the directly observable $y$-variables. The corresponding measurement equations reduce to identitles with $\lambda$ equal to one and the $\epsilon$-varlance equal to zero: $\eta_{1}=y_{1}, \eta_{2}=y_{2}, \eta_{3}=y_{3}, \eta_{4}=y_{4}$, and $\eta_{8}=$ $=Y_{15}$

The structural equation part $(4.7)$ now equals

$$
\eta=\mathrm{Bn}+\mathrm{\Gamma X}+5
$$

with $\eta=$ as above

$x^{\prime}=$ (EDT, SES, MEDFAM HSZ, AGE, FEM PSPR, LIHIST, FINC, WOPI, FHARD, GPDENS)

This model is identified because it can be split into three parts which are identifled each (see $e_{1}$. Wiley, 1973). A formal proof of the identiflcation of this model is provided in appendix 4D.

As input for the maximm likelihood estimation procedure the correlation matrix was used. It is worth noting from the correlation matrix given in appendix $4 \mathrm{~B}$ that the simple correlations between the knowledge test scores and the medical consumption variables of interest are fairly low but positive for SMED zero for GPON and negative for GPREF and FMED. The correlations between INACPI and the demand variables are similarly low but all negatlve. We will see what nappens to these assoclations when other influences are controlled for in the causal model structure.

Table 4.12 presents the estimation results (A-coefflcients, t-values and rellability coefficlents) for the measurement equations of the three latent variables. Comparison with table 4.4 (model 1D) and table 4.6 (MIMIC mode1) learns that integration of these measurement equations in a larger structure leaves the estimates virtually unaffected. If any change at all can be detected it is a slight improvement of the t-values and/or the p-coefficlents. This stability result is reassuring in view of the efforts that were made to obtain adequate measurements of the theoretical constructs. 
Table 4.12. Maximm Iikelihood estimation results of the LISREL measurement model for the three unobservables $y=\lambda \eta+\epsilon(n=949)$

\begin{tabular}{|c|c|c|c|c|}
\hline \multirow[b]{2}{*}{ FEALTH $\left(n_{5}\right)$} & $\begin{array}{l}\text { COOND } \\
\left(y_{5}\right)\end{array}$ & $\begin{array}{l}\text { PGEC } \\
\left(Y_{6}\right)\end{array}$ & $\begin{array}{l}\text { OOMPL } \\
\left(Y_{7}\right)\end{array}$ & $\hat{\theta}_{\in 65}$ \\
\hline & $\begin{array}{l}-1.0 \\
(-1) \\
.247\end{array}$ & $\begin{array}{r}-1.094 \\
(12.6) \\
.296\end{array}$ & $\begin{array}{r}-1.412 \\
(13.4) \\
.492\end{array}$ & $\begin{array}{l}.088 \\
(3.0)\end{array}$ \\
\hline \multirow[b]{2}{*}{ THEALTH $\left(\eta_{6}\right)$} & $\begin{array}{l}\text { LRAD } \\
\left(\mathrm{Y}_{8}\right)\end{array}$ & $\begin{array}{l}\mathrm{LRAD} \\
\left(\mathrm{Y}_{9}\right)\end{array}$ & $\begin{array}{l}\text { LDISAB } \\
\left(\mathrm{y}_{10}\right)\end{array}$ & $\hat{\theta}_{\mathrm{eg}}$ \\
\hline & $\begin{array}{r}-.776 \\
(18.3) \\
.318\end{array}$ & $\begin{array}{r}-.776 \\
(18.3) \\
.318\end{array}$ & $\begin{array}{c}-1.0 \\
(-5) \\
.527\end{array}$ & $\begin{array}{r}-.09 \\
(3.5)\end{array}$ \\
\hline \multirow[b]{2}{*}{$\operatorname{MEDNN} \quad(\eta 7)$} & $\begin{array}{l}\text { TEST1 } \\
\left(Y_{11}\right)\end{array}$ & $\begin{array}{l}\text { TEST2 } \\
\left(Y_{12}\right)\end{array}$ & $\begin{array}{l}\text { TEST3 } \\
\left(Y_{13}\right)\end{array}$ & $\begin{array}{l}\text { T2ST4 } \\
\left(y_{14}\right)\end{array}$ \\
\hline & $\begin{array}{c}1.0 \\
(-565\end{array}$ & $\begin{array}{c}.902 \\
(17.3) \\
.460\end{array}$ & $\begin{array}{c}.894 \\
(17.2) \\
.452\end{array}$ & $\begin{array}{c}.419 \\
(8.5) \\
.099\end{array}$ \\
\hline
\end{tabular}

Note: $\lambda$-coefficient, absolute $t$-vallue in parentheses, and reliability coefficient $(\rho)$

In table 4.13, the LISREL estimates of the structural part of the model are presented. The first four colums contain the unstandardized $\beta^{-}$and $\gamma$-coefficients (and their $t$-values) for the health care demand equations. If we go through the results from the top to the bottom of the table, we see first of all that these different demands are strongly interrelated. Self-medication (SMED) appears to have a negative effect on both the frequency of seeing a GP and using prescribed medicines. This probably reflects the fact that these overthe-counter arugs are often used for less severe health problems.5 Perhaps surprisingly, the number of GP contacts at the initiative of the patient has a negative influence on the number of GP contacts on referral. This suggests that most of the referred contacts result from earlier contacts before the period of observation rather than from patient-initlated contacts during this periad. It may also imply that these referred contacts occur mainly for more chronic patients under longer term treatment. Finally, both patient- and doctor-initiated contacts increase the use of prescribed drugs considerably. This is not surprising since pharmacotherapy is the far most common type of intervention used in Belgian general practice. 6

As in most studies of health care utilization, the impact of the health variables dominates all other influences. "Transitory nealth in the patient-initiated and permanent health in the doctor-initiated utilization equations show large and strongly significant negative 


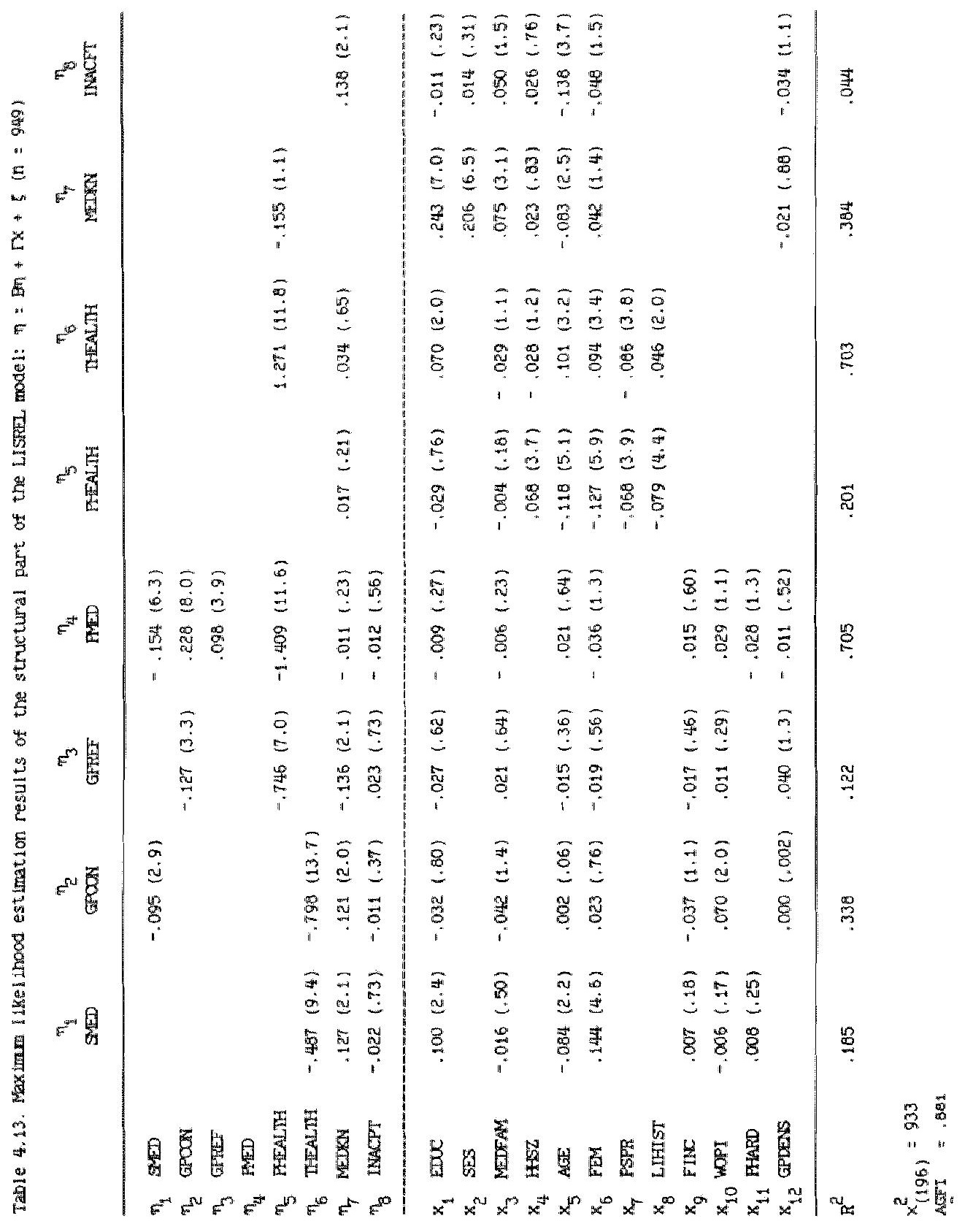


The effects of the varlables in which we are primarily interested in this study, MEDN and INACPT, are much smaller. Inaccuracy perception of general practitioners, as it is measured by the factor score INACFT based on 12 items, shows no significant effect on utllization at all which makes it not worthwile to look at the slans of the coefficients. Medical knowledgeability (MEDKN), on the other hand, has a positive coefficient for SMED and GPCON both significant at the $5 \%$ level), a negative coefflcient for GFREF (significant at the $5 \%$ level) and a non-significant coefficient for FMED. Two of these effects, namely on SMED and GPREF, are consistent with our theoretical predictions but the major prediction of this theory, 1,e. that more knowledgeable consumers should, ceteris paribus, denand less frequentIy information from their $G P$ is clearly rejected. It is even so that the opposite result seems to hold. A more elaborate discussion and interpretation of these effects is deferred to the conclusion of this chapter which also incorporates the results of a robustness analysis of sone madel modifications.

The effects of the exogenous $x$-variables on utilization are in general small and, with some notable exceptions, non-significant. Family income (FINC) is never signiflcant and the insurance dumy (WOPI) indicates that this category of insurance beneficiaries only have a significantly higher number of patient-initiated contacts with the GP. If health status, income, age and other differences are adequately controlled for in this analysis, then this finding could be interpreted as a pure price effect. It may, however, not only be a money price effect (GP services were free for these people) but may also reflect a time price effect: pensioned and disabled people can be expected also to face lower time costs when visiting a GP.

Neither the number of pharmacies (FHARD), nor the number of general practitioners (GPDENS) per capita show a statistically simificant influence on the frequency with which their services are being used by the sample population. However, it deserves mentioning that the only consumption category for which one could expect supplierminduced demand lover and above the time price effects of shorter distances and walting times) because it is care prescribed and delivered by the same provider, 1.e. physician-initlated referral contacts, also shows the largest avallability effect. The implied ellasticity at the means of GPREF and GPDENS equals .46 .7 Although it is statistically not significantly different from zero it deserves some closer investigation in future work. The non-significance may simply be a result of limited power of the test due to our limited sample size in which only $10 \%$ af the individuals report any referred contacts. Rossiter and Wilenski (1981) for example, who analyzed the $1977 \mathrm{VS}$ National Medical Care Expenditure Survey $(n= \pm 40,000)$, also found that physician density had a small but significant positive effect on physician-initiated but not on patient-initiated visits. Evaluated at 
the mean. they estimated on elasticity of .06.

For the remaining exogenous (taste) variables in the demand equations (EDC, MEDFAM ACE FEM) only some direct influence on SMED was found: women and higher educated people use more and older people fewer nonprescribed medicines. The direct effects of these varlables on the other types of demand were statistically insignificant and therefore negliglble compared to their indrect effects through health and mowledge.

When we turn to the structural equations presented in the last four colums of table 4.13, we see again that the integration of the submodels into the larger model, estimated in the measurement sections 4.2 and 4.3 has had little effect on the magnitude and sign of the estimated coefficlents. We will therefore focus our attention on the added simitaneous relationship between health and medical knowledge. The direct effects of MEDW on permanent and transitory health are positive but not statistically significant. This is remarkable because education does have a signiflcant positive influence on transitory health which implles that, ceteris paribus, the higher educated are less likely to report sick time. In contradiction to what one would expect, general knowledge capltal seems more beneficial to one's health than speciflc medical knowledge capital. This finding cannot be due to the fact that people with more extensive iliness experience also acquire more knowledge about health and medical care because this reverse causality has been introduced in the MEDKN equation: indeed a negative coefficlent is estimated for FH but it is not statistically significant. We must conclude that the cross-sectional association between knowledge and health is weak when other influences (e.g. education) were controlled for.

The squared multiple correlations for the structural equations are calculated as $\mathbb{R}_{1}^{2}=1-\operatorname{var}\left(5_{1}\right) / \operatorname{var}\left(\eta_{1}\right)$ (Joreskog and Sörom 1981 , $p$. I. 37). They indicate a reasonably good fit for most of the relations except the equation for INACPT. Explained varlance is highest (about $70 \%)$ for prescribed medicines and transitory health and lowest for self medication and referred contacts with the GP (less than 20\%). The $x^{2}$ test statistic value for the total model (measurement and structural part together) indicates rejection of the null hypothes is that the correlations between the observed variables have been generated by this model. We have mphasized before that the sample size and the non-normal distribution of several of the dependent variables tend to increase the value of the test statistic. According to some authors, our fit is not such a bad result at all with a sample size of about 1000" "We judge a ratio (test statistic divided by the number of degrees of freedom) of around 5 as beginning to be reasonable, based on our experience in inspecting the sizes of the residuals which accompany varying $x^{2}$ values" (Wheaton et al, 1977, p. 99\%. Since this

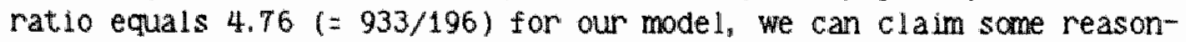
ability as to the goodness of the $f i t$ despite formal rejection by the 
$x^{2}$ test. The goodness-of $-\frac{f}{2} i t$ index adjusted for degrees of freedon (AGFI) equals. 881 and the total coefficlent of determination for the structural model $\left(R_{\eta}^{2}\right)$ is .618 . Both measures are difficult to judge at face value but will be used for compamison with alternative model specifications in section 4.4 .3 .

Finally, it is worthwile to examine the total effects of each variable on the endogenous variables in the model. Table 4.13 only reports the estimated direct effects but a lot of variables also exert indirect influences which have to be added in order to obtain the total effects. Furthermore, a meaningful comparison can only be made for the standardized estimates. These are given in table 4.14 for a selected number of 7 - and $x$-variables.

Some interesting findings emerge from this exercise. First of all, the indirect effects of FHEALTH on SMED and GPCON are much more important than the indirect effects of THEALTH on GPREF and FMED. The latter is even positive because THEALTH reduces GPCON and thereby increases GPREF. Note also, that, as a consequence of the simultaneous determination of FHEALTH and MEDN total effects of these variables on themselves are produced! Such "cycling effects" are calculated as the sum of an infinite geometric series (see Jöreskog and Sorkom 1981, p. III.92), which is equal to $\beta_{1} \beta_{2} /\left(1-\beta_{1} \beta_{2}\right)$, where $\beta_{1}$ and $\beta_{2}$ represent the mutual total effects of the two $\eta$ 's (BHEALTH and MEDKN). It can be seen that the series converges, at the value of -.003 , indicating stability of the system.

Furthermore, the positive direct effects of MEDKN on SMED and GPCON are 1 arger than the total effects. The indirect effects of MEDKN via SMED FHEALTH and INACFT reduce the total effect to about half the direct effect. This means that more self medication, silghtly better

health and a less favourable perception of general practitioner services reduce the partial positive impact of medical knowledge on patient-initlated GP contacts considerably. The remaining effect is stil1 positive. Thus we reach the same unexpected result as Hay and Leahy (1982) but nevertheless we can reject their interpretation of it. They argue: "It is certainly plausible to interpret these results as consistent with the wiew that medically informed people nave more faith in medicine, and ut lize services with littie true marginal effect but this begs the question of who is really medically informed." $(p$. 242$)$ This explanation is in contradiction with our finding of a negative indirect effect of MEDWN on GPCoN through INACPT, which is, however, much smaller than the direct positive effect: they seem to consult the GP more often despite the fact that they show less confidence in GP's in general.

We can observe once more that the health gains of both MEDWN and EDUC are small and that the signs of their effects on the demand for medical care are the same except for GPCON. AGE and FEM have substantial total effects on consumption due to their sionificant 
Table 4.14. Standardized total and drect effects of sone $\eta$ and $x$ variables on the m-varlables

\begin{tabular}{|c|c|c|c|c|c|c|c|}
\hline A. & $\begin{array}{l}\text { TOTAL } \\
\text { EFEXTS }\end{array}$ & $\begin{array}{c}\text { Th } \\
\text { FHEALTH }\end{array}$ & $\begin{array}{l}76 \\
\text { THEALH }\end{array}$ & $\begin{array}{l}\mathrm{MT} \\
\text { MEDNN }\end{array}$ & $\begin{array}{c}x_{1} \\
\text { EDC }\end{array}$ & $\begin{array}{l}X_{5} \\
\text { AGE }\end{array}$ & $\begin{array}{l}x_{6} \\
F E M \\
\end{array}$ \\
\hline$\pi_{1}$ & SMED & -.635 & -487 & .097 & .108 & -.063 & 184 \\
\hline$n_{2}$ & GPCON & -.966 & -.752 & .066 & -.051 & .043 & .065 \\
\hline$\eta_{3}$ & GPREF & -.600 & .096 & -.153 & -.035 & .073 & ". 057 \\
\hline 24 & PMED & -1.585 & -.087 & -.052 & -.009 & .218 & .134 \\
\hline$m_{5}$ & PHEALTH & -.003 & 0 & .017 & -.025 & -.119 & -126 \\
\hline$\eta_{6}$ & THEALTH & 1.263 & 0 & .055 & .047 & -.052 & -.065 \\
\hline$\pi$ & MEDAN & -.155 & 0 & -.003 & .247 & -.064 & .062 \\
\hline 78 & INACPT & -.021 & 0 & .137 & .023 & -.147 & -.039 \\
\hline
\end{tabular}

\begin{tabular}{|c|c|c|c|c|c|c|c|}
\hline B. & $\begin{array}{l}\text { DIFEXT } \\
\text { EFFETS }\end{array}$ & $\begin{array}{c}m_{5} \\
\text { FHEALTH }\end{array}$ & $\begin{array}{l}76 \\
\text { THEALTH }\end{array}$ & ${ }_{\text {MEDKN }}^{n}$ & $\begin{array}{c}x_{1} \\
\text { EDUC }\end{array}$ & $\begin{array}{l}X_{5} \\
\text { AGE }\end{array}$ & $\begin{array}{l}\mathrm{X}_{6} \\
\mathrm{FEM} \\
\end{array}$ \\
\hline$n$ & SMED & 0 & -.354 & .096 & .100 & -.084 & .144 \\
\hline$m$ & GPCON & 0 & -.581 & .091 & -.033 & .002 & .023 \\
\hline 73 & GPREF & -.370 & 0 & -.102 & -.027 & -.015 & .019 \\
\hline$n_{4}$ & PMED & -.698 & 0 & -.009 & -.009 & .021 & .036 \\
\hline$n_{5}$ & PHEALTH & 0 & 0 & .026 & -.058 & -.237 & .256 \\
\hline 75 & THEALTH & . B70 & 0 & .035 & .097 & .139 & .129 \\
\hline$m$ & MEDKN & -.103 & 0 & 0 & .323 & -.110 & .056 \\
\hline$n_{0}$ & INACPT & 0 & 0 & .103 & -.011 & -.138 & .048 \\
\hline
\end{tabular}

indirect effects via permanent and transitory health. The elderly seem to be particularly intensive users of prescribed medicines and younger people take more non-prescription drugs whereas women use more of both types.

Before drawing up some general conclusions with regard to our findings, we will first investigate the robustness of our model estimates with respect to some mode'l modifications in the next section.

\subsubsection{Robustness analys is}

The estimation results presented in the previous section brought out that some of the major predictions of our theoretical model were not confirmed or even had to be rejected. Because the estimated coefflcients on which these tests were based often showed substantial standard errors and the t-values were therefore sometimes close to the critical levels of statistical significance, it is worthohile to examine now robust these results are, $1 . e$. how sensitive they are to some changes in (a) the sample choice, and (b) the model structure. 
First, we will consider the question whether the sample choice is adequate. Until now we have analyzed the entire sample of adults whereas in fact, strictly speaking, the theory of the demand for diagnostic and therapeutic information only applies to individuals who experience their initial health status $\mathrm{H}_{0}$ as suboptimal and therefore consider whether or not to undertake action or seek advice on what to do. About one quarter of the sample did not report any health complaint during the whole observation period and consequently had little reason to contemplate a visit to their GF. Only about $3 \%$ of the non-complainers reported a GP contact. When this upper $25 \%$ of the health distribution is deleted from the sample, the remaining 720 individuals, who have reported at least one health complaint, represent a somewhat less healthy truncated subsample. 8 The majority of 'complainers' are stil1 non-users of medical care. By excluding the individuals without health complaints, we avoid the problem that patterns of utilization for preventive reasons may differ from those for curative purposes. For instance, it is not impossible that medically informed people consult a doctor more for preventive and less for curative reasons (see e.g. Hay and Leahy, 1982).

When the basic model was reestimated on the basis of the correlation matrix for this sub-sample, the results presented in table $4.15 \mathrm{~A}$ and $\mathrm{B}$ were obtained. In general, the deletion of a large part of the healthler individuals have weakened a lot of the observed correlations. Most of the estimated coefficients have the same sign as in the basic model but both the magnitude and statistical significance (as indicated by the $t$-values) is often reduced. For example, the effects of medical knowledge (MEDWN) on SMED, GPCON and GPREF are virtually the same as before but are now only significant at the $10 \%$ level. Although the coefficients of determination of the structural equations on average do not improve, the $x^{2}$ test statistic indicates a substantially superior fit of the model to these data. Clearly, this is mainly a consequence of the reduction of the sample size but even the AGII, which is independent of the sample size, indicates a silantly better fit. Some of the improvement in the goodness of fit measures may be due to the increased rellability coefficlents of all health indicators, except of course caMPL, in the measumement part of the model.

of primary importance for our purposes, nowever, is the stabillty of the major results: the effects of consumer information on the demand for care and information are the same for the sub-sample of individuals with some percelved morbidity as for the sample as a whole. 


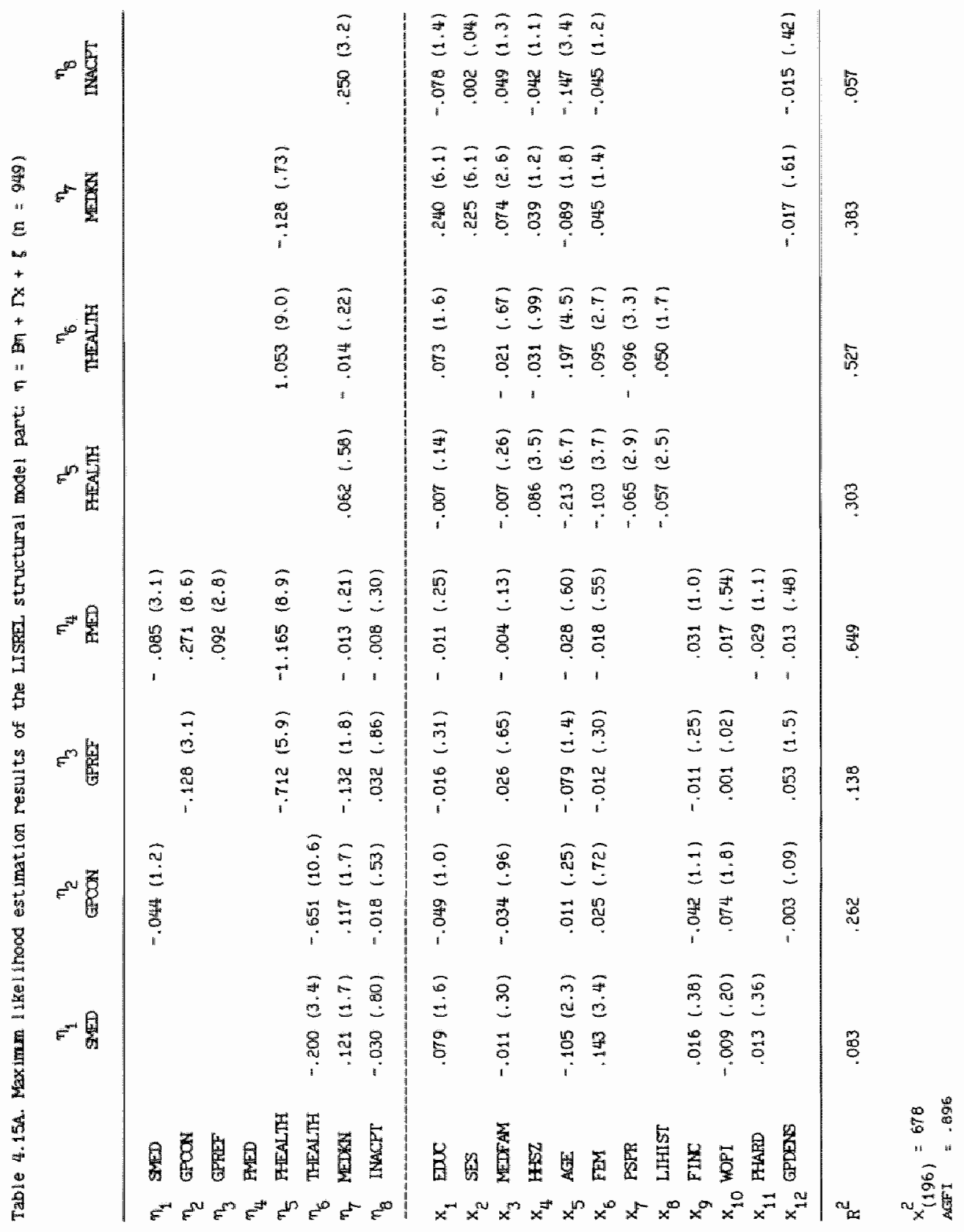


Table 4.15B. Maximm likelihoad estimation results of the LISREL measurement equations $y=\lambda \eta+\epsilon$ for subs ample $(n=720)$

\begin{tabular}{|c|c|c|c|c|c|}
\hline \multirow[b]{2}{*}{$m_{5}$} & \multirow[b]{2}{*}{ FHEALTH } & $\begin{array}{c}y_{5} \\
C C O N D\end{array}$ & $\begin{array}{c}Y_{6} \\
\text { PGPC }\end{array}$ & $\stackrel{Y_{7}}{C O M P L}$ & $\begin{array}{c}\operatorname{cov}\left(\epsilon_{5,} \epsilon_{6}\right) \\
\theta_{\epsilon 65}\end{array}$ \\
\hline & & $\begin{array}{c}-1.0 \\
(-) \\
.312\end{array}$ & $\begin{array}{r}-1.001 \\
(11.0) \\
.312\end{array}$ & $\begin{array}{c}-.845 \\
(9.7) \\
.223\end{array}$ & $\begin{array}{l}.002 \\
(.07)\end{array}$ \\
\hline \multirow[b]{2}{*}{$n_{6}$} & \multirow[b]{2}{*}{ THEALTH } & $\begin{array}{c}Y_{8} \\
\text { LRAD }\end{array}$ & $\begin{array}{c}Y_{9} \\
\text { LRAD }\end{array}$ & $\begin{array}{l}y_{10} \\
\text { LDISAB }\end{array}$ & $\begin{array}{c}\operatorname{cov}\left(\epsilon_{8}, \epsilon_{9}\right) \\
\theta_{\epsilon 98}\end{array}$ \\
\hline & & $\begin{array}{r}-.791 \\
(14.8) \\
.343\end{array}$ & $\begin{array}{r}-.791 \\
(14.8) \\
.343\end{array}$ & $\begin{array}{c}-1.0 \\
(-5) \\
.547\end{array}$ & $\begin{array}{r}-.150 \\
(4.7)\end{array}$ \\
\hline \multirow[b]{2}{*}{$\eta$} & \multirow[b]{2}{*}{ MEDKN } & $\frac{Y_{11}}{\text { TEST1 }}$ & $\frac{Y_{12}}{\text { TEST2 }}$ & $\begin{array}{c}Y_{13} \\
\text { TEST3 }\end{array}$ & $\begin{array}{c}Y_{14} \\
\text { TEST4 }\end{array}$ \\
\hline & & $\begin{array}{c}1.0 \\
(-) \\
.574\end{array}$ & $\begin{array}{r}.872 \\
(14.8) \\
.436\end{array}$ & $\begin{array}{r}.885 \\
(15.0) \\
.449\end{array}$ & $\begin{array}{r}.411 \\
(7.4) \\
.097\end{array}$ \\
\hline
\end{tabular}

Notes: see table 4.1

\section{4.3.2. Model structure}

Secondly, we considered the possibility that the results of our model might be very sensitive to some specification changes. In going from the theoretical model to this particular empirical specification tailored to the dataset at our disposition, some ad hoc assumptions had to be made with regard to which variables ought to be included in which equations. Some of the arbitrary choices that were made in this process, often on the basis of intuitive plausibility, may have had a substantial impact on the outcones. Inevitably, in a structural equation model as large as the one presented here quite a number of restrictions on the structure have to be imposed, not all of which can be justified from the theoretical basis. We have investigated two model modifications which may be expected to potentially affect the coefficients of the MEDWN and INACPT coefficlents.

First, we investigated the effects of deleting the education variable from all demand and health equations. In the demand equations, it has no other justification than as a control variable for "taste" differences among people with different levels of education. But because general knowledge and specif $1 \mathrm{c}$ medical knowledge are clearly strongly related, collinearity with MEDKN may affect the standard errors of the coefficients. 
By restricting the coefficlents of EUC to zero in the first six structural equations $\left(Y_{11}\right.$ to $Y_{61}$ in table 4.13$)$ we assume that education only influences medical care utilization and health indirectly through MEDNN and INACPT. Some of the results of this more restricted model estination are presented in table 4.16 . Only the reestimated coefficlents $B_{17}$ to $B_{67}$ for MEDWN and $B_{18}$ to $B_{68}$ for INACPT are reported because all others were onlymarginally different from table 4.13 and therefore did not need to be replicated here.

Table 4.16. Selected results for model reestimation with $\mathrm{six}$ education coefficients restricted to zero

$\begin{array}{ccc}\text { MEDWM } & \text { INACFI } & R^{2} \\ \eta_{7} & \eta_{8} & \end{array}$

\begin{tabular}{lrrrrr}
\hline$\eta_{1}$ & .216 & $(4.1)$ & -.025 & $(.81)$ & .183 \\
$\eta_{2}$ & .104 & $(2.1)$ & -.010 & $(.34)$ & .335 \\
$\eta_{3}$ & -.164 & $(3.0)$ & .024 & $(.75)$ & .123 \\
$\eta_{4}$ & -.021 & $(.48)$ & -.013 & $(.59)$ & .705 \\
$\eta_{5}$ & -.022 & $(.49)$ & 0 & & .209 \\
$\eta_{6}$ & .100 & $(2.3)$ & 0 & & .699 \\
$X^{2}(202)$ & $=944$ & & & \\
AGFI & $=.882$
\end{tabular}

From comparison with table 4.13 we notice that the effects are in 1 ine with what one could expect. In general, the INACPT coefficients remain insignificant, but the statistical significance of the MEDFN coefficlents improves as a result of the reduced collinearity. The effects of MEDKN on SMED and THEALTH have increased substantially because they now also capture the (signiflcant) indirect influence of education. However, none of the previous conclusions regarding the impact of prior knowledge on demand is changed by this model modiflcation. The increase of the $x^{2}$ test statistic equals $944-933=$ $=11$ and is associated with a gain of $\mathrm{six}$ degrees of freedom. It exceeds the $10 \%$ critlcal level $(10.6)$ but not the $5 \%$ critical level (12.6). Apparently, the fit improvement (due to deletion of four insignificant coefficients) by and large compensates the $f(t$ deterionation (due to the zero restrictions on two significant coefflcients). On the whole, there seems to be no reason to prefer this model specification to the basic one because the main effects of interest remain unaltered and the original specification allows to separate out the general schooling and speciflc medical knowledge effects.

The second model modiflcation which we considered produced more 
dramatic effects. When we wanted to test the validity of our assumptions that the direct effects of FHEALIH on patient-initiated demand (SMED and GPCON) and those of THEALTH on physician-injtiated demand are indeed zero, we ran into problems of convergence of the LISREl iteration procedure. The LISREL progran could not reach an optinal solution within the normal time 1 imit. This non-convergence problen is most likely to be due to the presence of a nigh degree of multi-collinearity between the two latent nealth variables. 9 The correlation between PHEALTH* and THEALTH*, as specifled in the basic model, was .807. Although we showed in section 4.2 .2 that this is still significantly different from 1 , it is relatively high for a conrelation coefficient based on a sample of some thousand individuals. To compare, the highest correlation among the observed variables is .633 between education (EDUC) and socio-economic status measured by some ordering of occupations (SES). Consequently, it becomes extremely difficult to disentangle the separate effects of both health variables in the same equation. Because we were forced to use no more than one health component variable in the demand equations, we chose to stick to our original specification.

\subsection{Conclus ions and discussion}

In this chapter an attempt was made to test empiricaldy some of the predictions of the theoretical model presented in the previous chapter. For that purpose, a structural equation model was developed to explain two patient-initiated denands for medical care (selfmedication and GP contacts) and two physician-initiated demands (referred GP contacts and prescribed drug use) of a sample of nearly a thousand adults drawn from the general Flemish population. Individual health status was measured as a latent vector consisting of two components: a permanent stock of health and a transitory flow of healthy time. In a similar way, two Bayesian concepts of consumer information about medical care in general, and about primary care provided by general practitioners in particular, were distingulshed: a MIMIC index for medical knowledgeablity was used to measure prior information and a principal component was derived to measure the respondents, perception of the accuracy of GP advice. The rellability and valldity of each of these constructs was examined by means of the LISRE mode1. The advantage of this MIMIC approach was shown to be that there is no longer a need to use determinants ('causes') or observable consequences ('indicators') as proxies for the relevant "true" concepts in the analysis. Instead several indicators are combined into one latent factor in onder to increase the reliablity by correcting for measurement errors. The vallaity of these indices was studied by relating them to a nuber of explanatory variables.

The results of these measumement submodels proved to be very robust with respect to integration into the larger structural model. This provides an important justification for the stepwise strategy which we 
adopted, of sorting out the measurement problems before performing any hypothesis testing in the total structural model. Especially for large and complex models this procedure seems fruitful and computertimesaving.

With respect to the tested predictions of the Bayes lan model of demand for information when product quality is uncertain, the following conclusions can be drawn. First of all, better medically informed Individuals do not initlate fewer visits to their GP. On the contrary. ceteris paribus, they report significantly more of such contacts, although the effect is sma11. The total effect of medical mowledgeabllity is smaller than the direct effect, mainly because it has also a positive influence on the use of self medication, which acts as a substitute for GP contacts.

The opposite effect was found for physician-initiated GP contacts: people with more medical knowledge had significantly less GP contacts on referral and the direct effect is reinforced by some indirect effects. No influence could be detected of prior information on the use of prescription drugs. Moreover, none of these demands was significantly affected by our measure of the inlaccuracy perception of GF diagnostic and therapeutic information. Estimation of the basic model on a subsample from which the 'healthy' individuals were deleted and some re-estimations with slightly modified specifications indicated that these results were fairly robust.

On the basis of these results, we have to conclude that neither for $\theta_{\mathrm{p}}$ nor for the analysis confirmed the predicted effects on the demand for infomation as measured by the number of GP contacts at the patient's initiative. The inconsistency of these results with some of the major theoretical predictions stands in sharp contrast to their consistency with earlier findings in the literature on the demand for health care. Investigators who did include proxles for medical knowledge in their empirical demand functions either found no significant effect (e.g. Maning et al, 1982; Wagstaff, 1980; Hay and Leahy, 1982 (Tobit function coefficlent) or a positive coefficient (e.g. Hay and Leany, 1982, oLswcoefficient). In all cases, if any effect was found, it was positive but small. only one study included a variable which is similar to our INACFT variable: Manning et al. (1982) used a four-item scalle to measure a 'favorable attitude toward the efficacy of doctors and medical services" It had a non" sigificant negative effect in a reduced form equation explaining (the logarltim of) outpatient expenditures for medical care of the adults which particlpated in three sites of the Rand Health Insurance Study.

Since all these results were based on larger sample sizes than ours we can have some confidence that our finding of a number of insignificant effects is not simply due to a lack of test power. Moreover, our structural modelling approach yields more insight into the causal processes that may have generated these results than the single equation reduced form approaches. For example, Hay and Leahy (1982) 
are not sure whether their finding of a positive effect of the MEDFAM (family member in medical or health service occupation) dumy variable is not due to better access ('professional courtesy office visits') or "more faith in medicine" of these people. our approach enables us to rule out these possibilities of spurious effects because we could include both medical mowledge and its nypothesized causes and consequences in the GPCON equations. We foumd that, when controlling for the positive effect of consumer prior information, MEDFAM and INACFT had (non-significant) negative effects on the demand for contacts.

A second advantage of our analysis is that we could distinguish between patient- and physician-initiated consumption and this distinction turned out to be crucial. For physician-initiated contacts, indeed the effect of medical knowledgeability is significantly negative and even larger than the positive effect on patient-initiated demand. Although this finding is consistent with Pauly's (1980) hypothesis that prior information effectively Iimits the provider's ability to induce demand, it does not necessarily rule out other possible explanations. For instance more informed GP clients may show better compliance with prescribed theraples and therefore need less repeat visits. However, in combination with the consistentiy positive, though non-significant, effect of general practitioner density in the place of residence, the existence of physician-induced demand for primary care through the generation of repeat visits, remains an interesting topic for further research. only the analysis of larger datasets, which include more observations on this patient-initiated consumption, and preferably complemented with similar information on the use of (in Belgium directly accessible) medical specialists, cam shed more light on this issue. But even when good data are available, the identification of supplier-induced demand by means of econometric analys is will remain a subject of controversy and debate among health economists. 10

Does all this mean that the theory of consumers (patlents) as Bayesian decision-makers, who demand information about a product with uncertain quality; can be rejected as inappropmiate for the demand for medical care? our results indeed suggest that pas ior information land thus uncertainty) has only weak linear effects on demand behaviour. Health status dominates virtually all other influences, including the consumer's perception of the qual1ty of GP information. Our conclusion is therefore that the demand for information theory, despite its theoretical appeal, contributes little to a better empirical explanation of the quantity of health care demand. oualitative effects could not be tested adequately with the avallable dataset. As was pointed out already in section 4.3.1. medcal knowledgeab111ty may manifest itself by more approprlate demand behavlour rather than in more or less overall utilization. If the level of consumption of the more knowledgeable consumers can indeed be considered as more appropriate, then our results suggest that the poorly-informed under- 
ut llize self-medication and general practitioner services.

It should also not be forgotten that the effects of information may be blased by the institutional obligation to seek professional advice in order to obtain a drug prescription, or a sickess absence certiflcate. As a result, sone proportion of the GP contacts may be "unnecessary" in the sense that patients knew in advance how to interpret and act upon certain symptons but were nevertheless legally required to contact their GP. Since this proportion is likely to be higher for more informed patients, any negative effects of prior information on utilization of GP semices tend to be reduced by this requirement.

As a by-product of the structural model analysis we also tested whether medical Whowledgeability nad any direct effects on individual health status. When educational level was controlled for no significant influence of MEDW could be estimated. Education only had a small positive (linear) effect on transitary health. This evidence contrasts sharply with the strong partial schooling-health correlations which are often found in individual cross-section studies (see Chapter 2). Moreover, it indicates that if schooling has a positive influence on health, it is not primarliy because the bettereducated are more knowledgeable about health and medical care matters, but rather because they perhaps enjoy more favourable enviromental circumstances loccupation, nygiene, housing, etc.). However, this conclusion is very tentative given the data limitation and the rather ad hoc specification of the health equations in this model. In the second part of this thesis, a more detalled and ysis of the educationhealth relationship is envisaged by making use of the advantages offered by longitudinal data. 


\section{THE}

1. In the meantime, cost-shaming has been substantially extended and modifjed with proportional coinsurance rates (see e. Wan Doorslaer, 1984).

2. Another possibility is to adjust the power of the test, 1. e. the probabillty to re ject an incorrect model (see e.g. Saris et. al. (1985), or Saris et al. (1906)).

3. General practitioner is too narrow here because also the molcal speciallsts are directly accessible without a refermal in geldium.

4. In 1976, the deductible mounts were 60 Burs for prescribed drugs and 40 Bfrs for a co visit, whereas the wOPI's only had to pay 35 Bfrs for prescription drugs.

5. Prescribed and non-prescribed use of these medicines according to the offerent drug categories is described extensively in Fots et al, (1965).

6. Nuyens (1900) repomts that $78 \%$ of all GF contacts result in pharmacotherapy (P. 95 table 8).

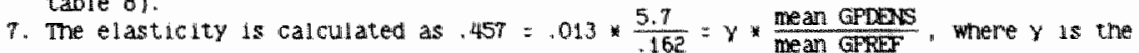
coefficient of GPDess in the GPREF equation when the covariance matrix of the observed variables was used as the input matrix. The $y$ 's can them be interpreted as normal regression coefficients. This is not so for the coefulcients obtained with the correlation matrix as input.

0. Hide effect of this truncation is that the skewnes of the distribution of the dependent warlables in our model (see appendix A) is scmewhat reduced and therefore closer to the nomality ideal.

9. According to wagstaft (1986), who encountered similar problems, the degree of aritrmetic precision required to ensure convergence becones extremely high when there is a hign degree of mitticoli inearity among the explanatory wariables.

10. Cfr. the recent editorials in the Jourmal off Health Economics by Reinhardt (1985), Pluelps (1986) and Fuchs (1986). 



\section{Part II. EDUCATION AND HEALTH}





\title{
Chapter 5. Economic analysis of the schooling-health relationship
}

\begin{abstract}
"The concept of hman capital ... is the joea that people spend on themselves in diverse ways, not only for the sake of present enjoyments but also for the sake of future pecuniary and non-pecuniary benefits" (Blaug 1980, p. 225)
\end{abstract}

\subsection{Introduction}

The first part of this thesis is concerned with an exploration of the direct I inkage between consumer information and the demand for medical care. It provides an examination of one specific mechanism 1.e. Bayesian decision making, through which hman capital, in the form of prior knowledge, might affect medical consumption and thereby health status. In this second part we take a broader view to investigate the overall effect of one type of ruman capital, 1.e. education, on the other type of human capital, 1.e. healtr. This chapter deals with the theoretical and empirical problems which are associated with an econometric analysis of the schooling-health relationship. But $f$ irst, we W111 glve an indication of the importance and relevance of the issue. both from a theoretical and a health policy point of view.

Probably the most comprehensive economic analys is of this relationship has been performed, again, by Grosman (1975). He argued: "Several recent studies in the united states indicate that among socio-economic varlables, years of formal schooling completed is probably the most important correlate of goad health ... This finding emerges whether health levels are measured by mortality rates, morbidity rates, or self-evaluation of health status, and whether the units of observation are indiwlduals or groups." (Grossman, 1975, p. 147). Mmerous European studles suggest that a similarly strong correlation also holds outside the U.S.A. (for a recent survey of socio-economic inequalities in health see Mackenbach and Van der Maas, 1987). Furthermore, the statistical relationship usually remains strongly significant when other covariates, such as income, are controlled for. 
These findings have led some authors (e.g. Auster, Leveson and SaracheK, 1969) to suggest that the rate of return on increases in health $v 1 \mathrm{a}$ higher expenditures on education may far exceed the rate of return on increases in expenditures for medical care. Others like Haveman and wolfe (1984), have argued that standard estimates of earrings differentlals due to incremental schooling have seriously underestimated the total benefits which also include a series of nonmarket effects, one of wich is increased health productivity.

Of course, these sort of arguments only hold if the correlation can be interpreted as a causa 1 effect of education on health but as Grosman (1975) has pointed out, there are at least two other possible explanations which have to be considered. The first is that some causality runs from better health to more education. Clearly, the possiblilty of this reverse causality is only present from childhood to early aldulthood when education is being received. It cannot account for some of the observed schooling-health correlation anong adults who have finished formal education. The second possible explanation, however, wich states that there is no causal relationship at all but that the correlation is generated by the influence of one or more 'third factors' (confounders) seems to be more important. Such third varlables could be genetic factors (e.g. mental ability) or early chlidhood enviromental factors (e.g. parents' schooling).

More recently a "time preference' hypothesis has been added to the third factor explanations (Fuchs, 1982; Farrell and Fuchs, 1982). It states that individuals with a high time preference $11 . e$. those who value future costs and benefits much lower than current costs and benefits) are less wlling to invest in both education and health because typically the benefits of these investments accrue much later than the opportunity costs involved due to forgone time and eamings. Whatever the third factor may be, the larger its effect on schooling and health the larger the spurlous correlation and therefore the larger the overestimation of the effect of education on health when the third variable is omitted from the analysis. 1

The objective of this second part of the thesis is to test and Identify the direct effect of education on individual health status. and the undrect effects through possible intervening variables. From the previous discussion it has becone clear that an appropriate empirical test of this relationship requires both a firm theoretical basis and an adequate data set and corresponding methodology. In order to justify oum own empirical research strategy adopted in the next two chapters, we will first review the theoretical and empirical issues raised in previous economic studies on this subject. 


\subsection{The effect of education on health deanand and production}

When we reviewed the economic theory with respect to health behaviour in chapter 2 of this dissertation, we pointed out that there exist mainly two competing hypotheses regarding the effect of education. The first one is due to Grosman (1972a). He uses the standard housenold production assumption that education operates as an efficlency-increasing factor in both market and non-market production. He specified the following Cobb-Douglas gross investment in health function: (Grossman, 1972)

$$
\ln I_{t}=\alpha \ln M_{t}+(1-\alpha) \ln T_{t}^{n}+\beta E
$$

This means that health increments $\left(I_{t}\right)$ are produced by combining medical care $M_{t}$ (or market goods in general) and ow time input $T^{h}$. The returns to scale are constant if $0<\alpha<1$, and education $\mathrm{E}$ increases non-market productivity if $\beta>0.2$ However, this basic hypothes is about the schooling effect is usually tested with crosssection data on individuals) by estimating a reduced-fom demand for health equation in which education enters with a coefficient equal to $B \epsilon$ in the pure investment model, or to $B y$ in the pure consumption model version. For the present analysis it suffices to know that, under reasonable assumptions about the marginal utility of healthy time and the marginal efficlency of health capital in producing healthy time, both $\epsilon$ and $y$ can be expected to lie between zero and one (see Wagstaff, 1986, pp 199-201). But even then, it means that a test of the positive education effect $(\beta>0)$ is conditional upon the assumptions about $\epsilon$ and $y$ and that any interpretation of this effect is also dependent on these assumptions.

An alternative assumption about the influence of education was made by Murinen (1982). She does not adopt the household production framework but instead invokes the concept of capital use intensity to make the depreclation rate of health o a negative function of education (see equation 2.16 in Chapter 2). Although this may seem "an intuitively more appealing device for handing environmental effects on health" (Mnurinen, 1982, p. 9), Wagstafi (1986) shows that the difference is merely a matter of accounting convention if the depreciation rate function is assumed to be of the form (see 2.18 )

$$
\ln \delta_{t}=\ln \delta_{0}+B_{1} t+B_{2} X
$$

This implies that the initial depreciation rate $\delta_{0}$ is augmented at an exponentially increasing rate as the individual ages $\left(\beta_{1}>0\right.$ is also assumed by Grossman) but also increases with the enviromental variables included in the vector $x$. If education $1 s$ one of the $x$ variables, then its coefficient in the demand for health function becomes - $B_{2} \in$ in the pure investment model and $-B_{2} \gamma$ in the pure consumption model (Wagstaff, 1986, p. 200). Since this implies that $\beta_{2}=-\beta_{1}$ the two approaches camot be distinguished at an empirical level by estimating demand for health functions. 
A second problem with estimating demand for health functions is that, in order to avold the use of non-linear estimation methods " two subnodels have to be estumated which sometimes give rise to very different results. In Chapter 2 we already mentioned wagstaff's (1986) finding that the coefficlent of education in the structural demand for health equation was slgniflcantly positive in the pure investment (PI) model but switched to signif lcantly negative when the marginal ut 11 ty of initlal wealth $\lambda(0)$ was controlled for in the pure consumption (PC) model. This division into sumodels is somewnat unsatisfactory because clearly health 1 s deranded both for the direct utility it generates ("feeling $f(t)$ ) and for its production benefits ('making someone capable of undertaking market and non-market production activitles"). Developments in non-linear estimation tecrniques may make this problem no longer insurmountable.

Thirdly, an important, though sometimes neglected, issue concerns the nature of the disturbance term in the demand for health equations derived by Grossman (1972a). It equals - $\epsilon$ in $\delta_{0}$ in the PI model and $-\gamma$ in $d_{0}$ in the PC model where $\epsilon$ and $\gamma$ are positive constants and $\delta_{0}$ is the depreciation rate in the initial period. In both cases it is treated as an error term with zero mean and constant variance. However, it is hlghly unl lkely that variations in $\delta_{0^{\prime}}$ the rate of health depreciation early in the life-cycle (e.g. at age sixteen) when individuals begin to make decisions themselves, is randomly distributed and uncorrelated with other explanatory varlables in the demand equation. In particular, it is conceivable that it depends on genetic inheritance, early childhood environment and perhaps other factors which also influence intelligence or learning ability and thereby the level of schooling (Grossman 1975). In other words $_{n}$ the onitted varlables influencing $\delta_{0}$ may be correlated with schooling and the correlated with schooling and the negative covariance between error term and explanatory varlable may cause an upward bias in the estimated coefflclent of schooling in the demand for health equation. This is essentially the argument presented in the introduction to this chapter about a third factor possibly causing a spurious correlation. In the next section we will discuss the possible remedies to this problem of omitted varlable bias.

Furthermore, testing of the demand for health function approach becomes difficult when the 'observed' actual stocks of health and the unobserved desired stocks differ because adjustment does not take place instantaneously Wagstaff, 1986" Grossman, 1975). The derived demand hypothesis, 1.e. that more medical care and other health inputs are demanded the higher the desired health stock, does not necessarily hold for the actual current health stock. on the contrary, without exception all investigations of medical care utilization find a strongly negative relationship with observed health status. This suggests that either the derived demand nypothesis, and thus the essence of the Grossman model, has to be rejected or that costs of adjustment from actual to desired stock have to be incorporated into 
Finally, important arguments in the demand for health function are the prices of the (endogenous) health inputs "In individual cross-section studies estimation of these price effects proved to cause problems because: (a) medical care prices typlcally show little variation between Individuals and (b) time prices are difficult to impute to those not earning an hourly wage rate. Researchers have solved (circumented?) these problems by using variation in regional prices or (sometimes endogenous) insurance coverage, and by restricting the sample to labour force participants, but both these solutions and their results are not very satisfactory. Medical care prices are often found not to have a significant influence on health demand and the limitation of the sample to labour force participants excludes a number of important groups of medical care users like the aged, disabled, housewives and children. Evans (1976) therefore argues that: "The result is to make any generalizations from these models to aggregate health care utilization very suspect" (Evans, 1976, p. 536). Although the basic idea that health increments are produced by combining medical care use and own time input may be sound, the difficulties to operationalize the relevant input prices for people with extensive insurance coverage for medical expenditures and sick leave, or for people not in the labour force, makes the testing of these assumptions through estimation of demand curves for health problematical.

The foregoing discussion serves to illustrate the difficulties involved in testing the predictions of the demand for health model empirically. However, for our purposes an alternative is available Which avolds most of the problems mentioned earlier. Since we are not so much interested in testing all of the Grossman model predictions but only want to obtain a good estimate of the education effect on health, we could use a more direct approach by focussing on production functions rather than demand functions for health. of course,

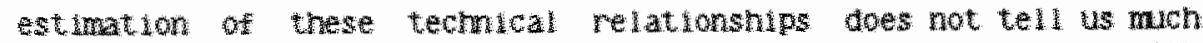

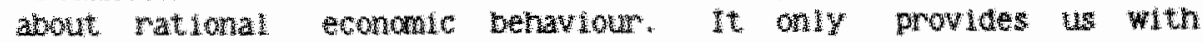

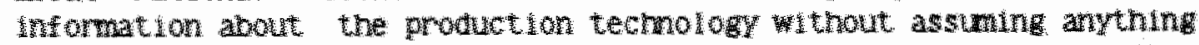

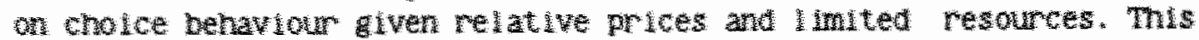

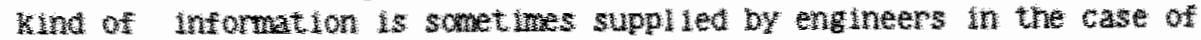

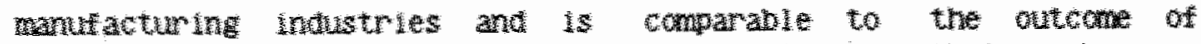

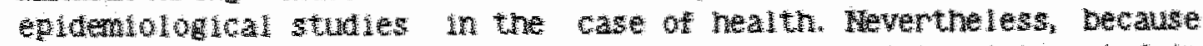

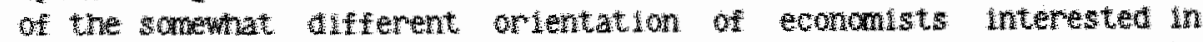

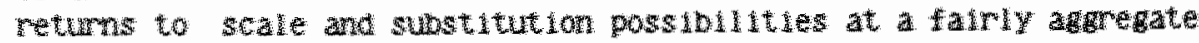

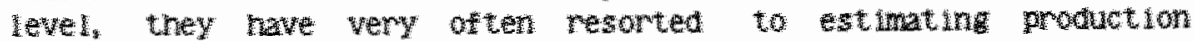

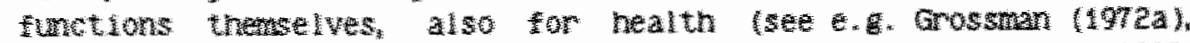

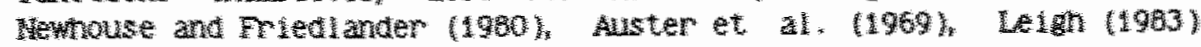

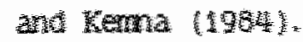

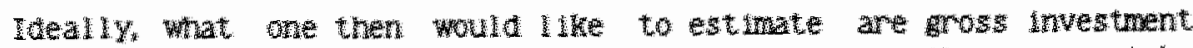

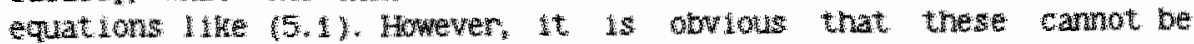


estimated directly because the health increments It produced in each period are not directly observable. A solution to this problem suggested by Grossman (1972a), is to corto ine the investment function (5.1), the depreciation rate function (5.2) and the definition of health change over time (equation 2.3 in chapter 2) to obtain the following function: (for a derivation see Grossman, 1972a, p. 43) ${ }^{3}$

$\ln H_{t}=\alpha \ln M_{t}+(1-a) \ln T_{t}^{h}+B E-B_{1} t-B_{2} X-\ln \delta_{0}$

or, in general form

$\left.H_{t}=f M_{t}, T_{t}^{h}, E, t, x, d_{0}\right)$

Although the dependent variable $H_{t}$ is now drectly observable, a few observability problems remain with the arguments of this function. The investment inputs medical care $\mathrm{M}_{t}$ and time spent investing in health $T^{\text {h }} t$ are difficult to measure, and if they can they are likely to be positively correlated with the disturbance term when $\delta_{0}$ cannot be measured. The downward bias caused by this correlation explains why some researchers (e.g. Grossman, 1975; Kema, 1984) found a large and significant negative impact of their measure of medical care use $\mathrm{M}_{t}$ on health status $H_{t}$ in OLs estimations using individual cross-section data. When a two stage least squares procedure was used to mitigate this bias, difficulties were encountered to calculate predicted values of the endogenous inputs: most (tmuly demand) instmment variables used in the first stage turned out to be poor predictors and the second stage results were very sensitive to the particular specifications employed.

When data are avallable about past health status, a much simpler solution to this problem of cmitted variable bias can be used. From the definition of net health change per period, one can immediately derive an estimable equation as follows:

$$
H_{t}=H_{t}-H_{t-1}=I_{t}-H_{t-1}
$$

or $\mathrm{H}_{t}=(1-\delta) \mathrm{H}_{\mathrm{t}-1}+\mathrm{I}_{\mathrm{t}}$

Where $I_{t}$ and $\delta$ can be substituted by their respective functions. Moreover, when the net change in the health stock $\mathrm{H}_{\mathrm{t}}$ can be observed arectly, it becomes possible to discriminate between the two competing hypotheses about the influence of education. Recall that the userelated depreciation hypothes is states that education reduces the use intensity and thereby the depreciation rate $\delta_{1}$ whereas the productivity increasing hypothesis postulates a direct effect on health investment $I_{t}$. The functional forms for $\delta$ and $I_{t}$ given in equations ( 5.1 ) and $(5.2)$ could directly be substituted in $(5.5)$, but this would make the equation non-linear and therefore difficult to estimate. Alternatives will be suggested in the next section.

In this section we have contrasted (a) the two competing hypotheses regarding the effects of education (capital) in demand for health models, and (D) the two types of functions which can in principle be estimated to quantify the nealth effects of education. It was argued 
that a number of theoretical and empirical problems could be avoided by refraining from estimating demand for health functions and instead focusing on production functions. When longitudinal data on health status are available, it does not only become possible to substantialIy reduce the problem of onitted variable bias but also to distinguish empirically the use-related depreciation versus efficlency-improving effect of education. In the next section, we will review the design and results of some empirical investigations and derive some implicatlons for our own approach.

\subsection{Methodological issues: a survey of prevlous research}

Previous studies of the (causal) relationship between an individual's level of schooling and level of health can be subdivided according to a number of criteria. Theoretical criteria include whether or not they were based on a formal model of economic behaviour and whether they specified behavioural (1.e. demand) or technical (1.e. production) relationships. Using empirical criteria one could distingulsh between cross-section and longitudinal data investigations, between studies which did or did not control for confounding 'thind variables' or which did or did not examine intervening variables or reciprocal caus ation.

Flgure 5.1. Various possible causal relationships between schooling and health

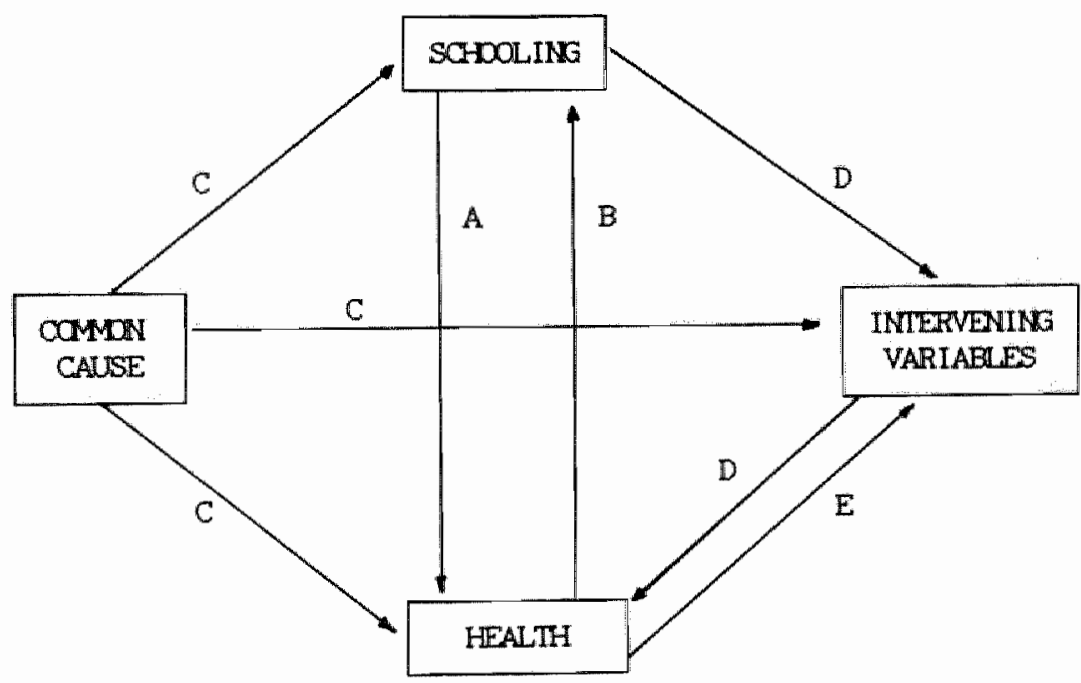


Figure 5.1 provides an overview of the various possible relations that could be considered. We are mainly interested in ldentifying the total effect of schooling on health which is the sun of the direct effect (A) and the indrect effects (D) via intervening variables like cholice behaviour.

\subsubsection{Reverse causality (B)}

In order to disentangle the effects $A$ and $B$ it is clear that longitudinal data are required about pre- and post-education health level. The temporal ordering of events then permits to investigate the causal effects in both ways. This approach is followed by Grossman (1975) who estimated a recursive health-schooling model using data on a sample of 3534 highly educated men who were married and in the labour force in 1969. A retrospective question was used to measure whether their health status was excellent, good, fair or poor when they were attending nigh school. With this past health measure and third variables (e.g. parents' schooling and ability measures) held constant, schooling is found to have a positive and statistically slemiflcant effect on the current subjective evaluation of health. However, allso past health has a significant positive effect on years of formal schooling completed. The elasticity of current health with respect to schooling is, 18 and dominates the reverse elasticity of schooling with respect to past health which only equals .03 (Grossman, 1975, p. 186).

Reciprocal causation was also tested by Shakotko, Edwards and Grossman (1981) between health and cognitive development of adolescents. The longltudinal data they use stem from cycles II and III of the Health Examination Survey of the US National Center for Health Statistics. Their panel consists of 1434 white adolescents who were between 6 and 11 years in the Cycle II period (1963-1965) and 12 to 17 years in the Cycle III perlod (1966-1970). Cognitive development is measured by an IQ measure derlved from an intelligence test for chilaren and a school achlevement measure derived from an aritmetic and reading test. Six measures of childhood and adolescent health were used, including indicators of oral health obesity, blood pressure, presence of slinificant abnomalitles, parent's assessment of overall health and school absence for health reasons. They estimated eight limear equations to explain the adulthood values of all elght measures by their childhood values and a number of famlly background varlables. 4 They found that the cross-lagged effects of cognitive development measures on health indicators are larger than the reverse effects. This is again interpreted as an indication that causality runs more strongly from cognitive develoment to health than vice versa. 
For our purposes, the problem of reciprocal causation can fairly simply be avolded by restricting the analysis to aduits who nave completed their formal education. Health during adulthood does not influence educational achievement during adolescence. However, the danger of spurious correlation caused by one or more thind factors (C in Figure 5.1) remains. One approach to solve this problem in crosssectional studies has been, of course, to include measures or proxies for possible third variables like parental characteristics (e. Shakotko, et al., 1981; Eowards and Grossman, 1983) or mental ability test scores (e.8. Grossman, 1975). But some factors, IIke genet Ic health endowments, are inherently unobservable and therefore bound to be conitted in any specification of a heaith equation. Nevertheless, if such factors can be assumed to operate once and for all and if the main aim is not to distinguish environmental from genetic effects, a straightforward solution to this measurement problem is to use longitudinal data. Observations at two points in time on the dependent varlable may be sufficient to avoid the bias which is caused by omitting the relevant but unobservable variable.

Consider the following simplified two-period model wich is similar to the one described by Shakotko et al. (1981):

$$
\begin{aligned}
& H_{t}=a_{1} H_{f}+b_{1} x+c_{1} \\
& H_{t+1}=a_{2} H_{f}+b_{2} x+c_{2} H_{t}+\epsilon_{2}
\end{aligned}
$$

where $H_{t}$ is health status in period $t$ and $H_{t+1}$ in period $t+1_{1} H_{f}$ represents an individual-specific but time-invariant third factor (genetic or environmenta 1 ); $X$ is a time-invariant background variable and $\varepsilon_{1}$ and $\varepsilon_{2}$ are disturbance terms. If $H_{f}$ cannot be measured, estimation of $b_{1}$ in equation $(5.4)$ leads to omitted varlable bias when $H_{f}$ and $x$ are comelated. 5 However, $b_{2}$ can be estimated without such bias if it can be assumed that $a_{2}$ is zero, i, e. that the impact of the third factor operates once and for all and is fully embodied in past values of the dependent variable. 6 under the latter, falrly restrictIve assumption, Shakotko et al. (1981) estimate the - what they call'dymamic' effects of such famlly background variables as mother's and father's education and family income. If the lagged level of health is controlled for, the estimated $b_{2}$ coefficlents of the $x$ varlables represent short-rum effects free of genetic bias. These estimates are to be distinguished from the $b_{1}$ coefficients abtained from equations without lagged health status which then measure the 'cumilative". long-mm impacts of such background variables.

Shakotko et al. (1981) estimated all nealth land cognitive development) equations with and without lagged nealth included. Not surprisingly, they found that the magnitudes of the "dynamic' effects were much smaller than the 'cumulative' effects. Only the level of mother's schooling showed some significant beneficlal influence on adolescents" health status when childhood health status was controlled 
for, and this in only three of the six health equations.

Distinguishing between so-called dynamic and cumlative effects is basically the same approach as the one adopted by Tauman and Rosen (1982) who estimated what they call 'health deterioration functions" of the following form:

$$
H_{t+1}=H_{t+1}-H_{t}=f\left(H_{t}, x, t\right)
$$

where the variables are the same as in equation (5.5) but the functional form is not necessarily I inear.

Given an initial condition $H_{0}$, difference equation $(5.6)$ can in principle be solved to obtain the following equation for $\mathrm{H}_{t}$

$$
H_{t}=g\left(H_{0}, x, t\right)
$$

When equation (5.7) is estimated in a cross-section and $H_{0}$ is treated as an unobserved random variable, the - by now familiar - problem of omitted variable bias occurs. Taubman and Rosen (1982) therefore suggest to estimate (5.6) instead. Of course, the estimated effects of $X$ 's on health changes over time are not directly comparable to their effects on health levels (cfr. the distinction between dynamic and cumulative impacts). The difference can be illustrated by means of Figure 5.2 which is similar to the one presented in Taubman and Rosen (1982, p. 124).

Figure 5.2. Two hypothetical health profiles over the life cycle

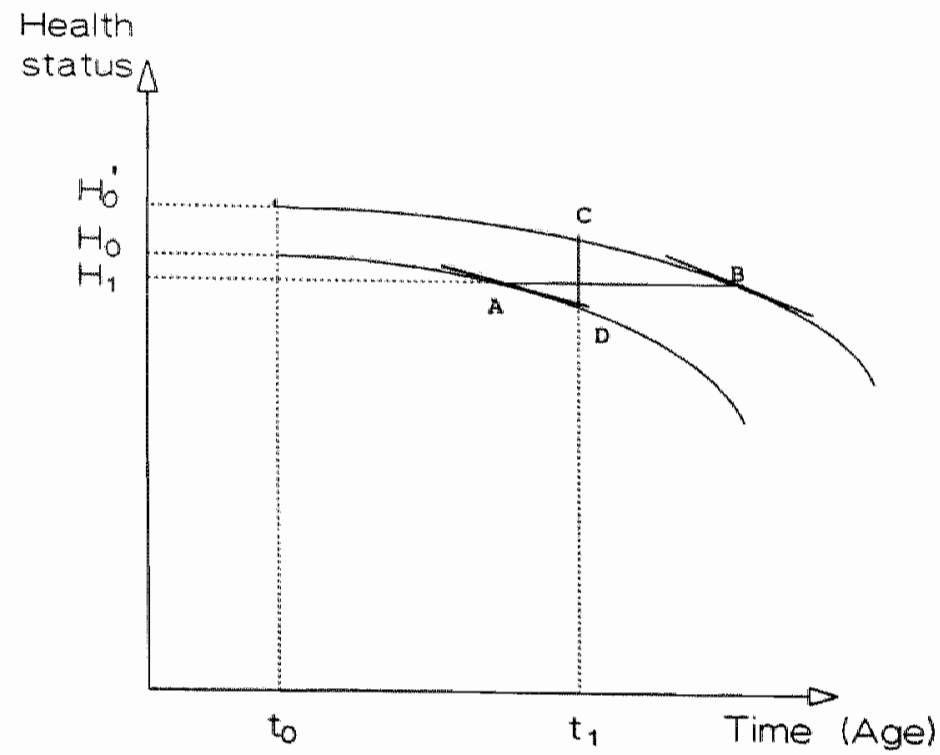


Suppose the life-time proflles of the health of two individuals with different levels of education $\left(E_{1}\right.$ and $\left.E_{2}\right)$ can be represented oy the Lines draw in Figwe 5.2. If the difference in initial health status $\left(\mathrm{H}_{\mathrm{O}}-\mathrm{H}_{\mathrm{O}}\right.$ ) at point $t_{0}$ is mobserved a cross-section estimate of equation (5.7) measures the distance between points $\mathrm{R}$ and $\mathrm{S}$ at some point $t_{1}$. Equation $(5,6)$, however, stimates the slope difference at points $P$ and $Q$ Given health status $H_{1}$. This is zero if the protles are parallel.

Tauman and Rosen (1982) used data from three waves of a panel survey to examine health changes over time. The Retirement History Survey was held among a randon sample of some 11,000 men and wonen between the ages of 58 and 63 in 1969, 1971 and 1973 . Health was measured as seltassessed health status compared to others of the same age ith three answer possibllties better, same or worsel. Since it is diflcult to calculate first differences of these nealth values without an arbitrary scaling method, the authors instead used a loginear model to analyse effects and interactions of explanatory variables. Conditional on previous health level, they examined models explaining the proportions in these three level categoriest and in three categories expressing health change since the previous interview improving, same, worsening. The authors conclude that health at one ture and its change over time are strongly related to education and marital status, even when controlling for family income, use of medical resources, and previous nealth $(p$. 140$)$. However, not all of these results can easlly be verifled. The article does not report the size of the sample that was analyzed. It must certainly have been smaller than 11,000 since apparenty only the data on men were used, each survey contains some missing data and panels also suffer from attrition. But even if the sample is close to 10,000 , the cell frequencies soon become very small when few interactions among variables are considered. ${ }^{\circ}$ No likelinood ratio and chi-square tests are reported but it is stated that "nearly all the variables discussed in the text are statistically signiflcant" (Tauman and Rosen. 1982 , p. 121).

\subsubsection{Intervening variables (D)}

Finally, a number of researchers nave looked at the possible intervening variables through which schooling may affect health. Unfortunately $Y_{\|}$most of those studies suffer from the deficiencies of cross-section data. Leigh (1983) explicitly attempts to test for direct and indirect effects of education on health measured on a 7point self-assessed individual health scalel through cholce of occupation and healthy habits. He estimates a recursive model on US cross-section data taken from the University of Michigan's Guality of moloyment surveys for 1973 and 1977 . The indirect effects of schooling through less smoking, more exercising and choosing less hazandous occupations far outweigh any direct effects. However, the results of 
this study have to be interpreted very cautlously, Because no control for initlal health status mase, and because the results differ very moch between the two years, it is dangerous to make causal inferences $11 \mathrm{ke}$ the author does. Moreover, due to a lack of theoretical framework, it is unclear whether the health equation is to be interpreted as a production or dernand function.

Two studies which did make explicit the underlying hypotheses and did attempt to control for initial health are Grossman (1985) and Kerna (1985). Grossman (1975) decomposes the total schooling effect on nealth into a direct (tecmical) and three indirect (allocative) effects which are supposed to represent increased ablitity to select a better health input mix. The three endogenous inputs considered are; wife"s schooling, job satisfaction and the difference between actual and ldeal weight (as a proxy for diet selection). The estimated indirect effects through these three intervening varlables are all strongly significant but represent only about $37 \%$ of the total schooling effect (controlling for initial health).

Kema (1985) examines three possible intervening factors in the schooling-health relationship: hazardous occupation, demand for doctor visits and weight. Doctor visits is deleted from the decomposition analys is because it is found to have a strongly negative impact on nealth according to the author due to unobserved differences in initial health not adequately controlled for by the proxy used (presence of chronic condition). The indirect effects of obesity and job hazards account for only a minor share, respectively 6 and $10 \%$ of the total schooling effect on health.

It is almost impossible to make any generalization from the above studies due to the large differences in samples analyzed, specifications used and results obtained. The main difflculty clearly seems to be the lack of longitudinal data in order to test for causality. A somewhat different research strategy was adopted by Farrell and Fuchs (1982). They examined the smoking behaviour of different cohorts of men and women ( $n=1183$ ) before and after they had completed their formal schooling. Their principal finding is that the negat Ive relation between completed level of schooling and smoking is generally as strong at age 17 as it is at age 24 for all cohorts. They, therefore, reject the hypothes is that schooling differences are causal to smoking differences in favour of a 'third varlable' explanation of the association. However a second important finding is that the relationshrp does appear to be health-motivated because it developed only after the spread of public information about adverse nealth effects of smoking. The authors therefore conclude that clgarette smoking is undoubtedly an important intervening variable in the schooling-health relationship but that the link between education level and smoking is not causal. "They are even able to reject the hypothesis that social class differences could be the 'cmitted third varlable' since father's schooling does not show any statistically 
In sum it appears that cohort analysis is one of the more promising research strategies to be adopted if causal inferences are to be arawn from empirical investigations of the schooling-health relationship.

\section{4. Conc lus lons}

In this chapter we discussed the theoretical and empirical problems associated with the analysis of the schooling-health relationship. It was argued that education effects on the health of the general adult population could better be examined by means of production functions than demand functions. The advantage is that one does not have to deal with a number of specific problems inherent to the demand for health approach. On the other hand, most of the ingredlents of a truly economic approach (e.g. rational behaviour under constraints) are deleted when an essentially technical relationship 1 lke a production function is estimated. For our purposes, and with the available data in mind, it was judged that the advantages of the production function approach outweigh the disadvantages.

on the methodological side, we identifled malnly four issues: (a) cmitted variable blas, (b) measurement error, (c) direct versus indirect effects and (d) non-linearity and interaction. With respect to the problem of omitted variable bias, it was shown that longltudinal data might provide an acceptable solution if the objective is not so much to identify 'omitted third factors' but rather to control for possible spurious correlation. Measurement problems are inherent to any investigation involving the mult dimensional and hardly quantiflable concept of health. None of the studies reviewed attempted to comoine several heaith measures into one index, if more than one indicator of health was avallable at all. All studies used years of schooling as the variable to quantify attained level of education.

Studies wich explored the linkage between schooling and nealth through intervening factors gave some support to the nypothes is that a lot of the effect works indirectly through allocation decis lons. But the problem with these studies is that probably the total effect is substantially overestimated as a consequence of onitted variable bias issue (a)).

Finally, only a few studles (e.g. Tauman and Rosen (1982), Kema (1985)) allowed for the possibl11ty of non-limear and/or non-additive effects of education. In the next two chapters, we w111 present two attempts to estimate education effects in health production. Mo dataset was avallable which allowed us to tackle all of these methodological problems simultaneously. However, each of the two 
datasets had different strengths and weaknesses compared to the other so that none of thern could be discarded for an empirical analys is a priori. We, therefore, analyzed both and placed different emphas is on certain aspects. 
ututes

1. Whe that this problem is very $s$ imilar to the one that ras raced by researchers westigating the ability blas in the income-schooling reliationship (e. aliches and Mason, 1972 ; Chamberlain, 1977 ).

2. E is not necessarily restricted to be one variable (own education) but can, acconding to the household production view, be extended to a vector including allso the lewels of education of other nousenold members (see e.8. Wagstaif, 1986).

3. Grosmar (1972) did not include enviromental $x$ variables in the depreciation rate fumction. Note that if ecucation is also included anong the $X$ varlables to allow ar a depreciation effect its coefficlent in equation $(5.3)$ reduce to $\left(\theta-\theta_{2}\right)$ were is expected to be positive and $\mathrm{g}_{2}$ negative. This approach is therefore unalute to discriminate between the two rival hypotheses.

4. Their interpretation of these (reduced form) equations as eitrer demand or production functions is unclear as it was also in Grossman (1975). Both input factor prices, which belong in a demand function, and quantitative measures of input factors, which belong in a health production function, are absent.

5. For a formal derivation of the magnitude of such an amited warlable bias, see e. Maddala (1979), p. 305.

6. This can be shown as follows: Rewrite equation $(5,4)$ to obtain

$$
H_{f}=\frac{1}{a_{1}} H_{t}-\frac{b_{1}}{a_{1}} x+\frac{c_{1}}{a_{1}}
$$

Then substituting Hf in equation (5.5) gives:

$$
H_{t+1}=\left|\frac{a_{2}}{a_{1}}+c_{2}\right| H_{t}+b_{2}\left|1-\frac{a_{2}}{a_{1}} \frac{b_{1}}{b_{2}}\right| x+\left|c_{2}-\frac{a_{2}}{a_{1}} c_{1}\right|
$$

or $\mathrm{H}_{\mathrm{t}+1}=\mathrm{VH}+\mathrm{t}+\mathrm{X}+\mathrm{e}^{\prime}$

If $a_{2}=o_{n}$ then $y=c_{2},=b_{2}$ and $e^{\prime}=c_{2}$

which gives agian equation $(5.5)$.

7. In 1971 and 1973 there was also a foum category. deceased.

8. For instance, only about $10 \times .04 \times .35=0.14 \%$ of this sample is divorced, has nad 16 or more years of schooling and considered their health status worse than others in 1969. 


\title{
Chapter 6. The marginal health productivity of schooling: A longitudinal latent variable model
}

\begin{abstract}
"1 agree with his (Fuchs") contention that the mechanisms via wich schooling affects health have not been fully identif led. I think that panel datasets, which allow one to control for "unobservables' can be used to shed $11 \mathrm{ght}$ on this and other Issues" (Grossman, 1982, p. Z)
\end{abstract}

\subsection{Introduction}

In this chapter we w11 construct and estimate a 1 ongitudinal model which is similar to the models specified by Shakotko et al. (1981) and Taubman and Rosen (1982). It differs from these previous approaches in at least three respects. First, we will pay special attention to the health measurement problem by combining several indicators to construct one index of general health using the MIMIC-approach. Secondly, by specifying a structural equation model we w11 be able to estimate simultaneously the 'cumulative' and 'dynamic' effects of education on health (cfr. Shakotko et al., 1981) and to decompose the latter effect into direct and indrect effects. And thirdly, we do not restrict the analysis to one particular age category but develop a model which is sultable for the adult (Dutch) population.

\subsection{Data}

The data used in this chapter stem from a two-wave panel survey that was held by the University of Lumburs for the Nederland OKe Foundation in 1981 and 1983. The total sample analyzed here consists of the respondents of two subsamples which completed the questionnaires in both years. A more detalled description of the stratified, multi-stage random sampling design can be found in Adriaanse et al. (1981). In 1981, the first subsample consisted of 1278 respondents draw from the 
general Dutch lactive) population in the age-group 21 to 65 . The second subsample contained 247 respondents dram from the so-called non-active population under 65. The latter consists of the following categories: unemployed for at least six months, disabled, early retired or not working due to illness for at least three months already. In 1963, respectively $77 \%$ in $=884$ ) of the original active population sample and $75 \%(n=153)$ of the non-active population sample completed the questionnaire (Halfens et al., 1984). After deletion of missing observations on some of the relevant varlables for this study. 895 was the combined panel size retained for analysis. No correction was made for attrition or for the oversampling of non-labour force participants which makes this sample somewhat less healthy than the general dutch population under 65 . The intervlews included a large number of questions on health and 11 lness status, opinions, attitudes, beliefs and behaviour and on health care utilization. The variables which were selected and constructed for this study are described in table 6.1.

Table 6.1. Description of variables from the Nederland OKé Survey $(n=895)$

ime an

st. dev.

\section{Health status variables}

SKHB1 = self-rated nealth status in 1981

(5 categories ranging from very good (5)

to very bad (1))

$3.915 \quad .818$

$3.923 \quad .754$

SFHB3 = self-rated health status in 1983

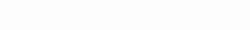
presence of at least one chronic condition or handicap in 1981

.284

.451

.285

.452

OHRON83 = equivalent in 1983

COMPLE1 = a 1 ikert sum score on a $1 \mathrm{ist}$ of 21 complaints (0 to 21) (see also Appendix 6.A)

OAML83 = equivalent in 1983

Background variables 1

FEM $=a(0 / 1)$ dumy varlable for female sex

AGE $=$ age in years

ELC83 = highest educational level attended (1.e. not completed) in 1983 (4 categorles ranging from primary school (1) to university and non-university higher degree (4))

DEDuce = dumy varlable for lower secondary educiation (EJUC83 $=2$ )

DEDucs = dumy varlable for nigher secondary education (EDUCB3 $=3$ )

DEDUC4 = durmy variable for university and nonuniversity higher education (EDCCB3 = 4) 


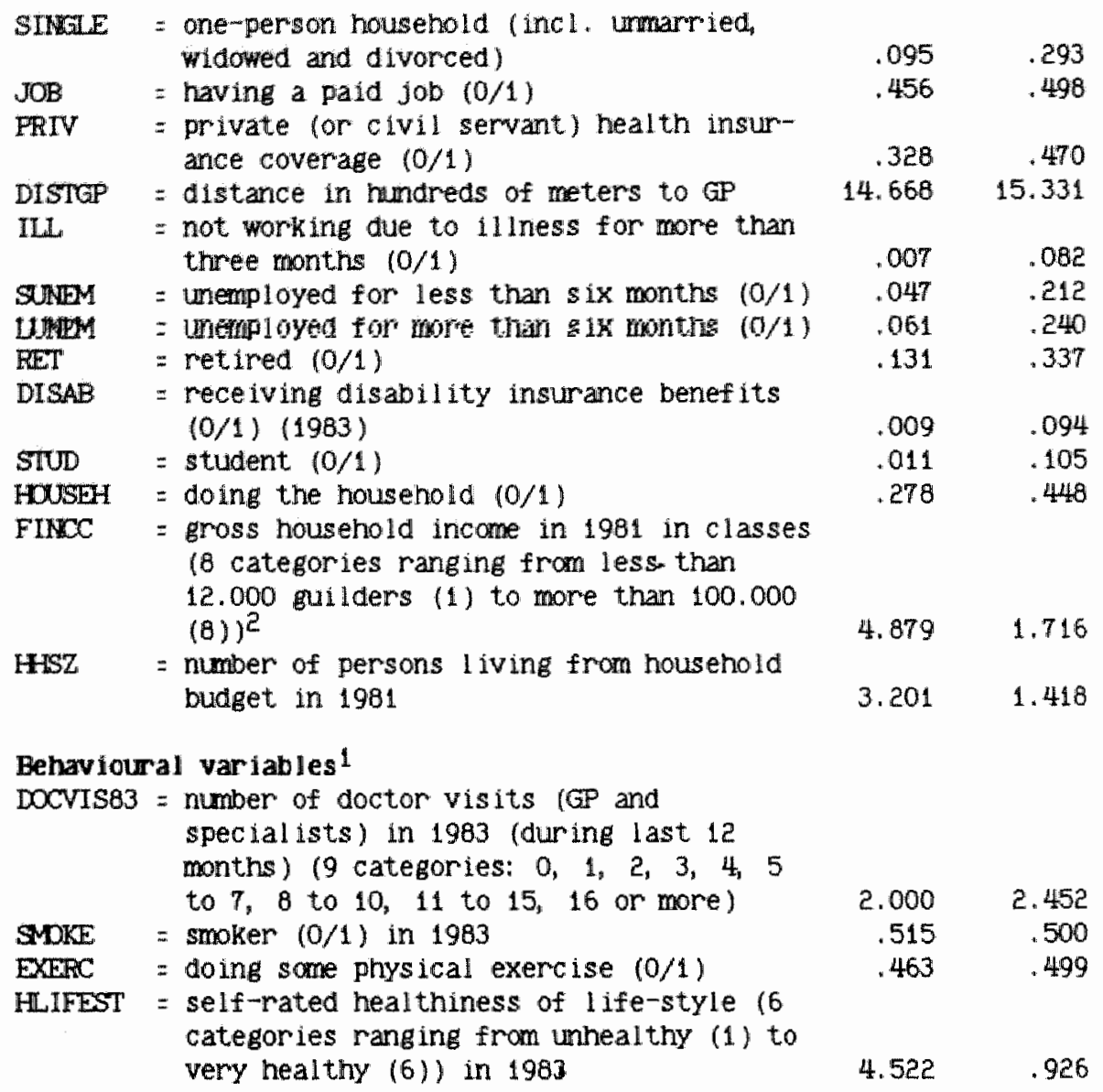

\section{Notes}

1. All variables refer to the 1983 values except when indicated otherwise.

2. If 1981 income was missing, 1983 was used instead if available.

\section{3. Measuring health changes over time}

\subsubsection{Variability of health}

The Nederland Oke Survey contained three indicator variables which can be used to measure the unobserved concept of individual permanent health stock: self-rated general health status (SRH), the presence of at least one chronic condition or handicap (CHRON) and a sum score on a list of 21 psycho-somatic complaints (COMPL). The Questionnaire for Research into Experienced Health status (OREH or WOEG in Dutch) was 
developed to measure stress by Dirken (1967). A transiation of the 21 questions is presented in Appendix 6.A. The list used here is a shortened version of the full questionnaire including 47 items.

Self-rated health status (SRH) is the most cormonly used (subjective) measure of 'permanent' or 'overall' health status of individuals in all previous studies. CHRON is a more objective measure of physical nealth status, and coMrL was designed to measure the psycho-somatic impact of stress. Van VIlet and Van Praag (1987) have recently shown that these three variables are reliable indicators of the individual permanent health status index of a representative sample of the Dutch population aged 18 years and over $(n=2153)$ and strong predictors of health care utilization. However, for our purposes it is important to know whether these indicators are sufficiently sensitive to measure any health changes over a relatively short time period of two years.

Table 6.2. Cross-tabulations of health variable frequencies for 1981 and 1983

a. Self-rated health status

\begin{tabular}{|c|c|c|c|c|c|c|}
\hline \multirow[b]{2}{*}{ SHR81 } & \multirow[b]{2}{*}{ very bad } & \multirow[b]{2}{*}{ bad } & \multicolumn{2}{|l|}{ SRH } & \multirow[b]{2}{*}{ very good } & \multirow[b]{2}{*}{ TOTAL } \\
\hline & & & fair & good & & \\
\hline very bad & 1 & 1 & 1 & - & 2 & 5 \\
\hline bad & 2 & 10 & 30 & 8 & 1 & 51 \\
\hline fair & 2 & 8 & 119 & 66 & 9 & 204 \\
\hline good & - & 5 & 57 & 378 & 98 & 538 \\
\hline very good & - & 2 & 13 & 110 & 111 & 236 \\
\hline TOTAL & 5 & 26 & 220 & 562 & 221 & 1034 \\
\hline
\end{tabular}

b. Psychosomatic complaints

COMPL83

\begin{tabular}{crrrrrr} 
COMPLB1 & 0 & $1-5$ & $6-10$ & $11-15$ & $16-21$ & TOTAL \\
\cline { 1 - 5 } & 96 & 67 & 12 & 2 & 1 & 178 \\
$1-5$ & 106 & 320 & 64 & 9 & - & 499 \\
$6-10$ & 12 & 99 & 101 & 24 & 3 & 239 \\
$11-15$ & 1 & 17 & 38 & 30 & 8 & 94 \\
$16-21$ & 1 & 2 & 2 & 9 & 11 & 25 \\
TOTAL & 216 & 505 & 217 & 74 & 23 & 1035
\end{tabular}

c. Chronic condition or handicap

CHRONBI

\begin{tabular}{lrrr} 
GHRONB1 & yes & no & TOTAL \\
\hline yes & 216 & 71 & 287 \\
no & 72 & 674 & 746 \\
TOTAL & 288 & 745 & 1033
\end{tabular}


In table 6.2 we have presented the cross-tabulations of these variables for 1981 and 1983. From these tables, transition probability matrices could be estimated if all cells had sufficient observations. However, it can be seen that the large majority of respondents is located on the diagonal, which means that their health status did not change, according to our measures, in the two-year perlod. For chrow the diagonal contains $86.1 \%$ of the sample, for sFH this percentage is 60.5, and for COMPL only $54 \%$ even if within-class off-diagonal elements are not subtracted. Clearly, compL offers most of the dymamic varlability but is also has got some disadvantages: the complaint 1terns, of course, do not cover all possible health complaints but only a selection of rather vage a-specific physical complaints. Moreover, within these 21 items, some 'health problems areas' have disproportionately large representation because the questionnaire was originally designed to measure stress: no less than 5 items refer to digestive complaints, 4 items refer to respiratory problens, 6 items refer to general fatigue or mental depression, and 2 tems only refer to pain (back and headache) complaints. Van der Zee (1982) identified these four factors in a varimax rotated solution of a factor analysis performed on the respondents of the 1977 Dutch Life situation survey (n $=4147$ ). On the other hand, some health problems are hardly or not represented: an example is restriction of moblilty, the first principal component identified by Wagstaff (1986) in the analysis of a similar list of health questions with Danish data. As a consequence, our COMPL sum score is particularly sensitive to some health problems (e.g. stomach complaints) and very insensitive to others. Nevertheless, we abstained from extracting principal components or factors because our explicit intention is to measure general health and not spec if ic health dimensions. By combining the OOMPL variable with SKH and CHRON, we hope to correct for measurement errors created by the arbitrary sumation procedure.

Finally, it is worth looking at the means of the health indicators in both years presented in table 6.1. For an ageing panel, one would expect the deterioration of health to dominate the recovery, but the reverse seems to be true: the means of SRH and GHRON are virtually unchanged and the mean COMPL score in 1983 is even slightly lower than In 1981: The latter result may be a consequence of the fact that in 1983 the 11 ist of complaints had been extended to cover all 47 original 1 tems which might have made the respondents a little more reluctant to give the yes answer too often (see e.g. Halfens et al., 1984). How ever, not too much attention should be glven to the comparison of means because this does not incorporate varlations in the distributIons around these means. More appropriate methods are considered in the next section.

6.3.2. Stability of latent health status

In Chapter 4 we have described how the LISREI model can be used to 
characterize latent, unobsemable variables by observable indicators. In this chapter, we will a similar measurement strategy but in addition exploit the possibility to examine the intertemporal covarlance of measurement errors when using longltudinal data.

A two-wave three-indicator health measurement model can be represented converiently by the following path-diagram.

Figure 6.1. Path diagram of a two-wave three-indicator model of health in 1981 and 1983

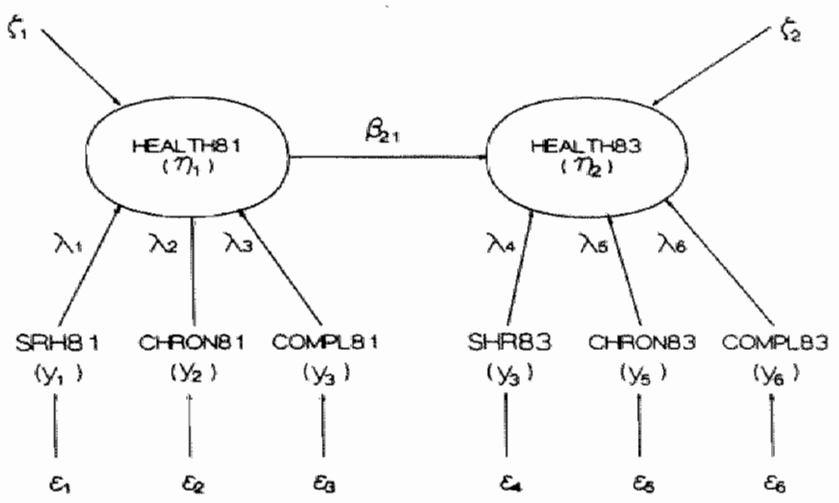

The LISREL notation (see e.g. Jöreskog and Sörbom 1977) is used to characterize variables, coefficients and disturbances. By fixing $\lambda_{1}$ and $\lambda_{4}$ equal to one, the latent variables get the same unit of measurement as the self-rated health (SRH) variables. An alternative identiflcation procedure is to $f \mathrm{x}$ the varlance of the unobservable varlables to one:

$$
\Psi_{11}=E\left(\zeta_{1} \zeta_{1}\right)=\Psi_{22}=E\left(\zeta_{2} \zeta_{2}\right)=1
$$

An advantage of the latter procedure is that it directly gives the standardized solution of the model which facllitates the testing of the psychometric properties of the measurement instruments isee Chapter 4, section 4.2). A disadvantage is that one cannot give a scale and direction to the latent variables in this way. We will report both parameterization results where appropriate.

We have first estimated two measurement models (I and II) separately for each year. Because the covarlance matrix of the observed varlables was used as the input matrix, the reported parameter estimates $(\lambda$ ' $s$, $B$ 's and $X^{\prime}(s)$ can be interpreted as the usual regression coefficients. The results are given in the first two colums of table 6.3. The 
150 0

$\pm=$

a

ڤำ

영 8

i"

$-m 0$

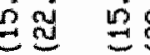

素号多

$0-0$

$\infty \infty$

$=$ 떠

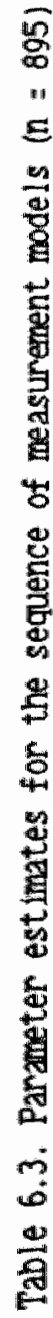

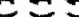

m

$\because 7$ 
estimates of both the magnitude and statisticall significance of the $x^{-}$ coefficients and the variances of the $\epsilon^{\prime} s$ (the $\theta_{\epsilon}$ 's) prove to be very similar in both fits which indicates a high stability of the measurement model over time. The goodness of fit cannot be judged on the basis of a chi-square test because the number of degrees of freedon is zero: the $s i x$ model parameters are exactly identified by the six input covariances between the $y$-variables.

In order to be able to calculate rellabllity coefficients for the nealth indicators, we re-estimated the models with the correlation matrix as input in order to obtain the standardized $\lambda^{*}$-coefficlents. The reliability coefflcients, defined as $\rho=\lambda^{2}$, are presented in table 6.4. SFH has the highest rellability and GRON clearly the lowest. This is as one could expect since CHRON measures the stock of health in a dichotomous manner which clearly creates a lot of measurement error.

In a next step, we have estimated the measurement model III which was presented in Figure 6.1. This is not a pure measurement model because it also contains one structural parameter $\left(\theta_{21}\right)$ to measure the stabllity of health over time. ${ }^{1}$ As can be seen from table 6.3 , the overall health of the sample has remained fairly stable between 1981 and 1983 (according to the value of $\beta_{21}$ in model III). The reliability coefficlents (see table 6.4) of CHRCN and COMPL have increased while the opposite is true for SRH. Although all estimated parameters are highly significant (most $t$-values have increased substantially compared to the separate model $f(t)$ the model is rejected by the chi-square test $\left(x^{2}(8)=430.9\right)$. This could mean that this model is too restrictive Jöreskog and Sorbom (1977) have pointed out that in this type of

Table 6.4. Reliability coefficients $(\rho)$ of the health indicators in the measurement models

\begin{tabular}{lcccc} 
& \multicolumn{4}{c}{ MODE } \\
& I & II & III & V \\
\hline SIRB1 & .713 & & .535 & .684 \\
CHAN81 & .357 & & .404 & .365 \\
COMPL81 & .513 & & .620 & .531 \\
SRHB3 & & & & \\
CHRONB3 & & .569 & .481 & .599 \\
COMPL83 & & .364 & .391 & .356 \\
\hline
\end{tabular}

Note: The $p$-coefficients are defined as the squared standardized $\lambda^{*}$ coefficlents. 
panel models, when the same instmments (test or questionaire) are used to measure the latent variable at both points in time, there may be a tendency for the errors in each variable to correlate over time because of memory or other re-test effects. Relaxing the zero restrictions on the intertemporal covarlances between the $\varepsilon$ 's of the same indicators can in that case contribute to a substantial improvement of the model $i 1 t$.

The highest modification index for model III indeed was found for $\theta_{e 25}$ $=\operatorname{cov}\left(\varepsilon_{2} \epsilon_{5}\right)$. It equals 232 which indlcates that the $x^{2}$-test could be reduced by at least 232 when the error terms of $C H R O N B 1\left(=y_{2}\right)$ and chrowB $3\left(=y_{5}\right)$ are allowed to covary. This model modification does seem to make sense. It is reasonable to assume that the (rather large) measurement error made by asuming health by the dichotomous variable CHRON in 1981* is strongly comelated with the same measurement error In 1983.

The zero restriction on $\theta_{\epsilon 25}$ was relaxed to estimate model IV. The test statistic for this model is 147.1 for 7 degrees of freedom (see colum IV in table 6.4 ). The reduction in the $x^{2}$ statistic associated with the loss of one degree of freedom $\left(x^{2}(8)-x^{2}(7)=430.9-147.1\right.$ $=283.3$ implies a statistically very significant improvement. Also the statistical significance of $\hat{\theta}_{e 25}=.045$ (t-value $1 \mathrm{~s} 13.5$ ) is very high but the model still has to be rejected.

When in a next step, a non-zero covarlance was also allowed for the errors of caMpl in both years, model $\mathrm{V}$ was obtained. This covarlance $\theta_{\epsilon}$ is estimated to be 4.849 and highiy significant (t-value is 10.5). Moreover, the $x^{2}$-test statistic has now dropped to 9.6 which means an acceptable flt with 6 degrees of freedom and at a $10 \%$ confidence level $(P=0.14)$. When also correlated errors of $S F H$ were allowed for in a next model VI, neither the estimated covariance, nor the reduction in $x^{2}$ were significant. Apparent $1 y$ only the measurement errors in GHoN and QREH are correlated over time.

We therefore choose model $V$ as the measurement model that best describes the evolution of the individual general health status over time. The estimated $\lambda^{\prime} s$ and $\theta_{\epsilon}$ 's are remarkably close to the or inal (separate) estimates in madel I and II. The same is true for the reliabli1ty coefficlents given in table 6.4. Note, however, that there has been a significant reduction in the magnitude of the stabllity coefficient $B_{21}$ from model II to $V$. This implies that a substantial part of the stabllity measured in model III was due to the correlated errors of two of the indicators over time. The standardized $B$ (not reported in table 6.4 ), which can be interpreted as the (corrected) correlation between the true health status of the sample individuals in 1981 and 1983, has similarly decreased from 1.00 in model III to .879 in model $V$. This is st111, however, much higher than the intertemporal correlations between the same indicator variables which are .556, "679 and.713 for respectively SRH CHRCXI and OCMLL. We can 
conclude that the correlation between the unobserved health status of individuals over time is higher than the same correlation between its indicators. Also this result seems to make sense and gives some confidence in the asurement procedure. In section 6.4 we will examine what happens to the stability parameter and the standardized correlation between the $\eta$ 's when the latter are assumed to be determined by a number of background varlables.

\subsection{A structural equation model of health production}

Rather than specify, estimate and test health production functions directly, we will proceed stepwise in this section. In the first step, we will explore whether the strength of the uncontrolled schoolinghealth association is as strong in our dataset as it has been found by others. Secondly, the dynamic and partial relationship is investigated by controlling for previous health and other determinants. In the third section, some health inputs into the production function are endogenized in order to test for direct and indirect effects through intervening variables. This stepwise procedure provides more insight into the various relationships considered and the separate contributions of explanatory variables.

\subsubsection{The schooling-health correlation}

The schooling level was measured in this survey by the highest of four possible levels of schooling that was followed (not necessarily completed) by the sample respondents in 1983 (EluC83). Only about $1 \%$ of the sample was still recelving formal education at the time of the interview (see table 6.1). Because the lower age 1 imit was 21, presumably most of these were receiving nigher (undversity or nonuniversity) education. table 6.5 presents the 1983 health indicator means by education level. No clear schooling gradient emerges from this table. All levels above primary school do show signiflcantly higher levels of good health but between these three higher levels the differences are not always so clear and the patterns deviate depending on the indicator used. A peculiar finding $1 \mathrm{~s}$ that the higher educated, though showing better health on falrly objective measures (CHRON and CaMPL) are more critical of the ir own health status: the subjective rating (SRH) is not higher than that of the two previous levels of education. On the whole, the (uncontrolled) association seems weaker than what is usually found in American studies of this kind. The relation does not seem to be linear and the largest discrepancy is between those who did and those who did not recelve more than primary education. Therefore, we will use three dumy variables (DEDUC2, DEDUC3 and DEDUC4) in what follows to measure level of schooling on an ordinal or ranking scale. The regression coefficlents can then be interpreted as the nealth gain due to schooling above the primary 
level.

Table 6.5. Health status by llevel of education $(n=1033)$

\begin{tabular}{|c|c|c|c|c|}
\hline $\begin{array}{l}\text { Highest level of } \\
\text { education attended }\end{array}$ & $\begin{array}{l}\text { SRHB3 } \\
\text { (mean) }\end{array}$ & $\begin{array}{r}\text { MRCAB } \\
\text { (mean) }\end{array}$ & $\begin{array}{l}\text { COMPL83 } \\
(\% \leq 6)\end{array}$ & Total $n$ \\
\hline \multicolumn{5}{|l|}{ Primary education and } \\
\hline Vocational training & 3.79 & .325 & $69 \cdot 3$ & 512 \\
\hline Lower secondary education & 4.07 & .244 & 80.8 & 238 \\
\hline Higher secondary education & 4.10 & .255 & 79.1 & 110 \\
\hline Higher education & 4.09 & .199 & 83.1 & 171 \\
\hline
\end{tabular}

\subsubsection{Cumulative and dymamic effects}

In this section we gradually expand the bivariate relationship between schooling level and latent health as it was constructed in section 6.3.2. We explained in section 5.2 that ideally one would like to estimate an explicit, linearized functional form of the production function for health like, for example, equation (5.3), which is basically Grossman's specification. In implicit form this equation could be written as follows:

$$
H_{t}=f\left(E, \quad t, \quad X_{4} \quad I_{t^{\prime}} \delta_{0}\right)
$$

where $H_{t}=$ health status at the end of period $t$

$\mathrm{E}=$ education level

$\mathrm{t}=$ time (age in cross-section studies)

$x=a$ vector of enviromental variables affecting the depreciation rate $\delta$

$I_{t}=$ a vector of health investment inputs used in period $t$

$\delta_{0}=$ the initial health depreciation rate

In order to 11lustrate the effects of not control1ing for $\delta_{0}$ we w11l estimate the following two-equation system simultaneous $1 y$ :

$$
\begin{aligned}
& H_{t}=\beta_{1} E+\beta_{2} t+\beta_{3} X \\
& H_{t+1}=\beta_{1}^{\prime} E+\theta_{2}^{\prime} t+B_{3}^{\prime} X+B_{4}^{\prime} I_{t+1}+\beta_{5}^{\prime} H_{t}
\end{aligned}
$$

Here, for simplicity $H_{t}$ and $H_{t+1}$ refer to 1981 and 1983. Due to the lack of good measures of the health inputs $I_{t}$ cown time and market goods), we did not attempt to estimate more sophisticated functional forms than a linear one. Restrictions or tests on the estimated coefficients (e. returns to scale tests) seem premature civen the arbitrary scaling of the input proxies we used and the present state of knowledge regarding health production functions. 


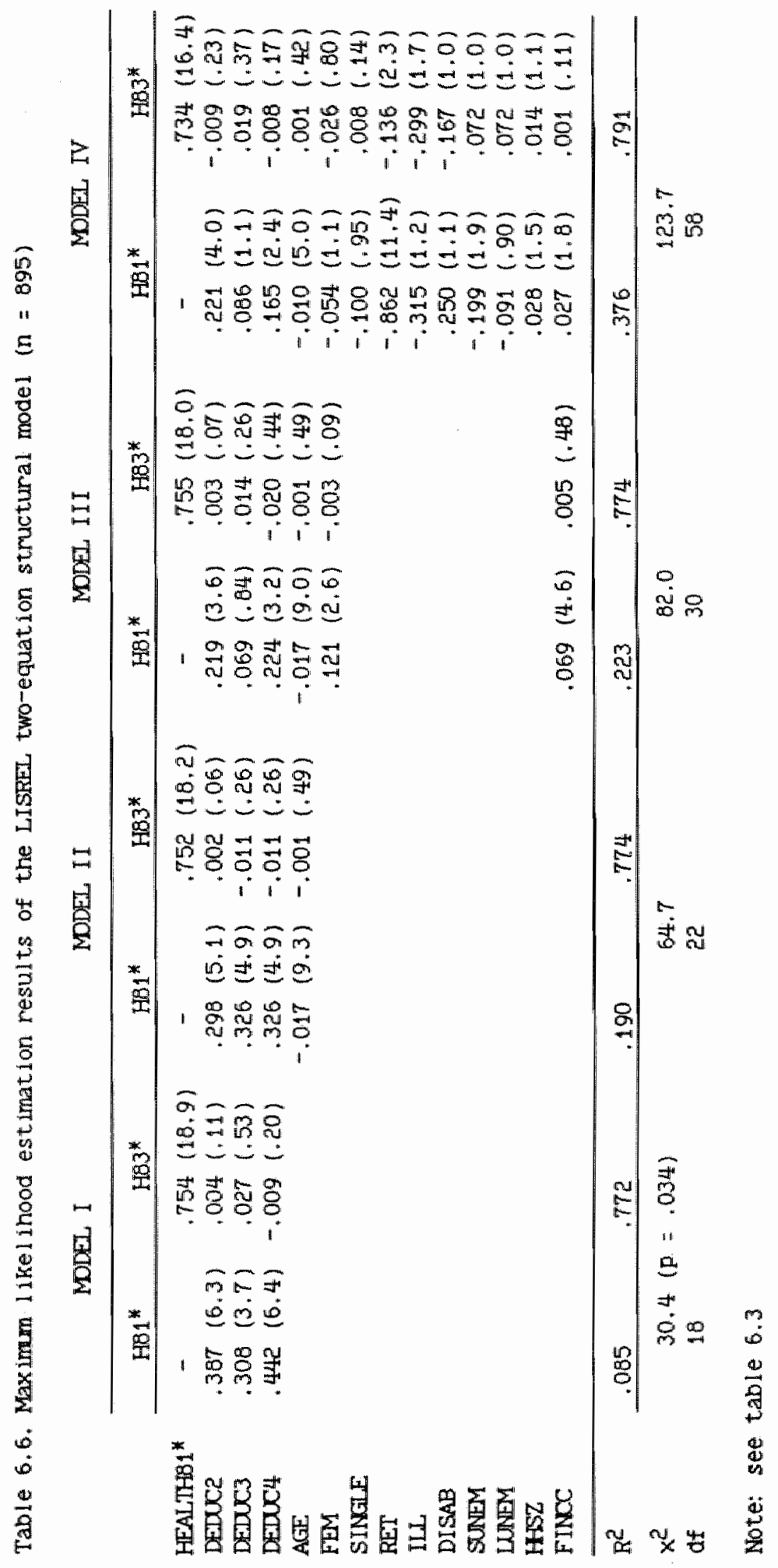


Starting from the wost simple model. with only $E$ and $H_{t}$ as explanatory varlables, we then added the other arguments of (6.3) in a stepwise manner. The results are show in table 6.6 . The measurement equations are not reported here because they differ only marginally from those

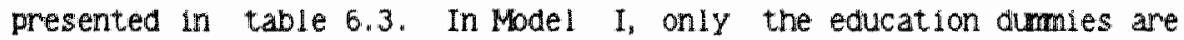
used. In the equation for HEALTHB1*, all education levels show a significantly better health status than the lowest level, but the coefficlents do not increase monotonically with higher levels. The ranking order is simllar to the one we saw in table 6.5 for two of the indicators (CHRON and COMPL) separately. The largest differences (and the only significant ones) occur between the lowest and the three nighest levels. However, all of these differences vanish when in the equation for HEALIHB3* previous health status two years earlier is controlled for! This imples that, although the total (cumlative) effect of educiation on health status level is substantial, its effect on health changes over a two year period is negligible, even when no other influences are taken into accoumt. In terms of the IIfecycles plctures we drew in the previous chapter, this finding means that the time paths of health status have different intercepts but identical slopes, 1.e. they are paralle1. Eut before we make a digression on the interpretation of this result, we wlll first describe what happens when other health determinants are held constant.

In Model II, we have added AGE which is an important correlate of education in cross-sections of individuals. It can be seen that indeed controlling for age (linearly) reduces the schooling coefficlents and shows a strong negative impact on health in 1983. However, Ilke education, it does not affect the rate of deterioration significantly in the second equation. Similar results are obtained in Model III, when also household income and female sex are controlled for. Both variables have a significant contribution to the explanation of HEALTHB $1^{*}$, but none at all to the explanation of HEALTHB $3^{*}$ when HEALIHB1* is held constant. The inclusion of FINCC in the nealth equations needs some Justification, Normally, price and income variables are" not amongst the arguments of production functions. However, one can interpret the household income in this equation as a proxy for unobserved health input (see Grosman, 1975, p. 175) or as a proxy for living conditions (e.g. housing, nutrition, life style) which is one of the environmental varlables affecting the depreciation rate.

The positive effect of FEM on health contrasts with the findings of a negative impact in most other studies of adult samples (see e. 8 . Chapters 4 and 7 of this book, or Van VIlet and Van Praag, 1987). However, it is most 1 kKely that this is a result of the oversampling of, mainly male, non-labour force participants for health or other reasons. In Model IV, we will also attempt to control for this peculiarity of the dataset. But first, we investigate whether the insensitivity of the latent health index to other variables besides lagged health is mainly a result of combining the information contain- 
ed in each indicator. Table 6.7 gives the results of three separate regressions for each health indicator on its 1981 values and the set of explanatory variables contained in Model III.

Table 6.7. Maximm likel inood regression results of model III for the three separate health indicators $(n=895)$

\begin{tabular}{|c|c|c|c|}
\hline & SRHB 3 & OHANB3 & COMPLB3 \\
\hline SFIIB 1 & $.468(17.1)$ & - & - \\
\hline OHANB 1 & - & $.645(24.7)$ & - \\
\hline OAMPLB1 & - & - & $.656(28.3)$ \\
\hline DEIUCE & $.003(.05)$ & $-.009(.30)$ & $-.372(1.4)$ \\
\hline DEDTC3 & $.053(.71)$ & $.060(1.5)$ & $-.454(1.3)$ \\
\hline DEnC4 & $-.022 \quad(.34)$ & $-.023(.68)$ & $-.243 \quad(.79)$ \\
\hline$A C E$ & $-.005(3.2)$ & $.004(3.9)$ & $.004(.48)$ \\
\hline FEM & $.053(1.3)$ & $.011(.50)$ & $-.073(.36)$ \\
\hline FINCC & $.039(2.9)$ & $-.003(.42)$ & $-.047(.71)$ \\
\hline & 31 & .473 & .512 \\
\hline
\end{tabular}

Note: see table 6.3

Remember that SRH is an indicator of 'good health' whereas GHoN and COMPL are "bad health" indicators. It appears that also these separate indicators remain fairly unaffected by the other independent variables as soon as the two-year lagged variable is included. Only age st11l has a significant influence on SRHB3 and CHRONB3, and FINCC on SFH 183 at the $5 \%$ level of signiflcance. The proportions of explained varlance of these observed scores are lower than the R-squared for HEALTHB3* (the 'time' score $\eta_{2}$ ) in table 6.6. Model III. This is mainly a consequence of the fact that correcting for measurement errors also reduces the variability to be explained. We can conclude that except for AGE the indicators are simliarly independent of the background variables as the health index when past health is controlled for.

Finally the $X$ vector was extended with a number of variables which indicate the household or employment status of the individuals in onder to obtain Model IV. Although we treated these characteristics as exogenous, causality cannot be inferred from these results because people may be in one of the considered categories (e.g. unemployed) for health reasons. 2 we do not find significant health differences between single-person and other households. Some of the non-active categories do show substantially inferior health status than the omitted category, which includes students and those working in a paid job or at home. But the effects are only statistically significant for the category of retired people in the sample (about 13\%, see table 
6.1). These are (mainly male) individuals who retired before the pensioner's age of 65 or who retired since 198\%. Not only is their health status much lower than average in 1981 but it has also deteriorated faster than average between 1981 and 1983 . As can be seen from the reduction in the coefficient of ACEE RET mainly captures the effect of accelerating health depreciation with ageing. Not surprisingly, also the respondents who are 111 for more than three months already report a considerably nigher health deterioration. The non-\$igniflcance of these effects may be due to the 1 imited number of people in this category (only $0.7 \%$ of the sample). The same applies to the DISAB category of people receiving a disabillty insurance allowance ( $B$ respondents). Also the effects of being unemployed for less (SUNEM) or more than 6 months (LUNEM) are not significant at the $5 \%$ level of significance. As expected, FEM does now have a negative coefficlent but is not sigmificantly different from zero.

Although the results of Model IV show that it is not so that our health construct is unable to detect any differences when past health is controlled for, on the whole, the background varlables considered here do not contribute much to the explanation of the (1imited) variation in latent health status changes during the two year period. Like Shakotko et al. (1981), we can conclude that the dymamic effects of background effects are much smaller than the cumllative impact, if existing at all. Schooling does not have a significant marginal effect on changes in health and its effect on levels of health does not show a clear increasing gradient with levels of education. In the next section, we abandon the rather 'passive' view of health production adopted in this section to explore the health impact of behavioural cholces.

\subsubsection{Direct and indrect effects}

In order to complete the health production function (6.3) that was specified in the previous section, the health inputs chosen by the individuals have to be added to the equation for HEALTHB $3^{*}$. In the orlginal Grossman (1972) model " the two input factors in household health production were market goods and own time spent investing in health. Medical care use or expenditures were mostly used in previous studies to measure health investment outlays. No attempt has been made to use a proxy for the time input, but other health inputs used in empirical studies include choice variables such as job hazards, job satisfaction, wives' schooling and the difference between actual and ideal weight, given height (see Grossman, 1975; or Kema, 1985 for examples). Lelgh (1983) also considered smoking and exercising behavlour. Except for Kema's (1986) cholce of a hazardous occupation function, none of these "other input" demand functions were derived from fully specifled theoretical models. In most cases, this would require an extension of the basic Grosman model to allow for joint production effects because clearly smoking cigarettes and physical 
exercise not only affect health but also produce other desired characteristics such as smoking pleasure or recreation (see e.g.

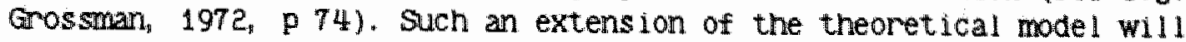
not be pursued here. our only aim is to decompose the total (dynamic) effect of schooling into direct and indirect effects. However, we saw in the previous section that this total effect was very small and nonsignificant. This implles that either also the direct and indirect effects are very unimportant or they cancel out in the aggregate.

To examine these effects through intervening variables, we have replaced the income varlable FINCC by two endogenous health inputs. The number of doctor visits reported by the respondent in the last 12 months before the second interview (DOCVIS83) is used to measure the medical care input. The respondent's judgement regarding the healthiness of his/her life-style (ranging from $1=$ umealthy to $6=$ very healtiny) wil be employed as a proxy for the time input (HIIFEST). The latter choice rests on two assumptions. First, that people reporting to have a relatively healthy life-style do on average have healthier hablts than those who do not. And secondly, that a healthier lifestyle also implies that more time is spent on health preserving or health restoring activities. 3 The demand functions for these two inputs comprise a similar set of predetermined variables as the health production function plus the income variable and, in the case of DOCVIS, a dummy for privately insured (FRIV). In contrast to those covered under the public sick fund scheme in the Netherlands, the privately insured of ten choose not to insure for GP services or take high deductibles (see e.g. Van de Ven and Van Praag, 1983). Consequently, the money price of a doctor visit is very often not zero for this category. The distance from the repondent"s house to his GP (DISTGP) was added as a proxy for the (travel) time price of a GP visit.

The estimation results for the structural model with endogenous health inputs are presented in table 6.8. The two household characteristics (SIKCIE and HHSZ) and the two unemployment Varlables (SUNEM and LUNEM), which did not show significant effects in Model IV have been deleted from the $X$ vector to restrict the total nuber of explanatory variables.

First of all, it can be seen that, as expected, HLIFEST and DOCVIS are strongly assoclated with initial health (HB1*): the better the 1981 health status, the better the life-style and the fewer doctor visits in 1983. More surprising are the effects of education: negative on Ife-style and positive on doctor visits but with only one dumy significant in each equation. Again, it is not impossible that the better educated are more critical in their judgement of their lifestyle. Women and older persons report nealthler 11 fe-styles, which in this context could be interpreted as a result of lower average time prices, ceteris paribus. A similar interpretation holds for the negative effect of FINCC if this acts also as a proxy for the wage 
Table 6.8. The structural equation model with endogenous health inputs:

\begin{tabular}{|c|c|c|c|c|c|c|c|c|}
\hline & 48 & $1^{*}$ & & $93^{*}$ & HLI & IFEST & \multicolumn{2}{|c|}{ DoCVISB 3} \\
\hline$H B 1^{*}$ & - & & .543 & $(13.6)$ & 411 & $(6.2)$ & -1.998 & $(11.8)$ \\
\hline $\mathrm{HB}^{*}{ }^{*}$ & - & & & & 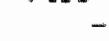 & - & - & \\
\hline HLIFEST & - & & .054 & $(3,6)$ & - & - & - & \\
\hline DOCVIS & - & & -.057 & $(8.0)$ & - & - & - & \\
\hline DEIUC? & . 257 & $(4,8)$ & .035 & $(1.0)$ & -.066 & $(.83)$ & .494 & $(2.6)$ \\
\hline DEIUC3 & .128 & $(1.8)$ & .029 & $(.65)$ & -.105 & $(.97)$ & .267 & $(1.0)$ \\
\hline DEDUC4 & .215 & $(3.5)$ & -.003 & $(.08)$ & -.210 & $(2.2)$ & .185 & $(.76)$ \\
\hline AGE & -.011 & $(6.5)$ & -.001 & (1.1) & .014 & $(5.3)$ & -.003 & $(.47)$ \\
\hline FEM & -.042 & $(.95)$ & -.008 & $(.30)$ & .190 & $(3.0)$ & .578 & $(3.8)$ \\
\hline RET & -.856 & $(12.1)$ & -.107 & $(2.2)$ & .000 & $(.001)$ & .398 & $(1.5)$ \\
\hline ILL & -.320 & $(1.2)$ & -.228 & $(1.4)$ & .306 & $(.84)$ & 1.389 & $(1.6)$ \\
\hline DISAB & .103 & $(.45)$ & -.162 & $(1.2)$ & -.011 & $(.03)$ & .316 & $(.40)$ \\
\hline FINCC & - & & - & - & -.031 & $(1.6)$ & .015 & $(.29)$ \\
\hline DFRIV & - & & - & - & & - & -.429 & $(2.4)$ \\
\hline DISTGP & - & & - & - & & - & -.001 & $(.12)$ \\
\hline$\overline{R^{2}}$ & .358 & & .841 & & & 101 & .319 & \\
\hline
\end{tabular}

Note: see table 6.3

rate and thereby for the opportunity cost of time. With respect to the dernand for physician visits, females, retired and 111 persons have higher and privately insured lower demands. Physician proximity (DISTGP) does not have an influence on visit frequency.

In the HEALTHB3* equation both input factors show a significant influence on health status, even when initial health is controlled for. However, the effects have opposite signs. Like previous investigators (e.g. Grossman, 1972a; Kerma, 1985), we find a very significant but negative impact of medical care use on health status. Clearly, this does not mean that health care has a large detrimental effect on health but rather that the visit frequency is an indicator of nealth deterioration. This finding casts serlous doubt on the tenability of the derived demand hypothesis for the bulk of medical care use. Since our estimate cannot be a consequence of a negative blas due to the omission of inital nealth it implles, again, a rejection of the basic Grossman model hypothes is that medical care use can be viewed as investment in good health.

Of course, the effects may look very different if very specific health measures and medical care interventions were considered but we are mainly interested in a fairly general, aggregate level model. We are not interested in testing whether indeed a course of penicillin has relleved the symptoms of a bacterial infection, but whether, on the 
whole, people who do go to see a doctor more often are ceteris parlbus, better off after two years time. Perhaps the view of health care as investment is more appropriate for preventive rather than for curative services but we were unable to test this hypothes $1 \mathrm{~s}^{4}$ due to lack of data on the reasons for physicians encounters.

since a life-style judged to be healthy does seem to improve health status (or rather decrease deterioration), we now reach the remarkable conclusion that education has two negative indirect (allocative) effects on health status in 1983. Adnittedly, these effects are very small and mostly not significant but they are in contradiction to what one would expect a priori.

Because the adequacy of our operationalizations of health input. factors may be questioned, these findings are to be considered as tentative and requiring re-testing with better measures of the health investment inputs.

\subsection{Conc Ius ions}

The general conclusion which emerges fron the empirical analysis presented in this chapter" is that schooling appears to have no marginal impact on health changes, i.e. on current health status when the nealth status of two years earlier is controlled for. The problem is that most of the other health determinants which show a clear 'cumulative' effect on health also have insignificant 'dynamic" effects. Notable exceptions are the influence of a healthy ife-style and medical care utilization but these channel negative indirect effects of education on health. However, the decomposition analys is of education direct and indirect effects is hampered by the absence of any signiflcant total (dynamic) effects.

When a statistical test does not indicate a difference, the conclusion is that either there is indeed no difference, or in other wonds, health proflles are parallel across levels of education; or the test has insufficient power to detect the differences. The latter interpretation is a real possibility here given the limitations of the dataset we analyzed. A sample size of 900 indiwiduals between 21 and 65 years old is not large if changes in permanent health stock over a period of two years are the subject of analysis. The problem of 1 imited dynamic variability is compounded by the latent variable approach: after correction for measurement error the correlation between the "true health scores' in 1981 and 1983 is extremely high. As a consequence, the proportion of explained variance in 1983 latent health status is extremely high $(84.1 \%$ in table 6.8$)$ despite the fact that only a few varlables have a statistically signiflcant influence.

Fortunately, we have the opportunity to test the hypothesis that the 
absence of a marginal health productivity effect of schooling may be due to a lack of discriminating power of the test that is being performed. This will be done in the next chapter. 


\section{1hothes}

1. Demonstration of the coveryidentifleation of this and subsequent models is analogous to. the procedure described in Appendix 40 . For a general exposition on the identiflcation of LISRE models for the aralys is of longitudinal datz see Horeskog and sombon (1979), Chapter. 5 .

2. Because we were minly interested in the equation explaining health in 1903 , we used the 1903 values for the employment status varlables. This may nave caused (anall) errors of class if ication of mespondents for the 1981 equation. For example it is possible that a small number of respondents were not yet retired, unemployed or disabled in 1991 .

3. Some conflidence in this subjective measure is obtained from the fact that the responses on HLIEEST correlate positively with physlcal exercising benavioun and negatively whin semoking behaviour.

4. Ectwands and Grossman (1983) found large slgnificant impacts of a preventive dental visit on the oral health (periadontal index and the decay lndex) of 412.1 adolescents but no effects at all of a physician checkup on measures of paysical health. 


\title{
Chapter 7. Use-related health depreciation and educa- tion: a fixed-effects model
}

\begin{abstract}
"Even physicians and epidemiologists have a hard time specifying the production function for health. The commodity is produced probabilistically substantially through the lifestyle choices of individuals." (Fuchs and Zeckhauser, 1987, p. 265)
\end{abstract}

\subsection{Data}

In this chapter, we analyse a different Dutch dataset which offers some advantages and some disadvantages compared to the one that was used in the previous chapter. These different characteristics both enable and require the use of a different method of analysis.

Since 1981, the Netherlands Central Bureau of Statistics (CBS) has been conducting a continuous Health Interview Survey. Each year a random sample of households is drawn from the general population excluding institutionalized persons. In principle, all residents at the selected addresses are interviewed, but since 1983 the maximum number of persons per household is four. The size of the response group amounts to about 10.000 persons a year. In addition to the continuous questionnaire administered each year, which includes

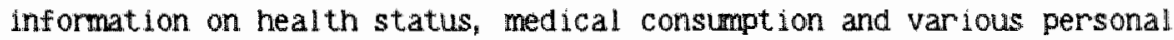
background characteristics, the 1984 version contained some extra, (self-administered) retrospective questions about health and insurance status five years earlier. This feature made this essentially crosssectional dataset also useful for a (1 imited) longltudinal analys is of individual health. The retrospective questions were only asked to the household members aged 16 years and over. This reduced the totai size of the sample to about 7500 respondents.

The level of education was measured by two variables: highest level attended (EDC1) and highest level obtained (EDUC2). In table 7. 1 the 
sample distributions for these two education variables are presented for comparison. It can be seen that a substantial part of the sample has followed a higher level of education than the one they also completed. This is only partly due to the fact that about $8 \%$ of the sample was still receiving education at the time of the interview.

Table 7.1. Sample frequency distribution according to three definitions of education level

Highest level Highest level
code completed

Primary

$\begin{array}{lcrrr}\begin{array}{l}\text { education } \\ \text { Vocational }\end{array} & 2 & 1854(25,9) & 911(12.7) \\ \begin{array}{l}\text { training } \\ \text { Secondary } \\ \text { education }\end{array} & 3 & 2327(32.5) & 2706(37.8) \\ \begin{array}{l}\text { Vocational } \\ \text { College }\end{array} & 5 & 2142(29.9) & 2402(33.5) \\ \text { University } & 6 & 206(2.9) & 234(3.3) \\ \text { TorAL } & & 7161(100) & 7161(100)\end{array}$

The percentage distribution of sample respondents according to the level of education completed corresponds very well with the same distribution obtained by Van Ginneken and Appelboom (1986) for the combined CRS Health Interview Surveys of 1981 to $1984(\mathrm{n}=30351)$. The sample can be said to be fairly representative for the educational distribution of the Dutch population aged 16 years and over. Before we explore the relationship between educational attaiment and health in section 7.3 , we w11 first discuss the way in which health (changes) wore measured in this survey.

\subsection{Measurement of health}

The CBS Health Interview Survey contains similar questions on health as the ones that were used in the Nederland Oke Survey. However, for the retrospective health question a somewhat different type of scaling was used. Respondents were asked to rate their general health status as follows:

(a) Can you give an appreciation mark for your state of health now adays? (please circle a number)

very bad

$\begin{array}{llllllllll}1 & 2 & 3 & 4 & 5 & 6 & 7 & 8 & 9 & 10\end{array}$


(b) And how was your state of health about 5 years ago? (please circle a number) very bad

$\begin{array}{llllllllll}1 & 2 & 3 & 4 & 5 & 6 & 7 & 8 & 9 & 10\end{array}$

By asking these questions subsequently, people were not only invited to "mark" the level but also the change in their health status during the last 5 years. The mean response was 7.87 for the health mark in 1984 (HMARK84) and 8.02 in 1979 (HMARK79), Which means that on average the nealth of this sample has deteriorated by 0.15 points on this (subjective) ten-point scale. The skewed distribution of responses around those means has slightly shlfted to the left from 1979 to 1984. This can be seen from the row and colum totals of the crosstabulation presented in table 7.2. Although again the majority of the sample (65\%) is located on the diagonal and therefore reports nealth to be stationary, some respondents also report important changes ranging from -9 to +9 . It seems worthwle to investigate whether this dynamic variability has some systematic component.

In Van den Berg and Van Doorslaer (1987) scome simple reliablity tests of the health appreciation marks were performed. It was shown that the average score for current health status (HMARKB4) of flve-year age groups did not signiflcantly differ from the score for health status five years ago (HMARK79) of the flve years older group. Therefore, there seemed to be no systematic blas due to "recall effects". It was also investigated whether respondents in the same category of selfrated health (SRH) gave different appreciation marks according to level of education. Also this nypothesis could be rejected: nigher and lower education groups gave similar average appreciation figures for health within each SRH category.

Another important issue is the reliability and validity of this appreciation mark "compared to other measures of good health. It resembles the self-rated health question (SRH), but it has more categories and has the additional connotation of a school mark in the Netherlands where 6 means 'suff 1clent' and 5 'insufficlent'. In order to facllitate comparison with the latent health construct that was used in Chapter 6, we re-estimated a LISREI measurement model with HMARK84 as an additional fourth indicator, besides self-rated health on a 5-point scale (SKH), a dumy for the presence of at least one chronic condition or handicap (DOHRON) and the score on the 21-1tem complaints 1ist (OCMPL21). The estimation results are presented in table 7.3. Model I is the four-indicator analog of the measurement model used in chapter 6.

It can be seen that the appreciation mark (HMARK84) performs very well: it has the nighest rellability coefflcient of all indicators. This is probably due to the fact that it shows somewhat more varlab11 ity than the second best ind Icator, SRHB4. For example, whereas $79 \%$ of the respondents report the ir health status to be good or very good (codes 1 and 2 for SRHB4), about the same percentage of respondents is 


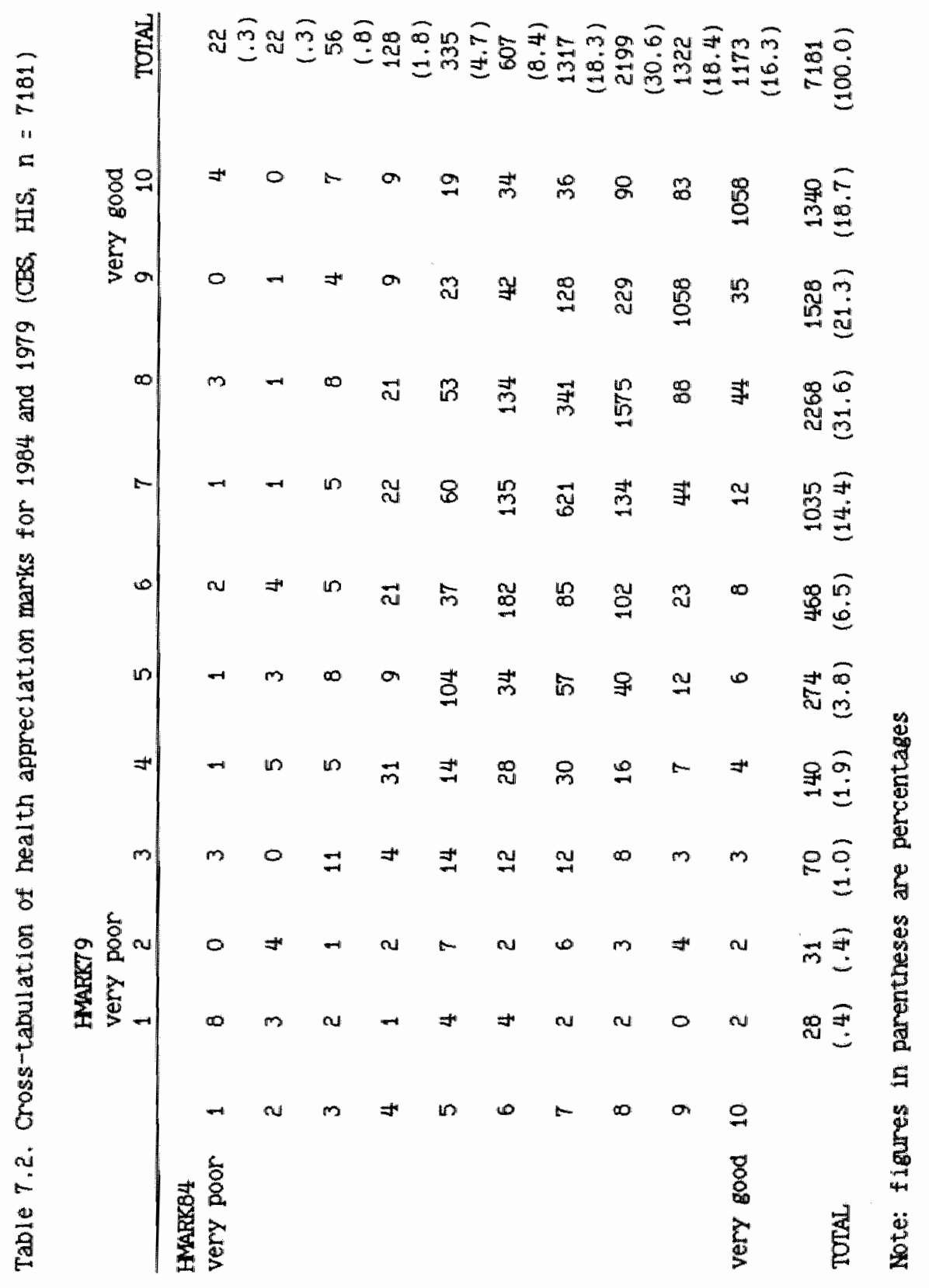


Table 7.3. Maximu likelinood estimation results of LISRE health measurement model with four indicators $(n=7150)$

\begin{tabular}{|c|c|c|c|c|c|c|}
\hline & \multicolumn{2}{|c|}{ I } & \multicolumn{2}{|c|}{ II } & \multicolumn{2}{|c|}{ III } \\
\hline & $\hat{\lambda}$ & $\hat{\rho}$ & $\hat{k}$ & $\hat{\rho}$ & $\pi$ & $\widehat{\rho}$ \\
\hline$Y_{1}=$ HARKS4 & $\begin{array}{l}1.00 \\
(-)\end{array}$ & .715 & $\begin{array}{l}1.00 \\
1-)\end{array}$ & .728 & $\begin{array}{l}1.00 \\
(-)\end{array}$ & .842 \\
\hline$y_{2}=\operatorname{SHHB} 4$ & $\begin{array}{r}-.569 \\
(62.0)\end{array}$ & .648 & $-(559.7)$ & .634 & $\begin{array}{r}-486 \\
(68.9)\end{array}$ & .555 \\
\hline$y_{3}=\operatorname{CMML21}$ & $\begin{array}{r}-1.904 \\
(55.9)\end{array}$ & .467 & $\begin{array}{r}-1.889 \\
(55.2)\end{array}$ & .468 & $\begin{array}{r}-1.666 \\
(58.3)\end{array}$ & .421 \\
\hline$y_{4}=$ DOMRON & $\begin{array}{r}-.193 \\
(28.3)\end{array}$ & .129 & $\begin{array}{r}-.182 \\
(25.5)\end{array}$ & .166 & $\begin{array}{r}-.168 \\
(27.9)\end{array}$ & .115 \\
\hline $\mathrm{x}_{1}=$ HARKT9 $\left(\hat{\mathrm{Y}}_{11}\right)$ & - & & - & & $\begin{array}{c}.606 \\
(67.2)\end{array}$ & \\
\hline$\Psi_{11}$ & $\begin{array}{r}1.788 \\
(39.0)\end{array}$ & & $\begin{array}{l}1.820 \\
(38.8)\end{array}$ & & $\begin{array}{l}1.148 \\
(39.9)\end{array}$ & \\
\hline$\theta_{\in \mathbb{1}}$ & $\begin{array}{r}.712 \\
(28.1)\end{array}$ & & $\begin{array}{c}.680 \\
(25.5)\end{array}$ & & $\begin{array}{c}.396 \\
(19.4)\end{array}$ & \\
\hline$\theta_{\in 2}$ & $\begin{array}{r}.316 \\
(35.0)\end{array}$ & & $\begin{array}{c}.327 \\
(34.9)\end{array}$ & & $\begin{array}{c}.398 \\
(48.0)\end{array}$ & \\
\hline$\theta_{e 3}$ & $\begin{array}{r}7.385 \\
(49.3)\end{array}$ & & $\begin{array}{l}7.374 \\
(49.0)\end{array}$ & & $\begin{array}{l}0.026 \\
(53.6)\end{array}$ & \\
\hline$\theta_{64}$ & $\begin{array}{r}.449 \\
(58.1)\end{array}$ & & $\begin{array}{c}.456 \\
(57.5)\end{array}$ & & $\begin{array}{c}.457 \\
(58.8)\end{array}$ & \\
\hline$\theta \in 42$ & & & $\begin{array}{l}.027 \\
(4.5) \\
\end{array}$ & & & \\
\hline $\begin{array}{l}x^{2} \\
d f \\
\text { ACFI }\end{array}$ & .0 & & & $\begin{array}{l}.04 \\
1 \\
00\end{array}$ & & $\begin{array}{l}340 \\
5 \\
96\end{array}$ \\
\hline
\end{tabular}

distributed across the four highest categories of HMARKB4 (7 to 10). It can be said to be more sensitive to small variations in health states.

Despite the extremely high t-values for all indicators, model I is rejected by the $x^{2}$-test with two degrees of freedom. DOHRON has the lowest reliability. 1 The highest modification index in model I was found for $\theta_{\in 42}$, the error covariance of the indicators SRHB4 and DCHRON, A very good fit $\left(x^{2}(1)=.04\right)$ was obtained when this parameter was not constrained to be zero in mode $\downarrow$ version II. One possible reason for the statistical significance (in madel II) of $\theta_{\epsilon 42}=$

$=\operatorname{cov}\left(\epsilon_{4} \epsilon_{2}\right)$ is that these two indicators show much less variation than the two others. Because they are measured on the two most 1 imited category scales (a two and a five-point scale), larger measurement errors are made by categorizing individuals according to their health.

Finally, we have related the latent, four-indicator, health index to 
the value for the appreciation mam for health in 1979 (HMARKT9) in order to obtain an estimate of the stability coefficient of nealth $\left(\gamma_{11}\right)$ (see e.g. Wheaton, e.a., 1977). The estimated stability $\left(\gamma_{11}=\right.$ $=.606$ ) is much lower than in the amalysis of the previous chapter.

We have tested whether this finding could be due to the fact that HMARK84 is corrected for measurement error wh1le HMARKT 9 is not. As a consequence, the randon fluctuations in HARKT9 could be larger than those in latent health $\eta$ which more or less equals HMARK84 corrected for measurement error. However, when the observed HMARR84 variable was regressed on HARKT 9 we obtained $\widehat{\gamma}_{11}=.627$ (t-value $\left.=70.6\right)$ which is only slightly larger than $\gamma_{11}$ in table 7.3 . Therefore, we have to conclude that health status, as measured by HMARK at two points in time with five years in between $1 s$ not as stable as the latent health status variable that was used in chapter 6 . In the next section we attempt to explain some of this variation.

\subsection{Analys is of covariance}

\subsubsection{Dymamic effects}

In Chapter 5 we have already indicated that the avallability of longitudinal data allows for a more drect test of education effects on health than the estimation of demand for health functions. This direct approach essentially amounts to using the basic health change ldentity of the Grossman model for estimation. Recall that this identity can be written as:

$$
H_{t}=H_{t}{ }^{-H-1}=I(t)-\delta(t, x) \cdot H_{t-1}
$$

Education can either directly influence health investment $I(t)$ (Grossman"s hypothesis) or have an influence through the depreciation rate o Murmen's hypothesis). Theoretically, there is the distinction between a technical production and an allocative userelated effect but empirically it becomes a matter of distinguishing between first and second order effects in an equation 1 ike (T:1).

In our case, and if we take one perlod to be 5 years, $H_{t}$ and $H_{t-1}$ are drectly observable but $I_{t}$ is not. The CBS-HIS 1984 does not contain good measures of health investment which cover the same five year period. No information on healthy or unhealthy habits is collected and the (detailed) medical consumption during the last two nonths before the interview canmot reasonably be assumed to be a good proxy of medical care use over the entire flve year perlod. Moreover, one would run into the same difflculties as in the previous chapter if one is unable to distinguish clearly between curative and preventive medical expenditure.

Therefore, we assumed health investment to be a direct function of a 
number of personal background characteristics (income, education, age and sex), the practlce adopted in those studies of health production functions where incone is used as a proxy for health inputs (see Chapter 5 and 6). Of course, this simplification serious $1 y$ weakens the test of the marginal productivity effect of education on health investment because it is now measured as the (reduced form) effect on $H_{t}$ and not as the (structural, but unobservable) effect on $I_{t}$. on the other hand, however, this approach has the advantage of enabling a direct estimation of $\delta$ and an exploration of its interaction with background characteristics. Comparison of the additive (or main) effects of these background variables with the interactive for secondorder) effects with initial health will provide more insight into the relative empirical importance of these two competing hypotheses.

We will approach the problem again in a stepwise manner by focusing first on the identification of main effects before introducing interaction. The size of the sample also permits testing for non1 inearity of the background effects on health change. We, therefore, started off with an analysis of variance. Essentially, it does not make any difference whether $\mathrm{H}_{\mathrm{t}}$ or $\mathrm{H}_{\mathrm{t}}$ is used as the dependent varlable when $\mathrm{H}_{t-1}$ is among the explanatory variables.

Estimating

$$
\mathrm{H}_{\mathrm{t}}=\mathrm{H}_{\mathrm{t}}^{-\mathrm{H}_{\mathrm{t}-1}}=\alpha+\beta \mathrm{H}_{\mathrm{t}-1}+\mathrm{x} \mathrm{x}+\epsilon_{\mathrm{t}}
$$

is virtually equivalent to estimating

$$
\mathrm{H}_{\mathrm{t}}=\alpha+\left(\beta^{\prime}\right) \mathrm{H}_{\mathrm{t}-1}+\mathrm{yX}+\epsilon_{\mathrm{t}}
$$

where $\beta^{\prime}=\beta+1$

and $X=a$ vector of (time-invariant) exogenous variables $\epsilon_{t}=\mathrm{a}$ disturbance term

Of course, taking the first difference of the appreciation marks ( $\mathrm{H}=$ HDIFF = HMARK84 - HMARK79) implicitly assumes that these are measured on an interval scale, i.e. the scale of measurement is unique up to a linear transformation (see e.g. Van de Ven and Hooljmans, 1982). One could argue that an appreciation mark only has an ordinal or ranking scale, i.e. that the scale of measurement is only unique up to a monotonic transformation. This would mean that the difference between, say $_{\text {a }} 3$ and a 4 is not necessarily equal to the difference between a 9 and $a$ 10. For the present analysis, we have made the simplifying assumption that health marks do represent a (categorical) interval scale. Future work should provide more insight into the scalability properties of health measures, perhaps also by experimenting with magnitude scaling techniques (see e.g. Lodge, 1981, Torrance, 1986).

Because we are mainly interested in finding out how much of the variance in HDIFF is attributable to education after the effects of other vamiables have been held constant, analysis of variance and analysis of covariance were considered to be appropriate techniques at the first stage. The questions we seek to answer are: 
1. Which education variable is the most appropriate for our purposes?

2. Does education contribute to an explanation of the variance in HDIFF, and if $s o$, what is the pattern of the effect?

3. How does the effect of education vary when other factors (= nonmetric variables in SPSS terminology) or covariates (= metric variables in SPSS terminology) are controlled for?

4. Is there any interaction between the effect of education and other control variables, or between the control variables mutually?

In order to be able to answer these questions, a stepwise analysis of (co)variance was performed. Tables $T .4 \mathrm{~A}$ to $\mathrm{C}$ sumarize the results regarding the effects for each of the three education variables. Table $7.4 \mathrm{~A}$ represents the effect of EDCl as the deviations from the overall sample mean for HDIFF $(=-15)$ for each of the five levels of education completed. The first row in each table contains the uncontrolled deviations from the mean. A remarkable finding is that we do not see a monotonically increasing schooling gradient but a curvi1 irear association: only the lowest and the highest education level show a health deterioration above the average. Especially the result obtained for the 206 academics ( $3 \%$ of the sample) is very unexpected. The pattern became much more pronounced when HMARKT 9 was controlled for in the next step: as a result, the gap between those with and without more than primary education widened, but the academics were still far below the level to be expected on the basis of the upward trend in all other levels of education. Nevertheless the standardized beta indicates a fairly strong positive effect of education. The $F-$ test statistics indicate that not only the main (first-order) effect of education but also its interaction with HMARKT9 is statistically significant $(p<.001)$. This result already stands in sharp contrast to the previous chapter where no dymamic effect whatsoever was found for education when initial health was controlled for.

Because the individual's age is probably the most important "confounder' in this relationship, it was introduced separately in the next step to obtain model A3. Indeed it was found that a large part of the effect of 'only primary education' could be attributed to age differences. Controlling for age did reduce but did not wipe out the significant effect of education on HDIFF. Because the effect of age as a categorical variable divided into 8 classes was found to be monotonically decreasing, the age variable was introduced as a (continuous) covariate in the next model in order to 1 imit the number of different cells. Consequently, models A4 and B4 do not contain twoway interactions with age. Adding also sex and incone (model A4) only slightly reduces the magnitude and significance of the education effect further. The increase in the significance of the interaction effect ( $F_{(33)}$ is now 2.6$)$ may be due to the deletion of the interaction effects with age. We can conclude that EDTC1 has a significant but non-linear partial effect on HDIFF.

The results for the highest level of education attended (EDUC2) are 


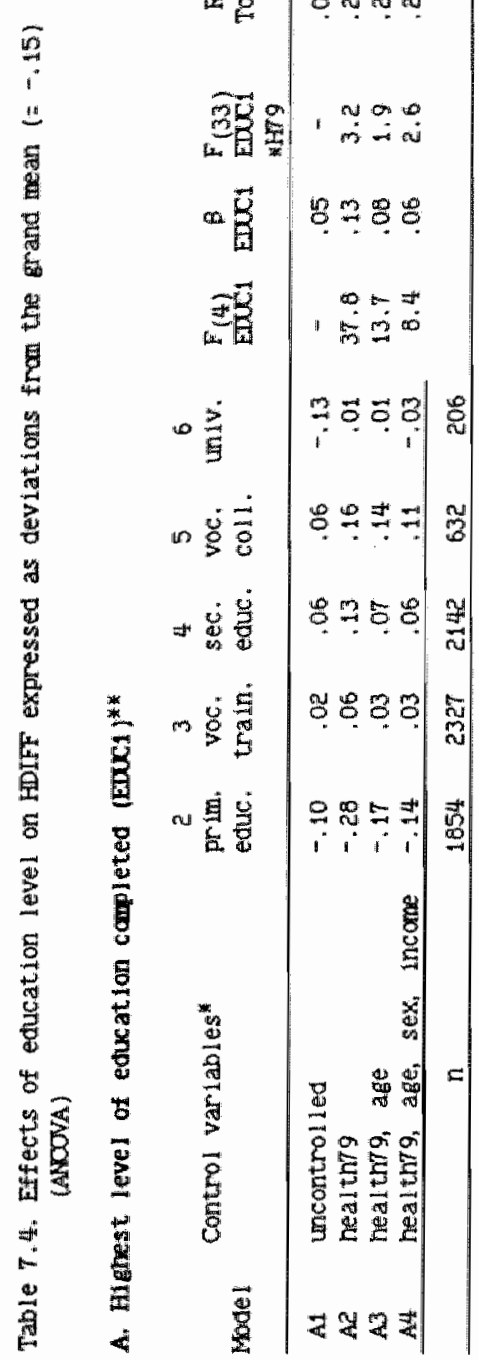

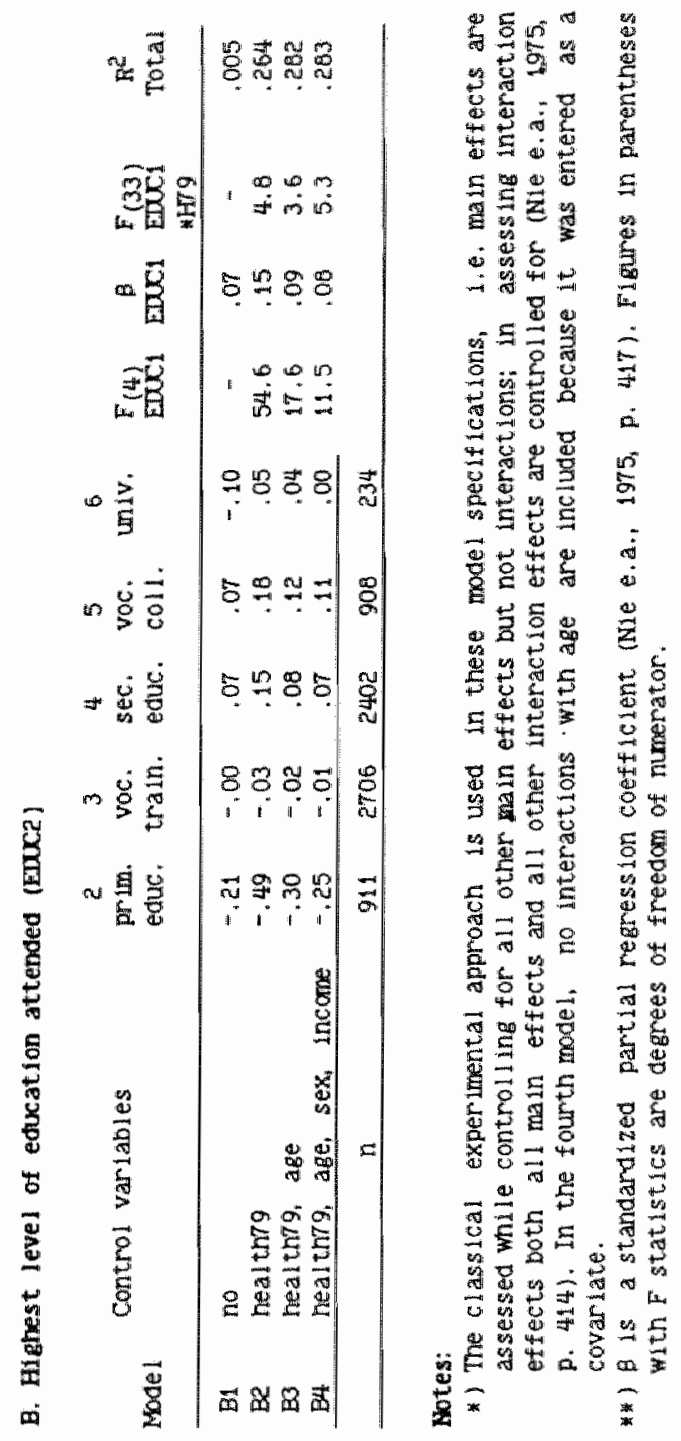


rather similar but with one important exception: by separating out those individuals who did not receive any more formal education beyond primary school, the differences at the lower end of the educational ladder become larger (see table $7,4 B$ ). This is the main reason for the higher statistical significance of the education effect. The position of the highest level of schooling (university) has slightly improved but is still substantially worse than that of levels 4 and 5 . Figure 7.1 illustrates the differences between the partial effects of EDCI and EDUC2 graphically with two histograms. It is clear that by "upgrading' those who did attend but not complete a higher level of schooling the lower education categorles show a somewhat worse health status evolution.

Figure 7.1. Partial effect of EDC1 (in model A4) and EDUC2 (in made $1 \mathrm{~B} 4$ ) on HDIFF

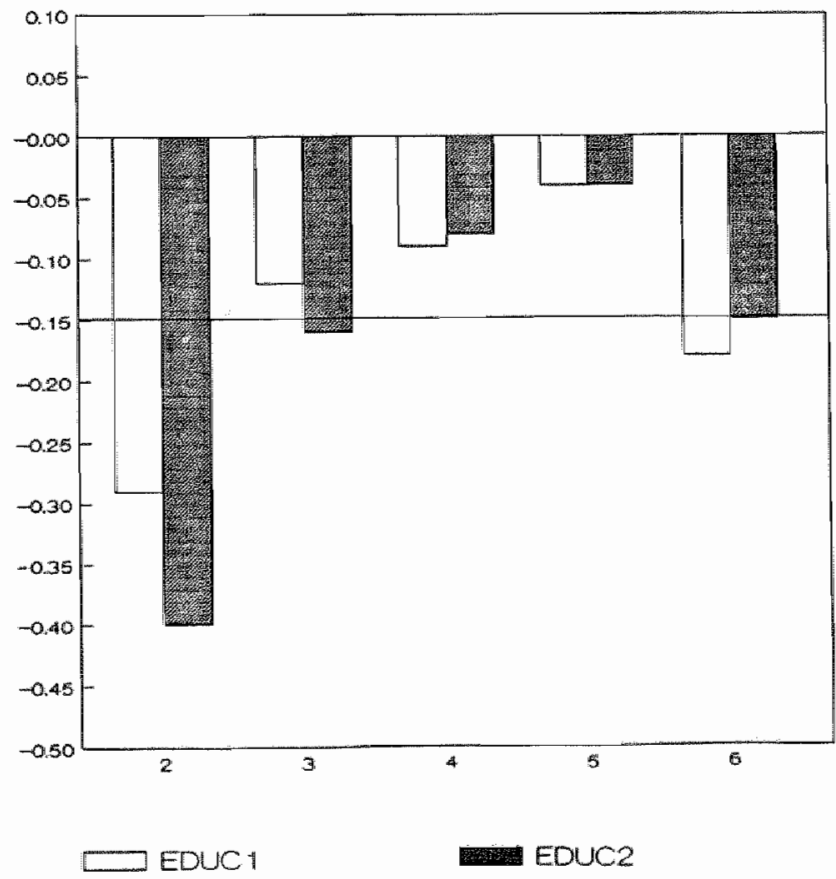

Statistical significance of differences between separate levels of education is not tested by the analys is of (co)varlance. This will be examined in the next section by means of a least-squares dumy variable approach to the fixed-effects model. However, the F-tests of the covariance analyses do bring out a clear statistical effect of all education variables and their interaction with initial health.

To illustrate the pattern and signiflcance of the effects of the control variables, we have presented the full analysis of covariance 
and multiple classiflcation results of model B4 in table 7.5 . Fron the decomposition of the total variation (= sum of squared (SS) deviations fron the mean) in HDIFF into SS due to covariate, main and interaction effects, it can be seen that by far the largest amount of variation is explained by inttial health (HMARK79). 2 There appears to be no difference in health change between males and females when other effects are controlled for. At the 0.05 level of statistical significance only the interactions between HMAKT 9 and EDUC2, and between HARKT 9 and HHNC are significant.

Table 7.5A does not reveal the patterns of these effects on HDIFF. The latter are visualized in the multiple classification analys is presented in table 7.5B. It clearly lllustrates how the small effect of SEX (female health depreciates .08 points more than male health) disappears after adjustment while most of the other main effects on the contrary becone more pronounced after adjustment. HNARKT 9 has, of course, a strong negative impact on HDIFF and HHINC shows a small but consistent positive effect. Again, especially the lowest income

Table 7.5. Analy's is of covariance and multiple classification results of model B4 $(n=7161)$

\section{A. ANALYSIS OF COVAFIANCE}

\begin{tabular}{|c|c|c|c|c|c|c|}
\hline Source of variation & SS & DF & $\mathrm{MS}$ & $\mathrm{F}$ & & $\mathrm{P}$ \\
\hline AGE & 56.84 & 1 & 56.84 & 44.5 & $<$ & .001 \\
\hline Main effects & 3676.75 & 20 & 183.84 & 144.0 & $<$ & .001 \\
\hline HMARKT 9 & 3625.54 & 9 & 402.84 & 315.6 & $<$ & .001 \\
\hline SEX & .21 & 1 & .21 & .2 & & .688 \\
\hline EDUC2 & 58.81 & 4 & 14.70 & 11.5 & $<$ & .001 \\
\hline HIINC & 38.24 & 6 & 6.37 & 5.0 & $<$ & .001 \\
\hline Two-way interactions & 413.19 & 131 & 3.29 & 2.6 & $<$ & .001 \\
\hline HMARKT 9 X SEX & 17.71 & 9 & 1.97 & 1.5 & & .129 \\
\hline HMARKT $9 \times$ EDUC2 & 144.37 & 34 & 4.25 & 3.3 & $<$ & .001 \\
\hline HMARKT $9 \times$ HHINC & 130.10 & 54 & 2.41 & 1.9 & $<$ & .001 \\
\hline$\times$ EDTCL & 10.08 & 4 & 2.52 & 2.0 & & .096 \\
\hline$x H I N C$ & .47 & 6 & .08 & .1 & & .999 \\
\hline EDUC2 $\times$ HHIN & 27.77 & 24 & 1. 16 & .9 & & .594 \\
\hline Explained & 4164.79 & 152 & 27.40 & 21.47 & $<$ & .001 \\
\hline Res idual & 8944.32 & 7008 & 1.27 & & & \\
\hline Total & 13109.11 & 7160 & 1.83 & & & \\
\hline
\end{tabular}

Note: SS = sum of squared deviations from the mean

$\mathrm{DF}=$ degrees of freedom

MS = SS dvided by DF (mean squared)

$F=$ MS divided by $M$ residual $(=1.27)$

$P=$ P-value associated with $F$ statistic 
B. MULTIPLE CLASSIFICATION ANLISIS

(as deviations from sample mean HDIFF $=-.15$ )

\begin{tabular}{|c|c|c|c|c|c|}
\hline & $n$ & unadjusted & eta & adjusted & beta \\
\hline \multicolumn{3}{|l|}{ FMARET9 } & .49 & & .54 \\
\hline 1 very poor & 28 & 3.36 & & 3.61 & \\
\hline 2 & 31 & 4.21 & & 4.42 & \\
\hline 3 & 70 & 2.85 & & 3.04 & \\
\hline 4 & 173 & 2.07 & & 2.25 & \\
\hline 5 & 237 & 1.28 & & 1.45 & \\
\hline 6 & 465 & .73 & & .87 & \\
\hline 7 & 1034 & .06 & & .12 & \\
\hline 8 & 2263 & -.18 & & -.19 & \\
\hline 9 & 1526 & -.34 & & -.41 & \\
\hline 10 very good & 1336 & -.40 & & -.47 & \\
\hline \multicolumn{3}{|l|}{ SEX } & .03 & & .00 \\
\hline 1 male & 3447 & -.04 & & -.01 & \\
\hline 2 fernale & 3715 & .04 & & .01 & \\
\hline
\end{tabular}

EIUC:2: see Table 7.4B, model B4

HIINC (in guilders per year)

$\begin{array}{llrr}1 & <18,000 & 929 & -.13 \\ 2 & 18-22,000 & 934 & -.03 \\ 3 & 22-28,000 & 1222 & .01 \\ 4 & 28-36,000 & 1096 & .01 \\ 5 & 36-45,000 & 946 & .04 \\ 6 & 245,000 & 824 & .08 \\ 7 & \text { missing } & 1212 & .02\end{array}$

.04

.06

$-.16$

$-.05$

.01

$-.02$

.09

.09

.04

ACE (model BI results)

116 - 24 years 1356

.05

$2 \quad 25-34$

1590

.08

$335=44$

1364

$987-.02$

.09

$4 \quad 45-54$

$864-.02$

$555-64$

$674-.07$

6. $65-74$

$280-.39$

$8 \geq 85$

$47 \quad-.93$

.22

.17

.05

$-.16$

$-.18$

$-.22$

$-.49$

$\mathrm{R}^{2}=.282$

category seems to be substantially worse of $f$, even when age and education are controlled for. If income is seen as a proxy for health investment behaviour, this could be interpreted as a marginally beneficial influence of behaviour. Even if the effect were largely a result of environmental characteristics (housing conditions, recreation facilities, etc.), the significantly positive influence on health change over time is remarkable. However, it is dangerous to interpret the association entirely as an income effect on health 
because household income cannot be assumed to be entirely exogenous.

Although AGE was entered as a covariate in model B4, we have also presented the results for the categorized age variable in model $\mathrm{B}$. Another remarkable $f$ inding is that health change is positive for the 16 to 24 years age category $(-.15+.22=.07)$ and almost constant for the 25 to 34 age category $(-.15+.17=.02)$ before health deterioration starts to increase beyond 35 , reaching a maximum of -.15 $+(-.84)=-.99$ for the over 85 years old. This finding suggests an age profile of health stock which reaches its maximm around thirty years and depreciates at an increasing rate thereafter. It should be mentioned that the rate of health deterioration in the higher age groups is probably substantially underestimated due to sample selection blas (see Van den Berg and Van Doorslaer, 1987). The elderly whose health deteriorated most during 1979 and 1984, i.e. those who were admitted to hospital or even died are not represented in our sample.

Altogether, these five explanatory variables account for about $28 \%$ of the variation in HDIFF, Neither the proportion of total explained variance, nor the patterns of the effects of the individual variables differed much from the full model results for $4 \mathrm{~A}$ (with EDUC1).

We can therefore conclude from this analysis of the dynamic variability of health by means of changes in appreciation marks that the lifecycle profiles of health are not parallel across education, age and income categories: health depreciates faster with rising age and falling education and income levels. Moreover, the effect of $\mathrm{H}_{\mathrm{t}-1}$ (the depreciation rate o) seems to depend on age and education as suggested by the use-related depreciation hypothesis. Before we look into these interaction effects in more detail, we first analyze the cumulative (cross-sectional) effects in order to be able to compare with the results of the previous chapter.

\section{$7,3,2$. Comulative effects}

Although we are not primarily interested in the cross-section results for the obvious reason that their causal interpretation is probllmatical, we do present them here for comparison with the previous chapter and with other explanatory studies of individual health differences. The dependent variable is now the absolute level of health in 1984 as measured by the appreciation mark HMARK84. The set of explanatory variables is the same as before but with $\mathrm{H}_{t-1}$

(= HARK79) deleted from the equation. Table 7.6 presents the multiple classification results with the F-test statistics of the corresponding analysis of variance. The education variable used is the highest level attended (EDUC2) and age is introduced as a non-metric categorized factor. 
Table 7.6. AROVA and multiple classification results with MMRKO4 as the dependent variable $(\mathrm{n}=7165)$

Grand mean $=7,87$

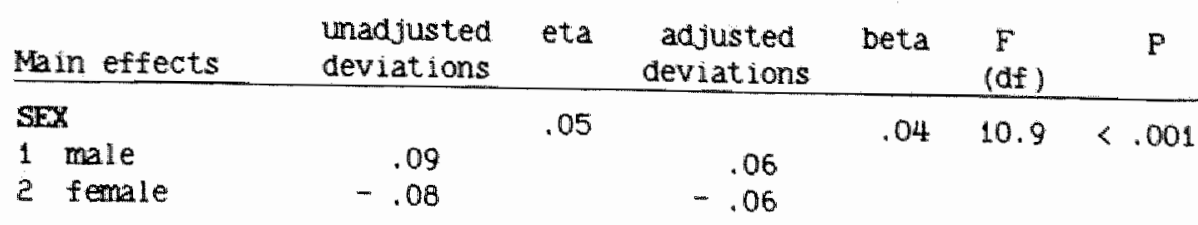

\section{EDTCer}

2 prim. educ.

3 voc. train.

4 sec, educ.

5 voc. coll.

6 univ.

$1<18,000$

$218-22,000$

$322-28,000$

$428-36,000$

$536-45,000$

$6 \geq 45,000$

7 missing

AGE

$116-24$

$225-34$

$335-44$

$445-54$

$555-64$

6. $65-74$

$775-84$

$8 \geq 84$

\section{HHIT}

.22

$$
\begin{array}{r}
-.82 \\
-.05 \\
.26 \\
.26 \\
.23
\end{array}
$$

Two-way interactions

SEX $\times$ EIDUC?

SEX $X$ AGE

EDUC2 $\times$ HHIN

EDUC2 \& AGE

HINC $\times$ AGE

$$
\begin{array}{r}
-.44 \\
-. .24 \\
.03 \\
.05 \\
.26 \\
.22 \\
.09
\end{array}
$$

$$
.62
$$$$
.44
$$$$
.09
$$$$
-.44
$$$$
-.51
$$$$
\text { - .67 }
$$$$
\text { - .98 }
$$$$
-1.23
$$

.08

$9.4<.001$

(4)

$.09 \quad 9.1<.001$

$-.27$

(5)

$.29 \quad 79.5<.001$

(7)

$\mathrm{R}^{2}=.123$

$\begin{array}{rrr}\text { df } & \mathbf{F} & \mathbb{P} \\ 4 & 1.96 & .097 \\ 6 & .15 & .989 \\ 7 & 5.09 & <.001 \\ 24 & .82 & .712 \\ 28 & 1.32 & .122 \\ 42 & 1.61 & .009\end{array}$

The analysis brings out the familiar relationships between health and the various background characteristics with lower health status for women, elderly, low income and lower education persons. In contrast to the dymamic analysis most of the adjusted associations are lower than the uncontrolled ones, which implies that the "risk factors" (e. age, education and income) are not independently distributed. Perhaps 
the most striking finding is that the adjusted deviations for EDCC? are not much higher than in the dynamic analysis of table 7 . 48 except for the highest level. This means that the cumulative impact of education is not ruch higher than the dynamic effect if at all. The deviations are now monotonically increasing with the level of education up until university level but the largest discrepancy remains between primary education and the others. The observed pattern of increasing health status with increasing level of education is consistent with the findings of Van Girmeken and Appelboon (1986) who descrubed differences on other health indicators according to the highest level of schooling completed.

The health difference by SEX now remains significant also after adjustment. The .12 points lower appreciation mark for women is consistent with recently reported results on sex differentials in health and medical consumption based on the combined CBS HIS data of the years 1981 to 1984. Van den Brekel (1987) has shown that despite their higher life expectancy, Dutch women raise more health complaints, suffer more often from some chronic conditions and are more often underweight or obese than men. Only the interaction effects between age and sex and between age and income are significant at the .05 level of the F-test.

The main conclusion from the analyses of (co)variance reported in this section is that not only the level of education (attended) shows a significant dynamic effect on health status but that moreover it is almost as large as the cumulative effect, and it interacts signiflcantly with previous health status. The former finding implies that, controlling for the health status of five years earlier is not as important for the effect of schooling on adult health as might be expected if both health and schooling were largely determined by a cormon cause (see Chapter 5). The largest part of the schooling-health association therefore does not seem to be spurious. The latter finding warrants a more detailed analysis of the pattern of interaction, especially with a view to test the use-related health depreciation hypothesis. This wil» be done in the next section.

\subsection{Interaction effects}

The Amcova results reported in the previous section showed that some two-way interaction effects were statistically significant according to an F-test. This meant that the effects of some variables were different for different groups. It could not be tested which groups exactly differed from which others and by how much. In this section, the objective is to unravel in more detail the interaction between age and education on the one hand and initial health status (five years ago) on the other. The fixed-effects model that will be specified is based on the information obtained from the ANCOVA results and Wil I be 
estimated using the least-squares dumy variable (LSDV) approach (see e.g. Hs lao, 1986). In principle, this approach is more general and it could also have been used in the previous section but it would have required the estimation of huge regression equations incorporating an enormous amount of dumy variables. These can now be simplifled using the ANCONA results. For instance, SEX will be left out of the analys is because of non-significance and AGE and HARKT will be introduced as continuous, metric variables because they both had consistent, negative effects. ${ }^{3}$ The income variable will be reduced to four $0 / 1$ dumry variables.

First, we have re-estimated model $\mathrm{BH}$, without the variable SEX or any interaction terms, by means of ols. The estimation results are presented in the first colum of table 7.7 . The first conclusion to be drawn from these results is that the coefficient of HMARKT $(-.42)$ is very close to $\beta^{*-1}$, where $\beta^{\prime \prime}=.60$ is the estimated stability parameter in model III of table 7.3. Income, age and education show similar effects as in the analys is of covariance and the coefficients of all dumies are significantly different from the reference category.

Table 7.7. OLs estimation results of regression models for HDIFF with and without interaction terms $(n=7158)$

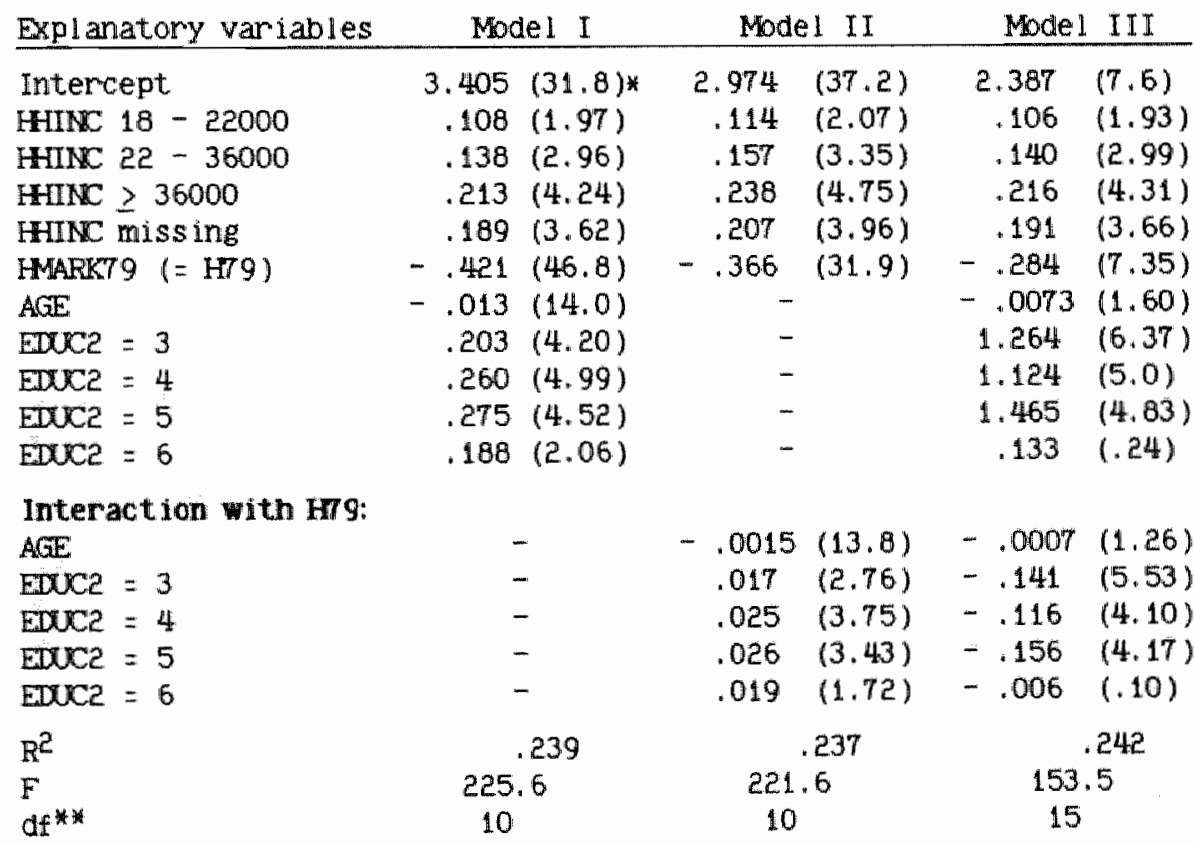

*) Absolute t-values in parentheses

*) df of nimerator, (df of denominator of F-test is always Larger than 7100 
Next we estimated a model II in which age and education are assumed to have only an indirect effect through the coefficient of HARIT (d) on HDIFF. The pattern which emerges is as expected: a negative influence of age and a positive influence of education. Because the effect of Euce again is not strictly increasing with each level but decreases at the university level, we also performed a test for the statistical significance of the differences between subsequent levels. By redefining the dumy variables for education as mirimal levels (greater than or equal) we obtained the results presented in table 7.8 . It can be seen that the largest (and most significant) difference is between the two lowest levels of education 2 and 3 (primary education and vocational training). After that, there is only a small increase from 3 to 4 (secondary level) but the latter does not differ anymore from the higher levels 5 and 6 . The decrease from 5 to 6 is not statistically significant. On the whole, the evidence indicates decreasing health returns to additional education.

Table 7.8 . OLs estimation results for models I and IV with increasing dumy variables for education

MODEL I MODEL II (interaction)

$\begin{array}{lrlrl}\text { EDUC2 } \geq 3 & .203 & (4.20)^{*} & .0172 & (2.76) \\ \text { EDUC2 } \geq 4 & .057 & (1.69) & .0077 & (1.87) \\ \text { EDUC2 } \geq 5 & .015 & (.32) & .0012 & (.22) \\ \text { EDUC2 } \geq 6 & -.088 & (1.01) & -.0072 & (.70)\end{array}$

*) absolute t-values in parentheses

Finally, we considered the possiblilty that there may be both in effects on HDIFF and interaction effects via HMARKT 9 for age and education by estimating model III. This caused some spectacular chariges in the results. Both the main and interaction effects of the AGE and EDUC2 variable have changed quite dramatically. Age no longer has a significant direct nor interaction effect on HDIFF. Because the simple correlation between AGE and AGE * HARIT9 equals "85, collinearity may, to some extent, contribute to an explanation of the large estimated standard errors for the coefficients of these variables. Nevertheless, the total effect of AGE evaluated at the mean of HMARK $(-.0073-.0007 * 7.87=.0128)$, is very close to the effects that were estimated in models $I$ and $\mathbb{I}$.

In contrast to the AGE effect, the total positive effect of the EDUC dumies is now not decomposed into two smaller positive effects, but into a larger positive main effect and a negative interaction effect with initial health (HT9). Probably as a result of muticollinearity (simple correlations between the EDUC2 dummies and the ir interaction 
variable with $\mathrm{HT} 9$ vary between .96 and .98) the ir estimated standard errors have increased. But because this increase is smaller than the increase (in absolute value) of the estimated coefficients, the $t$ values for trree of tre four dumies are higher than in the separate models I and II. The only exceptions are again the dumy" variable for university level (EDUC2 $=6$ ) and its interaction with HT9. Both have now very small coefflcients and very large standard errors.

Furthermore, because models I and II are nested in model III we could test the validity of restricting either the main effects or the interaction effects of $\mathrm{AGE}$ and ElUC2 to be zero by means of an $F$ test for coefficient restrictions. The following $F$ test was used to test the null hypothesis that some of the coefficients in model III are equal to zero, i.e. that either the main or interaction dumies for $A(E)$ and EDuce could be deleted from the equation (Kmenta, 1971, p. 371)

$$
\left|\frac{R_{Q}^{2}-R^{2} K}{1-R^{2} Q}\right|\left|\frac{n-Q}{Q-K}\right| \sim F_{Q}-K, n-Q
$$

where $R^{2} Q$, the coefficient of determination of the full model (with $Q$ variables)

$\mathrm{R}_{\mathrm{K}} \mathrm{K}_{\mathrm{K}}=$ the coefficient of determination of the restricted model (with $\mathrm{K}$ variables)

$n=$ the number of obsemvations

$Q-K=$ the number of restricted coefficients

Since for both the restricted models $Q-K=5$ and $n-Q=7142$, the tabulated critical value of $F_{5, \infty}$ at the $1 \%$ level of significance is 3.02. Both the $F$ statistic for the model I restrictions $(F=7.6)$ and for the model II restrictions $(F=13.2)$ exceed this critical value and therefore these hypotheses can be rejected. Apparently, the overall positive effect of education on HDIFF in models I and II conceal two opposite effects of which the positive dominates the negative one.

In a graphical representation of the (negative) relationship between health change (HDIFF) and initial health (HI9) the three models have very different implications for the regression $L$ ine differences between high and low education groups. These are 11lustrated in Figure 7.2. Subdividing in two levels of education - high (HE) and low (LE)and abstracting from the peculiar results for the highest level of EDuC2, the results can be described in terms of intercept and slope differences, i.e.:

Model I: parallel lines but HE higher intercept

Model II: same intercept but LE steeper slope and Ines diveriging with rising initial health

Model III: HE higher intercept but also steeper slope and regression 1 ines converging with rising initial health.

The graph clearly illustrates the biases introduced by restricting either the intercepts or the slopes of the two educational categories to be equal. on the other hand, it has to be noted that around the 
Figure 7.2 . Sifrilified graphical representation of different schooling effects in model I, II and III of table 7.7

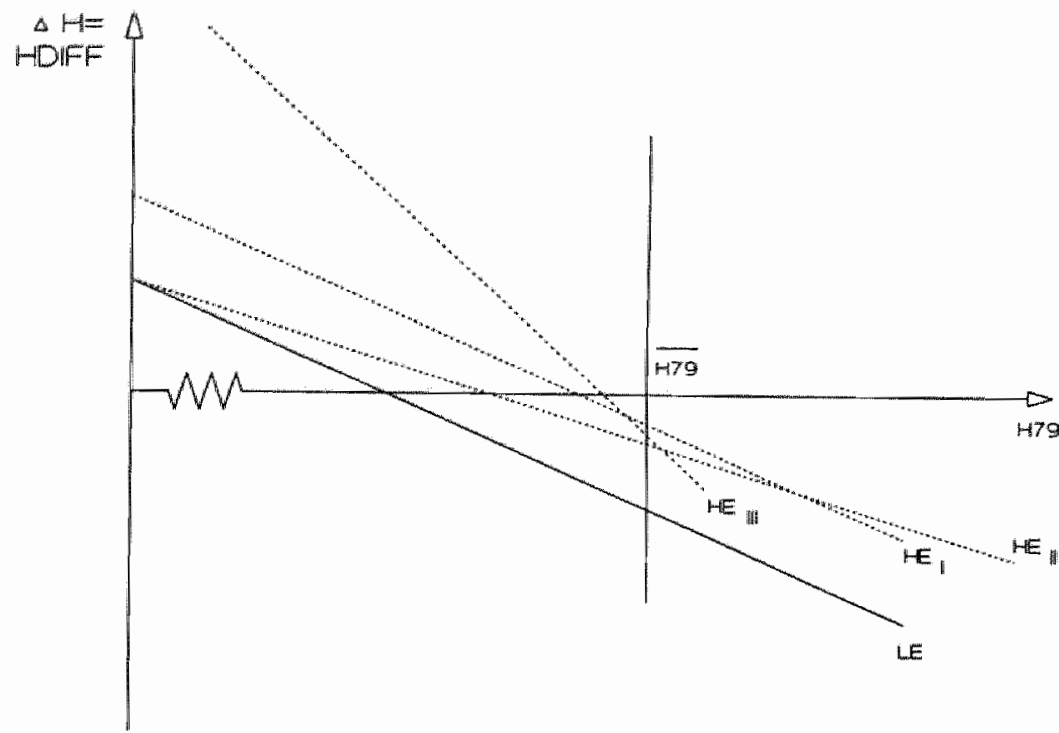

mean initial health status (A79), where the majority of observations is located, the differences in health change by educational group are very similar. Interpreted literally in terms of the health change equation (7.1), model III implies that the (positive) productivityincreasing effect dominates a (negative) use-related depreciation effect. However, due to the weak operationalization of health investment this inference is very premature. A replication of this test with more adequate measures of health investment than household incone is required before one can be more conclusive about this interpretation.

\subsection{Conc lus lons}

In this chapter we nave examined empirically the dynamic relationship between education and health by means of a dataset which differs substantially from the one we used in Chapter 6. Because also the results are quite different from the earlier ones, it is worthwile to sumarize the most important differences between the two samples. This is done in table 7.9 .

We think that most of these differences are crucial to understand why in Chapter 6 we did not, and in Chapter 7 we did ind a sigmificant 
Table 7.9. A sumbry of characteristics of the Nederland oke Fanel and the CBS H.I.S.

Nederland OKe

Sample size

Age group

Reference period

(health)

Time dimension

Health indicators used

Educational levels distinguished

Mederland Oke

895
$21-65$
$1981-1983$
panel
latent variable
based on three
indicators (SPH,
CHRON and CoMPL)

4
CBS H.I.S.

7158
$16+$
$1979-1984$
retrospective questions
appreciation mark
$(1$ to 10$)$

5

dymamic impact of education on health change over time. The main reason is undoubtedly an enormous gain in test power in the second analysis. This is not only due to the fact that the sample size is eight times larger but also to the larger variation in both the dependent (health change) and the independent (education) variable. Clearly, extending the reference period from two to five years and including the people over 65, substantially increases the dymamic variation in health, but also the retrospective health rating on a ten-point scale seems to be a more sensitive measurement instrument. Moreover; most of the health effect of education seems to be located at the bottom of the educational ladder. In that respect, the educational subdivision used in Chapter 6 is rather unfortunate because it lumps together $f$ ifty percent of the sample into the lowest education category.

For the reasons mentioned above, we believe that we were unable to identify a significant dynamic health effect of education in chapter 6 mainly because of a lack of test power. The analysis of the 1984 CBS Health Interview Survey reported in this chapter shows that:

a. Lifecycle proflles of health are not parallel across groups of people with different levels of education. Especially the health status of those who did not attend more than primary education depreclates faster than that of the other classes. A result which was not strong enough to be conclusive but consistent enough to be cause concern, was the negative marginal health returns to university education. No intervening factors could be examined in detail which could contribute to an explanation of this finding. one interesting $\mathrm{finding}$ was that this education effect did not differ between those who did and those who did not have a paid job. 4 This makes an explanation based on working conditions unl ikely.

b. On average, health deterioration only starts beyond the age of 30 but increases at an increasing rate thereafter. The acceleration 
occurs particularly after 65 and this is in line with the theoretical expectations of Murinen: If the impact of age on the rate of depreciation is seen as an exponentially increasing function of age, both the finiteness of life in a biological sense is guaranteed and also all these other (use-related depreciation) effects will ultimately become negligible in relation to the ageinduced decrease in health." (Murinen. 1982a, p. T)

c. By lack of a good measure of health investment during the five year perlod considered, household income was used as a proxy, which codetermines investment behaviour. A strongly positive effect on health change was found, irrespective of the specification used to estimate the relationship. It means that in the Netherlands not. only the absolute health level is positively related to incone (cfr. e.g. Van Viet and Van Praag, 1987; Van Ginneken and Appelboom 1987 ) but also the rate of change when initial health is controlled for.

d. In contrast to the previous findings the effect of gender on absolute health differences was not replicated by the dynamic analysis. When especially initial health is held constant, no sex differences in health change were found male health profiles are slightly higher than - but parallel with - female health profiles.

e. Appreclation marks are fairly reliable measurement instruments for general health status. They are sufficiently sensitive to analyze longitudinal differences.

f. Neither Grossman's marginal productivity-hypothes is nor Murinen's use-related depreciation hypothesis about the effect of education could be rejected. When estimated separately, both the direct main effect and the second-order interaction effect with previous health were statistically significant and had the expected sign. However, when both types of effects were introduced simultaneous Iy the interaction effect changed sign which indicates that the total or overall effect conceals two opposite effects. The latter finding is considered to be an interesting topic for further analys is with better measures of health investment. 
1. When the dumy DoHax was replaced by the number of chronit conditions or hand lcaps, the reliablity coefflcient increased to 396 . This is consistent with the falrly hich reliablity coefficlent obtained for this indicator by Van Viet and Van praas (1987).

2. A seneral exposition on the interpretation of the Awowh-tables abtained with the SPSS program can be found in e.8. Tabacmick and Fldell (1983), Chapter 7.

3. We do not conslder non-l inear relationships with these variables here.

4. The ANOONA results referred to mere not presented but were obtained by replacing the SEX

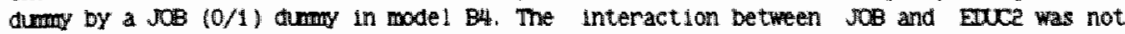
signiflcant whl the other effects handly changed. 


\title{
Chapter 8. General summary and conclusions
}

\begin{abstract}
-Great theorles are rarely simple in the ordinary sense of the term. Both quantum mechanisms and relativity theory are very difficult to understand; it takes only a few minutes to memorize the facts accourted for by redativity, but years of study my not suffice to master the theory and to see these facts in its context." (Polanyi, 1958, p. 16)
\end{abstract}

In the introduction to this thesis, we stated the central research question as follows: How, and to what extent, does the knowledge capital of individuals affect their behaviour with respect to health and with respect to their demand for medical care? Because the explicit intention was to approach this problem from an economic point of vlew. we first reviewed the theoretical models that had been used in the health economics 1 iterature in the (distant and recent) past in Chapter 2. The demand models that were discussed were classifled according to whether or not:

1. the demand for medical care was derived from the more fundamental demand for 'good health',

2. health was regarded as a human capital stock which depreciates over time but can be augmented by health investment,

3. health depreciation was considered as uncertain, thereby causing a demand for insurance and the need to distinguish between preventive and curatlve care, and

4. consumer information on the effectiveness of medical care was imperfect, leading to a derived demand for (professional) advice.

Although undoubtedly each of these model characteristics is important, and therefore ought to be incorporated in any attempt to construct a comprenensive theoretical model of health (care) demand behaviour, such an exercise was not our ambition. Because we mainly wanted to use the theoretical models as the basis for our empirical analysis, we chose to tackle the problem in two stages for pragmatic reasons. A static but stochastic model was chosen to study the relationship between consumer information or knowledge and the demand for medical 
care in Part I. The empirical analysis in the second part is based on a dynamic but deterministic theoretical model of the demand for health. Abstracting from intertemporal considerations in the first part, and from uncertainty in the second part, reduced the research problem to manageable proportions without in our view running the risk of oversimplification.

\section{Part I: Consumer information and the demand for medical care}

In Chapter 3 basically Kinlstrom:s (1974a) Bayes1an approach to the demand for information when product quality is uncertain, is adopted to describe demand behaviour in the health care market. The essence of the idea is that consumers are uncertain about the quality of medical care in terms of what it can contribute to their health status. It is assumed that they do possess some prior knowledge which is characterized by an a priori (normal) distribution of their bellef about the effectiveness of medical care, The larger the variance around the an of this distribution for the more diffuse the prior), the more uncertain they are and the more valuable the avallablilty of additional information. Information can be obtained from experlence but it can also be bought in the "medical advice" market. Basically", diagnostic and therapeutic information is precisely what is being purchased in most (primary care) physician-patient encounters.

It is further assumed that patients act as Bayesian decision makers in combining their prior knowledge and the advice recelved (the sample information) to arrive at a posterior knowledge (in the form of an a posteriori distribution) on which to base their decisions in order to maximize expected utility. In such a framework, the degree of consumer Ignorance (and thus sovereignty) varles continuously with the degree of uncertainty expressed by the prion and posterior distributions. It is then shown that the expected ut1lity gains of extra information (obtained from a doctor-expert or elsewhere) and treatment wil be weighted against the cost of information. Some comparative static results can be derived for the effects of income, prices, prior uncertainty and the perceived informativeness of medical advice on the demand for diagnostic and therapeutic information.

Additional problems arise in health care because a doctor visit very often is a joint product consisting of both information and care. The Bayesian decision making assumption provides a key to the issue of how suppliers of medical care may be able to induce additional demand for their services: by altering the accuracy of their advice and overstating the marginal effect of an intervention. The consumer's prior kmowledge and his perception of the accuracy of such advice provide limits to this discretionary power of the physician. How effective these 1 imits are is an empirical matter. 
This brings us to chapter 4 in which a (LISREI) structural equation model is specifled in order to test some of the theoretical model predictions. The dependent variables are two patient-initiated demands for primary medical care (self medication and GP contacts) and two physician-initlated ut1lization rates (referred GP contacts and prescription drugs). A sample of nearly a thousand adults was analyzed draw from the general Flemish population.

Special attention was paid to the measurement of health and knowledge. Individual health status was measured as a latent vector consisting of two components: a permanent stock of health and a transitory flow of healthy time. In a similar way, two Bayesian components of consumer information were distinguished: a MIMIC index for medical knowledgeab111ty was constructed to measure the prior information, and by means of principal components analysis a scale was derived to measure the respondents' perception of the accuracy of GP advice. The rellability of the various indicators we used and the validity of the constructs we developed was analyzed extensively in the measurement submodels. The results of these health and information 'modules' proved to be very robust when they were integrated into the full structural model. This indicates that it was justifled to adopt the stepwise strategy of sorting out the measurement problems before performing any hypothesis testing in the total model.

According to the estimation results of the basic model specification reported in table 7.13 , the following conclusions can be araw with respect to the tested model predictions. First of all, individuals with better medical information do not initiate fewer visits to their GP. On the contrary, ceteris paribus, they report significantiy more of such contacts but the effect is quite small. Its total (positive) effect is even smaller than the direct effect, mainly because knowledge has also a positive influence on the use of non-prescribed medicines. Because this acts as a substitute for GP contacts the indirect effect is negative.

Distinguishing between the initlator of consumption tumned out to be important because the opposite effect was found for physician-initiated GP contacts. People with more medical knowledge had significantly less GP contacts on referral. It was argued that this finding in combination with the consistently positive, though non-significant effect of GP avaliability, could be interpreted as evidence in favour of Pauly's (1980) nypothesis that prior information effectively constraints the providers' ability to induce demand for their servicos. It does not, nowever, rule out other possible explanations.

No influence was found of prior medical knowledge on the use of prescription drugs and not one of the demands we considered was signiflcantly affected by our measure of the (in)accuracy perception of GP diagnostic and therapeutic information. Education only showed a positive influence on the use of self-medication. 
In the discussion of these results in Chapter 4 we pointed out that their inconsistency with some of the major theoretical predictions stands in sharp contrast to their consistency with earlier findings in the literature. Either no or all positive effect was found of medical knowledge on physician visits. However, with our structural model approach it was possible to show that some of the interpretations which other researchers had given to this result were incorrect. In addition, we could show that the opposite result nolds for physician-initiated contacts.

our gemeral conclusion of Part one 1 s therefore that the Bayesian approach to the demand for information, despite its theoretical appeal. contributes little to a better empirical explanation of the demand for primary care. Even if the power of the tests could be raised by analyzing a larger sample or measuring more accurately than we did, some effects may become statistically more significant but it is unlikely that they 11 be much larger. The institutional requirement to buy professional information, in the form of a prescription, for the majority of health care may be one of the reasons why the effect of prior information is so small. In fact, such requirements may always cause a downwand bias in the information effect, even when in future research efforts it is attempted to distingulsh between more and less appropriate medical consumption.

Final $\Perp Y_{1}$ also the estimated partial direct effects of medical knowledge and education on health status were very small and of ten nonsignificant. This finding is inconsistent with the strong partial correlations between the level of schooling and health which are often found also in individual cross-section studies. This relationship is explored in more detall in the second part of this study.

\section{Part II: Education and health}

The second part of the study does not (only) deal with the speciflc mechanism through which knowledge might affect medical consumption but takes a broader view to investigate the overall effect of one type of human capital (education) on the other type of human capital (health). The theoretical and empirical problems assoclated with an analysis of the schooling-health relationship are discussed in Chapter 5 . It was argued that, for our purposes, education effects on the health of a Beneral adult population could better be examined by means of production functions rather than demand functions. By estimating an essentially techical relationship like a production function a number of specific problems inherent to the demand for health approach can be avolded. At the same time, nowever, most of the characteristics of the economic approach to health behaviour are neglected.

Through a review of earlier empirical studies of the schooling-health 
Link, we identifled mainly four methodologlcal problems: (a) onitted variable blas, (b) measurement error, (c) direct versus indirect effects, and (d) non-linearity and interaction. With respect to the issue of oulted variable bias, it was shown that longitudinal data might provide an acceptable solution if the objective is not so much to Identify the "onitted third factor (s)" but rather to control for possible spurious correlation. The problem of errors in nealth measurement can be reduced by using several indicators of the unobservable variable and combining them into one index. This procedure has hitherto only been used in (non-longltudinal) crosssection studies. Investigations of intervening factors in the linkage between schooling and health sometimes reported important indirect effects through allocation decisions. But the problem with these estimates is that posslbly the total effect is substantially overestimated due to lack of control for omitted variables. Finally few studles allowed for the possibility of non-linear and/or non-additive effects of education.

For our own analysis of education effects in health production, we had two datasets avallable, none of which allowed us to tackle all of these methodologlcal problems simultaneous ly. However each of the two had strengths and weaknesses compared to the other. Therefore, we could not discard any of them a priori and analyzed both separately.

In Chapter 6 a longltudinal latent variable model is estimated with data taken from the two waves of the Nederland Oke Panel Survey. The health status of the 895 individuals in the sample in 1981 and 1983 is measured as a latent variable with three observable indicators: selfrated general health status, the presence of a chronic condition or handicap and a 21-item psycho-somatic complaints score. By allowing for intertemporal correlation between the error terms of two of these indicators, a measurement model was obtained that fitted these data. A recursive structural equation model is then specified to estimate the cumulative effects of education and other exogenous variables on 1981 health status and the dynamic effects on 1983 health status. The main conclusion is that schooling appears to have no marginal impact on health changes, 1.e. on current health when the health status of two years earlier is controlled for. Both education and most of the other health determinants show a clear "cumulative" effect but ins lgniflcant "dynamic" effects. Notable exceptions are the influence of the two health inputs, 1.e. a healthy lifestyle and the number of doctor visits, but these channel negative indirect effects of education on nealth. However, a decomposition into direct and indirect effects of education is nampered by the absence of any significant total (dynamic) effects. This would imply that the health lifecycle profiles of the more educated have a higher intercept but identical slopes, 1.e. they are parallel. However, we have some doubt about the generalizablilty of this finding because the results also indicate that age does not have a dynamic effect on health 1 ,e, that health depreciation does not rise with age. Even though the sample only 
includes persons between the age 1 imits of 21 and $65_{i}$ one would expect some age impact on health change.

We therefore conclude that the absence of a marginal health productivity effect of schooling (and other variables) may be due to a lack of discriminating power of the test. By far the largest part of the high percentage (84\%) of explained variance in 1983 latent health status is accounted for by the health status two years earlier. Both the I Imited variation of the latent health variable over a period of two years and the 1 imited size of the sample may prevent the detection of significant dynamic effects. This hypothesis could be tested in Chapter 7 with the other dataset.

More recently another Dutch dataset has become available with which the dymamic relationship between health and education could be examined. The 1984 CBS Health Interview sumvey is not a panel but it includes a retrospective health question. Respondents were asked to rate both their current and past health status (five years ago) by means of an appreciation mark between 1 and 10. This was found to be a fairly reliable and sufficlently sensitive measure to analyze longltudinal changes in health. The longer reference perlod (flve years), the larger sample size $(n=7158)$ and the better subdivision of education categorles increased the power of the test substantially.

By means of an analysis of covariance of the health changes over time, we found that 1 ifecycle profiles of health are not parallel across groups of people with different levels of schooling. In particular, the health depreclation rate of those who did not attend more than primary education is nigher than that of the other classes (except university level), even when income, age, sex and initial health are controlled for. Although no intervening factors could be examined in detail, an explanation based on working conditions seems unlikely because this education effect did not differ between those who did and those who did not have a pald job. Further investigation is needed of the specific mechanisms through which this effect materializes. People with a low equcation level do seem to continue to be a high health risk group deserving the attention of health policy makers. our analysis indicates that differences in education levels increase health inequalities, thereby amplifying the initial inequality.

Not only the direct main effect of education on health change but also the interaction effect with initial health status was statistically significant. Both indicated a substantial health gain between the lowest and the second level of education but little health returns to additional education beyond vocational training. When both types of effects were introduced similtaneously, the interaction effect became negative. This result suggests that the positive overall effect of education would conceal two opposite effects rather than two complementary influences, as one would expect. It certainly contradicts the use-related depreciation hypothesis about the effect 
of education which could not be rejected when the interaction effects were estimated separately (without the main effects). The marginal productivity hyothesis could not be tested adequately due to the lack of a good measure of health investment. This will be a necessity in future work if one wants to discriminate more adequately between the two competing rypotheses.

with respect to the effects of the other background characteristics, a non-linear age influence was found: health deterioration only starts beyond the age of 30 but increases at an increasing rate thereafter. Male health proflles are slightly nigher but parallel with female health proflles: the initial sex difference remains constant over the lifecycle. In all estimates, household income showed a strongly positive partial effect on health which again indicates that initial socio-economic inequalities grow as people grow older.

The main general conclusion which emerges from the various analyses presented in the second part of this book is that the correlation between health and education is not spurious. More schooling does seem to have a beneflcial causal effect on health or; formulated negativeIY, a lack of education adversely affects the expected time path of individual health status. Future research $w 11$ have to concentrate on more specific causal mechanisms which may channel this influence. In order to identify how much of this effect can be attributed to working conditions, lifestyle, use of medical care or other intervening varlables, preferably panel data should be used but according to our analysis, also retrospective questions in cross-section surveys provide useful and less expensive alternative sounce of longitudinal information. 


\section{References}

Acton. J.P. (1985), Nomonetary factors in the demand for medical services: scane empirical evidence, Joumal of Polltical Econcmy 83, pp 595-64t

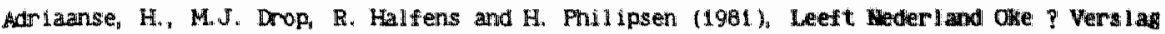

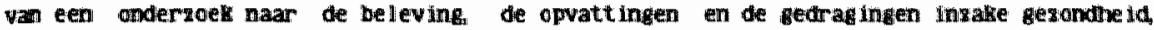
sticht lne Nerland oke. zeist

Amdersen, $R$, J. Kravits and $O . W$. Anderson (1975) (eds), Equity in mealth services,

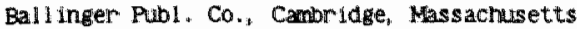

Arrow, X.J. (1963), Uncertainty and the welfare economics of medical care, faerican Economic Revlew, 53, pp 941-973, also reprinted in $M$. Cooper and A.J. Oulyer (eds), Health

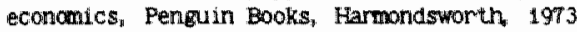

Auster; $\mathbb{R} \mathrm{D}_{n}$, 1. Leveson and D. Sarachek (1969), The procuction of headth an exploratory study, Joumal of Heag Resounces 4 pp $412-436$

Becker, G.S. (1965), A theory of the allocation of time, Economic Journal 75, pip 493-3i1T

Eentler, P.M. and D.G. Bonett (1980), Sigmificance test,s and goodness of fit in the analys is of covariance structures, Paychological Bulletin 88, Na, 3, pp $588-606$

Blaug; M. (1970), An introduction to the economics of education, Fenguin Books, New York

Buag, M. (1980), The methodology of econowics, or mow economists explain, Cambridge Untwersity Press, Cambridge

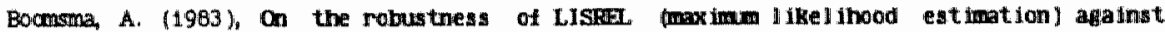
saill sample sire and nom-normallity, Fh. D. dissertation Groninger, Soclometric Research Foundation, Ams tendari

Brekel, E.J.G. van den (1987), Gezondneid en medische consumptie naar geslacht, Haandbericm Gezondhe ids statistiel CBS, 6, 2, pp 5-55

Breyer, $F$. (1982), Rational purenase of medical care and differential insurance coverage for diagnostic services. Journal of Health Ecomomics $\mathbb{1}_{1}$ pp 147-156

Erook, R.H., J.E. Ware, A. Davies-Avery et al. (1979), Overwlew of adult health status measures flelded in Rand's Health Insurance Study, Hedical Care it (Suppl. ), pp 1-131

Carrin, G. and J. Vam Dael (1984), An empirical model of the demand for health care in Belgitum Appllied Econanics; Vol. $\exists_{3}$ pp $317-334$

Chamerlain, G. f197T), Education, income and ablilty revisited, in: D.J. Aigner and A.s.

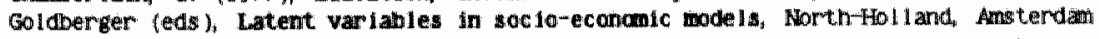

Coyte, P.C. (1963), The economics of Medicare: equilibrim withim the medical commity: Joumal of Labor Ecionemics 1, 3, P.P 264t-285

Coyte, F.C. (1985), The market for medical services and physicians: an application of hetonic price theory, Canadian Joumal of Economics 10, 2, pp $377-394$

Cropper, H.L. $14977 \%$, Health investment in health and occupational chodce, Jourmall of

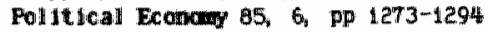

Cropper, M.L. (1981), Measuring the benefits from recuced morbldity, funerican Econamic Beview 71,2 , pp $235-240$

Oullis, I. and: P. West (1979), The econowics of healtir an introduction, Hartin Robertion, oxtond

oulyer, A.J. (1971), Is medical care different? In: $\mathrm{M}$ Cooper and A. J. Oulyer (eds), Health Ecconoulcs, Fenguin Books, Harwondsworth 


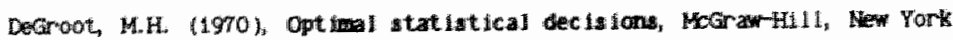

Dejardin, J. and $E$. Praet (1980), Invloed wan de verhwobde tegemetkoning van de verplichte

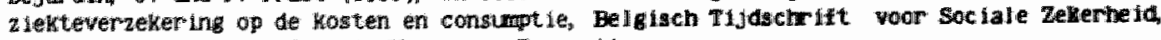
nir. 2 Mnisterie van Soclale Voorzorg, Erusisell

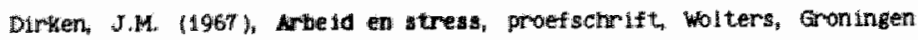

Doors I ater, E. K.A. Var (1964), Efects of cost-sharing on the demand for prescription drugs in Belgiun Acta laspitalia, No, 3, pp 69-81

Dorfman, R. (1969l, An economic interpretation of optinal control treory, warician Economic Bevien, $59, \quad$ pp $817-831$

Edwards, H.N. and M. Grossman (1983), Adolescent health, family background and preventive medical care, in: D. Salkever, I. Sirageldin and A. Sorkin (eds) Research in muen captal and derelopment, Yal. 3, IAI PTes:s, Pp 77-109

Eeckroudt. L.s T. Lebmun and J.C. Sallyy (1985), Risk aversion and pryshclans "medical

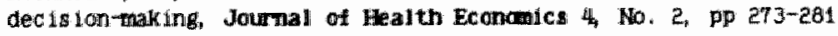

Englich, I. and G.S. Becker (1972), Market insurance, se 1 -insurance and self-protection, Jourtial of Polltical Economy, 60 , 4, pp 623 i-648

Evans, R.G. (1976), Book review af: M. Perlman (ed.), (1974), The econocics of health and medical care, London, MacMillan, ini Canadian Journal of Ecomewics 9,3, pp $532^{-537}$

Dvans, R. (1904), strained mercy. The econcaics of Canadian health care, Butterworths, Toronto

Farrell, P. and V.R. Ruchs (1982), schooling and health the cigarette connection, Jourtwal of Health Economics 1, pp $217-230$

Feldstein, M.S, (1974), Econometric Studies of Health Economics. In: M.D. Intriligator and D.A. Kendrick (eds), Frontiers of quantitative econdinics, Vol.2, North Holland, fusterdam

Foets, M. F, Bergmans and L. Janssens (1975), The primary health care project in Belgium; a survey on the utillization of services. Social science and Hedicine, vol. 20, No. 3, pp $181-190$

Freixas, $X$. and R.E. Kinlstron (1984), Risk aversion and information demand, in: M. Boyer and R.E. Kinlstrou (eds) Bayesian wodels in econcaic theory, Elsewier Science Publications, $93-104$

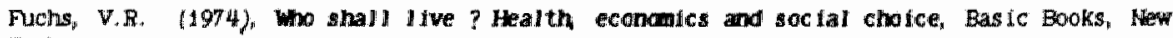
York

Fuchs, V.R. (19T9), "The economics of health $1^{2}$ a postindustrial society, me Public Interest $t_{4}$ pp $3-20$

Fuchs, V. (ed,) (1992), Economic aspects of health University of chicago Press, NBes Confermere Report, Chicago

Fuchs, W, R, (1986), The Falth Econcur, Hamard University Eress, Cambidge, Massachusetts

Gias, J. wan ofer and B. Wolfe (1983), Estimating the demand for medicall care: health as a critlcal factor for adults and children. Applied Econometrics Assoclation liyon

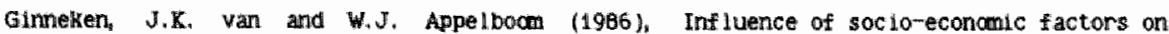
pencelved morbldity and the use of health serwices in the wetherlands "kandhericht Gezond he fdastat ist fell cas 5,10 , pp $5-9$

Goldberger, A.S. (1974), Unobsemable warlables in econcmetrics, in: P. Zarembka (ed.) Frontiers: of econometrics, ACademic Press, New Tork, pp 193-2137 


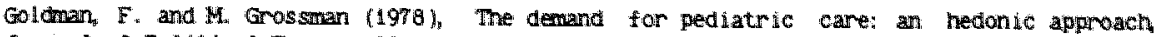
Journal of Polltical Ecomona 86, e, pp 259-200

ariliches, $z$. (1974), Errors in variables and other unobserwables, Econcinetrfica, 4e, also reprinted in: D.J. Algner and A. S. Goldberger (eds) Latent variables in socjo-conowic wodels, Horth-Holland, Amsterdam

Griliches, $z$. and W.M. Mason (1972), Education, income and ability, Joumal of Polltical Econowing $\mathrm{BO}_{4}$ pp $74-103$

Grossman, M. (1972a), The demend for health a theoretical and earpirical investifation National Bureau of Economic Research New York

Grossman, M. (1972b), on the concept of health capital and the demand for health Journal of Politicall Econcuy $80,2_{4}$ pp $223-255$

Grossman, $M_{*}$ and E.H. Rand (1974) $)_{\sharp}$ Consumer incentives for health services in chronic ll lness, in: S.J. Mushkin (ed.) Consurer incentives for health care, Prodist, New York pp 114-15i

Grossman, $M_{n}$ (1975), The correlation between health and schooling. In: $N_{n} E$. Terlechyl (ed. I Housiehold production and consumption, Columbia University Press, New York, pp 147-211

Grossman, $M_{.}$(1982), The demand for health after a decadie, Joumal of Health Econconics, 1 , 1. pp $11-3$

Grossman, S., R. Kinlstrom and L.J. Mirman (1977), A Bayes lan approach to the production of information and learning by doing. Review of Economic Studies, 44, pp 533-547

Halfens, R., M.J. Drop and H. Phil ipsen (1984), Leetwijgen en subjectiewe gexondheid wan cen panel uit de Nederlandse bevolking Rljksuniversiteit Limburg Mastricht.

Haveman, R.H. and E.L. Wolfe $(1984)$, Schooling and economlic well-being: the rale of nanmarket effects, Journal of Huan Resources, Vol. 19, No. 3, pp 377-407

Hay, J. and M.J. Leany (1982), Physiclan-induced demand. An empirical analysis of the consumer information gap. Joumal of Eealth Economics. 1, PP 231-244

Fyeckman, J. (1976), A lifecycle model of earnings, learning and consumption, Joumal of Polftical Economy 84, pp 11-44

Hey, J.D. and M.S. Patel (1983), Prevention and cure or is an ounce of prevention worth a polnd of chre? Journal of Health Econouics 2 , pp 119-1318

Hey, J.D. (1979), Uncertainty in micro-econcmics, Martin Robertson, Oxf ort

Hifshleter, J, and J.G. Rlley (1979), The analytlc.s of uncertainty and information. An expositary survey, Journal of Econowic Literature 17, pp 13T5-1421

Hooymans $E_{i}$ and $W$, var de Ven $(1992)$. Implementing a mealth status index in atructurall health care model. In: J. van der Giag et al. (eds) Econcuicis of health care, Fraeger Grants Economics Sertes, pp $302-322$

Hisia, C. (1986), Anally 13 of panell data, Cambridge University Press, New York

Ippolito, P.M. (1981), Information and the life cycle consumption of hazardous Boods, Economic Inquiry 19, pp 529-558

Johston, J. (1972), Econometrlc methods, McGraw Hil l, Wow

Joneskog, K. (1973), A ceneral method for estimating a sructural equation system in: Goldberger, A.S. and D. Duncan (eds) structural equation mode is in the soclall aciencies, Seminar Press, New York, pp 1-18 


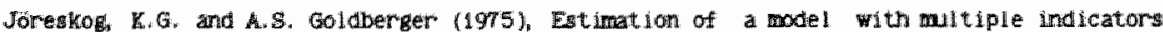
and rutiple calises of a single latert varlable. Joumal of the huerican statistical Association, Vo: Ta, pp $631-639$

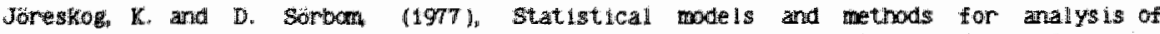
londitudinal data, in D.J. Alger and A.S. Goldberger (eds) Latemt variables in soc io

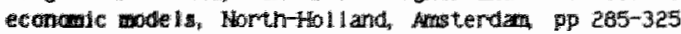

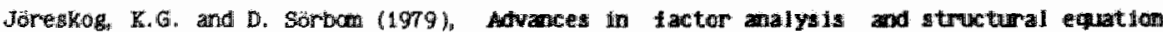

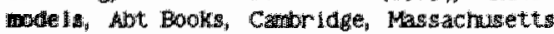

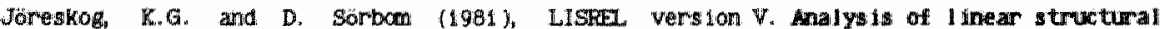

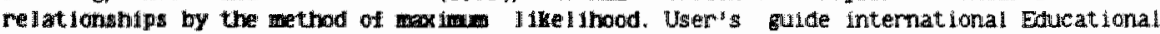
Services, chicago

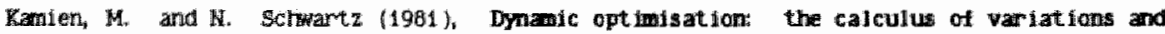

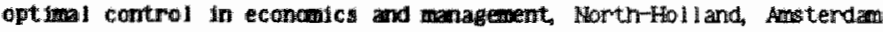

Keeter, E.B., I.P. Kathouse and C.E. Fhelps (1977) Deductibles and the denand for medical care semyices: the theory of a consumer facing a variable price schedule under uncertainty, ceonometrica: 45,3 , pp $641-655$

Kema, H.J.M.I. (H987), Work ing condituons and the relationship petween schooling and health Journall of Heaith Econtentes; Vol a, No, 3 , pp 165-281

Kentia, H.J.M. (1985), The relationship between schooling and health investigation into occupational iditiage, Ph. D. Dissertation, University of Pittsburgh

Kinlstrom, $R_{\text {. }}$ (197hb), A general theory of demand for information about product quality. Journal of Econcaic Theory $B$, pp $413-4,39$

Kinistrom R. (1974t), A Bayesian model of demand for information about product quality. Irtermational Economic Review Vol. 15, No, 1, pp 99-118

Wrenta, J, (1971), Ellements of econometrics, Macillan, New Vork

Kom, R. and K.L. White (1976), Health care. An International study, Oxford Utiversity Press; London

Lancaster, $\mathrm{K}_{\mathrm{J}} \mathrm{J}$. (1966), A new approach to consimer theory, Joumal of Polltical Econoug, $74, \quad p p 132-157$

Lee, $L_{i} F$, (1902), Health and wage: a simultaneous equation model with maltiple discrete indicator: Intermational Econonic Reviem Vol. 23, pp 199-221

Leigh, J.P. (1983), Direct and Indrect effects of education on heath Social science and Nadilo ine 17, 4t. pp $227-234$

Leu R.E. and $\mathbb{R}$. Dopman (1984), The demand for health care in switzerland - a latent variable approach. In: W. Van Eimeren et al. (eds) Third Internatiomal conference on system sclence in Heal th Care, Springer-Verlag Berlin

Levine, D $S_{4}$ and D. Yett $(1973)$, A method for constructini prosy measures of health status. In: R.L. Berg (ed.) Health Status Indexes. Hospital Research and Educational Trust. Chicago

Lodge, M. (1981), Manitude scaling: quartitative opinions, Sage Publications, Sertes on quantitative applications in the sociall sciences. Wo. 25 , Beverly Hills and London

Mackenbach J.P. and P.J. var der Mas (1987), sociale omgelijkheid en verschuler in gezondheld. Een overzicht wan de belanghljkste onderzoeksbevindingen, in: Wetenschappelijke Ragd voon thet Regeringsbeleid, De ongelljhe verdeling van gezomold, Serle voorstudies en Achtergrondent, $\mathrm{mr}$. $\mathrm{VSB}_{4}$ Staatsuitgeverij, Den Haag

Macurdy T.E. (1981) An empirical model of labor supply in a lifecycle setting Journal of Pollticil Econowy $99_{u}$ pp $1058-1085$ 


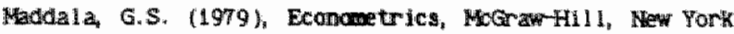

Wanning, W.6. Jr., J.P. Hewnouse and J.E. Ware, The status of health in demand estimation: ori beyond Excellent, Good, Fair Foor. In: $V_{k}$ Fuchs led.) Economic aspets of nealth MDER, University of Cnicago Press: pp 143-184

Hartus, G.B. (1979), Analying panel data. Sage Publications, series on quantitative applications in the social sciences, $N$. 18, Beveriy Hills and London

Michael, R.T. (1972), Education in nomarket production, Joumal of Political Econouy $80_{1}$ pp $306-327$

Muskin, \$. (1962), Healtin as investment, Jounal of Polltical Ecomory 70, pp 129-157

Mrchen, B. (1983), watent structural equation model inw with categorical data, in: J. de Leeuw, W.J. Keller and T". Wansbeek (eds), (1983), Interfaces between econometrics and psychometrics, Armal.s of Applied Econometrics, a supplement to The Journal of Econometrics, Val. 22, pp $43-65$

Murinen, J.M, (1962), Demand for health a generalised Grossman model. Joumal of Health Economics, Wo 1. 1, $\mathrm{No}, 1$, pp 5 m, 28

Murinen, J.M. (1982b), An economic model of health behaviour w the empirical applications to Finnish health survey data, Ph. D. Dissertation, University of York, York

Welson, $P,(1970)_{1}$ Information and consumer behaviour, Journal of Political Econosy T8

Newhouse, J,P. (1978), The econcanics of medical care, Addison wesley

Newhouse, J.P. (1979), The erosion of the medical market pilace, in: R.M. Scheffler(ed), Research in health economics, Vol. 1, JAI Press, Connecticut

Newhouse, J.P. (1981), The demand for medical care services: a retrospect and prospect, in: $J$, van der Gaag and M. Periman (eds) Fealth ecomonics and health econorics, Worth-Holl land, Arusterdam

Mewhouse, J.P. and L.J. Friedlander (1980), The relationship between medical resources and theasures of health: some additional evidence, Joumal of thwan Besources 15, ko. 2, pp 200218

Newhouse, J.P., C.E. Fhelps and M.S. Marquis (1980), on having your cake and eating it too: Econometric problems in estimating the demand for health services, Jourwall of Econometrics 13. pp $365-390$

Newhouse, J,P., J.E. Ware and C. Donald (1981), How sophlsticated are conisumeris about the medical care dellivery system? Hedical Care, Wol. 14, No. 3, pp $316-320$

MTA 2000. Over de antwikke ing van gezondheidsbeleid: feiten, beschouringen en beleids voormemens, Tweede Kamer, vergader,jar 1985-1986, 19500, nrs 1 en 2

Wryens, $Y_{\text {" }}(1980)$ De cerste Iijn is krom Wan Loghm Slaterus Deventer

Drgandsation for Econcmic Cooperation and Development (1965), Measuring health care 19601983. Expenditure, costs and perionance, social Policy studies, No, te

Pauly, M.V. and M. Satterthwate (1981), The pricing of primary care phys:lcian's services: a test of the role of consumer information. The Bell Mournal of Econamicis, Vol, 12. pp 489506

Pally M.V. (1900), poctors and the ir workshops: economic models of physiclan behavior, NEER, University of Chicango Press

Pauly, M.W. (1978), Is medical came different? In: W. Greenber (ed. Cometition In the bealth care sector, Aspen Systems Corf., Germantow 
Thelps, C.E. (1973\%, Twe deasud for health inswance: a theoretical and empirical

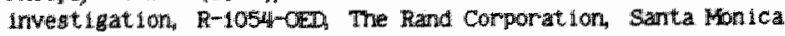

Phelps, c. E. (1976), Demand for reinbusentert insurance in: R.N Rosett led.) The role of health ingurance in the health services sectar, Hational Bureaul of Economic Research hew York

Fhelps, CiE. (1978), II lness prevention and medical insurance, Joumal or Hum Resources 18. Suppl lenent, pip $183-207$

Phelps, C.E. and I.P. Wewhouse (1974), Colinsurance, the price of time and the demand for medical services, Deview of Econcmics and statistics 56 , pp 334-342

Pollanyl, H. (1950), Personal knowliedge. Twards a post-critical philosophy. Routledge Kegan: Pauli, London

Robinson, P.H. and H.C. Ferrara (1977), The estimation of a model for an unobservable varlable with endogenous causes. In: D.J. Aigner and A.J Goldberger (eds) Latent variables in soclo-econcalic wodels, North-Holland, maserdam

Rossiter, L.F, and G.R. Wilenshy (1983), thexamination of the use of phys ician services: the role of physictan-initiated demand, Incwiry, Vol. 20 , pp 16c-172

Saris, W.E., J. den Ronden and A. Satorra (1985), Testing structural equation models, in: R.F. Cuttance and J.R. Ecos (eds) Structural wodelling Cambridge University Press, New Yomk

Saris, W.E., A. Satorra and D. Sorbon (1986), The detection and carrection of specitication error: in structural equation mode is, Sociometric Research Foundation, Amsterdam

Saris, W. and $H_{n}$ Stronkhorst (1984), Causal modell ing in non-exper incmtal research. Sociomic Research Foundation, Ansterdam

Shaktotko, R.A., L.K. Ecwards and M. Crossman (1981), An explorition of the dynamic relationshlp between health and cognitive development in adolescence, in: J. van der Gaas and M. Perlman (eds) Fealth economics and heallh econasics, North-Fiolland, Amsterdam

Sindelar, J.L. (1982), Behaviorally caused loss of health and the use of medical care, Economilc Inquiry 20, pp 458-471

Tabachnick, B.G, and L.S. Fidell (1983), Us ing wultivarlate statistics, Harper and Fow, Mew York

Tauman, P. and $S_{n}$ Rosen (1982), Healthiness, education and marital status, in: V.R. Fuchs (ed.) Bconomic pectur of health The Oniversity of chicago Press, chicago

Telser. L. (1981), The market for research and develofment: physician demand and drup company supply, in. R. Hielm (ed.), Drugs and health American Enterprise Institute, Washington D.C.

Torrance, G.W. (1986), Measurement of bealn state utilitles for economic appraisal: A review, Joumal at Health Economics, Vol. 5 , No. 1 , pp 1-30

Usher" D. (1975), Coments on "The correlation betwen hetath and schooling". In: N.E. Terlecky) (eds) Household production and consumption, Columbia University Press, Wew York, pp $212-20$

Ven, W. Wain de and J, van der Gaag (1992), Health as an unobservate. AmMC-model of the denand for. health care, Journal of Heal th Econcmics 1, 2, pp 157-1.83

Ven W.F.M.M. Van de (1987), The key role of health insurance in a cost-effective health care system. Towards regulated competition in the Dutch health care market. Health Policy 7. $\mathrm{pp} 253-27 \mathrm{e}$ 
Ven, W.P.M.M. var de and B.M.S. van Praag 1961 d, The demand for deductibles in private health insurance. A Probit model with sample selection, Journal of Ecmanetrics, 17 , pp $229-252$

Ven, wan de and E. Hooynans (1982), The Hurc mealtil status index: wat it is and how to use it. Report 82.17, Center for Research in Publ ic Economics, Leyden University

Viscusi, w. Kip and C.J, Q'Conor (1984), Adaptive responses to chemical label ing: are workers Bayes lon dec is ion makers? American Economic Bevlew 74,5 , pp 94k-956

VIiet, R.C.J.A. varn and B.M.S. van Pralag (1987). Health status estimation on the basis of MIMIC-health care models, Journal of Health Economics $6,20.1, p p 27-42$

Wagstaff, A. (1986a), The denand for health sume new erpirical evidence, Joumall of Elealth Economics 5, pp 195-233

Wagstaff, A. (1986b). The demand for nealth a simplified crossmam model, bulletin of Economic Research 38, 1, pp $93-95$

Welich, F. (1970), Education in production, Journal of Foliticall Economy 78 , pp $35-59$

Wenmberg, J.E. et al. (1982). Professional uncertainty and the problem of supplier-induced demand. Soctall Sclence and Hedicine, Vol. 16, pp 811-024

Wheaton, G., B. Muthen, D.E. Alwin and G.F. Sumers (1977), Assessing reliablilty and stability in panel motels with mitiple indicators, Im: D.R. Heise (ed.) Sociological Methoidologx, 1977, San Francisco, Jossey-Bass, pp $44-136$

Wiley, D.E. (1973), The identification problem for structural equation models with ummeasured variables, in: A.S. Goldberger and $O . D$. Duncan (eds) structurall equation models in the social sciences, New York, Seminar Press, pp 69-83

Wolfe, B. and J. var der Gaag (1981). A new health status index for children. In: J, van der Gaag and $M_{n}$ Perlman (eds) Health econcaics and health econonics, North-Holl and, Amstervian

Wolfe, B. and J. Behrman (1984), Determinants of women's health status and health care utilization in a developing country: a latent variable appinoacli the Revilew of Econowics and statistics, 56, Nov, "pp 696-703 


\title{
Appendices
}

\author{
APPEDDIX 4A
}

Description of variables from the frimery Health Care Survey

VAR. WAL DXGRIPIOA

Health care utillization variables

SED numer of different types of non-prescribed self-

medlcation used during 9 weeks (max. = 8 )

giroat rumber of contacts with op durins 9 weeks at patient's

giroos rumber of contacts with op during 9 weers at patient's
initiative (max. $=12$ ) number of contacts with GiP during 9 weeks at

atriter

physician's inltiative (max. $=13$ )

PMED

number of different types of prescribed medicines used

dur ing 9 weeks (max $=11)$

Health status variales

RAD(L) number of restricted activity days during 9 weeks $(\max .=63)$

NAD(L) number of non mactivity days or in bed during 9 weeks (max. $=63)$

OCOND numer of chronlc canditions or handicaps of respondent at the time of the interview (max. $=6$ )

oow number of different health complaints expressed by the respondent at the time during 9 weeks (max. = 3) "acute" (flu-cald, infectuous disease, tratma, digestive, NTE complaint categories)

ACUTE

ordod 'chronic" (heart, pain, psychosocial illness, headache, rheumatic, sleeping problems, other? "disability index" based on the frecuency $c a=$ never, 1 . somet jues, $2=$ ofter, $3=$ always $)$ wh which the respondent, (during 9 weeks)

- had been tuable to pertiorm daily work

- nad been unable to practice norma: hobbles or rexreation

- had felt himself more worried or less happy than normal

- had not slept very we ll

(1n. $=0$, max: $=26)$ the index is the sum of the score at the 3 interviews

\section{Rowledge varialles}

(answer categorles $01=$ wong, $1=$ do not know,

2 - correcty

TESTI sum of scores on 14 tems of general theoretical imetical knowledge

sum of scores on 16 items of theoretical medical Howledge with some practical relevance (9 to 32 )

TEST:

TESTy sum of scores on 11 itens of practicall medical how ledge (e to $2 \mathrm{e}$ ) sun of scores on e itens of knowledge of thealth care organization $(0$ to 4 )
MEAN VARIAMCE SREMNDSS

$\begin{array}{rrr}.803 & 1.232 & 1.60 \\ .575 & 1.242 & 3.53 \\ .162 & .535 & 9.13 \\ 1.105 & 2.911 & 2.03\end{array}$

$\begin{array}{rrr}16.453 & 15.899 & .32 \\ 21.121 & 15.638 & .08 \\ 11.664 & 14.261 & .19 \\ 2.896 & 1.166 & -.45\end{array}$




\section{Backeround variables}

SEX 1 = female

AGE min. $=16$, max. $=90$ years.

Euc education, 4 categories (a to 3$)$

$0.445 \quad 0.247 \quad .22$

$42.198 \quad 286.862 \quad .45$

0.997

1. 117

, 61

SES stacio-econcmic statuis based on occupation of

respondent for partner, or head of household),

13 categories

$3.854 \quad 11.733 \quad .43$

$3.416 \quad 2.309$

HST size of the household (1 to 11)
FIC thonthiy net-income of the household $(0$ to 3 ),

4 categories

$1.713 \quad 1.025-.27$

PSPR numer of psycho-social problems of respondent at

the tine of the interview (max. $=3$ )

$0.195 \quad 0.223 \quad 2.67$

IHIST(L) Illmess history of respondent, measured by weighted sum of chronlc conditions or handicaps the respondent had suffered from in the past (max. $=32$ )

$.762 \quad .940 \quad .82$

MEFAM muber of household members with medical or paramedical profession

$0.075 \quad 0.228 \quad 8.11$

WOPI anmy for widows, invalids pens loners and orphars which comprise a category of sickfund insured with lower deduct ibles

$0.156 \quad 0.132 \quad 1.90$

GPDES GP density at mulcipal level (per 10, 000 population)

5.692 pharmacy density at muicipal level (per 10,000 population)

$4.296 \quad 4.070 \quad .17$

Principal component factors

INACPT"

INACPE see text

$-.284$

1.991 .01

ACGURP?

3.7818

2.023

.00

4.516

1. 859

$-31$

(L) This means that the variable is transformed according to in (VAR + i) in onder to reduce skewness. 


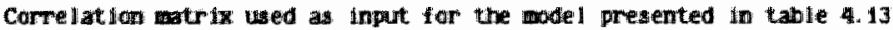

\begin{tabular}{|c|c|c|c|c|c|c|c|c|c|c|}
\hline & $\frac{1}{3+1}$ & $\frac{2}{\cot }$ & $\frac{3}{G F T E F}$ & $\begin{array}{l}4 \\
\mathrm{HED}\end{array}$ & 5 & $\begin{array}{l}6 \\
\mathrm{Patc}\end{array}$ & $\stackrel{7}{\text { OXNPL }}$ & $\begin{array}{l}8 \\
\text { LRAD }\end{array}$ & 9 & $\begin{array}{l}10 \\
\text { LDISAB }\end{array}$ \\
\hline 1 & 1.000 & & & & & & & & & \\
\hline e & 0.110 & 1.000 & & & & & & & & \\
\hline 3 & 0.017 & 0.057 & 1.000 & & & & & & & \\
\hline 4 & 0.15 & 0.557 & 0.323 & 1.000 & & & & & & \\
\hline 5 & 0.054 & 0.239 & 0.172 & 0.426 & 1.000 & & & & & \\
\hline 6 & 0.061 & 0.389 & $0.20 \%$ & 0.485 & 0.348 & 1.000 & & & & \\
\hline 7 & 0.605 & 0.350 & 0.153 & 0.519 & 0.292 & $0.33 \mathrm{C}$ & 1.000 & & & \\
\hline 10 & 0.103 & 0.266 & 0.137 & 0.305 & 0.252 & 0.209 & 0.284 & 1.000 & & \\
\hline 9 & 0.085 & 0.389 & 0.100 & 0.407 & 0.204 & 0.228 & 0.259 & 0.220 & 1.000 & \\
\hline 10 & 0.182 & 0.368 & 0.212 & 0.446 & 0.296 & 0.323 & 0.413 & 0.434 & 0.489 & 1.000 \\
\hline 11 & 0.129 & $-0,009$ & $-0,082$ & -0.042 & -0.085 & -0.049 & 0.067 & -0.022 & -0.031 & -0.001 \\
\hline 12 & 0,105 & 0.027 & -0.040 & -0.023 & -0.040 & -0.040 & 0.075 & 0.003 & -0.045 & 0.013 \\
\hline 13 & 0.114 & -0.007 & -0.099 & -0.031 & -0.0188 & -0.043 & 0.046 & -0.001 & -0.052 & -0.003 \\
\hline 14 & -0.001 & -0.009 & -0.043 & -0.045 & -0.012 & 0.049 & 0.055 & 0.020 & 0.035 & 0.056 \\
\hline 15 & -0.005 & -0.041 & $-0,017$ & -0.081 & -0000 & -0.115 & -0.032 & $-0,0488$ & -0.006 & -0.036 \\
\hline 16 & 0.138 & -0.109 & -0.099 & -0.140 & -0.173 & -0.122 & $0.02 \theta$ & -0.100 & -0.064 & -0.0164 \\
\hline 17 & 0.145 & -0.009 & -0.059 & $=0.089$ & -10.127 & -0.035 & 0.048 & -0.036 & -0.063 & -0.016 \\
\hline 10 & 0.0544 & -0.033 & -0.005 & -0.037 & -0.018 & -0.056 & 0.033 & 0.009 & -0.023 & 0.026 \\
\hline 19 & 0.010 & -0.080 & $=0.062$ & $-0,193$ & -0.231 & $-0,146$ & -0.100 & -0.051 & -0.062 & -0.119 \\
\hline 20 & -0.106 & 0.133 & 0.120 & 0.295 & 0.355 & 0.209 & 0.075 & 0.141 & $-0.00 \%$ & 0.107 \\
\hline 21 & 0.178 & 0.065 & 0.051 & 0.119 & 0.079 & 0.139 & 0.169 & 0.088 & $-0,060$ & 0.107 \\
\hline 22 & 0.069 & 0.099 & 0.024 & 0.094 & 0.135 & 0.098 & 0.136 & 0.081 & 0.153 & $0.23 \frac{48}{4}$ \\
\hline 23 & 0.036 & 0.045 & 0.0446 & 0.140 & 0.067 & 0.157 & 0.146 & 0.081 & 0.029 & 0.097 \\
\hline 24 & 0,074 & -0.121 & -0.101 & -0.169 & -0.260 & -0.255 & -0.036 & -0.118 & -0.036 & -0.031 \\
\hline 25 & -0.034 & 0.166 & 0.099 & 0.254 & $0.3: 40$ & 0.193 & 0.098 & 0.150 & 0.062 & 0.081 \\
\hline 26 & 0.045 & 0.028 & 0.058 & 0.056 & 0.087 & 0.081 & 0.100 & 0.003 & 0.1 & 0.072 \\
\hline \multirow[t]{3}{*}{27} & 0.021 & 0.002 & 0.041 & -0.013 & -0.064 & -0.053 & 0.032 & 0.007 & 0.014 & 0.032 \\
\hline & 11 & 12 & 13 & 14 & 15 & 16 & 17 & 18 & 19 & 20 \\
\hline & TEST1 & TESTE & TEST3 & TEST 4 & INACPT & EDTC & SES & MEXNA & HBSZ & AGEE \\
\hline 11 & 1.000 & & & & & & & & & \\
\hline 12 & 0.506 & 1.000 & & & & & & & & \\
\hline 13 & 0.502 & 0.462 & 1.0000 & & & & & & & \\
\hline 14 & 0.227 & 0.252 & 0.200 & 1.000 & & & & & & \\
\hline 15 & 0.105 & 0.106 & 0.105 & 0.059 & 1.000 & & & & & \\
\hline 16 & 0.437 & 0.351 & 0.370 & 0.187 & 0.120 & 1.000 & & & & \\
\hline 17 & 0.416 & 0.340 & 0.317 & 0.143 & 0.088 & 0.633 & 1.000 & & & \\
\hline 10 & 0.154 & 0.162 & 0.203 & 0.017 & 0,088 & 0.2 .24 & 0.162 & 1.000 & & \\
\hline 19 & 0.076 & 0.070 & 0.129 & 0.038 & 0.031 & 0.147 & $0.12^{4}$ & 0.021 & 1.0000 & \\
\hline 20 & -0.207 & -0.150 & -0.234 & -0.127 & -0.164 & $=0.404$ & -0.175 & $=0.130$ & -0.317 & 1.000 \\
\hline 21 & 0.021 & 0.129 & 0.043 & $-0,006$ & -0.032 & -0.035 & 0.0003 & 0.073 & 0.020 & -0.018 \\
\hline 2 & $-0,014$ & -0.023 & $=0.006$ & 0,029 & 0.015 & -0.026 & -0.033 & -0.037 & -0.018 & 0.015 \\
\hline 23 & 0.002 & 0.019 & -0.027 & 0.015 & -0.009 & -0.050 & $=0.032$ & 0.014 & -0.117 & 0.140 \\
\hline 24 & 0.292 & 0.291 & 0. 224 & 0.135 & 0.093 & 0.411 & 0.456 & 0.090 & 0.290 & -0.364 \\
\hline 25 & -0.159 & -0.145 & -0.185 & $-0.10 \%$ & -0.061 & -0.235 & -0.189 & -0.061 & -0.265 & 0.510 \\
\hline 26 & 0.062 & 0.081 & 0.0118 & 0.036 & -0.002 & 0.074 & 0.121 & 0.046 & -0.138 & 0.046 \\
\hline 27 & 0.000 & -0.026 & -0.025 & -0.024 & $-0,037$ & 0.003 & 0.030 & 0.047 & 0.010 & 0.032 \\
\hline
\end{tabular}

\begin{tabular}{|c|c|c|c|c|c|c|}
\hline FEM & $\frac{22}{15 F}$ & $\begin{array}{c}23 \\
\text { I. THWT }\end{array}$ & $\begin{array}{c}24 \\
F D N\end{array}$ & $\begin{array}{c}25 \\
\text { WOPI }\end{array}$ & $\begin{array}{c}26 \\
\text { FARD }\end{array}$ & $\frac{27}{\text { GPDDNS }}$ \\
\hline 1.000 & & & & & & \\
\hline-0.001 & 1.000 & & & & & \\
\hline-0.095 & 0.094 & 1.000 & & & & \\
\hline-0.011 & $-0,026$ & -0.303 & 1.000 & & & \\
\hline 0.060 & 0,019 & 0.087 & -0.426 & 1.000 & & \\
\hline 0.007 & 0.040 & 0.116 & 0.056 & 0.011 & 1.000 & \\
\hline$-0,044$ & 0.022 & -0.005 & -0.013 & -0.045 & 0.158 & .00 \\
\hline
\end{tabular}




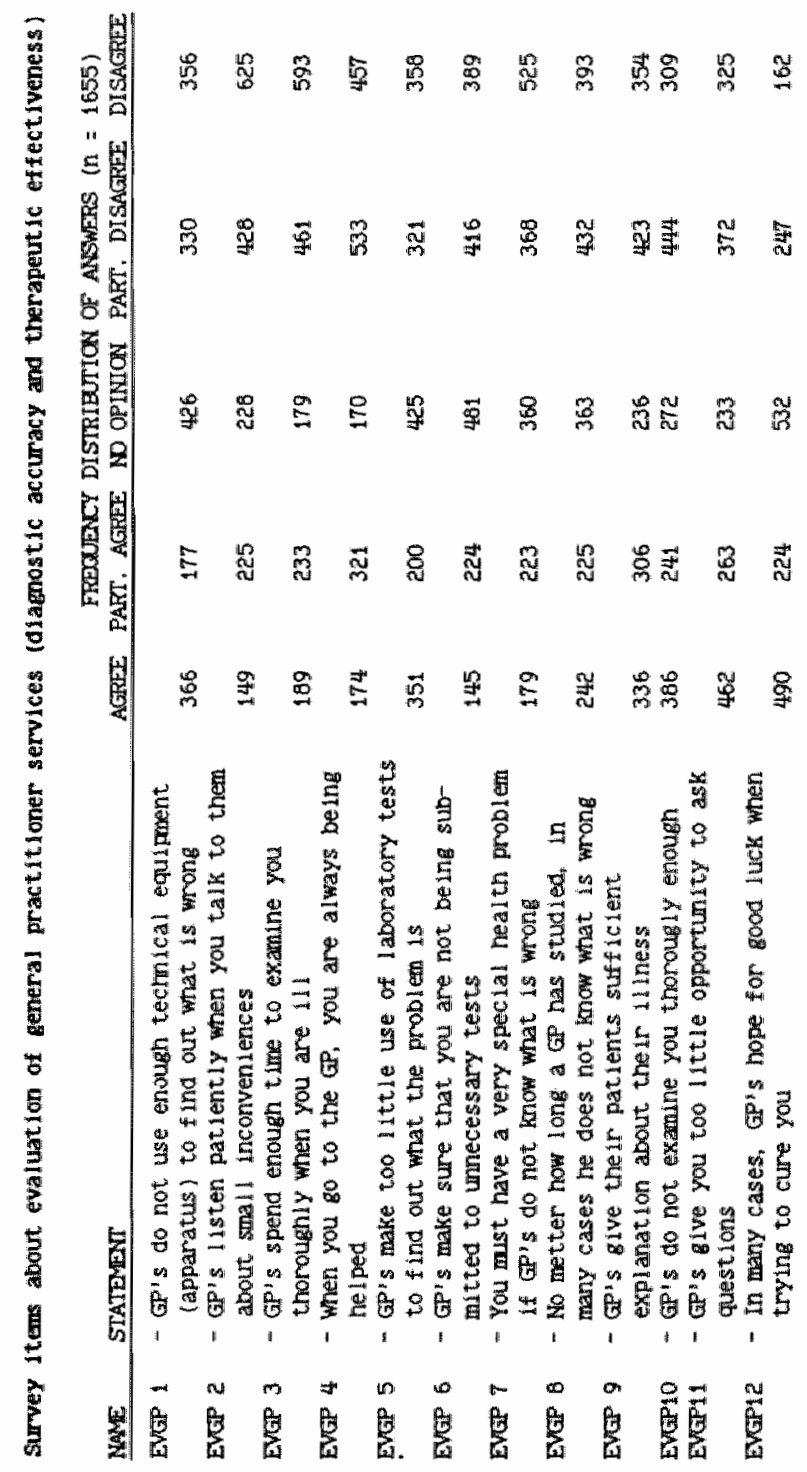




\section{APPDEOTX 4D}

lomellication of the basic structural equation model presented in tables 42 and 4.13 (by E. Tary

1. The rodel can be writter as follows:

\section{A measurement wodel:}

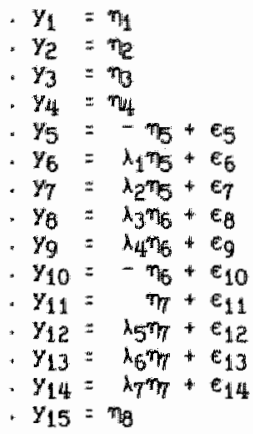

and a structural model:

" $\eta_{1}=B_{16} \eta_{6}+B_{17} \eta_{7}+\beta_{18} \eta_{9}+Y_{11} x_{1}+\gamma_{13} x_{31}+\gamma_{15} x_{5}+y_{16} x_{6}+\gamma_{19} x_{9}+\gamma_{1,10} x_{10}+z_{1}$

. $\eta_{2}=\beta_{21} m_{1}+\beta_{26} \tau_{6}+\beta_{27} m_{7}+\beta_{28} m_{9}+\gamma_{21} x_{1}+\gamma_{23} x_{3}+y_{25} x_{5}+\gamma_{26} x_{6}+\gamma_{29} x_{9}+y_{21} 10 x_{10}$ $+52$

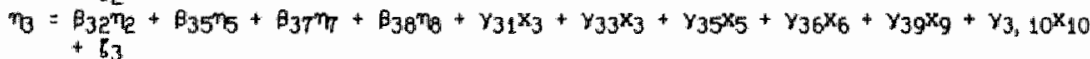

$\eta_{4}=\beta_{41} \eta_{1}+\beta_{42} \eta_{2}+\beta_{43} \eta_{3}+\beta_{45} \eta_{5}+\gamma_{47} x_{7}+\gamma_{48} x_{6}+\gamma_{41} x_{1}+\gamma_{43} x_{3}+\gamma_{45} x_{5}+\gamma_{46} x_{6}$ $+\gamma_{49} \%_{9}+\gamma_{4} 10 x_{10}+5_{4}$

. $\eta_{5}=y_{57} \eta_{7}+\gamma_{51} x_{1}+\gamma_{53} x_{3}+\gamma_{54} x_{4}+\gamma_{55} x_{5}+y_{56} x_{6}+\gamma_{57} x_{7}+y_{50} x_{8}+y_{5}$

. $\eta_{6}=\beta_{65} \eta_{7}+\beta_{67} \eta_{7}+y_{61} x_{1}+y_{63} x_{3}+y_{64} x_{4}+y_{65} x_{5}+y_{66} x_{6}+y_{67} x_{7}+y_{68} x_{8}+y_{6}$

$\eta_{7}=\theta_{75} m_{5}+\gamma_{71} x_{1}+y_{72} x_{2}+y_{73} x_{31}+\gamma_{74} x_{4}+y_{75} x_{5}+y_{76} x_{6}+57$

. $\eta_{8}=B_{87} \eta_{7}+\gamma_{81} x_{1}+y_{82} x_{2}+y_{83} x_{3}+\gamma_{84} x_{4}+\gamma_{85} x_{5}+\gamma_{86} x_{6}+\gamma_{8}$

* = the variance-covamiance matrix of the $b$ 's is diagonal.

All covariances between the $\varepsilon^{\prime \prime}$ equal zero except $\operatorname{cov}\left(\epsilon_{5}, \epsilon_{6}\right) \neq 0$, cov $\left(\epsilon_{8}, \epsilon_{9}\right) x^{\prime}$ We can spilt the whole model into three parts (surmodels):

1. a measurement model,

2. a simul taneous structural model, and

3. a recursive stmotural model 
2. The first part specifles the following measurament nodel:

$Y=A \mp+\epsilon$, with

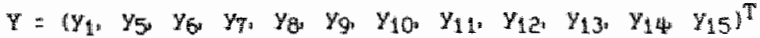

$\mathbf{A}=\left|\begin{array}{rrllllllllll}1 & 0 & 0 & 0 & 0 & 0 & 0 & 0 & 0 & 0 & 0 & 0 \\ 0 & -1 & \lambda_{1} & \lambda_{2} & 0 & 0 & 0 & 0 & 0 & 0 & 0 & 0 \\ 0 & 0 & 0 & 0 & \lambda_{3} & \lambda_{4} & -1 & 0 & 0 & 0 & 0 & 0 \\ 0 & 0 & 0 & 0 & 0 & 0 & 0 & 1 & \lambda_{5} & \lambda_{6} & \lambda_{7} & 0 \\ 0 & 0 & 0 & 0 & 0 & 0 & 0 & 0 & 0 & 0 & 0 & 1\end{array}\right|^{T}$

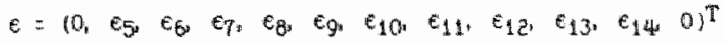

$\eta=\left(\eta_{1}, \eta_{5}, \eta_{6}, \eta_{7}, \pi_{8}\right)^{T}$

with $\operatorname{cov}\left(\epsilon_{5}, \epsilon_{6}\right)=\theta_{56} \neq 0_{4}$

$\operatorname{cov}\left(\epsilon_{B}, \epsilon_{9}\right)=\theta_{B 9} x 0^{\prime}$, and $A_{3}=\lambda_{4}$

Al. other covariances between the e's equal zero. The equations $y_{2}=\eta_{2}, y_{3}=\pi$ and $Y_{4}=7_{4}$ can be neglected for the identification of the measurement model because these $\eta^{\prime \prime s}$ are directily observable.

This measurement model is Idertifled if the covariance matrix of the wis (var (r)], $A$ and $\theta_{c}$ can be determined uniquely from the covarlance matrix of the $y^{\prime} s$. The identification of VAR( $\eta)$ can then be used to identify the structural part of the whole model.

Let $\left(\sigma_{i j}\right)_{j=y_{1}, \ldots .15}^{j=1_{1}}$ be the correlation matrix of the observed $y$-variables. Then, $\operatorname{cov}\left(\eta_{1,} \eta_{5}\right), \operatorname{cov}\left(\eta_{1}, \eta_{6}\right), \operatorname{cov}\left(m_{1}, \eta_{7}\right), \operatorname{cov}\left(\eta_{1}, \eta_{3}\right), \operatorname{cov}\left(\eta_{5}, \eta_{6}\right), \operatorname{cov}\left(\eta_{5}, \eta_{7}\right)$, $\operatorname{cov}\left(\eta_{5}, \eta_{8}\right), \operatorname{cov}\left(\eta_{16}, \eta_{6}\right)$ and $\operatorname{cov}\left(\eta_{7}, \eta_{8}\right)$ are determined by $\sigma_{1,5}, \sigma_{1}, 10, \sigma_{1,11,}, 1,15$ $\sigma_{5,101} \sigma_{5,11}, \sigma_{5,15}, \sigma_{10,15}$ and $\sigma_{11,15}$ respective $1 \%$.

Next we determine

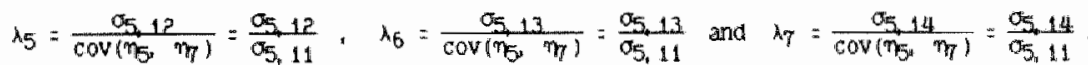

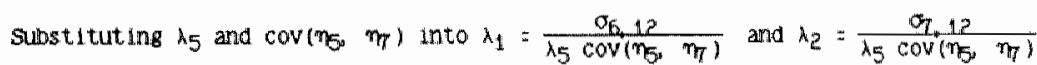

yields $\lambda_{1}=\frac{\sigma_{5,12}}{5,12}$ and $\lambda_{2}=\frac{\sigma_{1}, 12}{\sigma_{5,12}}$. Now we can determine var $\left(\eta_{11}\right)=1, \operatorname{var}\left(m_{5}\right)=-\frac{\sigma_{5} I_{1}}{\lambda_{2}}=$

$=-\frac{\sigma_{5,7} \sigma_{5,12}}{\sigma_{7,12}}, \operatorname{var}\left(m_{1}\right)=\frac{\sigma_{11,12}}{1,5}=\frac{\sigma_{11,12 \sigma_{5,11}}}{\sigma_{5,12}}$ and $\operatorname{var}\left(\eta_{6}\right)=1$.

Fron $\sigma_{1,8}=-\lambda_{3} \operatorname{cov}\left(\eta_{1}, \eta_{6}\right), \sigma_{9_{1}} 10=-\lambda_{4} \operatorname{var}\left(\eta_{6}\right)$ and $\sigma_{8_{11}} 10=-\lambda_{3} \operatorname{var}\left(\pi_{6}\right), 1 \mathrm{t}$ follows that $A_{3}, \lambda_{4}$ and $\operatorname{var}\left(\pi_{6}\right)$ are determined. Hence $\Lambda$ and $\operatorname{var}(\eta)$ are udent if $l_{e d}$ as well as $\theta_{e}$ the wariance-covariance metrix of the $c$ s. Hence the measurement model is identidid.

3. The second part is a structural simultaneous (sub model specifying the pelations between $T s$ and $T$

$$
\begin{aligned}
& \eta_{5}=\gamma_{1}^{T}+x_{57} x_{7}+y_{58} x_{8}+B_{57} \eta_{7}+55 \\
& \eta_{7}=y_{2} x+x_{72} x_{2}+B_{75} n_{5}+57 \\
& x=\left(x_{1}, x_{31} x_{4} x_{5} x_{6}\right)^{T}
\end{aligned}
$$

where $\left|\begin{array}{c}v_{1}^{T} \\ \gamma_{2}^{T}\end{array}\right|=\left|\begin{array}{lllll}\gamma_{51} & \gamma_{53} & y_{54} & \gamma_{55} & \gamma_{56} \\ \gamma_{71} & \gamma_{73} & \gamma_{74} & \gamma_{75} & \gamma_{76}\end{array}\right|$ 
Let 6 be the matrix

$\left|\begin{array}{cccccc}1 & 157 & y_{1}^{T} & 0 & y_{5 T} & y_{50} \\ 071 & 1 & y_{2}^{T} & y_{72} & 0 & 0\end{array}\right|$

According to the rank condition, identifucation is established if the matrices $C_{1}$ and $C_{2}$ consist of collums of $\mathrm{C}$ for which the first respectively the second row are zero elements. In this catse

$c_{11}=\left|\begin{array}{l}0 \\ y_{72}\end{array}\right|$ and $c_{2}=\left|\begin{array}{ll}157 & 150 \\ 0 & 0\end{array}\right|$

Hence, if $y_{72}=0$ and $y_{57}=0$ or $\gamma_{58}=0_{1}$ then the model is ldentifled.

4. The third part consists of the remining structural equations. This part can be rewritten in the form $A Y=\Gamma X+b$, wh $A$ an upper trianguim matrix witm ones as Wagonal elements and (var (r) a non-singular diagonal matrix. It is well known that such recurs lve models are always ldentif led.

Decause each of the three parts is ldentified and the covarlances between the error terms of the subsystens are uncorrelated, it follows that the whole mode! is identified (see e. Wiley, 1973 ). 
APFENDL 6.A. Translation of the 21-item Questionale for Research into Dxperienced Heal th Status (OREH)

1. Is your appetite less good than you consider nomal?

2. Does your stomach often feel full and blazted?

3. Do you get short of breath easily?

4. Do you of ten have pains in the chest or heart region?

5. Do you regularily have pains in the stomach region?

6. Do you bften have an unpleasant on swetish taste in your mouth?

7. Do you regularly suffer from palpitations?

8. Do you often feel tight in the chest?

9. Do your bones or muscles ever ache?

10. Do you ofter feel tired?

11. Do you of ten have headaches?

12. Do you of ten nave indigestion?

13. Are you ofter troubled by back-ache?

14. Is your stomach regul arly upset?

15. Do your arms and legs often go dead or bet pins-and-needles?

16. Do you get tired sooner than you would cons ider nomal?

17. Do you often feel dizz?

10. Do you often feel listless?

19. Do you of ten have stomach trouble?

20. Do you often feel sleepy or slugsish?

21. Do you generally get up feel ing tired and unested in the forming? 


\section{CURRICUIM VITAE}

Eddy, K.A. Van Doorslaer werd op 24 februari 1958 geboren tx Willebroek (B). Hij behaalde het diploma Moderne Himaniora, Weten" schappelijke A aan het $H$. Pius X Instituut te Antwerpen in 1976. Ir 1980 werd hif licentiaat in de Toegepaste Economische Wetenschappen, whting bedrijfseconometrie aan de Universitaire Faculteiten st. Ignatius te Antwerpen (UFSIA). Van 1981 tot 1983 genoot hij een CIM Fellowship van het Interuniversitair College voor Doctorale Studies ir Managementwetenschappen te Brussel. Hij behalde de M.Sc. Degree ir. Health Economics aan de Universiteit van York (GB) in 1982. Sedert 1983 is hij als universitair docent verbonden aan de Vakgroep Economie van de Gezondheidszorg van de Rijksuniversiteit Limburg en verrichtte daar voorname 1 ijK onderzoek naar het gebruik van gezondheidszorgvoorzleningen. 